


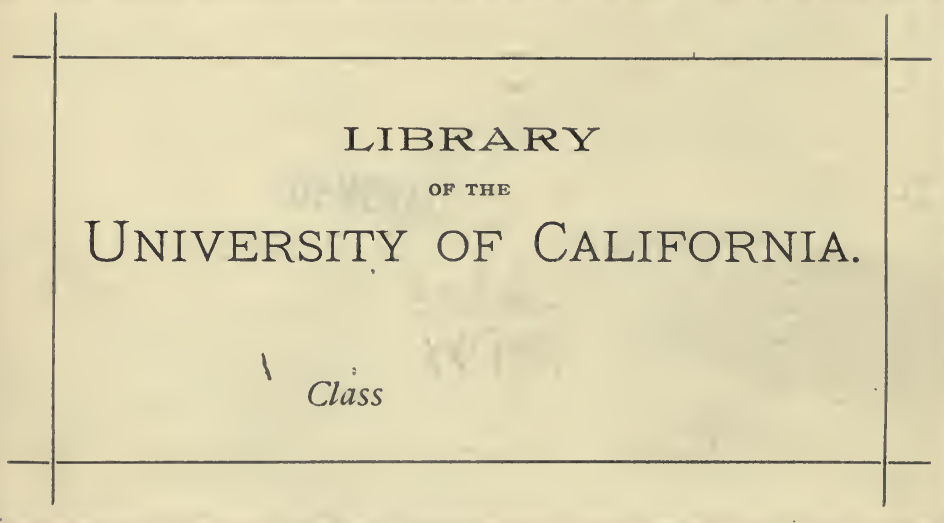






Digitized by the Internet Archive in 2007 with funding from Microsoft Corporation 



\title{
METHODS IN TEACHING
}

\author{
BEING THE STOCKTON METHODS
}

IN ELEMENTARY SCHOOLS 
Ther $2 x<$. 


\section{METHODS IN TEACHING}

\section{BEING THE STOCKTON METHODS \\ IN ELEMENTARY SCHOOLS}

BY

ROSA V. WINTERBURN

FORMERLY SUPERVISOR OF ENGLISH AND HISTORY IN THE STOCKTON CITY SCHOOLS

INCLUDING A CHAPTER ON NATURE STUDY

BY

EDWARD HUGHES

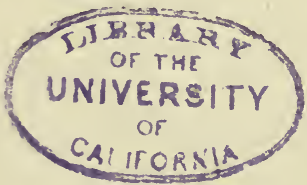

Nelo York

THE MACMILLAN COMPANY

LONDON: MACMILLAN \& CO., LTD. 


\section{GENERAL}

COPYRIGHT 1907

By THE MACMILLAN COMPANY

Set up and electrotyped. Published May, xgo7 


\title{
TO MY MOTHER
}

FROM WHOSE BEAUTIFUL NATURE

\author{
I LEARNED
}

MY FIRST LESSONS OF LIFE 



\section{FOREWOR D}

Among the exhibits at the St. Louis and Portland Expositions was one from the Stockton Schools. It was so arranged as to show in the smallest possible compass as complete a picture of the development of the course of study as could be presented in written form. The work in all bound volumes was shown in the following sequence:

I. A typewritten monograph, or method sheet, treating of the subject illustrated in the volume.

2. The course of study in the subject in printed form.

3. The teacher's daily program.

4. Work from the pupils, showing all the written lessons given in the subject from the first lesson in September to the last lesson in June.

Under this arrangement the methods followed, the course of study to be carried out, the time value of every subject, the results secured, were shown in every volume. There were ninety-two monographs, or method sheets, illustrating fully the methods followed in the different subjects taught. In all cases these monographs were written by the principals or teachers.

These volumes of method sheets, illustrated as they were with the results secured from pupils, met with a generous commendation from the teachers of America. Since the close of the Expositions hundreds of letters have been received asking if the Stockton methods could be secured in 
printed form. To meet what seemed to be a real demand, it was decided to issue " The Book of Stockton Methods."

The labor of editing the monographs was committed to Mrs. Rosa V. Winterburn, under whose skillful direction as Supervisor of the Primary and Grammar Schools of Stockton much of the work has been developed. From this proposed editing of teachers' and pupils' work the present more ambitious book has grown, in which are given many experiences and suggestions that were not embodied in the original plan. In the use of the teachers' monographs repetition has been avoided and in many cases the methods have been condensed, but the thought and the wording have been preserved in so far as practicable.

The book does not pretend to be an answer to the question, "What are the best methods of teaching?" It does seek to show what is being actually done by teachers under working conditions when they strive intelligently to make their methods rational and useful. No claim is made that the methods given in this book are models for others to follow; but it is claimed that they are methods of practice rather than of theory. As such they are submitted to the teachers of America.

Stockton, California,

$$
\text { JAS. A. BARR, }
$$

City Superintendent of Schools.

June I, 1906. 


\section{PREFACE}

"Where no wise guidance is, the people falleth;

But in the multitude of counsellors there is safety."

Out of the experiences of many people, tested, retested, and tested again, this book has grown. May there be in it words of help and direction! In a sense it is a composite, but it is only in the way in which the civilization of today is a composite of what has gone before. No man dare say that he stands alone in his achievements; preceding ages and contemporaneous efforts have helped place him where he is, no matter how strong within him may be the personal element. So with this book. Superintendent, supervisors, teachers, and pupils, with perhaps an unusual degree of harmony, have worked together over the problems of the schoolroom. Some of the helpful deductions thus made are recorded here.

This is a book of methods rather than of subject matter. Both might well be presented, but to do so would overburden such a publication. While it is true that without subject matter methods are valueless, the supposition is that a man or woman who is admitted today into the schoolroom is fairly well provided with the knowledge requisite for the task. Many teachers fail, however, in handling their equipments; many and many a pupil wastes a large part of his time in school because of the imperfect way in which the subject matter of even a common school education is presented; many parents, eager for the best interests of their children, find themselves bitterly disappointed with the 
product turned out by the schools which have been controlling the intellectual development of the children for eight years.

Character, individuality, citizenship, knowledge, industrial ability, general culture,--these have been the desired lines of progress for our schoolrooms. Along them there has been felt a strengthening, intensifying, broadening influence that has been unquestionable in its formative power. It is in the hope of aiding to perpetuate these aims-known and reached out after by all true teachers-that we offer this book to our fellow-workers.

Grateful acknowledgments are extended to Mr. James A. Barr, Superintendent of the Stockton City Schools, for his unfailing help and ready suggestions; to the teachers, who have kindly permitted the use of extracts from summaries submitted by them of their work and methods; to Mr. Edward Hughes and Mr. S. H. Cohn, who have made possible a greater completeness of treatment by their liberal contributions on nature study and geography; and to Mrs. Alice Smallfield Schneider, whose careful development of the word study is the basis of the thoughts here presented on that subject.

Believing that ordinarily the busy teacher has time for only a few reference books, the lists appended to the subjects are short, containing only some of the books that have been found to contain the most direct help or the most suggestive guidance.

Los Angeles, California,

ROSA V. WINTERBURN.

May 23, 1906. 


\title{
CONTENTS
}

\author{
PART I.
}

\section{LITERATURE LANGUAGE WORD STUDY}

CHAPTER I.

Genkral Thoughts on Literature for Elementary Schools 3

CHAPTER II.

Presentation, AcQuisition, and Illustration of Literature in Primary Grades ..$\quad \cdot \quad \cdot \quad \cdot \quad \cdot \quad \cdot \quad \cdot 9$

CHAPTER III.

Presentation, AcQuisition, and Illustration of Literature in Grammar Grades . . . • • . . • •

CHAPTER IV.

Importance of Language Training for All Pupils . 48 CHAPTER V.

Oral and Written Language with Primary Grades • $\quad 58$

CHAPTER VI.

Oral and Written Language with Grammar Grades . 78

CHAPTER VII.

WORD STUDY

\section{PART II.}

ARITHMETIC

CHAPTER VIII.

General Aims: Introductory Thoughts; Summary of the Development of a Course in Artthmetic . . . . I27 
CHAPTER IX.

Subject Matter and Methods in Fourth, Fifth, Sixth, Seventh, ANd Eighth Grades . . . . . . 145

CHAPTER X.

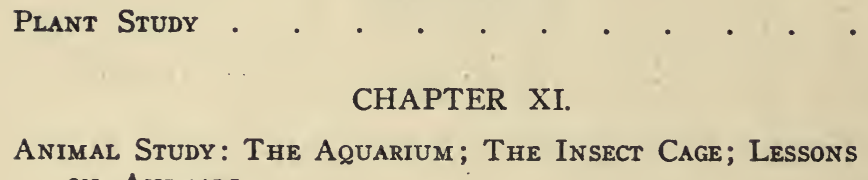

\section{PART III. \\ NATURE STUDY GEOGRAPHY}

on Animals

. 190

\section{CHAPTER XII.}

Non-Living Things . . . . . . . . . . 201

CHAPTER XIII.

GEOGRAPHY .

\section{PART IV.}

\section{HISTORY CIVICS}

CHAPTER XIV.

Introductory Words. History in the Primary Grades .

.263

CHAPTER XV.

History in the Grammar Grades

CHAPTER XVI.

Crvics .

$$
\text { PART V. }
$$

CHAPTER XVII.

Drawing. Music. Physical Culture. Sewing • • 333 


\section{PART I}

LITERATURE LANGUAGE WORD STUDY 



\section{LITERATURE}

\section{CHAPTER I}

GENERAL THOUGHTS ON LITERATURE FOR ELEMENTARY SCHOOLS

To prepare the child for life is the aim of education. $\mathrm{He}$ who knows how to read, and who desires to read valuable and instructive books has gained a great part of his education.

A course in literature for grammar grades should tend to produce in the pupil the desire to read, the ability to understand accurately what is read, a familiarity with books that will result in discrimination in buying or in selecting reading from the shelves of libraries. None of these aims may be actually attained, but as potentialities they are worth striving for long and earnestly.

In this education there are three personal factors: the parent, the teacher, the child. The parent in the home is

Personal

Factors the mainspring. Where it is possible for him to provide suitable books for his child, to direct his selections, and to encourage acquisitions in various lines of thought, there need be little fear for the future reading. Home impulses and training, 
when they are real forces, are the strongest influences in a child's iife.

The teacher's place in this scheme of education is most difficult. He should guide many minds in many directions; Guidance

he should direct the school for the general good of all, and at the same time he should discover individual strength and preference, for he is training to secure the best results for the race as well as for the individual. To select reading for a number of young people is no light task. Too often only general interest or amusement is considered, and it is forgotten that these should be but means toward the end,-life and progress. It is not sufficient to encourage reading; sometimes it must be checked. Many pupils read too much instead of too little. Seventh grade boys have been known to draw a library book every other day. Such a condition usually means unwholesome reading and a sieve-like mind. It requires restraint as surely as the sprouting fruit tree needs the pruning knife at the proper season. A child frequently becomes interested in one kind of reading and is prone to refuse all else. An eighth grade boy said that if he had ten dollars to spend for books, he would buy nothing but Henty's stories. This is a perverted taste, for specialization in any subject should be preceded by underlying information on many. General knowledge is imperative for the broad foundation that is most useful for all lines. Moreover, different kinds of reading may open up new possibilities of life work, and may so guide the pupil into a variety of interests,-history, travel, science, poems, biography, art, that a breadth of view is acquired that prevents narrowness in later specialization. 
The center of this education is the pupil, who should learn self-control and self-guidance. He should gradually be led The Pupil to make conscious and self-earned advances. Let him read with unconscious happiness and interest what has been selected, enjoying with childish abandon story or biography; but when another choice is made, lead him to consider the opportunity of broadening out into new fields of thought and knowledge as well as exploring more thoroughly the old ones. By this means, he will learn to choose books more judiciously and to lay a more systematic foundation in all subjects.

In the first two grades the stories are told to the children by the teacher. Compared with reading, this method in-

\section{Story}

Presentation volves some loss of time and literary style; but it means on the part of the pupils deeper interest, closer attention, greater concentration, more sympathetic response; on the part of the teacher it means more careful preparation, through which comes a stronger fellow-feeling in the presentation, and the cultivation of the art of story telling, a power with children. In the third grade stories may be read, although telling is still preferable. A short story should be told as a whole. This is demanded by the natural longing to get to the end, which, fortunately, aids the teacher in cultivating the sense of a complete thought or narrative. In long stories there are natural divisions which should be observed, for young minds retain best a short, connected recital. These breaks do not destroy continuity of thought or interest, for every portion of a well written story has within itself certain elements of completeness; on the other hand, long narratives are confusing and tend to weaken continuity of thought. Every 
part should make a finished little production, so told that the next division fits on naturally.

Reproduction follows narration. Every member in the class should feel that he is held responsible for some part in Reproduction this exercise; he should be able to answer questions if he can not tell the whole story. By dividing the class into small sections, every pupil may be asked for a part, perhaps all, of the reproduction. This is valuable training for little ones, for, added to the growth in English, there is the greater purpose of developing a sense of responsibility. The child comes to understand that here is a duty for him to perform to the best of his ability. He feels that in order to meet this responsibility to his work and to himself he must listen well, remember accurately, and reproduce fluently. A teacher can not develop too early a feeling of pleasure and satisfaction in a self-completed task. Written reproductions can be commenced during the first year, for the children soon take pleasure in forming composite stories for the teacher to write on the board. The children should be conscious of continuity of thought in these exercises. That is, no sentence given by the class should be written anywhere except in its proper place in the development of the story, and the teacher should either tell why it is not used in the place suggested or have the children themselves explain the reason. In making these composite stories many opportunities are found for improvement in sentence structure and for noting vulgar and incorrect idioms for future correction. Frequent reproductions add rapidly to a child's vocabulary and to a correct use of the new words learned; continuity of thought is strengthened by making complete stories; there is a gain in self-possession 
by rising and narrating before the class; clear concepts are formed if care is taken that the dramatic situations are pictured mentally; the composite productions furnish abundant material for reading lessons, copying exercises, drawing, and spelling.

Narrative drawing by the children is of greatest assistance in forming clear concepts of striking scenes. No matter

Drawing how crude the child's illustration may be, his ideas are clearer for his efforts to put them into pictures. The better, more logical drawings that may be put on the boards by the teacher or by older pupils are a help and pleasure to the children, for they aid in fixing the development of the story, consequently, in acquiring continuity of thought.

In teaching a poem the pictures presented by it should be seen clearly by the pupils before they try to commit to memA Poem ory. In these first grades the poems are usually narrative, as in that pleasing little account of the raindrops:

"Some little drops of water,

Whose home was in the sea,

To go upon a journey

Once happened to agree.

"They had a cloud for carriage And drove a playful breeze, And over town and country,

They rode along at ease.

"But oh, there were so many,

That soon the carriage broke, And to the ground came tumbling

Those frightened little folk. 
"Then through the moss and grasses,

They were compelled to roam,

Until a brooklet found them

And carried them all home."

The description of the home, the journey, the breakdown of the carriage, the run home again, can be made most interesting first in story form. The poem is then welcomed with delight; difficulties in meanings and constructions vanish; memorizing is almost without effort. Formal and formative studies on a poem should be kept distinct. While a child's mind is absorbed in the journey of the raindrops in their cloud carriage from the ocean over the land, down the brook, and back home to the sea, it should not be confused and distracted by a search for definitions of "happened" or "agree." If the meaning is understood the enjoyment should be unalloyed; later, there can be taken up studies of words, constructions, and reproductions, when the mind may find in these more formal studies a pleasure equally as great as that given by the poem itself. Synonyms can be given and used. Five or ten minute drills two or three times a week in word exercises are invaluable, giving surprising results.

The reviews of poems and stories should be tactfully arranged, so that they do not become tedious. By this means, Dramatic Element memory and power are fostered. The dramatic element can be preserved. Simple acting by the children, even of the stories given early in the first year, is very enjoyable, and it serves to emphasize action and to vivify concepts. 


\section{CHAPTER II}

PRESENTATION, ACQUISITION, AND ILLUSTRATION OF LITERATURE IN PRIMARY GRADES

\section{FIRST YEAR GRADE}

During the year it is possible every month to learn a short poem and to use a folk tale or a Bible story for narration, reproduction, reading lesson, and other drills. Many teachers are able to add a history story occasionally to the month's story material.

A teacher ${ }^{1}$ in a first grade gives some of her experiences with the children :

About twenty minutes are taken for telling a new story to the class. The second day about the same length of time Presentation is taken for questioning the pupils to help them remember the story. This is the first step in reproduction and memorizing. The third day individual reproduction can begin. At first, one child rarely tells the whole story. The stronger or the older pupils open the way; one begins, another continues, and so on, until three or four have taken part; finally, more and more eager little hands are raised, until nearly every child in the two upper divisions can tell the complete story.

Sometimes a little play is made of part of the tale. A tiny maid in her red hood makes a dear "Little Red Riding Acting Hood," on her happy way through the forest to see Grandma; some small boy delights in the hoarse growling that is supposed to belong to

${ }^{1}$ Mrs. Edna O. James. 
the part of the old wolf. Cinderella, her gracious fairy godmother, and her wicked step-sisters often converse for the edification of the other babies, who, in their turn, enact Silver Hair and the three bears, Tom Thumb, Dick Whittington, and the other heroes of the fiction dear to children.

Fortunately, little ones do not tire quickly of these stories and representations, and ten days or two weeks pass pleasResults antly in the efforts to reproduce in good language the story that has been listened to with such rapt attention. In the meantime, all unsuspected by the children themselves, much more than the story is being learned. The first problem that teachers of first grades must meet is how to induce the babies before them to forget their shyness and talk about the things that it is desirable the class should be learning. The above exercises accomplish much in this line in addition to all the progress possible in language and general culture; this is especially true when the stories are acted out. The dramatic instinct, or playing, is in every child; if it has an opportunity to express itself, it becomes an important factor in self-forgetfulness, one of the first requirements for the happiness of a child in the schoolroom. There now follow formal language lessons, and the formation of a composite story for reading and copying.

Toward spring the story of Hiawatha's childhood is taken, preceded by two or three weeks on Indian life. Much illusHiawatha trative material can be obtained for class use. The children examine everything, ask questions, and are told interesting facts. After a fairly clear child's idea of the Indians has been formed, the poem is begun, and for several weeks the many stories about the little Hiawatha are a source of delight to all. During this 
introductory work one day, at least, is given to Mr. Longfellow and his love for children.

The childhood of Hiawatha is presented in several divisions, some of which are: the cradle, lessons in the sky, the fire-fly, the rainbow. Wherever an opportunity for a science lesson presents itself, it precedes the literature. The fire-fly, for instance, is studied before taking up that part of the poem that tells about it. In this way the pupils understand the references with perfect ease. The story is first presented to the children in prose narrative. After it has been enjoyed, understood, and reproduced, the partial version is read or repeated to the pupils, who learn as much of it as can be remembered without too great an effort. In fact, the greater part of the memorizing is almost unconscious on the part of the pupils. The first grades use from the sixty-fifth to the two hundred and thirty-fifth line, and about one-third of this amount is remembered by the majority of the pupils.

During the year we have taken but a step, it is true, into the wonderland of story; but if we have created in the children a desire that will lead them toward an enjoyment of the best in literature, have we not done much?

\section{SECOND YEAR GRADE}

In this year the poems to be memorized are taken from the writings of the Cary sisters, Eugene Field, and Longfellow.

Material

and

Method They are first presented orally by the teacher, who tells the story involved, often using the words of the poet, if they are understood by the little ones. It is very desirable that the children should form clear-cut mental concepts of the pictures in the poems. To facilitate this, expressive drawings 
by the children supplement excellently the narratives of the teacher. Oral reproductions follow, some of which are written on the board, as was done in the first grades. A composite story produced in this way by the pupils is copied, thus aiding in the proper use of capitals, punctuation marks, and words, and in correct spelling. The poems are learned as early in the presentation as seems advisable to the teacher, difficult ones being given more time to be thoroughly comprehended. Several stanzas are often almost committed to memory before the teacher is really aware of the fact, simply by using the poet's words and constructions frequently in telling the story, and by encouraging the children to do the same in their reproductions.

During the last half of the year pupils may be permitted to write original reproductions, in which they should be enheartened to advance towards the accuracy of the copied work.

In connection with the poems and sometimes with the stories, a little knowledge may be gained about authors. Authors Field, the Cary sisters, Longfellow, can all be made real characters to the children. Short stories about them are interesting; something of their lives can be seen in their writings, even by these little folks; poems that are not in the regular course can be read aloud, several times perhaps, just for enjoyment, general culture, and familiarity with the poet.

The following are thoughts from a second grade teacher : ${ }^{1}$

In the second grade about twenty minutes a day are devoted to the literature stories during two weeks of every school month of the year. This time does not include formal

${ }^{1}$ Mrs. Mae Simms. 
language drills, nor does it cover all that is spent in the final writing of the stories. The former belongs to the language lessons, and some time for the composition work is found in the penmanship period. One of the most enjoyable stories for our grade is "Horatius," by Lord Macauley. The portions used are those that are full of life and action, where the story interest carries the child over language difficulties.

It is surprising how many stanzas can be understood by the children, who follow with keen delight the preparations

Telling

"Horatius"

of the enemy against Rome, the flight of the country people to the city, the desperation of the "city fathers," and the heroism of Horatius. As this poem is long and is used for both literature and history, it is permitted to run through the month, provided the children show no signs of tiring of it. Usually, from the beginning to the end, the interest never flags, not even in the writing and formal language drills based upon the poem. The primary instructor well knows that in all the teaching in which she is the first source of the material for the class, the inspiration also must come from her, and that the results will be in accordance with the enthusiasm that she can arouse. If the pleasure is deep and sincere, the tongues of the listeners will be unloosed in willing and eager reproductions, and the writing that follows will be no task. When introducing a new story, it is advisable to tell it to the children in the morning while the teacher and the class are at their best. Then let the narrator put into the presentation all her power to make the subject interesting and attractive. Let her strive to so impress the listeners that later mention of the hero or heroine will bring a glow to the cheeks and a sparkle to the eyes. It is a good 
plan to refer to the story several times during the day after it has been narrated, instead of leaving it untouched until the hour for reproduction. It can be kept fresh in the minds of the children by a question or two or a talk of a few moments, which can be brought in without interference with other lessons.

In the regular period for reproduction members of the class are called upon to tell different episodes, until, after a Reproduction few days, any child can tell the complete story, or the portion of it that has been given; or he can take it up at any point and continue it. Telling the story at home is encouraged, for it gives added power to be able to make a continuous narrative when there is no teacher or eager classmate at hand to suggest or to assist. Pupils who tell the story to parents, brothers, or sisters, usually show more rapid growth in language and a better command of the continuous thought of the narrative than do those who have only the class drill.

About the third day after the introduction of the story the children are ready to write some part of it. The morning Writing hour is generally taken for this purpose. A simple outline is placed upon the board, as: Rome, hills, gate, river, bridge, Lars Porsenna, soldiers, Horatius. This is to assist in keeping the continuity of thought, a difficult task for children. An outline for this purpose should be made thoughtfully by the teacher. It should be a careful arrangement of successive thoughts in the natural progression of the story, whose relation one to another is self-suggestive to the inexperienced little composers. For twenty or thirty minutes the children write, telling the story in about the form that it has already been 
given in oral reproductions. To the writers, however, it probably seems like a totally new presentation of the story; and so it should, for to many of them it will be the first complete reproduction. Care must be taken not to tire the little writers. If at the end of a half hour the papers are not finished, they should be taken up, and the completion of the story left for the next day or for several successive days. The writing must not become burdensome; it should be a pleasure.

To find material for the stories is not so difficult as is often imagined. Children like life and action, and delight in many a story that has been considered adapted only to older pupils. Good, interesting writers in both history and literature furnish abundant material; still more can be found in periodicals. Children often need more solid intellectual food than is given in many school courses, and they thrive wonderfully upon it.

The following is an original reproduction by a second grade child, written independently after the oral class reproductions. The periods and capitals are well placed. Note how the story interest carries the continuity of thought.

\section{Horatius.}

Rome was built on seven hills.

Rome had a large wall around it.

Rome had four gates in the wall.

And Rome had a large river and the name of the river was the Tiber river.

And the Romans called it the Father Tiber river.

Horatius was the gate keeper.

A man came to Rome and wanted to be a council men and 
they did not want him to be and he went off and got an large army of soldiers.

Some men heard that Lars Porsena was getting an army of soldiers.

They went around to the houses and told all the people.

It took them three days and nights.

They got in to Rome and they saw the soldiers.

Horatius and two other men went with him across the bridge.

they killed the first three soldiers.

They killed the next three.

They called Horatius and the two men.

The two men ran across the bridge.

Horatius stayed too long and the bridge fell down and Horatius was alone.

He prayed to the river and he jumped in.

They thought that Horatius would not come out of the river.

But he did come out and the Romans were glad.

\section{THIRD YEAR GRADE}

In this grade the teacher reads many if not all of the stories and poems, so that the words of the writer become familiar to the children. Easy narration by the teacher, to vivify or to simplify the words of the author, is made supplementary to the reading. The pupils should now be reading many stories for themselves, for they should be appreciating and using the power gained by their knowledge of the mechanics of reading, and they should be learning how to get from books the enjoyment that they have been receiving through the lips of the teacher. 
In composition original reproductions should now supersede composite exercises, the latter being used only for trainComposition ing in acquiring continuity of thought or in illustrating some special features of writing. For such purposes composite lessons remain valuable for several years. In the original reproductions topics should be given for short papers. If these are chosen from consecutive stages of the story the child will have eventually the complete narrative, a satisfaction to him, and a pleasure to the teacher and the parent. Such papers should be made into a note-book, as in the second grade. The first draft should be the one preserved unless mistakes are very numerous; and even in this case it is advisable to keep the original as well as the rewritten sheet, in order to stimulate the child to do more careful work on succeeding first efforts. Weakness is being educated when a child is allowed to rewrite frequently. Insist upon clear pictures before the reproduction is attempted. If a child can close his eyes, so as to shut out intrusive externals, and can imagine that he sees Sleepy Hollow, Ichabod Crane, or the wild ride on Gunpowder, he will be able to tell a more concise and vivid story than if the writing is entered upon without the clear mental pictures.

The following story of King Midas is an original, uncorrected third grade reproduction:

\section{The Golden Touch}

I.

Once there was a very rich king whose name was Midas. He had a little daughter he liked odd names so he called her Marygold. He had a dungeon under his palace. When he 
wanted to be happy he would go down into the dungeon. Marygold went out to pick buttercups and dandelions. Midas said Poh, if they were as golden as they look they would be worth picking. Before Midas was so rich he had a garden of roses he thought the roses were very pretty. He use to go down in the dungeon and wish that the sun when it was setting it was gold and could be squeezed into a golden cup. One day a shadow fell upon his gold. He said in a surprise that he locked the door tight. The stranger said, are you satisfied. No said Midas, I wish that everything I touch would turn to gold.

II.

The stranger promised King Midas that he should have his wish. Tomorrow at sunrise you will have the Golden Touch. When he woke the next morning he touched the things around him and they remained the same he thought that he was fooling him. After the sun came over the hills he put his clothes on and they turned to a suit of gold. He went out and touched all the roses and they became a thin plate of gold and the worms in the heart became gold.

He went back to the palace to get his breakfast. King Midas ordered Marygold to be called, very soon he heard her coming around the house crying bitterly when she opened the door he said what is the matter, Marygold said that all the beautiful roses are gold and have know fragrance. Everything that he ate turned to gold. He thought that if he ate it quick it wouldn't turn to gold. So he put a hot potato into his mouth and it turned to gold and he danced around the room. Marygold came in the room and said what is the matter and when he put his lips to kiss her she turned to a golden statue. 
These extracts from a reproduction show the difficulty in combining mechanical accuracy with literary creation. There are many good points for a third grade writer,-life, vigorous treatment, continuity of thought, accurate spelling, a fair conception of paragraphing, and the use of periods and capital letters; and there are several indications that the writer possessed knowledge that was not used. Some sentence structures are weak and loose, especially where the thought grows more rapid, but the sentence structure is very good in other parts of the story. Personal revision by the writer, when undivided attention could be given to mechanical accuracy, would probably remove the greater number of the mistakes and strengthen many weak places.

\section{FOURTH YEAR GRADE}

In the presentation of a story in this grade the children read for themselves whenever the books are provided in Method sufficiently large numbers to permit of a class exercise. Otherwise the teacher reads. Individual reading is encouraged constantly under all circumstances, so that the pupils are learning to use and to understand books for themselves and are deriving pleasure from their efforts. Pupils should read many more stories than those treated as class work, and the teacher should have on hand a store of pleasing and profitable reading for odd moments during the day.

Reproduction follows the reading, usually after an interval of a day. It is either oral or written, preferably both. Only the regular stories, one a month, are so treated; those read by the pupils for themselves or by the teacher as a relaxation are rarely taken up a second time. The monthly 
story serves many purposes, literary and linguistic. The reproductions are on detached but consecutive topics, giving opportunity for short, clearly pictured scenes in the papers that are preserved in the notebooks.

There is a great deal of material for language lessons in these stories. In fact, the reproductions, the composition work, the correction of papers, are all treated under language. Correlation is very close in all of the essential branches; differentiation belongs to analyses of methods and material, pupils need not be troubled with it:

The purpose is not to give an immense amount of information, but to arouse the child's lasting interest in the subPurpose ject, to show him how to read, and to put exhilarating material into his hands. There is subject matter enough in any one of the Bible stories or the narratives from the "Odyssey" for much more advanced pupils, so care must be taken not to tell these fourth grade children too much. Such a mistake would overload the course of study, and, probably, by making teacher and pupils feel hurried, it would create a distaste for many of the stories. The first thought in presenting the stories is pleasure,-childish, natural enjoyment. This can be gained only by easy narration or reading, interspersed with conversations. The reproductions should have the same purpose in mind, although progress must never be forgotten. Rightly handled, however, progress, in both literary and mechanical directions, is one of the keen enjoyments of the work.

Three aims should be kept constantly in mind:-interest in our world heritage through participation in the well known stories that are a part of the world's culture; selfdevelopment through this world heritage, or a conscious 
growth in power on the part of the child; acquisition of knowledge. If the first two purposes are remembered the third follows as a matter of course.

A fourth grade teacher ${ }^{1}$ gives in the following paragraphs some of her ideas about teaching literature stories:

Literature as presented to the children is not the intensive study that is given to mature minds, even when the subject matter is the same. In the elementary grades, the teacher's aim is to lead the pupils into enjoyment of literature, for pleasure in good and beautiful stories is the first step toward future appreciation of authors.

A little mystery or a suggestion of tragedy quickly arouses interest. David's encounter with Goliath, Ulysses and the Cyclops, are received with avidity. Repeatedly the question is asked, "What is the name of the book that has that story in it?" Or, "Is that story in the public library?" Thus the children are led into reading for themselves.

After the story has been given and some parts repeated, it is discussed by the pupils, who ask questions about the

Stories and Poems portions that have not been understood, or in which they have taken special pleasure.

In this way the teacher is able to measure the interest of the class as a whole, as well as of individual pupils, a great assistance in knowing how to prepare the next story for presentation. The poems, which are usually short, are presented in a somewhat different manner. Every poem is either written on the board or mimeographed, so that a child can have his own copy. The pupils read it slowly, discussing the thoughts, and getting the story. They are asked to tell from the poem itself, if they can, why the poet wrote ${ }^{1}$ Miss Lottie Grunsky. 
it. They talk about it freely, choosing favorite expressions or thoughts, pointing out "pictures," finding new ideas, making it their own. Many portions are memorized almost unconsciously; some poems are learned outright. There are many explanations and discussions based upon the poems, but there are few reproductions except of the story running through any one of them. 


\section{CHAPTER III}

\section{PRESENTATION, ACQUISITION, AND ILLUSTRATION OF LITERATURE IN GRAMMAR GRADES}

\section{FIFTH YEAR GRADE}

Pupils in the fifth year in school enjoy many poems by Longfellow, who has a delightful power in picturing vividly Material scenes of life and action. The poems should not succeed one another too rapidly, nor should they be hurriedly presented. The teacher's observation of the attitude and attainments of the class should be the guide in both respects. The first thing to be considered is that the pupils gain a view of a complete poem. This can be accomplished in several ways: The teacher may read the poem through, stopping over every stanza long enough for the children to give naturally its substance, and, at the end, the whole poem may be summarized; the pupils, instead of the teacher, may read, a similar stanza analysis being given; the pupils may read the poem for themselves before coming into class, looking out the thoughts for themselves. The last treatment is the most difficult for children; it should not be insisted upon too rigorously nor too often, for to do so would probably result in dislike for poems. Pupils of this age grow but slowly into individual analyses, especially of poems, although they greatly enjoy this work with the teacher. The purpose in this preparatory glimpse of the poems is to gain the power of uniting several successive 
thoughts into a complete whole; to enjoy the poem; to be constructive rather than analytic; to have in mind the whole instead of the parts. Pupils must be trained in the acquisition of this power. Classes may read in the ordinary schoolroom manner such a poem as Longfellow's "Ropewalk" several times without any interest in it, for they have obtained no clear conception of what it is about; but when they picture to themselves the long alley, the making of the rope, and the poet musing over the various uses to which the rope here made can be put, they will not only enjoy a short study of the poem, but they will also suggest several important uses of rope that Longfellow seems to have forgotten.

We enjoy literature from the complete thoughts that we take out of it. To begin a poem with minute analysis or Intensive Study intensive study tends to leave an impression of details, not of a whole. If such an introduction to beautiful poems is distasteful to the more mature minds of high school age, which are often turned forever from poetry because of the interminable details and analyses forced upon them, how repugnant it must be to younger pupils! Impressions thus gained are responsible for much of the dislike for "school reading." If, by getting the complete story into their minds, the children enter first into the life, motion, vigor, of such a poem as "The Skeleton in Armor," they usually take up readily more detailed study of difficult words and passages; indeed, they frequently want to know what these very portions mean, for they come to see that some thought is not complete without an understanding of the more intricate passages. This is usually all the intensive work needed by young children, or that it is advisable to give them. 
Word studies should be growing in importance by the time the fifth grade is reached. Selection of synonyms, de-

Word fining words, giving attention to root syllaStudies bles, prefixes, suffixes, and their meanings, may all be made interesting research for the children, who are thus growing in knowledge of words and power over them. Training should be given in the mysteries of the dictionary, for, to a child beginning its use, it is really a sealed book.

The training of earlier years in forming clear concepts should be continued. Narrative drawings by the pupils

Clear

Details strengthen the ability to do this by giving visible form and completeness to the imagined pictures. Outlines improve the judgment and the power of analysis, both of which are weak with children of this age. Maps make more real the geographical references, thus broadening the child's knowledge of the world. Where the globe and wall maps are used intelligently, and no attempt is made to require a child to memorize all that is told him, map work is a delight to children, who pore over maps again and again, thus gradually absorbing what it would be impossible for them to learn and assimilate in many lessons of drill.

The pupils see some of the simpler beauties of the poems if their attention is called to the comparisons, which can soon be differentiated into similes, metaphors, and personifications. There should be no intention of teaching figures of speech; the desire is to show how more enjoyment can be obtained from the poems. The result, however, is that many of the pupils do learn these three figures very accurately, while others are prepared by observation to learn them more 
readily in later years. This recognition of the figures by fifth grade pupils and naming them correctly should come slowly and by imitation, rather than by drills and direct teaching. The teacher explains often how she recognizes each one, and the children gradually acquire the same power. The first step, that of selecting a comparison, will be enough for many slowly maturing minds.

The following thoughts are from a fifth grade teacher: ${ }^{1}$

Little reproduction is attempted with the poems by Longfellow, for it is thought better to have the child retain the Reproduction poet's own charming expressions. Two of the main objects of this year are to inspire in the child a love for the beauty of the thought expressed in a poem, and a recognition of some beauty of form as found in rhythm and musical rhymes. If a reproduction of such a poem as "The Village Blacksmith" is asked for, we find it all cheapened, even to the child himself. He is right when he says, "I know it, but I can't say it." Who would attempt to express those thoughts in any language but that of Longfellow? In a poem like "The Wreck of the Hesperus," where a clearly defined story is found, reproduction is in place; but it is the story of the whole that is asked for, not an exhaustive paraphrase of stanza after stanza.

After reading the poem for the first general conception, we go back and make a more intensive study. The pupils

Detailed Study are asked to look out for themselves the meanings of the new words found in the stanzas, slow work at first, for at the beginning of the year a fifth grade pupil is but slightly acquainted with his dictionary, and has to be given special lessons in its 
use. Again we go through the poem to see the pictures to be found there. The pupils look for the number of changes, the "pictures," which they can find and describe. Sometimes the passage is read to them while they sit with eyes closed, and then they tell all that they have imagined, going even into details. What one does not see, another sees; and many times, when ideas do not agree, very animated discussions are brought out as one pupil tries to convince another about the right interpretation. Finally, out of a combination of the suggested ideas and of those clearly expressed, a very/definite word picture is brought forth. The child has been made to see with his mind's eye, and has been led to stand and express himself in words coming from independent thinking, not in the language of reproduction.

Personal study along various lines is carried on every day. The dictionary is to be used, words are to be studied, papers

Personal

Study

are to be written. The greater part of the time for these purposes comes from periods set aside for the more formal language work and for penmanship. Sometimes the pupils are asked to copy a poem, especially for training in punctuation, spelling, and accurate transcribing.

Finally, the poem is read through carefully, considered line by line, stanza by stanza, in order to leave with the chil-

Final

Reading dren a clear understanding of the complete thought. Then an outline is made by the class. The pupils suggest the topics, the best ones are chosen, written on the board in proper arrangement, and copied during the next study period. Part, or often all, of a poem is learned, and in some cases written out from memory. In such poems as "Excelsior," where a 
moral lesson may be inculcated, the deeper thought is left until the last. Merely the story is taken first; then, if the children seem ready for the inner thought, it is taken, but it is never forced. Recently, after the study of "Excelsior," a particularly appreciative child asked if the poem did not have another meaning than the one that had just been brought out by the story. The question led to a discussion of the great life lesson suggested by Longfellow, after which the children loved the poem far more than they did the others studied. Toward the close of the school year, when a paper was written on "My favorite Poem," more than half the class chose "Excelsior" and "The Village Blacksmith," giving in substance as a reason for the choice that the first might apply to themselves, and that the second might mean any good man whom they knew. The time given to these poems varies considerably. Such a one as "The Skeleton in Armor," where the life of a strange people in a foreign country and a distant age has to be discussed as a preparation to the poem itself, may take from two to three weeks. The shorter poems may be completed in two or three days.

The papers of the pupils, saved throughout the year, show that a great deal is gained from ten months' study of LongResults fellow. There are drills in reading and writing; the arousing of independent thought; the inspiring of a love for Longfellow and his poems; the memorizing of many poems, usually with little effort; an ability, gained by nearly all the class, to read and enjoy for themselves the simpler poems of our writer, and to see and appreciate some of the beauties of his style.

The following reproduction of a poem by Longfellow was written by a fifth grade girl. It is accompanied by a study 
of words and another of figures given the class in connection with reading the poem. Probably the majority of the pupils knew much or all of the poem by heart. The quotations used are from memory, as is shown by the failure to remember the arrangement of lines. No corrections have been made.

\section{The Wreck of the Hesperus.}

It was a cold stormy day, and the schooner Hesperus was sailing along the coast of Massachusetts. The skipper had taken his little daughter with him to bear him company. She was a beautiful little girl with eyes as blue as the fairy flax.

He was standing beside helm watching the veering flaw blow the smoke in different directions when an old sailor came up to him and said, I pray thee put into yonder port, for I fear a hurricane. Last night the moon had a golden ring, and tonight no moon we see." The skipper did not believe what the sailor had said and paid no attention to him.

Down came the storm and smote the vessel in its strength. The skipper called his little daughter to him and said, "do not tremble so, for I can weather the roughest gale that ever wind did blow." He wrapped her in his great seaman's coat and bound her to a mast.

The little girl said that she heard the church-bells ringing and asked her father what they were and he answered that it was the fog-bell on a rock bound coast, and he steered for the open sea. She heard the sound of guns and asked her father what it ment and he said, some ship in distress that can not live in such an angry sea." Again she cried out that she saw a gleaming light and asked what it was, but her father answered never a word for he was dead. 
He was lashed to the helm all stiff and stark and a lantern gleamed on his fixed and glassy eyes. When the child saw her father was dead she prayed that she might be saved, and she thought of Christ who stilled the wave on the Lake of Galilee.

The vessel swept through the sleet and snow tow'rds the reef of Norman's Woe.

The vessel struck on some rocks, and like a vessel of glass she stove and sank. In the morning a fisherman stood on the shore aghast to see the beautiful child lashed to a drifting mast. The tears were frozen on her eyes and her hair like the brown sea-weed floating on the waves.

"Such was the wreck of the Hesperus,

In the midnight and the snow

Christ save us all from a death like this

On the reef of Norman's Woe."

In ordinary class work this paper, which is presented in uncorrected form, would be returned to its writer for personal correction. Omitted words would be supplied in all cases, probably, with a possible exception in the last sentence, where the child's ear might not recognize the necessity of the verb in connection with "floating."

Sentence structure, so difficult a problem for children, is faulty in the repetition of "and." There is excellent drill for the class in putting such sentences on the board and in having the pupils develop better structures by the omission of " and" or by the use of relative pronouns or adverbial connectives.

There can be no objection to the use of the poet's own words in such a paper. The child is consciously reproducing 
or quoting, and the elevation of thought and language is very evident.

\section{Word Study Lesson.}

I. Schooner, sharp built vessel, having two or more masts. 2. Skipper, master of a small vessel. 3. Helm, instrument for steering a ship. 4. Veering flaw, changing wind.

(This careful defining of words is a frequent exercise, every lesson containing from fifteen to twenty-five words.)

\section{Similes.}

As the fairy flax. As the hawthorn buds. Like yeast. Like the dawn of day. Like a frightened steed. Like a sheeted ghost. Like icicles from her deck. . As carded wool. Like the horns of an angry bull. Like a vessel of glass.

\section{SIXTH YEAR GRADE}

Literature and history are still alternated in this grade in periods of ten weeks each. Whittier is the poet for the year. Material

The first ten weeks are given to several short poems and "Snow-Bound"; during the second literature period some more of the short poems and "Among the Hills" are read. It is desirable that the teacher plan to keep before the pupils the complete thought of a short poem, and of every division of a long poem. This is more important as the works read grow longer and the opportunities for intensive study increase. There is great pleasure for pupils in "Snow-Bound" and "Among the Hills," provided that the methods and difficulties belonging to maturer study are not forced upon their young minds. Many involved sentence constructions are readily mastered by grammatical analyses; that is, by connecting subject with predicate, locating modifiers, or by using simple diagrams. 
This is not done in the grammatical spirit ; it is for assistance in literary interpretation, although the practice strengthens the child greatly in understanding his grammar and in applying it to his daily needs.

There are delightful character studies in "Snow-Bound." The pupils should observe, discuss, and recreate the character of the father, mother, aunt, and other members of the family, not forgetting Whittier himself. Have them interpret a New England home and the life of the affectionate Quaker family. Lead them to enjoy the beautiful figures of speech. Some of the last stanzas are too difficult for pupils of this grade, but that is no reason why they should not read all the delightful first portion of the poem. What can not be understood can be omitted, or, better yet, it can be shown as a fitting conclusion by means of the teacher's interpretation.

The prelude to "Among the Hills" should rarely be attempted by sixth grade pupils for a beginning, but it may be used as an admirable ending and summary of the poet's thought. After the scenes of the poem itself have been pictured, the children are ready to imagine the drowsy heat of the summer day and the desolate, forlorn homes, where love is lacking.

Careful attention should be given to oral reading. Pupils in the grammar grades lose much of the proficiency in reading aloud that has been gained in the primary classes. This is due in part to growing self-consciousness on the part of the maturing boys and girls, and in part to the fact that silent reading is supplanting reading aloud, making the latter seem only an exercise instead of a means of acquiring knowledge as it was in younger days. 
The following methods and experiences are taken from the work of a sixth grade teacher: ${ }^{1}$

Some of the aims in literature for this grade are, to give the children a genuine appreciation of a few of Whittier's Aims beautiful and uplifting thoughts; to cultivate the ability to read intelligently aloud and silently; to train a readiness in expression, both oral and written.

In "Snow-Bound" and "Among the Hills" the pupils are prepared by a discussion of the geographical setting of Treatment

the poem for the climatic conditions and the occupations that will be referred to in the reading. The pupils then listen appreciatively to the reading of "Snow-Bound" by the teacher. These discussions and readings may take three days, but after them the children are ready and eager to begin their own work with the poem.

After a general but complete thought of the poem has been grasped by means of the reading by the teacher, the poem is divided into three parts for ease in studying it:- the storm, the evening at the fireside, and the day following the storm. The pupils now read, giving their own interpretation of difficult thoughts and phrasings. Aided by a few suggestions from the teacher, they picture the Whittier home on the dreary December day,--the low-hanging clouds, the great circle around the sun, the east wind bringing from the distant shore the roar of the angry ocean, all forerunners of the coming storm. We imagine the day's work, digging a path to the barn and preparing for the coming night, when all gather around the blazing fire to listen to songs and stories. The kitchen, too, is new and strange to all the class.

${ }^{2}$ Miss Charlotte Treanor. 
The children are greatly interested to know that the old house is now owned by the Whittier Memorial Association; and that the bake-kettles, bellows, foot-warmers, candle moulds, and some pieces of old china are still preserved. The first division of the story having now been read, it is completed by narrative drawings, written descriptions, brief outlines of different topics, and language exercises.

The second division of the poem with us is the evening at the fireside, where,

\section{"Shut in from all the world without, We sat the clean winged hearth about."}

This we try to picture very clearly, for this is the home life of the Whittier family as seen by the loving son and brother. At last the great logs crumble down; the "bull's eye watch" points to the hour of nine; and the pleasant circle separates for the night. The uncle remains behind to cover up the embers; the mother stays to express in quiet her grateful thanks for the blessings that have been granted all; the boys climb to their chill attic, where they lie listening to the storm sounds without. Soon sleep steals over them, guiding them into

"The summer land of dreams."

Through this part of the poem comparisons of the characters are made and short sketches are written about the members of the family.

The third division of the poem deals with events after the clearing of the storm, when, at last, with the coming of the village newspaper, the ice-locked door of the world swings open again, and the family is in touch with fellowmen. It 
is with regret that we reach the point where Whittier closes the book of his memories, for by this time the members of the family are our friends and their interests are ours. The last two stanzas, however, are too difficult for sixth grade children, and the poem closes for them with Whittier's apostrophe to memory, the "angel of the backward look."

The papers, or "stories," based upon the poem are now written. When they are finished enough time has elapsed

Final

Reading after the second reading of the poem so that it can be given its final reading without the repetition being at all tiresome. This final reading serves to put all the thoughts together as a whole, to connect its pictures, to interweave its characters and recitals, and to discover new beauties. These are found in the figures of speech, which are studied for the enjoyment that they give, not to develop rhetorical knowledge. One result, however, is that the pupils, already prepared in the fifth grade by their studies of comparisons, recognize with considerable readiness nearly all the similes, metaphors, and personifications, calling them by their proper names. This understanding of the simpler figures adds greatly to the pleasure of the children in the poems.

Memorizing is frequent, but is made as easy as possible. The children are at an age when they remember easily and Memorizing constant supervision is given to training and exercising the memory. Much of the poem is learned almost unconsciously. The teacher may start a line, asking someone to continue, someone else to go farther in the quotation, then still another to give the whole. By almost daily observance of this practice the pupils form the habit of memorizing, and the amount retained by some pupils 
is surprising. Memories thus trained hold on most tenaciously to what is read.

The treatment of shorter poems is about the same as that of divisions of long poems; that is, mastery of a comShort Poems plete thought; the connection of successive thoughts; a first reading for understanding the poem, for grasping its complete thought ; a second reading for detailed study, for grasping and connecting the successive thoughts; separation of the purely interpretative and the purely analytical ; oral reproductions or narratives based on the thoughts of the poem; written reproductions; word studies; a final reading to leave in the mind the poem as a whole, encasing its beautiful wordings and thoughts. A few of the shorter poems by Whittier receive special geographical treatment, as "The Fishermen" and "The Lumbermen." "The Poor Voter on Election Day" may be read after a mock election.

Illustrations of various sorts are used. There are Perry pictures and selections from magazines and other publicaIllustrations tions; the children make narrative drawings of incidents selected by themselves or suggested by the teacher. This year Whittier's home on "that bleak December day" was constructed by the children. The house, the corncrib, the wellsweep, were made by the boys; cotton was used for the snow; the members of the family were represented by tiny dolls dressed by the girls. The miniature stage was set to show

"Sweet doorway pictures of the girls,"

as the oxen and the drivers came plodding along down the hillside. 
The term closes with a sketch of Whittier's life as it is known after twenty weeks spent in the study of his poems.

By the time the sixth grade is reached the papers are too long to be given in their entirety. Extracts, however, show some of the progress made by the pupil in composition and in his comprehension of literature. They also indicate lines of correction and guidance for the teacher.

\section{Among the Hills.}

Prelude.

Whittier commences the prelude of "Among the Hills" by telling of a hot, quiet, sultry, summer day. There was only a little wind and that was a high one, because just the tops of the maples made a faint motion. Everything seemed to be lazy and the only sounds were the locust and a hay wagon creaking along with the driver half asleep. The goldenrods were drooping in the sun and through the door came a drowsy smell of heliotrope, clover and mignonette. The harvesters were resting under the trees as it was in the hottest part of the day, which was noon. As they were resting there they told riddles and sang.

The day was very hot and hazy and the sheep were huddled up against the stone wall, for it was the coolest and shadiest place they could find. Whittier had been busy a long time writing and lecturing about slavery but now, when he has finished, he begins this poem. He says that all are not idle, a farmer's son who took a fancy to work did his work in the field and was proud of it.

The farmer and his family were willing to do their work and as there was love, harmony, and beauty in this home the 
work seemed easier. As the farmer loves his wife, he is just, generous, and tender toward her. After Whittier described this home he said,

"I know too well the picture has another side."

Then he thinks of away back and describes a bad, dirty home. The people are well off but they are so stingy and selfish that everything seems uncomfortable and they grow old before their time. There is no love or beauty or harmony in their home and nothing seems happy as in the other home. They have no flowers, trees, or vines around and the only things growing are weeds and burdocks, because they grow without cultivation. These people do not notice anything beautiful, as the turning of leaves in October, the sparrow's and bobolink's song, the beautiful hills, the woods, and the sun and flowers.

They go to church because they are afraid of the unseen Powers, but when it comes to pay pulpit-tax or pew rent they grumbled.

The walls of the house were blistering in the sun, because there were no vines or trees to shade them. Instead of curtains, rags were stretched across the window panes. There was confusion in the kitchen and the floor was not washed, the only times it was cleaned was with a broom. The best room was like a cellar and as it was always shut up from the air it was damp and suffocating. There were no books in this room and the only picture was that of an old green haired, peony cheeked woman sitting under willows that couldn't be recognized.

The women that lived here were always complaining and quarreling and the men were cross and sullen. These peo- 
ple had no love, and they piled up their rubbish against the chimney, then covered it with logs so that it couldn't be seen, and they were also talking ill of their neighbors most of the time.

They tried to save in everything and when they had pork, they only put a little salt on it. They thought that the "Sermon on the Mount" is no more than an outdated almanac. These people had plenty of land but they didn't till any more than half of it. When the beggar came for something to eat they refused him but he thought that he was better off in his best than they were by the way they were living.

Whittier says that a home is not like the one just described when there is love, happiness, and beauty, and people plant flowers and vines. He also says that if people have the money they should have nice homes as most of them are now but once in a while a bad one is found. At the last of the prelude Whittier calls happiness "Golden Age" and he thinks that it ought to come to every one living in this country,

"Where whoso wisely wills and acts may dwell As king and lawgiver, in broadacred state, With beauty, art, taste, culture, books, to make His hour of leisure richer than a life Of fourscore to barons of old time."

This paper shows what is so often found in those grammar grades that are so fortunate as to be encouraged into thought growth and thought expression, - a power of thought in advance of mechanical accuracy. It is a natural condition under the circumstances just mentioned, and it is far safer for the child's development than when the reverse 
is true, and mechanical processes are drilled and drilled upon with little or no thought behind them, and less possibility for its development.

The nature of the mistakes made indicates the kind of drills needed, probably by the majority of the class. Indeed, almost every error in this paper is suggestive of class work, rather than individual correction; while it would be almost labor lost simply to write corrections on the composition. The errors are not careless, they are the result of growth, and they have deep, underlying reasons which must be laid bare to the child and drilled out of his use. Some of them are indications of the most necessary grammar work; some show the needed help in rhetorical lines. Generally speaking, they are lack of agreement between pronouns and their antecedents; lack of continuity in the tenses of the verbs; occasional disagreements of number between verbs and their subjects; punctuation lags behind the sentence structure, for semicolons are needed in several places, and a number of constructions with the comma called for by the sentences are evidently unknown to the pupil; the paragraph sense is rather weak.

These are all rather mature points for sixth grade pupils, and they are undoubtedly just the ones that are being presented in the class drills as preparatory to direct instruction in them later.

That which it is important to note is the clearness with which the child's production points out the next steps that are desirable in instruction. If this is a typical paper, the class drills are easily seen. 


\section{SEVENTH YEAR GRADE}

If, as the children mature, an appreciation of the reading selected for school courses is to be fostered, extremes must Selection of Material

be avoided:- there must be neither too much nor too little; it must be neither too difficult nor too childish. Too much reading gives no opportunity for thought; too little is mental starvation. Thoughts that are too difficult discourage a child; those that are too childish disgust him with class discussions and drills. Without the thoughtful consideration that can be given a limited number of books, there can not exist that appreciation of the finer literary qualities which brings æsthetic rest for the mind, and which helps clothe the ever pressing practical side of life with poetry and nobility. On the other hand, if reading is scanty and lacking in the elements through which intellects grow, the minds are left empty and barren of all the great thoughts of the centuries. Sometimes, a meager supply of reading in class comes from the desire of the teacher to analyze exhaustively every sentence, thereby limiting the amount that might otherwise be mastered. Grammar grade pupils are not ready for this kind of study, although it is true that they can be held to its performance. Such a method is almost sure to deaden any love for the great masters in literature. Children should not analyze their writers, they should revel in their works. This must not be considered as meaning that pleasure is the only profit in reading; but, with grammar grade pupils, a desire to read and an enjoyment of the books read are the most important aims to be attained. During every school year there should be enough reading material handled to train the pupil's mind 
to a ready comprehension of a complete story or poem, and to create the sense of power that comes with rapid acquisition. On the other hand, the amount should be so limited that the striking beauties of every selection can be appreciated, its great thoughts sounded, its characters known, and its author made familiar to the reader through the general features of his style.

Written exercises should be short and frequent rather than long and occasional. One power to be fostered and guided by reading is the ability to use good English. An excellent way to stimulate such an ability is to write frequently and while in close enough touch with the author to be inspired by his genius. There need be little fear of educating plagiarists. Where there is much conscious reproduction, the pupils will distinguish for themselves between an original use of words and thoughts and borrowing from an author.

The following is a résumé of some of the work done in a seventh grade class: ${ }^{1}$

Seven works are read in class during this year: "The Talisman," "Ivanhoe," "Courtship of Miles Standish," "Evangeline," "Rip Van Winkle," "Legend of Sleepy Hollow," and "The Spy." The first two are abridged, the others are in complete form. These seven do not seem too many books to read, discuss, study, and write about during the ten months of the school year. "The Talisman" and "Ivanhoe" come in connection with some history work on the Crusades, which precedes our history of the United States in this grade. "Miles Standish" and "Evangeline" are connected with the colonial period. "Rip Van Winkle," ${ }^{1}$ Taught by Mrs. Carrie Berdine Goode. 
"Legend of Sleepy Hollow" and "The Spy" precede or accompany the Revolution.

The maximum time permitted in the schoolroom every day for preparation, reading, discussion, and written work Time is fifty minutes. Many pupils, however, who take a pride in their notebooks, spend much extra time upon them. This does not interfere in the least with other studies; it is simply utilizing leisure time.

Independent preparation must be insisted upon, for selfdependence is a most necessary lesson to learn. The pages or the topics assigned should be carefully studied. The teacher often gives definite assistance by putting on the board such directions as these: Read the chapter attentively; be able to reproduce it orally; define the following words, - ; explain the following lines, __ ; picture to yourself certain scenes; how is this lesson connected with the preceding reading?

The recitation following this preparation is as varied as possible. There are readings and discussions; words are studied; difficult constructions are explained; all kinds of allusions are noted, explained, or assigned for the next day ; a few rhetorical figures, principally those familiar in the lower grades, are considered, and new ones are occasionally taken up, if prominent in the reading. The lesson as prepared by the pupils is always the basis for the recitation, but it is far from being the limit; for the recitation is more than a period for testing; it is an opportunity to teach good habits of work, to show the desirability of broad information on many subjects, and to develop the mental powers of the children. The humor of the author, his vivid descriptions, his ability to make his characters live for us, are all talked 
about. Many questions are asked to bring out the thoughts conveyed by the lesson. One question often asked in some form or other is, "What has made this chapter so interesting ?" or, "Why has this chapter not been as interesting as the preceding?" Spirited and varied are the answers of the youthful critics.

During the reading in class, while the more careful study is under way, pictures of scenes in the story are presented. Pictures

For this purpose books are brought from the public library, magazine articles are utilized, and home libraries become more familiar to the children. As abridged editions of "The Talisman" and "Ivanhoe" are used in class, the teacher often reads some of the vivid descriptions in complete form and recommends them to the pupils, many of whom read the longer edition.

The written work based on the literature averages about twenty minutes a day for ten months. Notebooks are kept, Written Work and every pupil is responsible for every subject treated, for every map, and for every drawing. The notebooks are in every day use and are taken care of by the pupils themselves. Ordinarily a paper is written and submitted to the teacher for criticism, then it is copied if necessary and put into the notebook. Many of the portfolios thus made consist entirely of first papers, that is, of uncopied papers which have required little or no correction. Before writing begins a clear statement is made of what is desired. If the paper is to be a character sketch, a short narrative, or a description, a short outline is placed before the pupil as a guide. If it is to be an outline of a chapter or of a poem, the class work it out either as a composite production or they do it individually. 
While the pupils are writing the teacher passes among them, dropping a hint, suggesting a change, or making a correction. After the papers are completed one is selected for criticism by the class. Portions are placed upon the board; pupils point out faulty constructions or erroneous ideas, and reconstruct the passages. This method is followed about once a month, but all the papers are corrected by the teacher every time a set is written. The corrections made in the papers by the teacher relate to spelling, punctuation, grammatical errors, and poor style. A few words on the margin of the paper often indicate the nature of the weakness, as: "A poor beginning." "Reconstruct this sentence." "Meaning not clear." "Rewrite the entire paper." "I cannot understand your thought." "Story too long." "Too much repetition."

Some of the most interesting lessons of the year are those spent in determining what has been learned about the author Gains by the Pupils through his book; in discussing the qualities that make certain characters the hero and the heroine; in recalling incidents similar to those mentioned in the story; in bringing out the lessons taught; in discussing the inspiration for living that one can gain from such characters as Rebecca, Ivanhoe, Miles Standish, Evangeline, Priscilla. There is, however, a subtle impulse that pupils receive from the right kind of literature that can not be described by the teacher nor illustrated by any visible sign. Many a pupil may read an entire book, study it all carefully, write frequent papers upon it, and yet not be able to give account of the most valuable information that has been imparted by its pages; but, if he has been enthusiastic, he has gained a desire to read more works by tal- 
ented authors. Companionship with great writers means that a child's leisure may be valuably filled, and that an intangible, immeasurable influence may have begun to elevate his life. No matter how many ends have been served by the child's study of literature, surely, this is the highest.

In literature, as in the other studies, a notebook is kept by every pupil. Some of the papers it contains are original, some are the result of class work, some are given in substance by the teacher; there are maps, drawings, illustrations, suggestions from various sources. The result is often a very pleasing whole, although failures and imperfections mar this phase of the work as frequently as any other, for the notebooks are as purely individual as any other part of the year's work.

\section{EIGHTH YEAR GRADE}

During this last year of the grammar grades the works read are principally from American authors, although Scott Material and Dickens are also represented. It is intended to associate every American author read with the period of history in which he belongs, and to present some of the formative influences of his times. Period dates are to be kept in mind, but it is hoped to accomplish this by grouping events around a central date rather than by sheer memory of many dates.

Acquaintance with the author is broadened and deepened by reading aloud to the class additional poems or extracts from stories and essays, and in many ways the teacher tries to keep the pupils interested, thoughtful readers. In their pleasure will be found an incentive to read more; in their 
thoughtfulness will be the means of growth; and in the wise selection of books, toward which they should be guided through the school acquaintance with authors, will be the safety in their reading. 


\section{LANGUAGE}

\section{CHAPTER IV}

IMPORTANCE OF LANGUAGE TRAINING FOR ALL PUPILS

To use good English is of as much importance to the business man as to the frequenter of social functions, but this

Language Training "good English" must not be interpreted as meaning simply scrupulous grammatical accuracy. Such precision is important to the cultured, thoroughly educated man; but of far more importance to the future of the ordinary boy or girl is the acquirement of an easy flow of language, spoken and written, that is concise and accurate in the choice of words, terse in the utterances, explicit in the details, truthful and convincing in argumentation, according to the pleasure or need of the occasion. Such a power is of inestimable value in the home, the workshop, the office, in any professional career. Natural to some people, almost denied to others, the school is the training room for its acquisition by all.

In our city there is carried on throughout the eight years of the grammar schools a definite, systematic plan for the elimination of common errors of speech and for the training into an easy, tolerably correct, and ready use of English in written and spoken form. From the first year three divi- 
sions are made in this training and three kinds of drill are constantly practiced. These divisions are:-oral language; technical work, consisting of applied grammar in the four lower grades and of drills and textbook grammar in the four higher grades; composition.

Since to converse is a necessity for all, why should not a part of the school time be used in exercises that tend defi-

Oral

Language nitely toward gaining power in oral expression? Children of the first grade should begin to reproduce stories, to narrate incidents of personal experience, to describe persons, actions, and objects. This training, simple as the child's own life, should accompany his development, broaden with his widening horizon of thought and observation, and adapt itself to the growing power of expression that belongs to every succeeding year of school life. Oral exercises should be of about the same grade of difficulty as the written ones, and should precede when both are given on the same subject. There should be as great a variety of topics as possible, chosen from the known elements of the child's life. Narration predominates in all grades; but there should also be simple, accurate descriptions, expressions of opinions, pictures of people. While talking, the child should be very free from the restraint of formal training, telling freely his thoughts about the suggested subject; later, there will be a special time for the consideration of errors and the substitution of correct forms.

One of the methods to which children respond most readily and unconsciously in oral language is the reproduction of stories. It is a useful servant in all grades, but, like other servants, it should not be overworked. The effect of this 
exercise is quickly seen in an increased vocabulary, new and easier expressions, greater continuity of thought, and a better conception of the development of a story and the story interest. Reproductions should not be permitted by the teacher to degenerate into mere memory recitals; they should have some of the vim and skill of the raconteur. To develop this power one must never lose sight of the interest in the story, felt by nearly all children, and also of the natural desire to gain power, to do better and better work, to be wiser today than yesterday.

In the primary years it is advisable to have some reproductions on the same day as the narrative by the teacher,

Steps in

Reproduction

while the interest is still keen and the memory retentive. Volunteers are called for, perhaps; or, the teacher selects some pupils who are sure to make a very good beginning in the reproduction. Gradually, all of the pupils take part, and all of the desired portion is given. The whole is a composite, made up of many small offerings, not the least of which is to be scorned. It is very difficult for some little ones to offer anything at all; moreover, the tiniest piece of marble may be just what is required to give proper form or the right touch of color to the finished mosaic.

What to do with this oral rendering, this composite story, is often a puzzle to the teacher. As a finished product it is unsatisfactory; as a step in training it is acceptable. It is, therefore, as a part of the training that it must be considered; here it serves several important purposes. It lays bare the pupil's faults in speech; it suggests to the class the material that every pupil should eventually be able to give alone in reproduction; touched up by the teacher, all or part 
of it may be written on the board, where it serves as a reading lesson; later, when the pupils can write, it is copied from the board, the first composition work possible for the youngest pupils.

The errors noticed in the conversations and reproductions furnish subject matter for many technical drills, which should

Technical be a part of the training in every year; for Drills accuracy in either written or spoken language can be gained only by long and patient observation and drill. Monotony must be guarded against, that enemy of technical language drills. In the teacher's mind the corrections should be grouped around grammatical principles, not because the child is to learn grammar, but because the teacher will do more effective work if the errors are treated systematically.

The past tense of the verb is one of the topics that the teacher should have in frequently recurring drill. To be is a good starting place. Were is an almost unknown word to many children. It must be introduced to them, then there must be explained its use when speaking of more than one person or object ; many drills must follow. "You was," "we was," "they was," are the torments of all primary teachers, and they are not unknown to the ears of even grammar and high school teachers. Even young children can learn that these forms are incorrect, and they can be given the right word as a part of the conjugation:

$\begin{array}{ll}\text { I was } & \text { we were } \\ \text { he was } & \text { you were } \\ \text { she was } & \text { they were }\end{array}$

The pupil readily accepts the conjugation as correct, and he 
sees that "you was" does not belong in his speech; then comes the effort to use the new form. To see and to do are separate matters, but the doing is easier when the reason for it stands out clearly. A At first the pupils say the conjugation, often completing a sentence with every form, as :

I was hurt yesterday

He was hurt yesterday

She was hurt yesterday
We were hurt yesterday

You were hurt yesterday

They were hurt yesterday

These repetitions give the necessary knowledge, fix the correct forms in the memory, and train the ear and the tongue. After the conjugation, the pupils give many short sentences, using the correct word. Such drills should be short, from five to ten minutes long, but the work should be rapid and unflagging.

There must be no attempt to teach technical grammar to thè little children, except in so far as it is a natural and comprehensible explanation of errors and an aid to their removal. On the other hand, corrections are rarely effective when confined to incidental suggestions in the schoolroom, because a reason for the change in speech is often necessary to convince a child of an error in the customary form. This is natural. A child from a careless or ignorant home, who never hears "you were" but who hears the incorrect "you was" fifty times or more a day, can not be expected to accept readily the really foreign "you were" by simply hearing it a few times in the schoolroom and by being corrected occasionally. Only a naturally self-observant child, desirous of progress, will thus change his language. It is useless for the teacher to become discouraged; equally valueless are scoldings and faultfindings. The child must be given a 
desire to speak properly, and a reason why the old usage is not right; the correct form must be clearly understood; then must follow long and patient drill to overcome habits of years and existing daily environment. The mind must be convinced, desire must be aroused, the ear and the tongue must be educated, and the memory must be brought into active.service; by these means considerable progress will be made. That so many children do acquire a correct use of English must be the teacher's encouragement in this somewhat disheartening task.

Composition, or some form of written exercise, is an imperative part of language work. It should be used freComposition quently in every year of school life. The conversational ease and frequent laxity of oral exercises can be turned into more polished constructions and accurate expressions when put into definite written form. To a first grade child a written sentence should be a pictured thought with letters, capitals, and punctuation marks all properly arranged. By frequent drills, made so interesting that they do not deaden the desire to acquire power and knowledge, this acquaintance with a sentence must pass into mechanical accuracy, until easy sentences are written properly, without that struggle for correct expression that so frequently mars the pleasure of writing. Pupils like to write. Unfortunately, injudicious teaching too often transforms the pleasure into a dreaded task.

Composition follows the lines of development observed in oral exercises, through narration, description, and explanation, into character sketches, biographical details, judgments, discussions, debates. The first step is copying the composite stories. Original reproductions come next. These, rare in 
the first year, are permitted more and more frequently as the pupils grow older, until copying is used only for the most technical drills. The two forms differ radically from each other. Copying is mechanical, formal, requiring close attention to accuracy in details; the original reproductions,

Original Writing while based upon memory, permit some use of the creational, formative powers, demanding an absorption into the thoughts of the subject that is often detrimental to the mechanics of composition. Manifestly, the methods of producing the two forms of writing, and the purposes that they serve in the training of the child must differ greatly. The copying is for mechanical accuracy; the original writing is for thought development and growth.

In the original writing the interest must be preserved. The flow of ideas in the story telling must not be checked by reiterations about mechanical details; these will be attended to at another time. When the child can write by himself let him spend some unbroken time over his narrative or description. Let him express his thoughts unchecked, just as a mature person must do if he is not to lose the inspiration. That is, give the inspiration opportunity to develop, unhampered by the fear of mechanical errors. Separate the formal from the formative. Since training for habit must always be a part of our work with children, this freedom from interruption during writing must not mean careless work. The pupil should try to write as correctly as he can in this first draft. He will be assisted in doing so if correct spelling, capitalization, punctuation, are referred to by the teacher before the writing is begun, and the pupil is encouraged to make this first writing as free as 
possible from mistakes. But errors will occur. Who is absolutely free from them in making a first draft of a manuscript? The teacher should not be impatient nor the child discouraged. Put the papers away for a day or two, as a more mature writer would be liable to do, then give them back to their writers for corrections, and it will be surprising how many of their own mistakes the children will notice. This is the most helpful kind of correction, for it is self-help.

There are two lines of correction and criticism to, be observed constantly:-known errors, or those on which there

Correcting

Papers

have been class drills which have made them familiar to all the pupils; unknown errors, or those which the children have not yet learned to recognize as mistakes. The method of correction should be radically different for these two kinds of errors. Pupils should be held to self-correction of the former, just so soon as the drills have been sufficiently thorough to warrant thus throwing the responsibility on the child; but they can only be assisted to understanding the second class of errors in preparation for later study. Advanced grammatical points, good sentence structures, unity and harmony of thought, composition of paragraphs, can be subjects for class criticisms, suggestion, and drills, gradually and whenever the pupils reach the necessary development for their comprehension. It is surprising how critical children become about their own productions, and how helpful they are to one another, under friendly, suggestive guidance. This is the beginning of real power. It is learning to recognize and to correct one's own weaknesses.

Writing papers belongs to the literary side of education, to the intensive, the inspirational, the formative; but cor- 
recting papers belongs to the analytical, the technical, the accurate, the formal. Correcting papers is a serious and difficult task in all grades, even in the first, for upon the success of the criticism and the correction depends the growth of the child. It is wasted energy for the teacher to spend solitary hours in correcting papers or in indicating their errors. Such efforts rarely result in more than correct papers, while it is the child who is to be corrected, and who must learn to correct himself. The only true help is in guiding others to help themselves; and to wear out the teacher over piles of exercises is a false conception of values. The teacher's freshness, enthusiasm, and vigor should be for some immediate work with the children; they belong in the schoolroom, not in solitary work at a desk over papers. At the same time, the pupils must have the advantage of careful corrections or their writing will be in vain. This can be gained in various ways. Oral class drills make plain the common errors and the correct forms that should replace them; class correction of a few papers out of nearly every set handed in shows the care taken by some pupils and the thoughtlessness of others, it is also further drill in correcting old errors and in pointing out new ones to be avoided; holding the pupils responsible, within reasonable limits, for overseeing their own papers opens the way for them into selfhelp, while, incidentally, it relieves the teacher of much drudgery; an occasional exhaustive criticism of a whole set of papers gives exact valuation of the work of every pupil. Constructive criticism leads out into new fields of exerCriticism tion; consequently, children should be helped, stimulated, encouraged, into new efforts. Adversative, severe criticism belongs only with 
carelessness; it should be for the purpose of throwing the burden of careless errors where it belongs,-upon the pupil. Pupils trained to these two kinds of criticism, and through them out into self-criticism and self-correction, write more surely, accurately, and willingly than do those whose papers are regularly corrected by the teacher for the pupils to rewrite. 


\section{CHAPTER V}

\section{ORAL AND WRITTEN LANGUAGE WITH PRIMARY GRADES}

\section{FIRST YEAR GRADE}

The following thoughts from the schoolroom are by a first grade teacher: ${ }^{1}$

During the first four months of the first term in school the time devoted to language has for its special purposes

First Lessons

in Language accustoming the child to freedom in expressing himself, leading out as rapidly as possible into the substitution of correct forms for the many errors that mar the speech of the ordinary child. Ten minutes are used for this purpose in the morning, ten more in the afternoon. At first the pupil is led to talk easily and naturally about any familiar object, animal, or game. He is making statements, or "telling stories." A tiny narrative is often the outgrowth of such a talk. Written upon the board, this pleases the children and gives opportunity to impart the technical information that a capital letter should be used at the beginning of a sentence and a period at the end. A proper noun is often used, also requiring a capital. These stories furnish material for lessons in reading and copying ; they are often enjoyed more than the stories in the readers.

When "telling stories" with their punctuation are well known, practice begins with "asking stories," or questions.

${ }^{1}$ Miss Susie M. B. Spooner. 
The children are requested to ask about something. Some of the questions are written upon the board, attention being called to the mark that is now put at the end. Correct punctuation does not come until the child discriminates accurately between the statement and the question, and this is an accomplishment that is acquired more slowly than is usually recognized by teachers.

Very early in the year the daily time allotment for language can be put to two uses,- - ten minutes for story telling, or the bringing together of material; and ten minutes for formal language drills, or the correction of errors noted in the telling of the stories or in the child's conversation. The two periods should be distinct, separated by an hour or more, so that the pupil does not get the idea that his language is under severe surveillance when he is talking. Self-consciousness increases the number of mistakes with many pupils and often destroys all spontaneity of narration. Correction of errors is not the sole purpose of the narrations, and the children should not feel that such is the case.

Among the many errors noted during the first four months the following were taken for special, daily drills: "I seen,"

Technical

Drills " have got," " is broke," "I goed," "aint," " he give," " blewed," " drawed," " keeped," "brung," "writed," "you was," "they is," "I are," "I runned," and " tored." One error is taken as the special thought for a week, although many other corrections are made during the same time. Many correct sentences are given by the children in quick, snappy drills. Some of these sentences are written upon the board for general reading and for drills in capitalization and punctuation.

By the beginning of the fifth month the pupils are copying 
on the board from their readers, and copying from the board

Written

Language

the composite stories from literature, history, or nature study. These are drills for correct forms. By the end of the seventh month the pupils are able to write little original stories occasionally, in which they use their own reproductions in place of the composites and try to remember capitals and correct punctuation.

The children often illustrate their little stories with their own crude drawings. Sometimes pictures are collected from newspapers or magazines and placed upon the teacher's desk; every pupil chooses one, names it, pastes it on his paper, and writes the story that it suggests to him. This is a satisfactory basis for a written exercise.

The above report is adapted from the words of a teacher engaged in a quarter of the city where there are many children of foreign parentage, some of whom hear little English except when in the schoolroom. In other schools, where pupils come from homes in which English is the usual language, and where parents ordinarily work intelligently and sympathetically with the teacher, more is accomplished in the first year and different methods can be employed, although the general work is the same.

From the many exercises found in a notebook belonging to a first grade child, a few have been selected. They are uncorrected, just as the pupil copied them from the board.

\section{I}

Questions and Answers. (Written in January.)

Did you go to the train? I went to the train. He went home. 
Is your pencil broken? My pencil isn't broken.

Is the ruler broken? The ruler is not broken.

\section{II}

Use of is and are.

The books are on the box. The boys are good to the girls. The rat is in the dish of milk. The little kitten is fat.

There are six kittens. Your hands are on the book.

\section{III}

Abbreviations. Capitals for proper nouns.

Dr. Hammond is Ada's friend. Hiram knows Dr. Cross. Mr. Barr is our superintendent. Mr. Tumelty is our janitor.

Our school is on Washington St. I live on Harrison St.

\section{IV}

Nature Siudy Story. (Class Composite.)

We have two new caterpillars.

Etta and Laura gave them to us.

See the black rings on their green backs.

One has yellow spots and the other has orange spots on the black rings.

They eat parsley and anise.

\section{SECOND YEAR GRADE}

In this grade there are continued the systematic efforts begun during the preceding year to develop power over lan-

Oral

Language guage and to make its use more accurate. There are conversations on common objects of the pupils' lives; descriptions of pictures ; stories suggested by pictures; reproductions of the stories in 
history and literature; little, very simple descriptions of people, places, objects; short narrations.

The correction of errors is turned a little more along grammatical lines than in the first grades. Not that the Technical Drills pupils are conscious that this is the case, for there is no desire to teach them grammar; but the teacher's work becomes more systematic if it is arranged along known lines of knowledge, and a great aid is given the comprehension and memory of the pupil when work is put before him systematically. The conjugations continue with a slowly increasing number of verbs, and they are always enjoyed by the pupils if the teacher is tactful in handling them. As a result of their use the ear is accustomed to new sounds, and the tongue becomes ready with what were oftentimes previously unknown words. Pronouns are corrected and drills are given if such care seems necessary; but if one pronoun is corrected, others should be associated with it, so that there is shown to the child a series of related corrections. It must be constantly remembered that persistent drill upon a few is better than haphazard correction of many. Perhaps only ten awkward, incorrect expressions can be eliminated during a school year; but, if the number seems small to an eager teacher, just imagine the pupils' conversations without those ten prominent, ever-recurring errors. Would not such a result be a delight to the ears of a language-sensitive teacher or parent? Would it not really be great progress?

The past tenses of several verbs are a part of the work Verbs for this year. These are generally irregular ones, but whenever mistakes occur in regular verbs they are immediately added to the list for correc- 
tion. It is of advantage to drill one day on regular verbs, separating them completely from irregular forms. The ear is aided by this plan. Saw and did are among the first drills of the year, although they also belonged to first grade work. The simple verb, I did it, is not drilled upon at the same time as the compound form, I have done it. These are two drills, for separate days even. Many children use the past participles of these two verbs correctly; consequently, the drills given are for learning to use correctly the words saw and did, comparatively new to many children. In this way it is possible to escape falling into the solecism, "I have saw," an error often blundered into through over-zealous efforts to use the new words.

When the mistake is in the use of the past participle, the drills are on these forms of the verbs, saying nothing about the past tenses, which are probably being used correctly. The past participles specially suggested to the teachers of this grade are: written, broken, eaten, bitten, flown, blown. The past tenses for special drills are: ran, did, saw, ate, flew, blew, dug.

Drills continue in the use of the period and interrogation mark. The comma is used in address, for attention words,

Punctuation

Word Drills to separate words in a series, to precede a quotation. Several new abbreviations are learned, accompanied by the required period. Word exercises are frequent, as in distinguishing between their and there; to and two; too is included as soon as used. Many common adverbs are taught; as, well, nicely, slowly, kindly. Such colloquialisms as "busted," "ketched," "slung," and others taken from the pupils' vocabularies are discouraged by suggesting better forms in their places. While it 
is true that many pupils will continue to use these expressions, the leaven of better language will be surely at work. Drills must accompany all this word work; it is the only way to fix the points involved.

The written work is of the same general nature as the oral, a development of self-expression, the use of an accurate Composition and growing vocabulary, the formation of compact sentences instead of loosely connected clauses. Little letters to some friend or relative give opportunity to teach proper letter forms. Reproductions are frequent, both the composite, copied from the board so that capitalization, punctuation, and spelling shall be correct; and the original reproduction, written after careful oral lessons over the same material.

Simple as these individual versions may seem to a mature mind, for the child they present difficulties and responsibilities. Spelling and capitalization become more formidable if the writer is obliged to think for himself, even if he helped decide about every word of the composite when the teacher was writing it on the board. Moreover, there is the necessity of thinking out the story, remembering the details and putting them into proper order.

Such "original" composition should not be given as busy work. It should be under the careful supervision of the teacher. In this way mistakes can be avoided, infinitely preferable to correcting them after they are made. To get the right form into the mind first is worth much in the training of a child and in the acquisition of knowledge. The pupils must be at liberty to ask about any doubtful point in spelling, capitalization, punctuation, choice of words, form of sentence, general arrangement. They should be encouraged 
and trained to recognize their weaknesses and uncertainties and to ask for information rather than to make a mistake. On the other hand, they must not be permitted to become dependent. That which they have been taught thoroughly they should be expected to know and to use without assistance. Pupils respond quickly and happily to such selfresponsibilities when they are firmly but kindly enforced. Just before beginning a paper have the children recall points for which all must be on the watch during the writing. This assists in remembering what has been learned and in putting it into practice in a new paper. After such a reminder many a pupil will produce a creditable paper instead of a faulty, unacceptable exercise. This is not direct assistance; it is one of the steps in training the child's mind to be observant.

There follow three written verb drills from second grade pupils.

See saw seeing $\left.\begin{array}{ll}\text { I } & \begin{array}{l}\text { has } \\ \text { have } \\ \text { had }\end{array}\end{array}\right\}$ seen

See, see, the dog is running away.

I saw an automobile up town yesterday.

I have seen Eva today.

\section{II}

Write wrote writing $\left.\begin{array}{l}\text { has } \\ \text { have }\end{array}\right\}$ written

Our teacher is writing.

Our teacher wrote something on the board.

Billy has written his lesson on the board.

Gladys, the teacher has written a sentence. 


Do did doing $\left.\begin{array}{l}\text { has } \\ \text { have } \\ \text { had }\end{array}\right\}$ done

My work is done.

We have done the drawing.

Who did it? The teacher did it yesterday.

Did the janitor do the cleaning?

You did the drawing but mother has done the painting.

\section{THIRD YEAR GRADE}

Reproductions are continued, the pupils telling the stories that have been told or read by the teacher. Narrations are

Oral

Language

based on some topic chosen from the life of the pupil. Descriptions, simple but accurate, are given of what may be readily seen or heard by the child. Sentence structure is carefully watched to prevent the repetition of loose connectives. A knowledge of how to form compact sentences must be gained from the drill periods, but in the time for oral language the child should be held to practicing what he has learned. The pupils are being led to self-observation in sentence making, continuity of thought, and other accuracies and niceties of language. Until they learn to criticise themselves there will be no sound basis for progress. This they can soon learn to do concerning the points which are known, and it is the work of the drill period to make known certain definite corrections for the child to incorporate into his language.

In the technical work, the year is begun with a careful Verbs review of the points that have been drilled on in the preceding grades. A number of new abbreviations are learned. Quotation marks are 
used in many simple sentences. The principal parts of a number of the commonly used verbs are learned, as: break, go, see, sit, eat, tell, fall, give, come, take, sing, begin, draw, forget, speak, drive, write, tear, let, (to correct the use of "leave" in the sense of permit), know, blow, do, shine. The pupils learn the four principal forms of the verb, as: break, broke, breaking, broken. They are written upon the board, where a list soon grows, with distinct columns. It must be remembered that this is simply a method to correct speech, not a grammatical learning of conjugations; consequently, if the pupils speak of the "second form," the "fourth form" of the "word," there is no need to feel troubled. The aim is to learn to use these forms, and the arrangement in columns helps a child greatly in remembering which form is used without a "helping word," which one requires such assistance. Incidentally, much grammar is absorbed, even names of forms coming easily to the lips of some of the pupils. Sentence making, in which the various forms of the verbs are used, is an important and frequent part of this drill. So also is the simple saying of the four forms; calling quickly for the fourth form, the third form.

A beginning is made in this grade to teach pronouns systematically. The idea of a subject of a sentence is developed Pronouns in order to learn to use I, he, she, correctly. No attempt is made to teach the grammar of these subjects, for third grade children are being dealt with; but even these little folks quickly get the subject sense in a sentence. At this stage of the work little or nothing is said of me, him, her, as these forms are probably being used correctly.

The number of common abverbs in the vocabularies of the 
children can be greatly increased in this grade by combining Adverbs them with the verbs in the verb drills, thus developing in the child's mind that idea of relation between verbs and abverbs that is imperative to the correct use of the latter. In these drills care is taken to avoid predicate adjectives, as, he looks neat; they would be very confusing to these children.

The use of relative pronouns is taught by introducing them into the vocabularies of the children for connectives in the

Relative

Pronouns

sentence building exercises. If "and," "and," " and," " but," " but," " but," are taken away from the children, something must be given in their places. Relative pronouns, conjunctive adverbs, and well-chosen conjunctions are given, and the children gradually pass into the use of fairly well-formed complex sentences, without, however, being troubled about their grammatical analyses. If relative pronouns are grouped together, if on certain days a list of conjunctive adverbs is placed upon the board for use in sentence building, if the teacher is systematic in the presentation of this material, the children will, however, acquire their knowledge systematically, and later grammatical work is made easier and more practical. Combining sentences by these aids permits considerable individuality and is fascinating to the pupils. A list of relative pronouns and two or three short sentences are put upon the board :

who I have a book. I am reading from the book. whom Then the children combine: I have a book from which which I am reading. I am reading from the book what which I have. Have you the book from which I that was reading? 
After a little help lists of relative pronouns written upon the board are used readily and quickly by the pupils. Participles are made a part of the child's vocabulary by the same method. Thus complex sentences become familiar to the children and the sentence structures are steadily improved.

Some kind of composition work is given every day. Narration predominates, interspersed with frequent descriptions. Composition

Correction of the papers is carried along on two lines: self-correction by the pupils, after the lapse of a day or two, of errors that have been subjects of drills ; correction by the teacher of errors that come from imperfect knowledge, those that will in later months become subjects of drills. It is not necessary to correct all papers. Experience gained by frequent writing will soon be manifest in self-correction or in avoidance of errors, especially if, before beginning to write, attention is called to the common mistakes so that they shall not appear in the papers.

Illustrative Third Grade Papers

I

Questions and Answers

A question is a sentence that asks something. A question is followed by a question mark. Lucy, are you going home now?

\section{II}

\section{Definitions}

A statement is a sentence that tells something. I have a pen at home.

An initial is the first letter in a name. May Agnes Tierney, M. A. T. 
An apostrophe shows ownership and omission. Mary's coat is on the rack. Don't you like to go up town?

\section{III}

\section{Special Words and Homonyms}

Will you pare the potatoes? My pencil is broken. She is going to my house. Let me see it (not "leave me," etc.). Mamie writes well (not "good"). Their yard was dirty.

\section{IV}

Break

Tell

Go broke

told

went breaking telling

going broken

told

gone

I have broken my cup and vase. I told you the answer. She has gone away. I have given you some candy. My pen is broken.

\section{FOURTH YEAR GRADE}

In the oral training reproductions, descriptions, and narrations are continued, with careful attention to vocabulary

Oral

Language

\section{building and to sentence structure. Personal} criticisms by the listening pupils are encouraged so long as they are helpful and sympathetic, but they are checked if they become unkind, sarcastic, or personal. The children are still so young, however, that it is very easy to guide these class corrections along friendly, helpful lines, thus making them sources of great assistance and enthusiasm. In the technical work abbreviations are continued, and quotations, simple and broken, are frequently drilled upon. Capitalization and punctuation progress by the addition of new rules as demanded by the 
work and development of the pupils. Constant effort is made to bring the children into mechanical ease and accuracy in the use of the rules already learned.

Many adjectives, appropriate for nouns in common use, are suggested and used. Gradually, these displace those that Adjectives have been used loosely or incorrectly. Children need this drill upon adjectives, as is indicated by the exaggeration and inaccuracy in their use heard on all sides. The comparison of all the adjectives in use is learned, adding materially to the vocabularies. Plurals of all nouns used by the children are taught. The possessive singulars are given, but the possessive plurals are left for fifth grades unless the pupils show themselves especially proficient in acquiring them.

The principal parts of all the verbs learned in the third grade are reviewed, and as many more are taken as the chilVerbs dren can master. The individual teacher must be the guide here, for classes differ greatly in language development and abilities. The following are some of those considered most important for this year's drills: shall and should, distinguished from will and would; may and might, distinguished from can and could; lie and lay; ride, set, hear, lead, sink, drink, swim, hide, show, shoe, throw, rise, know, spring, slide, write, shake, drive, grow, choose. As in the third grade, the conjugation of the present and the past tenses is learned as are the principal parts of all the verbs studied. Sentence drill with the verbs is the important part of the work.

A sufficient study is made of the sentence to see clearly the subject, predicate, and object. Clauses are used, as in the 
third grade, by combining short, simple sentences by means of relative pronouns, participles, and conjunctive abverbs. Sentence Structure Phrases are formed with prepositions, participles, and infinitives. Phrases and clauses are used both as adjective and as adverbial modifiers. The teacher speaks of the different sentences as simple, complex, and compound; the phrase and the clause are given their proper names, but no attempt is made to have the children discriminate. If they learn to distinguish one from the other accurately much has been gained; but there is no effort to teach these grammatical points, for all that is desired is that the pupils shall be using naturally and correctly all three forms of the sentence. Whatever more is learned about them by fourth grade pupils is pure gain. Of course, in putting clauses together, it is often necessary to suggest which relative pronoun to use, or which connective, but this is exactly what the drills are for. Lists are frequently written upon the board, from which the pupils select words that will unite smoothly the short, simple sentences into one complex whole; but this should not be done until the pupils have been well drilled on the individual words that make up the list.

In all this applied grammar care must be exercised constantly or the teacher will be trying to teach technical gram-

Applied

Grammar

mar. Such a mistake would be fatal to the real purpose. The children may and do absorb much grammar, but to hold them, down to its acquirement would seem useless to them, would divert the attention of pupil and teacher from the real object, and would probably create intense distaste for the work. The purpose is to improve the ordinary speech of 
the child by many suggestions and corrections, which are made far more effective by being grouped around simple, elementary principles of grammar. The children see reasons for the corrections; several of a kind are grouped together, thus forming a basis for a rule ; systematic arrangement leads to an assurance through which the children are often guided into self-help, where incidental corrections would have left them helpless on generalizing out into new corrections. The pupils are not retarded in this progress if the teacher uses proper grammatical terms, adverb, noun, pronoun, verb, adjective, phrase, clause, sentence. Indeed, it is a help rather than a detriment in the work itself and in the preparation for coming years.

In the composition work original writing is more clearly differentiated from imitative than heretofore. The latter

Composition includes reproductions, copying, dictations, illustrations given by the teacher either orally or by reading. Its purpose is well defined in the mind of the teacher; it is to aid in developing ease and grace of style, accuracy in the mechanics of writing, and improvement of the vocabulary. Reading a choice description or a vivid narration from some good writer and commenting a little on how the effect was produced is an incentive to personal efforts in similar lines. Original writing is the purpose of a course in composition, but the steps leading into it are made easier and quicker for all, while the road itself is opened to many, if these imitative steps precede attempts at originality. A desire for individuality can be fostered by leading the children to enjoy the most original papers and by seeing the weakness when someone accepts another's thought in place of his own. Papers should be frequent, 
but short, and subjects should be so definite that pupils know just what they are expected to do.

The mechanical divisions of an article are the sentence and the paragraph. A knowledge of each should be cultivated in the fourth grade. The possibility of expanding and contracting sentences has already been suggested to the children by third grade work on combination of several short sentences into one long one. Still more can be done in the fourth grade by changing adjectives and adverbs into phrases and clauses, or vice versa; or by using participles, relative pronouns, and subordinating conjunctions. The weak sentence structure, so noticeable in the speaking and writing by children, is more frequently ignorance of better forms that might be used than carelessness or disinclination to employ more elegant constructions. There should be special thought given to sentence structure. The children must be guided for some time along one line of progress, as the use of relative pronouns; then another must be taken up, as dependent adverbial clauses; then still another must be made familiar; and all the time that which was first learned must not be neglected. While working over any special phase, have the pupils correct their own papers in that one respect, so that they will grow observant.

The sense of the paragraph can be more easily developed by having the pupils write two or three paragraphs on a subject, than by calling for one. Selection and division of material is imperative to the formation of paragraphs ; writing only one gives no chance for this thoughtfulness. The teacher must not become discouraged in showing again and again the proper use of the sentence and paragraph. Both are very difficult, even for older pupils, and these younger 
ones must move slowly in the comprehension of what each means. The pupils are not yet mature enough to discriminate very accurately, but they are learning to use both correctly.

The pupils should learn how to correct and improve their own papers. Sentence and paragraph structure, especially Correcting Papers the former, choice of words, the possibility of expanding and contracting thoughts, continuity, harmony in the material chosen, are all matters for criticism. Pleasant beginnings and comprehensive conclusions should be discussed in class; witty and earnest papers should be read aloud for all to enjoy and appreciate; the general style of a paper should be analyzed occasionally, in a manner adapted to the age of the pupils. These efforts at composition should be frequently criticised, every few days, but the general impression left with the pupils must be that of guidance and inspiration, not of discouragement. Unfriendly attacks upon the creative powers used in composition tend to make sensitive pupils afraid of further writing, and careless pupils antagonistic toward all composition. Criticism, especially with such young children, should be constructive, not destructive.

Pupils complete primary work with the fourth grade. There has been no textbook preparation in formal grammar, but by systematic application of some leading principles during the primary years, the children have passed the first difficulties of technical grammar and have made a fair beginning in composition. Five of the parts of speech, noun, pronoun, adjective, adverb, and verb are well known by use, and most of the children are talking about them by their proper names and recognizing them readily in their ordinary 
uses. Verbs are conjugated in the indicative mode, the principal parts of the common verbs are known. Descriptive adjectives are compared and used. Many adverbs are used with a fair degree of accuracy, and most of them can also be compared and used in the forms thus presented. Singulars and plurals of nouns in ordinary use have been learned, and their possessive cases, both singular and plural, are in constant and generally correct use. The nominative and objective forms of the personal pronouns are known and used correctly by the majority of pupils who will pass out of the grade at the end of the year. Several relative pronouns are in use, although the pupils know but little about them technically, probably not even their name. There is also some acquaintance with prepositions and conjunctions; with the former in connection with the work on pronouns; and with the latter through the efforts to improve sentence structures. Adjective and adverbial clauses are in frequent use, with a very clear idea that they belong to the noun or the verb modified, but there is no technical knowledge whatever about them.

\section{Illustrative Fourth Grade Papers}

I

Comparison of Adjectives

$\begin{array}{llllll}\text { bad } & \text { worse } & \text { worst } & \text { near } & \text { nearer } & \text { nearest } \\ \text { good } & \text { better } & \text { best } & \text { many } & \text { more } & \text { most } \\ \text { late } & \text { later } & \text { latest } & \text { sweet } & \text { sweeter } & \text { sweetest }\end{array}$

II

Correction of Errors noticed by Pupils

"I saw a wagon full with men." I saw a wagon full of men. 
"I will haf to close the window." I will have to close the window.

"After a while some boys come along in a wagon." After a while some boys came along in a wagon.

"One man had a small popular tree in a flower-pot and the tree was about two feet tall." One man had a small poplar tree about two feet tall in a flower-pot.

"It aint planted." It isn't planted.

"I aint going." I am not going. I'm not going.

"I seen her go by." I saw her go by. 


\section{CHAPTER VI}

\section{ORAL AND WRITTEN LANGUAGE WITH GRAMMAR GRADES}

\section{FIFTH YEAR GRADE}

After a brief but careful review of the work of the preceding years in punctuation, the children are held responPunctuation sible for what they have learned. They must use what they have been taught, the teacher does not stand ready to put in whatever is forgotten by the child. Several new rules for the comma are now demanded by longer and more involved sentences, some of which also call for one or two of the simpler uses of the semicolon; even the colon is needed by a few pupils. These should all be given as needed, accompanied always by an abundance of illustrative drill. Although but few pupils are writing sentences requiring semicolons and colons, the needed rules for their use should be given to avoid incorrect punctuation by those few; other writers may also be led into strengthening their sentence structures in order to employ the new marks after their uses have been explained. Wrong ideas of the relation between the parts of a sentence may be imbibed if these rules are not given. It is still necessary to drill on the use of quotation marks, the punctuation of quotations, and the possessives of nouns in both singular and plural. Their mastery is not easy, and, although they have been in use since the first grade, new conditions spring up, some of which seem stranger to the 
children than at first thought appears possible to teacher or parent. One must be in close touch with the workings of these young minds to comprehend the nature and reality of their difficulties.

The correction of vulgarisms and common errors must be carefully continued. The child's own pride in ready and

Applied Grammar cultured language is coming more and more to the help of the teacher; although, at the same time, there has to be overcome the feeling that is peculiarly strong in these middle grades, that the school, in some occult way, is not life, real life, and that its lessons are for the schoolroom only, to be forgotten as soon as the outside air is reached. To counteract this feeling, it is well to keep in touch with some form of everyday life that stands close to the pupil. Show what carefully selected language is used by some persons, known and respected by the pupils; read an extract from a speaker who will appeal to them, calling attention to the fact that the verbs are properly used, that pronouns are in their right cases; various means can be employed to impress upon the children that good language, far from being a schoolroom bug-a-boo, is a recognized necessity of cultured life.

The grammatical drills are beginning to take on a more formal nature. A conjugation is called a conjugation; the

Technical

Grammar indicative mode is thoroughly learned by all; distinction between shall and will is impressed, although a teacher must not be flattered with the thought that it will be definitely learned; present and past participles are used in phrases as adjectives, adverbs, nouns, and in their verbal significations, in order to show their flexibility. While the technical element is 
growing in these presentations, they should still be considered as language rather than grammar; but if pupils see that the third and fourth forms of verbs have a variety of uses, future grammar is simplified. Adjectives and adverbs are frequently used in drills, and their comparisons should now be well understood, both with the use of er and est and of the words more and most. Nouns should be readily recognized, and their plurals formed. Pronouns should be declined, in order to ensure their correct use. Frequent oral drill, in which every pupil of the class is involved, must be given the nominative and objective cases. This includes a fairly clear idea of prepositions and of the subject and object. The use of who for persons and of which and that for animals and inanimate things should be taught. The teacher must be constantly on guard not to be drawn off too far into formal grammar; the pupils are still immature, and practice, or application, should far exceed theory or memorizing. The grammar should be presented, for the pupils are old enough to understand many of its simpler principles, but there is no great loss, as yet, if the technical reason for a correction or for a drill is forgotten, provided the application is remembered. The explanation has served its purpose in clarifying the correction; it will be remembered by many pupils, and wholly forgotten by only a few.

Composition progresses constantly. To write well, a pupil must be permitted to enjoy creative work; individuality Composition must have expression or writing will be a bore. Encouragement and growth mean pleasure to teacher and pupil; discouragement opens up a cheerless prospect for both. Before beginning to write have the pupils tell what must be remembered in mechanical 
lines; then let the writing go on freely, without every thought being hampered by the idea that the critical teacher is peering over the shoulder, or that the paper "wont pass" if the periods and spelling are not correct. Even a mature writer of ability, buried in the inspiration and enjoyment of his creation, may make technical mistakes that he will stare at later in astonishment; but he will correct every page of his manuscript with the utmost care before permitting it to go to the public. Give the child an equal freedom of creation, teach him an equal patience in correcting.

Subject matter is comparatively easy to find, for it is the handling of the material that is of importance. A painting from a master's hand may be only a weary laborer halting for a prayer in obedience to the call of the bell in his village church. The canvas may be small. It is not the subject, it is not the size, that makes the painting immortal; it is the treatment. The subject for a child's composition must be as simple as are the experiences of that child. His training is in expression. A wandering bee, buzzing in the window; a bird, twittering over the spring nest; a dog, coaxing and fawning for his evening meal; a horse, cross and rebellious at being cinched up under the saddle,-is there any end to the thoughts about which a child will talk or write? Give ideas, not subjects. The former inspire, the latter deaden. Do not trouble about the subject, a paper can be named after it is written.

Then there are real and imaginary letters, narrations, descriptions, reproductions, and simple character sketches. Children readily express personal opinions about poems and stories. All papers should be short, sometimes a few lines will be all that can be given. The clothirg of the thought 
in many words should be carefully guarded against, lest mere verbiage takes a hold upon the writer. The study of figures of speech in the literature of the year will probably lead to some embellishment of the pupils' papers. While these efforts should meet with encouragement, they also need guidance, so that a florid, unnatural style is not developed.

The study of the sentence and the paragraph can not be relaxed, for the power of the children over them is weak and vacillating. Study the effect produced by long and short sentences; illustrate changes in emphasis resultant upon transposition of words, phrases, clauses. We are dealing with children, and only childish results can be expected; but there should be a steady, even if slow, growth in power over written expression.

Fifth grade pupils need to know the subject, predicate, and object of a sentence in order to discriminate in the use of nominative and objective cases. A faint conception of these features of a sentence begins in the more favored fourth grades; pupils of fifth grades, even where the language difficulties are greatest, make this knowledge clearer, not for grammatical purposes, however, but for use. Some illustrative papers, uncorrected, follow.

\section{I}

The subject of a sentence is that part of a sentence which denotes that about which we are thinking.

The predicate of a sentence is that part of a sentence which asserts something about the subject.

The strong man works.

The sharp knife cuts.

The watchful dog barks. 


\section{II}

A story about the raindrops, written after a friendly class conversation on the subject; that is, after oral composition came the individual writing. The paper is uncorrected, just as it came in the first draft from the pupil, except that the effective original illustrations are omitted.

\section{The RAINDROPS}

The little raindrops were playing merrily on their velvet carpet one day long, long ago when all of a sudden they began to sing, hop, and dance because they were leaving their home and were going to live on the earth.

"Oh! such fun we will have," exclaimed one little raindrop. Another said, "we will dance on umbrellas, and play hide-and-seek on the house tops."

These little raindrops were merry wee creatures dancing, jumping, and singing to one another.

One little raindrop flew on a wee baby plant and it sent the raindrop down deep into its roots to help it to grow tall and pretty.

The paper was handed back to the child for personal correction, and the most noticeable errors were seen and corrected by the writer herself. Some changes were made in the language of the last paragraph by the teacher, in order to avoid repetition of words; but the original paper, where the creative power was at work and the mechanical accuracy was slumbering a little, is the one given above.

\section{SIXTH YEAR GRADE}

Formal grammar from a textbook begins in this grade, but it should develop so continuously from the applied 
grammar of the preceding grades that the pupil is always conscious of the direct and important relation between grammar and written or oral expression. The aims in teaching grammar are broadening by the time the sixth grade is reached. To speak and to write correctly have so far been the only purposes, but now there must come the recognition of the fact that many pupils continue their studies in higher institutions of learning, and that preparation for work there must begin in the grammar grades. The textbook is now, necessarily, the basis of the year's work in grammar, and a well written, elementary rhetoric should be in the hands of the teacher for guidance in composition. The growing self-consciousness of pupils in the sixth, seventh, and eighth grades tends to weaken and shorten oral expression with many, but papers are often correspondingly better, because in writing there is a feeling of freedom from direct supervision and observation.

There follows a summary of some thoughts by a sixth grade teacher ${ }^{1}$ on composition with her grade:

The aim in this work is to apply the knowledge gained from a study of technical grammar to oral language and to written exercises. Much drill is given in the correct use of prepositions that are commonly misused, of pronouns, adjectives, and adverbs; of the conjunctions as if and as though in distinction from the preposition like, so frequently used for them, as in the sentence, "It looks like it would rain." Several verbs belong also in this frequent drill, lie and lay, sit and set, and others that, in spite of careful oversight in lower grades, still exist in the vocabularies of the pupils in

${ }^{1}$ Miss Margaret Meehan. 
incorrect usage, or have returned into them through force of environment.

In sentence structure, commencing with simple sentences containing adjective and adverbial modifiers, we develop

Sentence

Structure phrases and clauses, and study compound and complex sentences. For example: A golden wreath was given to the victor. A wreath of gold was given to the victor. A wreath that was made of gold was given to the victor. A wreath was made of gold and it was given to the victor.

To make sentence structure plainer, we begin analyzing and diagramming sentences. At first only the simplest form of sentence, with only a word subject and a word predicate, is taken. Then follow sentences with simple word modifiers, then with phrases and complements. The compound sentence is treated next; and, last of all, the complex sentence. All puzzling constructions are avoided, for the pupils are not studying diagramming, they are simply clearing away difficulties in sentence structure in order to speak and write more correctly. Analysis and the diagram are for them a means to an end, not the end desired.

In developing the singular and plural numbers of the different persons and cases of pronouns, the following device is found helpful :

\section{Pronouns \\ took - books with \\ - took - books with}

The children are told to fill in the blanks in the first sentence with the pronoun standing for the person or persons speaking, thus: I (or we) took my (or our) books with me (or us). The second is to be filled in with the pronouns standing for the person or persons spoken to; a 
third, with the pronouns for the man or men spoken of; a fourth, with the pronouns for the woman or women spoken of.

Considerable drill is given on the correct use of two pronouns in one construction, as: Hattie spoke to and - - - and - are going. They invited and - When the children are puzzled, as frequently happens, they are helped out by being told to put in one pronoun at a time, and then to put in the two together. There is often heard such a form as, "He gave it to you and I." The test in these cases is to try the pronouns alone. No child in the sixth grade would say, $\mathrm{He}$ gave it to I.

The pupils are also drilled in the use of who in its different cases. For example, _ is going? _ _ did you see? In the latter sentence the children are told to find out the subject, and even to diagram the sentence, so that the subject and object are clearly pictured. Time is also taken to show that the same word may be used as different parts of speech, as: salt, the noun, verb, and adjective.

Throughout the term of ten months we work in combining several short sentences into a larger one, using the pronoun, adverbial, and verbal connectives. In paragraphing, such work is done as is within the capacity of the pupils; both sentence and paragraph structures are kept constantly before the pupils, but the drills come at varying intervals, so that they shall not be monotonous. A brief study is made of the stanza, developing the difference between it and the paragraph. Letters, both friendly and business, are written, with careful observation of the proper forms, and many suggestions as to what may be put into the body of a letter. 
Subjects for compositions are made as varied as possible within the scope of the children's knowledge: some familiar work or exercise; the noted pictures, studied during the term from reproductions on the walls of the schoolroom, or from the small Brown and Perry pictures; original stories of some event; phrases suggestive of some occurrence, as, in the woods, under an old oak, beside the stream; a list of words to be used in a story, as, toad, cellar, pile of bricks, pan of milk, coal-man; a familiar occurrence, as, a Stockton flood, spearing wood, a tramp in the woods.

That use is the keynote of the sixth grade language lessons is shown by the number of the compositions in the year's notebooks. These are first drafts, self-corrected, or revised by the teacher, three necessary phases of progress in composition. There are also many lists of grammatical points, as exercises on pronouns, adjectives, adverbs, principal parts of commonly used verbs, diagrams of easy sentences, and application in illustrative sentences of the points studied. A few of these exercises are appended.

\section{I}

\section{Combining Sentences}

He drew a picture of his home. It showed the house. He was born in it. It also showed the barn. The orchard was also to be seen.

The picture he drew of his home showed the house which he was born in, the barn, and the orchard.

The orchard, barn, and the house he was born in were all shown in the picture he drew of his home.

He reached his home. He gave orders. He was not to 
be disturbed. He went to bed. He tried to sleep. He tried in vain.

When he reached home he gave orders not to be disturbed. He went to bed and tried to sleep but in vain.

Combining sentences, begun in the third grades, is also a frequent device in teaching sentence structure, showing the use of relative pronouns and conjunctive adverbs, and in giving a general suppleness in handling sentence forms.

II

Use of Who, Whose, ANd Whom

To whom did she speak? Whose book is that? Whom did you see? Who is going? Of whom did you write? To whose house did you go? Whom did she know? Whose pen is that? At whom are they looking? To whose house did you go? Whom is writing?

An interesting fact is illustrated by the above exercise. The drill has been largely upon whom and whose, and there has developed in the child's mind a little vagueness as to the use of the nominative who. This indicates the necessity of clearing up the sense of the nominative, and of drilling upon who until confusion disappears.

\section{SEVENTH YEAR GRADE}

During the seventh grade the pupils continue the textbook study of grammar, keeping the work in close touch with the practical needs of ordinary speech. Composition exercises are frequent, and considerable inspiration is drawn from the writers studied in the literature throughout the year. Maturity of selection and treatment become more noticeable; expressions of opinions, analyses of subjects, comparisons 
of authors and of characters, are made more prominent than in the lower grades. Narrations and descriptions are studied carefully in order to acquire an apt and forceful style. Individuality of treatment, without eccentricity or absurdity, is always encouraged.

A seventh grade teacher ${ }^{1}$ says of her work:

The aim throughout the year is to gain power in originality and readiness of expression, and to foster a literary appreciation of good authors. During the first part of the year careful reviews are made of the punctuation and capitalization studied in lower grades. Reproduction exercises are continued, material being drawn principally from the history. During the early part of the term much of the written work consists of reproductions, as they furnish opportunities for putting into practice the principles that are to be impressed. The mind, not being busy with original thought, is left free to exercise care in grammatical constructions, punctuation, paragraphing, sentence formation. These exercises tend to make the accuracies of writing more and more mechanical, a condition to which teacher and pupils are consciously trying to attain. At the same time, the pupil is gaining power of expression and a certain balance and proportion in style from studying the writings of great authors. During some of the literature periods there is paraphrasing, for the purpose of learning to make clear the thought of the author with little repetition of his language. Such exercises are both oral and written. There are also some book reviews during the year; they are practice in giving in concise form the thoughts of an author, and they also train the pupil in forming and expressing an

${ }^{1}$ Miss Ella Daly. 
opinion of an author and of his writings. As a preparation for writing, the teacher occasionally puts a few suggestive questions on the board; or the pupils talk over the subject in class; or an outline may be developed and left in sight, especially if the paper is not to be composed largely of personal opinions, or if it is to be long and somewhat involved.

In writing narratives one device is to ask for some event in the pupil's own experience, as: Trying to keep a secret. The trick that failed. An afternoon visit. One day the class was asked to write an account of a runaway that had occurred as it might appear in a daily newspaper. Several members of the class were called upon to read their papers, after which the question was asked, "Which account do you consider best?" Three papers, which, by the way, were really the most creditable, were the favored ones. The question, "Why?" called out a spirited discussion, in which many merits and demerits were laid bare. As the criticisms were kindly, they resulted in stimulating the desire to write more articles of the same nature, and the next newspaper report was not only less irksome, but it was also much more successful and businesslike.

Considerable attention is given throughout the year to letter forms and to original thought of various kinds. Imaginative writing is interesting to a large part of the class, and is very helpful, provided it is kept along healthy lines. In connection with the history study of the battle of Lexington and the reading in literature of the ride of Paul Revere, the pupils were asked to imagine themselves living on the outskirts of Lexington on the eighteenth of April, 1775, and to tell the story of that thrilling night and the following day: the approach of Paul Revere, the stir occasioned in the 
home, some loved ones up and away at the country's call, the anxiety and interest in the battle, the result of the conflict, and the return of the patriots.

It is not deemed necessary, or even advisable, for the teacher to correct all the written work, although many sets

Correction of Papers

of papers are so treated. Sometimes the pupils themselves read over their papers a few days after writing, and it is surprising how many of their own errors they are able to correct. One method of class correction is to place upon the board for class criticism, by which is meant only friendly criticism, several paragraphs from the work of various pupils, without giving names. Such extracts are taken up, sentence by sentence, improvements being suggested by the class. Very often some of the best ideas come from the writers of the papers, showing that more careful or more deliberate consideration is all that is necessary for better work. In this form of criticism, where self-consciousness is engendered under even the most favorable circumstances because of the publicity of the corrections, teacher and pupils make favorable comments on good points noticed. Appreciation is as helpful as adversative criticism. If one is striving toward a higher standard, and knows what he is trying to do, many weaknesses drop off of themselves, and the attitude of the worker towards his work is reversed,by consciously adding strength, not depressed by being turned constantly toward his mistakes. Sometimes one of the best papers is copied on the board, to show that glaring errors do not always occur, and as an incentive to bring up the average work of the class.

One of the most valuable forms of correction, or one of 
the farthest-reaching in its effects, is for the teacher to pass from desk to desk while the writing is in progress, calling attention to mistakes as they are made, the pupils correcting immediately. The force of the correction seems to be more easily comprehended by both teacher and pupil. This plan is most feasible in reproductions, where little interruption to the thought is to be feared.

In these days one mentions formal grammar almost with an apology for the words; but, no matter what the fads of

Formal

Grammar the day, a scholar always has a wholesome respect for the essentials of English grammar. If every child could be brought up where he heard only correct expressions, he might never have to hesitate between right and wrong forms of speech; but, as such ideal conditions rarely exist, all pupils need careful training in grammar and in its application. I think that it was Holmes who said: "Grammar is the humble, oft-despised, but truly loyal hand-maid of thought's best expression."

During this year, formal grammar takes a recognized place in the curriculum, and a fairly thorough study is made of the parts of speech with their forms and modifications. When any part of speech is taken up its various uses in a sentence are carefully dwelt upon, and illustrative sentences are constructed. That is, the noun as subject of a verb; object of a verb, participle, infinitive; a predicate noun; object of a preposition; possessive modifier of a noun or an infinitive; appositive modifier of the subject, object, predicate noun; as an adverb. The other parts of speech are treated in the same way, and the vocabularies of the pupils grow visibly more flexible through the knowledge gained. 
The time devoted to language and grammar is twentyfive minutes daily. Compositions based upon other subjects are written during the periods given to those branches. "Evangeline's Search for Gabriel," "A Day at Ichabod's School," belong to the literature period; "The Battle of Lexington," "Our Flag," are history writing; "The Story of Belgium," "Eve of Waterloo," are geography papers; but any of them may come into the language period for correction and discussion as to treatment.

Several seventh grade drills, taken from the notebooks of pupils, are given below.

\section{I}

Use of May, CaN; Mrght, Could

Statements to be remembered: May asks and gives permission. Can implies ability to do something.

Can I go? means, Am I able to go?

You can go, means, You are able to go.

May I go? means, Have I permission to go?

You may go, means, You have permission to go.

I, myself, know best whether or not I can do a thing. Whether or not I may do a thing usually depends upon my receiving permission to do so.

I hope I can go, but I am not yet well.

I hope I may go, but my father may not consent.

You may go, Charles, and see whether you can unlock that door.

Mr. Brown told John he might stay over night.

I wish you could get your lessons without help from others. 


\section{III}

\section{COMMON ERRORS}

Lie lay lying lain.

Lay laid laying laid.

Lay requires an object.

$\mathrm{Lie}$, meaning to rest, never requires an object.

The autumn leaves lie scattered on the pavement.

The rain will lay the dust.

I found a horseshoe lying in the road.

Mother has lain down to rest.

Many poets have been laid to rest in Westminster.

The snow will not lie long on the ground.

The men are laying a concrete sidewalk.

Do not leave your hat lying in a chair.

Will you lay aside your work?

Lake Ontario lies between New York and Canada.

\section{IV}

\section{A Nest in a Pocket (Uncorrected)}

One spring day, a bird in search of a place to build a nest, was flitting about our back yard. This bird was a sparrow, not very beautiful I thought, but she seemed so restless.

Finally she peeped into the granary; she stayed there quite a while, and then I noticed her carrying in grass and stuffs, and of course I knew what she was doing; but I kept right still and did not let anybody know. No one knew where she built her nest, and I know nobody could guess. It was in the farmer's coat pocket.

There she built her nest and in a few days more I heard a tiny chirp up in the granary where the grain was stored. 
We let them alone until one day the farmer missing his coat, thought he would go up into the granary and get it. When he stepped on the floor of the loft he heard a most awful chirp and then such a fluttering.

Although he needed his coat he let the birds stay there until they could fly. He went home and told his wife who advised him to leave them there.

A few days later the mother and all the family were seen flying about, and so we knew she had left the pocket. She came up to the door one day and just the same as said, "Thank you," for the nest which she had borrowed.

The farmer felt very proud of the coat and showed it to nearly every one who came to his house. He left the coat up in the granary to see if another bird would want it for a nest.

The creative spirit expresses itself beautifully in this paper, and the mechanics are not very faulty for a seventh grade child. There is abundant suggestion in it for the teacher in guiding the whole class. "A most awful chirp" calls for the selection of an appropriate adjective. Several places need punctuation study. Some of the pronouns need to be attached more closely to their antecedents. A few of the sentence structures can be strengthened. Seventh grade pupils should be using the connective that more frequently. Care should be taken in such corrections that the teacher's personality is not impressed upon the literary side of the paper, but that the individuality of the writer is preserved.

\section{EIGHTH YEAR GRADE}

In this, the last year of the elementary grades, the work is governed largely by textbooks. The grammar is com- 
pleted, and the composition is aided and guided by a beginner's rhetoric and composition textbook, in the hands of the teacher. Plenty of practice, so arranged as not to become monotonous, is given in writing. Pupils are held to what has been learned in grammar and writing, just as they would be in any other subject. Mistakes in known capitalization, punctuation, spelling, are looked upon just as inaccuracies in multiplication would be considered in arithmetic.

There follow some extracts from a paper on language, submitted by a teacher in an eighth grade: ${ }^{1}$

Composition is along the lines of invention, description, reproduction. Numerous quick pencil sketches are required; these are discussed in class, or privately if the errors are special rather than general. The necessity for unity is discussed, and the means of obtaining it. One way of investigation is reading from good authors. The pupils note the points that, in their opinion, make the description strong; they tell the effect upon their own imaginations; they analyze as well as they can; they discuss the way in which the description grows. After this consideration by the class, papers are written, in which the pupils try to embody some of the essential points that have been noticed.

For a subject on which to write after such a discussion something familiar is suggested, some pleasing feature of our own surroundings, perhaps. The pupils are asked to go to the place, to think about it, to study it while before it, and to try to make their observations and ideas real to others by means of pen and paper. In narration, an account of some occurrence on the playground or in town may be called

${ }^{2}$ Miss Belle Mitchell. 
for. This may be talked over in class, so that the points stand out clearly, then a quick sketch is asked for. Pupils who did not witness the event write it up from the talk, while those who saw it are expected to give it the vividness of an eye-witness.

All the pupils keep their written work for the year in portfolios. Occasionally, the class period is devoted to selfstudy and criticism, by looking over these papers and writing down the observations made. Such information as the following is frequently given by the self-critics:

"I am careless in the use of commas, of 's, and of quotation marks." "I often use the wrong form of the pronoun and verb." "I do not place my phrases and clauses so as to express my meaning clearly." "I put two paragraphs into one." "My paragraphs lack unity."

It is needless to add that such a search into one's own weaknesses is often the most effective cure.

From many eighth grade papers a few are chosen illustrating drills in sentence structure, one of the particular points for the year; others show special features of training.

\section{I}

Sentence Structure

The poorly constructed sentence is given first, followed by the recast, sometimes obtained by concerted class action, sometimes through correction or suggestion by the teacher, while sometimes it is the individual effort of the child.

$a$

Just a short distance from the pavilion is the palace, with 
its long arcades and ornamental columns, and its gardens which are called the Generalife.

My sentence sounds as if the gardens were the Generalife instead of the palace.

Just a short distance from the white pavilions is the palace, or Generalife, with its long arcades, its ornamented columns, and its gardens.

\section{$b$}

At these missions were where the Indians built their homes, and it was there that they were converted to the Catholic religion, to cultivate the soil, to do carpentering, and to build adobe houses.

The sentence is so poorly constructed that the meaning is not clear.

It was at these missions that the Indians built their homes, were converted to the Catholic religion, learned to cultivate the soil, to do carpentering, and to build adobe houses.

Second correction: It was at these missions that the Indians built their homes, learned to cultivate the soil, to do carpentering, and to build adobe houses. It was here also that they were converted to the Catholic religion.

\section{II}

\section{USE OF ADVERBS}

Sentences taken from various papers by the pupils.

We always should prefer our duty to our pleasure.

It is impossible continually to be at work.

The heavenly bodies are in motion perpetually.

Not only he found her busy, but pleased and happy even.

Rule to guide in the correction of the above errors: Place 
adverbs where there will be no doubt what word or thought they modify.

\section{CoRrections}

We should always prefer our duty to our pleasure.

It is impossible to be continually at work.

The heavenly bodies are perpetually in motion. Or, The heavenly bodies are in perpetual motion.

He not only found her busy, but even pleased and happy. Or, He found her not only busy but even pleased and happy. 


\section{CHAPTER VII}

\section{WORD STUDY}

One charm in a ready speaker lies in his mastery of words. Whether this power is natural or acquired it is the Power Over growth of years. Observation, accuracy, Words use, are the means by which it is built up. Observation of new words; accuracy of meaning and pronunciation; frequent, familiar use in conversation and writing. Children begin their word studies with phonics, which should be continued through three or four years, until a thorough foundation has been laid for all ordinary pronunciations and spellings. The dictionary and analysis of words carries forward this systematic acquaintance even into the high school, where language studies supplement the work begun in the phonics of the first grade.

Drills in phonics are daily exercises during the first three years in school. The first thought is to secure distinct articPhonics ulation and accurate pronunciation, and, by providing a key to language, to prepare the children for independent, self-reliant reading. Both the ear and the eye must be trained. The ear must learn to recognize sounds readily, through slow pronunciation, or separation of a word into its sounds; ear training should precede sight training. The eye must learn to know instantly the letter, syllable, or word presented to it. For this purpose every primary room should be provided with cards, on which are the letters, phonograms and sight words to be 
taken up in the daily drills of the year. Type words are made the bases for the accumulation of many lists of words in the first three or four grades.

From the first acquaintance with words careful attention is given to their spelling, one of the essentials in a school Spelling course. Spelling can not be learned incidentally; much can be taught in connection with all written exercises, but a regular place should be provided on the program for persistent daily drill on selected words. A carefully chosen list for every grade is a necessity. It is the core of the work in spelling, and should be made up of a stock of common words from the vocabularies of the children. It should not be so exhaustive as to prevent the teacher from adding other words that are needed from day to day.

The majority of pupils learn to spell most accurately through the use of the eye; many, however, acquire a surer knowledge through the ear; all are assisted by speech. The best results are secured by appealing to the mind through all these avenues of approach. The unit of pronunciation is the syllable, and no method has produced better readers or spellers than the old-time oral spelling with its pronunciation of syllables.

Pupils are trained to avoid guessing at spelling. In the primary grades, if they do not know how to spell any word needed in their writing, they are encouraged to ask help from the teacher; in the grammar grades, they consult the dictionary. Teachers keep lists of words frequently misspelled, and the children are encouraged to make notes of words which they have missed. Occasionally some pupil's list is taken as the basis of the day's spelling. In all grades, 
as an incentive to self-criticism, pupils sometimes make up the list of words for the lesson from those that they feel ought to be known, but which are really troublesome. The names of the days, months, seasons, holidays, objects in the schoolroom, articles of clothing, household utensils, things bought at a grocery store, occupations, words alike in terminations, words illustrating a certain sound of a letter or diphthong, words having a common syllable, are suggestions for interesting and important spelling lists. All unfamiliar words are used in sentences, oral and written. Many words are defined as well as used. The common homonyms are carefully taught, associated with the meaning, and so presented in writing that the one will not suggest the meaning of the other.

The pupils are led to formulate inductively the more important rules for spelling, such as: retaining or dropping final $e$; doubling a final consonant; retaining or changing final $y$. Before taking up these rules the pupils must be able to distinguish clearly between vowels and consonants.

The study of phonics leads naturally into word analysis. In the grammar grades word analysis is phonics, grown into Word Analysis a scholar, investigating the history and radical make-up of the words that, in the primary grades, were his playthings as he formed them from letters and phonograms. Anglo-Saxon prefixes, suffixes, and roots are taken first, as they are simpler and more frequently found in the vocabularies of the children; but Greek and Latin elements, as they occur, are used in an elementary way, as: tele-phone, tele-graph, telescope; geo-graphy, tele-graphy, bio-graphy, ortho-graphy. 'After attention has been called to such a syllable, short lists 
are made of words in which it is found. These lists are usually left on the board for several days, so that the words sink into the memories, and so that new words can be added as suggested by the children. This work is generally very interesting, pupils hunting eagerly for more words to add to the lists, thus, unconsciously, adding rapidly to their vocabularies. The treatment is not formal or mechanical, nor is it in the nature of textbook presentation. To the children the lesson seems to be suggested by the reading; but the teacher really has in mind a definite plan that aids in the selection of certain words and the exclusion of others. Affixes are most readily taught, but root syllables are also frequently made bases for lists, as: art, art-istic, art-ist, art-izan, art-ificial.

There should be regular lessons, at least once a month, taking the place of some exercise in language or literature. These lessons should be so carefully planned that they progress from month to month. Too much must not be attempted. Thorough knowledge of a little is power, a smattering of much is weakness.

\section{FIRST YEAR GRADE}

The first step is to train the beginner to recognize the various sounds of which a word is made up. The name of a

Ear familiar object is pronounced slowly, as, Training $\mathrm{c}-\mathrm{a}-\mathrm{t}$; the pupil recognizes the word, pronounces it himself, so as to give the three sounds; then he gives it as a whole, but trying to hear the sounds. Many words are given in the same way, those being chosen which are familiar and that have distinct sounds, easily separated and reunited. The teacher gives 
action words; such as, jump, run, skip, sing, cry, separating them into their sounds, the pupil performing the act as soon as he recognizes the word. The pupils pronounce words in a similar manner for their classmates to perform the action, or for the teacher or pupils to guess. This is a very important part of the work, requiring much time and patience. Its mastery by the pupils means quick recognition of sounds; hurried and inaccurate training leaves the children incapable of taking this first step in phonics, and subsequent work will be weak and full of errors. Games, frequent changes of teacher and pupil in giving sounds, action words, guessing contests, all tend to keep the interest from lagging, until the pupils are led into a high degree of accuracy in recognizing words from their sounds and in separating one sound into several. Children even begin to notice the inaccuracies of pronunciation, as, in for ing, kin for can, although wholly dependent upon the teacher in this respect.

When the child recognizes quickly the word as a whole from its sounds, and can separate a word quickly into its Phozograms sounds, work begins with phonograms. Some phonogram, as at, is chosen. When, as in this case, it is a complete word, the children use it as a word in sentences, until the teacher is sure that they know just what the word is and how to use it. The children get the sounds, $a-t$, by slow pronunciation. They are drilled to associate thoroughly the letter with its sound. The letter is made and the sound called for; the sound is given, and the children are asked to give or find the letter; they write the phonogram.

When the teacher is convinced that the phonogram is 
known, word building begins. The picture or a cat is shown, and the word is placed upon the blackboard. The sounds are given, the children discovering almost immediately that cat contains the same combination, at, with which they have just been working. A hat is shown the children, the sounds of the word are given, and the word is quickly classified with cat and at. The accumulation of words now proceeds rapidly and pleasantly. The phonogram at being well known, the drills are really to teach the children the consonant sounds that precede in the various words, cat, rat, Nat, hat, mat, bat. The children must become thoroughly familiar with these consonants, for much depends upon the knowledge now gained.

New phonograms, as, it, et, ut, ot, follow. Every day's lesson is introduced by a three or four minute drill on those already learned, sets of cards being a convenient way of conducting a rapid recitation. As lists of words are made out, it is well to have the pupils define the words they give, especially if there is any probability that they are giving sounds in place of known words. Although the definitions may be crude, the vocabularies will be strengthened by the new familiarity with the words.

After the study of the phonogram at, there are taken up those formed with the vowels and $b$, as, $a b, e b, i b$, etc.; then with $d$, as, $a d, e d$; with $g$, as, $a g$; with $m$, as, $a m$; with $n$, as, an, en. The pupils are now ready to study the long vowels. Many of the words already listed can be used, as, at, ate; fat, fate; mat, mate; met, mete; pet, Pete; bit, bite; not, note; $c u b, c u b e$. Other sounds of the vowels can now follow, and diphthongs begin to appear.

In spelling, the children first learn to distinguish forms 
and to see the word. Careful attention is given to this in Spelling the different subjects,-reading, drawing, numbers. The first real attempt at spelling is to reproduce the word by copying from the blackboard. This is done with the cardboard letters with which every teacher is supplied; later the word is copied upon the board by the child. After much preliminary work of this kind, flash spelling is introduced and continued throughout the year. Words and simple sentences are dictated.

The names of the letters are used only incidentally at first; but as the child becomes familiar with the long and the short sounds of the vowels and with the consonant sounds, there are associated with the characters their alphabet names. When a pupil leaves the first grade he should know all the letters by name and be able to give them in order.

\section{SECOND YEAR GRADE}

The first work of this year is to review carefully what was done in the preceding grade, for little folks forget Phonics easily. For new drills some of the sounds that were only touched upon in the first year are used, as: $a$ in ask; $o o$ in stoop and in look; $u$ in rude; $p h$ in cipher; $g h$ in laugh, and others that proved too confusing during the first lessons. This is an individual matter with every class, depending upon conditions often external to the schoolroom. Abundance of material is found in the words of the day's lessons in history, literature, nature study, reading, numbers.

Copying exercises and flash spelling are continued throughout the year. There are oral and written lessons in 
spelling every day. Words and simple sentences are dictated. Many lists are used from the vocabularies of the Spelling children and from the various lessons of the day. Words of more than one syllable are divided into their parts. Pupils in advanced grades often make the mistake of dividing words anywhere, because they are ignorant of the proper divisions. This can be prevented, in part at least, by training the children from the first to recognize the syllables of a word in spelling and in pronunciation, and often in lists for writing. The use of the hyphen is not necessary, the word is spaced, joy ful ly. If a division comes at the end of a line the hyphen is used. The meanings of simple prefixes and suffixes are easily studied, and, although much is forgotten by these little folks, so much is retained that the effort is well worth making. Some of those used are, ing, as in going, coming; er, in faster, nearer; est, in sweetest, hottest; less, in careless, homeless; ness, in kindness, sickness ; ful, in careful, useful.

Contractions, as don't, can't, are expanded to find out what they really are made up of. Synonyms, homonyms, and definitions help interweave the word study and the language work.

The following is summarized from a year's work with second grade pupils: $:^{\cdot}$

As in the first grade word study generally means phonics and spelling. Fifteen minutes are given to phonics daily throughout the year. Ten minutes daily are given to written spelling, five minutes to oral spelling. Lists of from ten to fifteen words are given during the first part of the year; later, the number is increased to eighteen or twenty. Two 'Teacher, Miss Flora E. LaRue. 
or three sentences are used in every written lesson, in order to present some of the words from the lists in their connection with other words and in sentence meaning. During a large part of the year a period of fifteen minutes a week is given to a spelling match. In this, as in all oral spelling, all words must be divided into their syllables, which are pronounced as spelled.

The first two weeks of the year are devoted to a review of the sounds and names of the letters. Beginning with $a$, the sounds of the vowels, diacritically marked, are placed upon the blackboard. These are pronounced carefully by the children, who also give lists of words containing the sounds. The set of phonic cards supplies a means of rapid oral drill.

In the second month, the study of final $y$ is begun. The pupils are accustomed to calling the vowels sisters, and the Final $\mathbf{Y}$ consonants brothers; they know that there are seven sisters and many brothers. This device, whose usefulness soon passes, is very helpful at first, when so much depends upon distinguishing between vowels and consonants, but while the process is still difficult for such little children. Many words are shown the children; as, boy, boys; baby, babies; play, plays. After some study it is discovered without the teacher's help that words ending in $y$ with a "sister" before it add $s$ in the plural; but that if the final $y$ has a "brother" before it, $y$ changes to $i$ and $e s$ is added.

With the help of the teacher, so that no mistakes are made, a list of plurals is made out of words ending in $y$. Word building can now be greatly enlarged, and such lists as the following are made: try, tries, tried; play, played, 
player, plays; gay, gayer, gayest. Word building with words of this kind is given constant attention throughout the year.

During this same month word building with ing is commenced. The first words taken are those in which the

The

Suffix

Ing syllable is simply added, as in play, playing; the next list is of words like come, coming, where final $e$ is dropped; finally, the words used are like stop, stopping, where the final consonant is doubled. Having already learned that final $e$ is dropped on adding the suffix ing, the pupils now learn that it is dropped upon adding any suffix beginning with a vowel; as, bake, baking, baker; baked, bakes. That is, as the little folks say, "Two sisters do not stand together in these places, they want a brother between them." A great deal of attention is also given to words doubling the final consonant; as, fit, fitting, fitted, fitter. Words of this class are the most difficult of all to master; they need much patient drilling for more than one year with the majority of pupils.

Some very simple prefixes and suffixes are studied to show the meaning which they give to words and to impress their spelling. The ones usually selected

Prefixes

Suffixes

Roots are, ful, joyful ; less, homeless; un, unkind; $a$, ashore. There is easy word building with roots. Some simple word, as truth, is taken from a reading lesson and derivatives are called for. The pupils enjoy this work greatly, and lists are quickly made up. They readily give such words as truthful, truthfully, truthfulness; the negative forms are given with just as much ease, untruth, untruthfully, untruthful, untruthful- 
ness. If the children are told that a certain word or affix is to be studied the next day in class, they delight in bringing in lists. These are sometimes surprisingly long and complete, resulting in a remarkable increase in the size of the child's vocabulary and in the accuracy of its use.

Lists of words are frequently marked as to syllables and pronunciation. Punctuation and capitalization in the sentence writing are carefully watched. Early in the year the children begin to use ink in writing the daily lessons; this calls for great care, for all scratchings and repetitions are counted as errors.

No brief summary can reproduce the work of a year, but the above suggests its scope and spirit. In the hands of an earnest, inspiring teacher, who sees the value of knowledge for its own sake and for the power that it gives a child, even phonics become deeply interesting to many pupils and exceedingly practical for all. If up to this time the children have been carefully trained in their phonics and word studies, if the phonograms have been thoroughly learned, if frequently met groups of letters, as tion, have been drilled upon until absolutely familiar to the children, if diacritical and accent marks have been in constant use, difficulties in pronunciation are about ready to slip away into the past. The teacher must be the guide and help a year or two longer, then the dictionary will become the proper tool for the student's own use. It is surprising how much the children can learn to do in these first two years and how keenly they enjoy their progress and accomplishments.

In the second grade there is a variety of exercises; among them are many lists of words, marked and unmarked, for 
spelling lessons; sentences in which the words for spelling are used (I.) ; illustrative use of certain affixes (II.) ; adding ing (III.); lists formed upon some given root syllable (IV.).

\section{I.}

Polliwogs eat insects.

They become frogs.

Buttercups are now in bloom.

The teacher has given me a pencil.

Our lessons keep us busy.

I have been reading a fairy story.

Have you much work?

II.

Ish means like.

child ish

self ish

fool ish

salt ish

girl ish

baby ish

boy ish

clown ish
Less means without. Un means not. mother less sleep less home less father less care less friend less pain less hope less un like un done un told un able un buttoned un written

Er means one who. teach er play er danc er dig ger sweep er, catch er

Er means more.

hard er

sweet er

near er

firm er

clos er

high er

\section{THIRD YEAR GRADE}

Material for word study, either as phonics or spelling, constantly surrounds the teacher; in fact, it is so abundant that the whole subject is frequently neglected because the 
task of classification and systematic use seems too vast. First of all, it is the common words that should be made usable for the children in as simple and practical a manner as possible, for the most frequent mistakes in pronunciation and spelling are in the words that are in most general use. How frequently one hears " ud" for would; "I'd a done it," for I'd have done it; "callin" for calling, and so on through an endless list of pronunciations, while the number of misspelled words is equally perplexing. There is no way of eliminating these errors except by vigorous, unremitting treatment, and the earlier it is begun the better. If the word work and the language lessons have been well done during the first two years, the pupils are already struggling consciously with several of the most flagrant errors, and an excellent basis has been laid for correct English. These word studies give definite reasons for the required pronunciations and spellings, and association with other words aids greatly in memorizing forms and sounds. English is a difficult language to learn under the best of circumstances, and children need all the aid that can be derived from carefully planned word lessons.

The third grade begins with definitely arranged reviews of the sounds learned in the preceding grades, listed in words adapted to the growing powers of the pupils. The new words of a day's lesson are put upon the board, with the syllables indicated and the sounds marked for pronunDrills ciation wherever it is deemed necessary. The children are drilled upon these lists so that mispronunciations are avoided with many pupils and words. A constant watch is kept for words that in everyday conversations are mispronounced or slurred by the 
children, and these are drilled upon frequently. Five minutes of such drill every day of the year will work wonders in correct pronunciation, and, incidentally, in spelling also; for words clearly written and properly enunciated according to syllables are not ordinarily misspelled except by very careless pupils.

Spelling is carefully attended to in both oral and written exercises every day. Words are given in lists and in senSpelling tences. Pupils are held responsible for the words found in the day's lessons, so that the habit of noticing new words and of retaining old ones is constantly encouraged. Compound words that do not require the hyphen are included in the spelling lists, for this is a much abused part of correct word writing. Some new affixes are studied, such as: under, underdone; well, welcome; ly, manly, nicely; er (one who), worker, builder; $e d$, learned, shouted. This material should be carefully listed by the teacher, so that the work for the month or the year is in mind. It varies greatly according to the development of the class, but it is always to be found in abundance in the subjects read or studied by the children.

\section{FOURTH YEAR GRADE}

During this year the pupils become acquainted with all divisions of letters,-vowels, consonants, their various sounds, and their combinations into digraphs and diphthongs; also with such equivalent sounds as $a$ in ate and $e y$ in they; $e$ in even and $i$ in machine. Calling attention to these points and making a few lists of illustrative words obviates many of the difficulties of spelling. The simple rules of phonics, to be found in any good manual on the 
subject, are made familiar to the children before the end of the year. They are not thoroughly learned, it is true, for the pupils are not ready for this step, but there is formed with them that general acquaintance which must precede later drills for possession and mastery.

Oral spelling is given every day in the week, if time permits. In addition to words from the adopted speller, lists Spelling

are made from the various studies, from daily conversations, and, very insistently, of such words as have been generally misspelled by the pupils. Only constant diligence and patience on the part of both teacher and pupils can make good spellers of many children. English is full of phonetic etymological puzzles.

Prefixes and suffixes are given occasional lessons, based upon the vocabularies of the children and upon any other

Word

Studies source from which lists of practical words can be built up. Common roots are noticed, thoughtfully defined, and lists of derivatives made. Even some roots of foreign origin, especially from the Latin, occurring in words frequently used, are studied, thus throwing unexpected light on meanings and spellings. If these exercises are kept easily within the abilities of the pupils, they are very helpful for adding to the vocabulary, acquiring a correct and discriminating use of words, and fixing accurate spellings. Lists of words are marked diacritically by the pupils; the syllables are indicated. Simple rules of phonics that have already been drilled upon in preceding years are learned; such as the value of final $e$ in pin, pine; bat, bate; nap, nape.

An adopted text-book is used in the spelling, but words are also chosen from all other subjects. Dictated sentences, 
two or three in every lesson, and about thirty words form the daily assignment. Lists of misspelled words are kept Spelling by both teacher and pupils for weekly reviews. From two to four times a month lessons in homonyms are given, consisting of ten or twelve sentences dictated by the teacher or the pupils. Several rules for spelling are developed during the year. Some may be entirely new to the pupils, others may be the consummation of the inductive reasoning of preceding months or years.

In word analysis, simple affixes, in, un, a, less, ness, ish, let, are used in forming new words; or words having these prefixes or suffixes are chosen from the lessons, their meanings are given, and other words having the same syllable are suggested.

Some fourth grade analyses of words are also shown here.

\section{a.}

delight ful full of delight

leaf less without a leaf

a fire on fire

plumb er one who plumbs

un happy not happy

un certain not certain

use less without use use ful full of use

a shore on shore

$b$.

bright ness the state of being bright

sad ness the state of being sad 
joyful ness the state of being joyful

full ness

the state of being full

c.

Words ending in $e$ preceded by a consonant should have the last letter dropped on taking a suffix beginning with a vowel.

$\begin{array}{ll}\text { bite } & \text { biting } \\ \text { come } & \text { coming } \\ \text { give } & \text { giving } \\ \text { have } & \text { having } \\ \text { hope } & \text { hoping } \\ \text { live } & \text { living } \\ \text { lose } & \text { losing }\end{array}$

\section{FIFTH YEAR GRADE}

The pupils are now old enough to develop understandingly and usably the most important of the rules for spelling, a step rendered easier by the work in phonics and word analysis that has been done in the lower grades. Many of the rules will be but wording and putting into easily remembered form the practice of the preceding years.

Course in Spelling
Systematically arranged drills are found in text-books on spelling, where words are usually classified as to sound, form, use, and meaning. These lists are supplemented constantly by words selected from the various subjects studied, and from conversation vocabularies. The dictionary now becomes the frequent aid of the pupils in spelling and pronouncing, and careful training should be given in the use of this valuable language tool. 
The children are probably acquainted with many of the familiar prefixes, suffixes, and roots. Pleasure and interest

Word Analysis in such lessons is fostered if they are accompanied by short talks on the people and the countries from which the words came, showing that words, like people, can travel long distances, bearing with them lasting traces of their original homes. By the time the child has finished the fifth grade, he should be familiar with the following:

Anglo-Saxon prefixes: A, after, all, al, be, for, fore, mis, out, un, under, well, wel. Suffixes: ar, ard, dom, ed (d or t), er, est, ful, head or hood, ing, ish, less, ly, ness, s or es in plural, 's or ' in possessive, some.

Latin prefixes: ab, ad (with the change of letter dependent upon the first letter of the root to which it is affixed), bene, circum, contra, subter, re, semi. Suffixes: able, ess, eer, er.

Greek prefixes: ex, hemi, tele. Suffixes : ist, ise, ize.

At the beginning of the fifth year the pupils purchase their own dictionaries, and they also have free access to the The unabridged edition. They must be taught Dictionary how to use these new books, which, without instruction, long remain sealed, like the prophecies of old. The teacher calls attention to the alphabetical arrangement of the words, then to the second letter, ba before bea, be before bi; then to the third letter, bar before bat. The children are trained to open quickly to the desired place, every one in his own dictionary, by asking for $\mathrm{A}$, for $\mathrm{M}$, for any section, and even for first or last part of the section devoted to any letter. This may seem almost childish training, but one only needs to com- 
pare the awkwardness and helplessness of some people with the accuracy and rapidity of others, to realize the effect of training and habit in handling the dictionary. The diacritical markings may seem difficult at first even to a child trained in their use in class; but a little explanation makes them perfectly clear. The use of the typical words at the bottom of the pages should also be noticed.

The many definitions, varying from one another by shades of meaning, are puzzling to the children; so also are the many abbreviations. A verb may be followed by v., t., imp., and pp.; then come the languages through which it has passed into the English. All of this must be explained, if not to fifth grade pupils, then to those in the more advanced grades. The definitions need to be considered, so that the children can discriminate among them; and attention should be called to the help afforded by the punctuation. Occasional lessons should be given in definite explanation of the dictionary. "The unabridged dictionary is a much neglected book," but, by such studies, it takes its place as one of the most available and practical aids to the student.

\section{SIXTH, SEVENTH AND EIGHTH GRADES}

Throughout the last three years of the grammar grades the rules for spelling are developed inductively as rapidly Spelling

as they can be illustrated satisfactorily, comprehended, and remembered. As in the preceding grades, material is found in the assigned textbook, the daily lessons in all subjects, and the new words noticed in the vocabularies of the children. The pupils are trained to notice constantly the spelling of new words found in the reading. In word analysis an accepted textbook is 
completed, or such a portion of it as is considered suitable for grammar grades. New work is always presented through use, leading out into generalizations, the formation of rules, and the classification of knowledge.

There follow a few papers from pupils, giving a slight view of the work done.

The various lists for the sixth grade are of the same general nature as those in the fifth grade. Some of the sentences illustrative of the use of words are here given.

When Scipio died he left orders that his bones should not rest in a city which had proved so ungrateful as Rome.

Cato ended every one of his speeches by saying, "Carthage must be destroyed."

Cornelia's jewels were her two sons. She was the daughter of Scipio Africanus.

"Run for your lives!" said Horatius, "I will keep the bridge."

Gnats and mosquitos are very troublesome insects. They bother us in the summer.

The governor is the chief officer of the state.

The seventh grade notebooks contain drills in spelling, definitions, sound marking, homonyms, synonyms, and a variety of lessons in world analysis, some of which follow.

\section{I.}

\section{HoMONYMS}

I heard the lowing of a herd of cattle.

There are their books where they were put by the children. 
Sweating through every pore, the workmen pour the melted iron into the molds.

A hale and hearty old man was hurrying along in the midst of the rain and hail.

The rest may rest while I wrest the prize from him who would win it.

\section{II.}

\section{USE OF INDICATED WORDS}

Conrad feigned to be a friend of Richard, but he was a traitor.

The vein in his hand broke.

These aquatic flowers are not very pretty.

He came with an invincible army.

\section{III.}

Word Analysis

\section{a. Root word}

The Latin root pes means a foot. Ped has the same meaning. Many words are formed on this root.

ped al belonging to the foot

bi ped two footed animal

quadru ped four footed animal

ped dlar one who travels afoot

ex ped ite to free the foot

ex ped ition the act of expediting

im ped iment hindrance

The pedestrian stopped at our house for refreshments. The men sent an expedition to the New York colonies. 


\section{IV.}

\section{Word Analysis}

\section{b. Prefix}

The Latin verb cedere means to yield, to go. Cede and ceed are forms of the verb cedere.

$\begin{array}{ll}\text { ac cede } & \text { to yield } \\ \text { con cede } & \text { to go with } \\ \text { ex ceed } & \text { to go beyond } \\ \text { inter cede } & \text { to go between } \\ \text { pre cede } & \text { to go before } \\ \text { pro ceed } & \text { to go forward } \\ \text { re cede } & \text { to go back } \\ \text { suc ceed } & \text { to go beyond any one else }\end{array}$

Harvey Birch wished the Americans to succeed in war.

Captain Dunwoodie was interceding for Captain Wharton.

\section{V.}

\section{Word Analysis}

\section{c. Suffixes}

Judge, verb, to determine.

Judge, noun, one who determines.

Just, adjective, lawful.

judge ship office of a judge

judg ment being judged

just ify to make right

just ness the quality of being just

just ly lawfully 


\section{Prefixes}

pre judge to judge beforehand

ad judge to judge to

re judge to judge again

un just not just

ad just to make right, to make just

The above lessons are given without change from the notebook of the pupil, showing the seventh grade conception of the meaning of the words as gained from roots and affixes. Prefixes and suffixes have been studied separately and in connection with simple words ever since the fifth grade, so that their meanings as used in the above exercises are not touched upon. They belong to the knowledge that is already fixed. New affixes are taken up from time to time as the occasion demands. Later language studies will, of course, broaden all this acquaintance with words.

From the many lists in the notebook of an eighth grade pupil the following uncorrected exercises are chosen, illustrating studies in homonyms, use of words in sentences, spelling and defining. Occasional lists are made of words frequently mispronounced; these are carefully marked as to sounds of letters and accented syllables.

I.

\section{Spelling and Defining}

precurser one who runs before

(precursor)

accessory have access to

itinerary from place to place

alleviate to lessen

hypocrisy deceive 
enunciate act of enunciating

indelible not erasable

Apennines mountains of Italy

asphaulton

cognizant

recommend

Philippines

\section{understood}

give authority of

islands (asphaltum)

\section{II.}

Alaska was formerly isolated.

He will lubricate the wheel.

They manipulated the books.

He meditated deeply.

She will participate in the event.

Electricity is a subtle power.

The school suppressed a laugh.

She assumed a dignified air.

The guide preceeded the party.

(Preceded.)

They relinquished all claims.

III.

Gamble at cards.

To gambol on the grass.

The soil is barren.

A German baron.

Two quarts.

A vein of quartz.

A minor matter.

A coal miner.

A gilt frame.

To confess a guilt.
To sell at profit.

A weather prophet.

A boiled carrot.

It weighs a carat.

An easy lesson.

Pain will lessen.

To bathe in the surf.

The serf was set free.

A broad base.

A bass voice. 

PART II ARITHMETIC 



\section{CHAPTER VIII}

GENERAL AIMS: INTRODUCTORY THOUGHTS; SUMMARY OF THE DEVELOPMENT OF A COURSE

IN ARITHMETIC

Arithmetic in the public schools should lead to definite results along two lines,-knowledge and power. The Knowledge knowledge gained should be a sufficient arithmetical basis for any occupation or profession entered by the pupil after leaving school. It should include the fundamental operations with integers; fractions, both common and decimal; percentage, with its application to reckoning interest. An important element of this work is the recognition of number as the "tool of measurement" in a concrete study of lengths, areas, volumes, values, and other relations liable to arise in after life. These topics, with an elementary study of accounts and common business forms, furnish ample material for the knowledge element of the subject. By the end of the eighth school year all pupils should be thoroughly grounded in the essentials just mentioned.

Arithmetic offers abundant opportunity for training in habits of logical thought and exact statement; while the Power ability to form a clear-cut mental picture of the quantity represented by any number, integral or fractional, is so important that it should be developed constantly. Its value is not confined to arithmetic, it belongs to all subjects. All judgments and infer- 
ences should be expressed completely and accurately. In this development of mental power no factor is of greater consequence than the solution of well selected problems.

Measurement is the origin of the number idea. Consequently, from the first, the child is led to measure some-

Measure-

ments thing, to compute through measurements, and to think in terms of known value. $\mathrm{He}$ is to think as well as to measure, for " thought is the main thing in mathematics as well as in language." No matter whether the child is considering length, breadth, time, space, weight, or value, he can express his thought in figures; but he must never be permitted to work with the figures alone, separated from the magnitude that is represented. To do so, is to deal with the abstract, an unnecessary, if not an impossible feat for the immature mind. If the child's difficulties are to disappear, he must see, actually or mentally, the thing that is to be measured or computed. Dimension measurements are drawn in some prominent place in the schoolroom, on the wall, on the board, where there can be marked off and preserved before the eyes of the pupils an inch, a foot, a yard, a square inch, a square foot, a square yard. The dimensions of the room, the building, the yard, are measured and frequently mentioned. The length of a city block is learned in feet or yards; the distance to some near-by public building is spoken of as a certain portion of a mile; some well known object a mile away is located. These distances are referred to frequently, as is also some fraction or multiple of them, until their value is well recognized by the pupils. The children estimate and then measure accessible distances. They draw lines of estimated length, 
and then measure them to see how nearly correct their efforts are. This sense of magnitude is kept before the pupils for years, if necessary, until accuracy is gained. There is no need of permitting the exercises to become monotonous, if the teacher only uses ingenuity in varying the processes employed. The value of these actual measurements is immediately apparent if even advanced pupils, who have not had such training, are asked to draw lines of given lengths, or to estimate areas, widths, or capacities. They guess wildly, showing that the abstract figures, not the actual values, have absorbed their efforts.

Training in analysis begins early in the course, starting with the simple reasoning from one to many and from the Analysis many to one. When a problem is stated, the first requisite is to find the starting point; the second, to see the steps by which the end is to be gained,-multiplication, division, addition. The child is not permitted to start his analysis until these points are assured, for not until the process is seen clearly can it be accurately performed. There is no objection to the individual methods of analysis developed by this kind of training, provided clearness and accuracy are retained. Moreover, if the pupil's expressions are awkward and inapt, he is glad, through the teacher's guidance, to adopt easier and more set forms of speech usual to analysis.

Oral work is so important that from one-third to onehalf the time for arithmetic is devoted to mental training.

Mental Arithmetic processes too involved to be grasped readily. The pencil

Every new topic is introduced orally, and written work supplements the oral only when the numbers are too large or the 10 
is used only on a problem that can not be solved without its aid. Pupils who understand the principles of arithmetic and can apply them to oral problems have little difficulty with arithmetic. The majority of the problems contain small numbers. Applicants for admission to our high schools and normal schools fail constantly on problems dealing with numbers of one figure. Pupils are trained to give and to solve original problems. The thoughtful reading of problems is emphasized in all grades. Pupils are led to forecast results, so that unreasonable answers are at once noted. In all grades many problems are given in which the processes to be performed are indicated by signs.

Many of the problems given in all the grades are based upon prices of labor and material, for which teacher and pupils secure data from the store, the market, the mill, the post office, the lumber yard, the wood and coal yard, the insurance agency, the tax collector, the transportation agent. The various ways of making change, of levying a street assessment, of collecting taxes, of marking goods, of depositing money in a bank, and of remitting money are investigated.

Business forms, especially letters, receive much attention. All pupils above the fourth grade should be able to write a thoughtful letter, correct as to form, spelling, punctuation, and capitalization in the superscription and conclusion. Tax receipts, insurance policies, money order blanks, checks, bills, receipts, notes, and other business forms and papers in daily use are brought into class for study and comparison.

In all grades a minimum amount of required work is assigned for all the members of the class, and sufficient 
optional exercises to keep the most proficient busy. The required work covers all the essential principles; and the elective work is made interesting, broad in its scope, practical, and closely related to home and business affairs.

It is claimed that the results obtained in arithmetic in many schools are not at all commensurate with the time Assignments given the subject. No one doubts the justice of the criticism. Consequently, fewer and more practical topics are assigned the various grades in our schools, and the time given to arithmetic is increased in every grade above the second. The elimination of obsolete and impractical matter, combined with an increase in time, should lead to better results, more particularly if the following points are borne in mind by the teacher:

Cultivate the spirit of self-reliance in the pupils.

Give mental arithmetic its due proportion of time.

Lead pupils to think of the conditions of the problems before "figuring."

Give full attention to development lessons and to objective work.

Lead the pupils by accurate observation into clear thought and exact statement.

Have a definite plan for every lesson.

Do not give conundrums.

Require the pupils to think more and to depend less upon the teacher.

Teaching arithmetic has passed through so many tormented phases of being that considerable valuable information is to be found in the way in which a modern course of study has come into being. This is so clearly shown in an article by Superintendent Barr of the Stockton schools, 
published in "Primary Education," January, 1904, that part of it is here reproduced.

"In May, I892, a careful study of the conditions in the Stockton schools was begun to determine just what results Arithmetic in 1892 were being secured in each subject in the school course, the time given to the subjects, the grade when the pupils begin to leave school. Briefly, here are some of the facts shown by this investigation:

"I. From one-third to one-half of the school day was given to arithmetic in grades one, two, and three.

" 2 . In the judgment of the majority of the teachers the pupils were not well prepared in the work.

" 3 . The children could not read many of the problems that they were expected to solve, nor could they apply with a fair degree of readiness the number facts learned to simple problems taken from their own experiences.

" 4 . In general, the training in other subjects, especially in reading and language, had not kept pace with the training in arithmetic.

" 5. Practically all pupils remained in school at least four years.

" Obviously, the problem for 1893 , even from the standpoint of arithmetic, was to emphasize reading and language so that the pupils could grasp the thought in the problems to be studied. This naturally led to the cutting down of the time given arithmetic; yet, to the surprise of all, the classes were better prepared in that subject at the close of the year than before.

"This happy result led to the further emphasis of reading and language in 1894 and to a further cutting of the 
time given arithmetic, and again did the work in arithmetic improve."

"In I895, all formal instruction in arithmetic was omitted from the first half of the school year, the time so gained

Incidental

Work

being given to reading and language, based on nature study and on stories drawn from history and literature. In 1896, instruction in number work was made incidental throughout the first school year. In I900, the incidental period was extended to include the first half of the second school year.

"The results secured by the omission of formal instruction in arithmetic in the first term of 1895 , in the second in 1896, in the third in 1900, showed clearly (at least to the observers in Stockton), that other subjects are much better adapted to the needs of the pupils during the first year and a half of school life than is arithmetic. The final results in 1903 have also demonstrated that, compared with 1892 , the pupils, by the close of the third school year, can not only read better, spell better, use their mother tongue better, but that they are fully as well prepared in the mechanics of arithmetic, and are far readier in the application of what they have learned.

"In 1903, the following is the time devoted to arithmetic:

Arithmetic I903
"First school year, instruction incidental. "First term, second school year, instruction incidental.

"Second term, second school year, thirty minutes daily. "Third school year, sixty minutes daily.

"In the primary grades of the Stockton schools, the pupils are grouped into small sections for the study of such 
essential subjects as reading and arithmetic. The number of sections is determined by the needs of the class, the Group Work teacher being the judge. With a class of forty pupils the number of sections will vary from three to six and even to eight. Not only do the number of groups vary in the different rooms, but the number of pupils in each group and the time given to the group vary as well. In the drill work the group usually gathers around the teacher, and the rest of the class is given carefully prepared busy work in arithmetic, in drawing, or in language. This method not only enables the teacher to develop the child along the line of his needs, but it leads to self-reliant habits of study on the part of the pupils at their seats.

"The following aims have been kept constantly in mind in teaching arithmetic in the primary grades in the Stock-

Basic ton schools: $\mathrm{I}$. The securing of accuracy in Aims all mechanical processes. 2. The application of the number facts learned, first to the experiences of the child, later to other experiences that he can readily grasp.

"The incidental work of the first three terms is a preparation for the later systematic study of arithmetic. Only as the child feels the need of number in

The

Incidental

Period expressing the relations that arise in his other work, is number supplied him. Nature study, reading, drawing, and other studies furnish ample material for developing the number idea during these three terms. With their interest aroused through seeing the need of number, and with the maturity 
that has come through the three terms' work, the children are eager for number work.

"Without seeking to exhaust the 'how' of the incidental period, which is as varied as are the individualities of the teachers and the needs of the classes, the following are among the lines of work taken up during its last two years :

"As number deals with the relations of quantity, eye and mind are trained in seeing relations, even during the inciComparisons dental period. By means of objects in the schoolroom, of lines drawn on the board, of surfaces, many indefinite comparisons are made. As the child's number sense develops, and he demands more definite terms than 'longer,' 'shorter,' 'higher,' 'lower,' the common measuring units are introduced.

"All pupils are supplied with rulers, one foot long, with sticks of various lengths, with cardboard squares, one inch Measuresquare, with shoe pegs, etc. In the work ments in drawing the use of the ruler is soon mastered. The half, the fourth, and other simple fractional relations are as easily seen and mastered as are integral relations. The following exercises, selected at random, will give an idea of the work during the latter part of the first year and the first part of the second:

"I. Measure sticks and draw lines as long, beginning with one inch.

“2. Measure a one-inch cardboard square. Draw it. Place two squares side by side. Measure and draw. " 3. Place sticks so as to form a square, a triangle, an oblong. Measure and draw. 
“4. Draw a line, by judging, one inch long. Measure and correct.

" 5. Draw a one-inch square, by judging. Measure and correct.

“6. On blackboard draw, by judging, lines one foot long. Measure and correct.

"Children enjoy the rhythm of counting. As they are brought into touch with the idea of number through comCounting parisons, measuring, games, counting is made definite, not only in giving the consecutive number names, but in applying them to corresponding groups of objects. The children are led to recognize instantly objects in unit groups of two, three, four, and five. In any work above five the smaller group units are used. This work is never given until the child has met with the number again and again in his nature study, drawing, or other studies. In training in the instantaneous recognition of unit groups, all sorts of objects are used,-dots, lines, marbles, flowers, boys, girls. Care is taken not to go beyond the maturity of the child. In most cases the pupils, before the close of the incidental period, can count by ones and tens to one hundred and back."

\section{SECOND YEAR GRADE}

\section{Second Term}

"With the beginning of the second term of the second school year formal instruction in arithmetic is begun. AdThe Steps dition and subtraction are taught together; multiplication, division, and partition, together. During the first three months of the term addition and subtraction are emphasized. 
"Discovery, through observation of the number fact to be taught; drill, to fix the fact in mind; application of the fact to the experiences of the children and to relations that they can readily grasp, is the order of instruction usually followed in taking up the formal study of number. At this time the utmost skill of the teacher is required to know the content of the child's mind. When the child says that 4 and 3 are 7 , for instance, has he imaged 4,3 , and their sum, 7 ? Does he see clearly the relation that 4 and 3 bear to 7 or has he, parrot-like, repeated a sentence without meaning to him? Every pupil is led to discover the combinations and separations for himself, again and again, until he knows them. During this stage of the work the figure processes are kept in the background, and the number fact is discovered, applied, and emphasized. Figures are then introduced with good old-fashioned drill to fix the facts.

"Training in the instantaneous recognition of the unit groups, 2, 3, 4, and 5, is continued. Clear mental images Imaging are formed. By this grouping the pupils are led (assisted by objects whenever necessary), to image 6 as 3 and $3 ; 7$ as 5 and 2 ; also as 3 and $4 ; 8$ as 4 and 4 , and as 5 and 3 . Subtraction is imaged as readily as addition. The same process of imaging in groups, followed by persistent drill, is used in taking up the work in multiplication, division, and partition.

"As soon as four or five combinations are learned, column addition is begun. In this work great care is taken

Column Addition

by the teacher in preparing exercises, as no combination is presented that the children have not already learned. The work in counting and writing numbers is continted within reason- 
able limits, seldom extending beyond one hundred. The pupils count by I's, 2's, 5's, and Io's, both forwards and backwards.

"In applying the number facts learned, such common measuring units as the cent, nickel, dime; inch, foot, yard, Measuring Units square inch, square foot, cubic inch; pint, quart; pound; dozen, are constantly used. In so far as possible, the measuring units are used by the children themselves. Estimates by observation and verification by measurement are an important factor of the work. Drawing lines and surfaces at the blackboard, modeling at the sand table, stick laying, stringing beads, measuring water or sand, are among the exercises that may be noted in the various grades.

"The following from a second year plan book will give an idea of the use of the foot rule in the application of the

Use of

Ruler number facts learned:

"I. Addition. Measure a stick. Draw a line one inch longer; two inches longer.

"2. Subtraction. Measure a stick. Draw a line one inch shorter; two inches shorter.

"3. Multiplication. Take two sticks equal in length. Draw a line as long as the two together. As long as three sticks. Measure a cardboard square. Draw an oblong as long as four squares; as two.

“4. Division. Measure a stick. Draw as many one-inch lines as equal it. As many two-inch lines.

"5. Partition. Measure a stick. Draw a line half as long. Draw one one-fourth as long. One and one-half times as long. 
"6. Estimates. Draw on the blackboard, by judgment, a line one foot long. Measure and correct. Two feet long. Half a foot long. Similar simple exercises are worked out for other measuring units."

\section{THIRD YEAR GRADE}

"In the third school year, the greater portion of the time during the first term of five months is devoted to addition and subtraction. Seeing, memorizing, applying, these are still the successive steps followed in presenting the work.

"Objects are used occasionally, but only when the children need help in imaging the combinations given. A reThe Combinations view of the combinations in addition and subtraction, previously given, is combined with their systematic application to all possible combinations within the number space IIo. As subtraction is but the inverse of addition, the two are correlated, the emphasis, however, being placed on addition. Beginning with the combinations 2 and 3 (although any other combination will do as well), the pupils commence the formal work of the year as follows:

$$
\begin{array}{rrrrrrr}
3 & 3 & 3 & 3 & . & . & 3 \\
2 & 12 & 22 & 32 & \ldots & \ldots & 102 \\
- & - & - & - & - & - & - \\
2 & 2 & 2 & 2 & . & . & 2 \\
3 & 13 & 23 & 33 & \ldots & \ldots & 103
\end{array}
$$

"After the pupils have mastered these combinations, the 
work is reversed, and the corresponding combinations in subtraction are taken up.

"Simple questions are now given, in which the pupils are led to apply the combinations formed with 2 and 3 to relations and measurements that they can understand. Returning to the combination work, the next step taken up is with 5 ( 2 and 3 ) and 4 . The same work is given as that indicated with 2 and 3 . Column addition is now begun with $2,3,4$. Adding 10, 20, 30, etc., to the 2 , the drill is continued until the pupils can add the columns accurately and quickly.

"The third combination taken is 9 and 3 . Here the pupils must be led to understand the increase by tens. After taking up all the combinations with 9 and 3 within the number space IIo, the pupils continue the drill with column addition, taking $2,3,4,3$, and adding successive tens to the lower figures as long as may seem best.

"The multiplication tables are developed by addition, generally by means of rectangles or circles drawn on the

The

Tables board and divided into the proper number of parts by the children. Division and partition are correlated with multiplication. When the child learns that $6 \times 3$ are 18 , and that $3 \times 6$ are 18 , he can readily see that there are six 3 's and three 6 's in 18 ; that one-third of 18 is 6 , and one-sixth of 18 is 3 ; also that two-thirds of 18 are 12 , and that 12 is twothirds of I8. When the children see how any particular table is formed, they are drilled in it, sometimes by sequence, always by skipping about, until they know it.

"Much of the drill work in multiplication is combined 
with addition. This is frequently done with the more difficult combinations in addition. For in-

Addition

with

Multiplication stance :

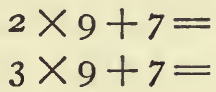

etc.

In real life a large part, in the schoolroom most, of our multiplication is combined with addition. There is economy both of time and effort in such training, as well as excellent preparation for the work in long multiplication.

"A thorough drill is given on inexact divisions, not only for the thought involved, but as a preparation for short division. As soon as the table of 2's is completed the work is begun with short multiplication and short division.

"In the application of the number facts learned, the common measuring units are kept before the children. Applied Arithmetic

Through estimates and measurements of lines, surfaces, solids, and other magnitudes coming within the experiences of the pupils, they are trained in seeing relations, both integral and fractional. When the measuring unit can not be handled by the pupils, they are given a clear mental picture of it. For instance, it is a mile from the Court House to East Street. John has walked the mile between these points in thirteen minutes; Henry has covered it on his bicycle in six minutes. In giving any problem involving miles, it is always related to some particular mile taken as a unit.

"Children like to draw, to make things. This constructive faculty is made use of, not only in the third school year, 
but in the first and second as well. In the third year rectangles are drawn by measurements in developing the multiConstructive Work. plication tables. Many simple problems are given for blackboard and seat work, that can be solved by means of diagrams. Simple exercises in drawing to scale are given. Pupils are encouraged to make things from paper, pasteboard, wood, according to definite measurements.

"Through similar constructive work the pupils are led to add, subtract, multiply, and divide fractions, no attention Fractions whatever being given to processes. Here is the way four such questions, given as busy work, were solved by a pupil during the second school month of the third grade, the telling being preceded by drawings in each case:

"I. I drew a line $2 \frac{1}{4}$ inches long. I added to it a line $\mathrm{I} \frac{1}{2}$ inches long. My line is $3 \frac{3}{4}$ inches long.

" 2 . I drew a line $\mathrm{I} \frac{1}{2}$ inches long. I drew another twice as long. My last line is 3 inches long.

" 3 . I drew a line $2 \frac{1}{2}$ inches long. I cut off $I \frac{1}{4}$ inches. My line is now $1 \frac{1}{4}$ inches long.

" 4. I drew a line 5 inches long. I divided it into half inches. There are ten half-inches in the line.

"Such exercises develop not only observation and thought, but what is of equal importance, expression.

"Only simple problems are given. In so far as possible they are drawn from the experience of the children. BeProblems ginning with the second year simple problems are given as a part of many reading lessons. No part of the arithmetic work has a greater value than this. In reading problems, the children are 
trained to note what is given, what is asked for. They are led to feel that reading the problem is the first great step in its solution.

"While the pupils are trained to explain in simple language the problems given, all the whys and wherefores are not demanded in either the problem work or in such mechanical processes as 'borrowing' and 'carrying.' Nor is it considered criminal if pupils fail to be able to apply all the numbers taken up. While applied work and measurements are important and are not neglected, the principal aim of the year's work is facility in handling the combinations given. Even in the third year something must be left to the growing maturity of the child."

From the many exercises in arithmetic by pupils of the third grade three are given below.

\section{I.}

I drew a square one inch on every side.

I drew two squares. There are two square inches in it.

I drew a rectangle 4 inches long and 2 inches wide. It is twelve inches around it. There are 8 square inches in the rectangle.

One square is $\frac{1}{8}$ of the rectangle. Five squares are $\frac{5}{8}$ of the rectangle.

II.

I have a small square. In my square are four triangles. Each triangle is $\frac{1}{4}$ of my square.

III.

\section{Problems}

A farmer had 275 horses. He sold 78 of them. He had I97 horses left. 
One pencil cost 5 cents. I bought 5 pencils and had to pay 25 cents for them.

There were 23 cows in one field and 57 cows in another field. In the two fields there were 80 cows.

There were 400 cows in one field and the farmer put 127 of them into another field. There were 273 cows left in the first field. 


\section{CHAPTER IX}

SOME SUBJECT MATTER AND METHODS IN FOURTH, FIFTH, SIXTH, SEVENTH, AND EIGHTH GRADES

\section{FOURTH YEAR GRADE}

The work of this year includes daily oral drill in addition, subtraction, multiplication, division, and partition of

Subject

Matter numbers through I44. Many combinations are given, such as $25+18 ; 80-21$; $9 \times 400$; the indicated operations being performed mentally. Long division, easy factoring, practice in reading and writing numbers through two periods, are also in the allotment for fourth grades. Such Roman numerals as are found in the reading lessons are taught.

Certain fractions are taken objectively; such as, $\frac{2}{3}, \frac{3}{4}, \frac{2}{5}$, $\frac{3}{5}$, and many others. Where the results are integers, parts of numbers are found. By the use of the ruler and of blackboard illustrations, pupils are led in a simple, concrete way to add, subtract, multiply, and divide fractions, continuing the work begun in these lines in the third grade. To aid in the thorough comprehension of fractions, different concrete, fractional forms and results are frequently compared with one another.

By the use of the common units of measurement, the pupils are kept familiar with inch, foot, yard, mile; square inch, square foot; cubic inch, cubic foot; pint, quart, gallon; ounce, pound; unit, dozen, gross; second, minute, lour, week, month, year. 
Throughout the year problems are considered very important. At least one a day is required in written work, and every day several are given orally. They are taken from a variety of sources,-geography, nature study, the stories, daily events; there are simple exercises in buying and selling, and in making change. No problem is given requiring more than two mental operations, and a clear statement of his problem is required of every child, whether he is solving it orally or in writing.

By constant association of concrete forms with their actual measurements, empirically determined by the children; by training to see relations, both integral and fractional, the solution of these problems is raised out of guessing into careful calculation and accurate knowledge. These are two of the important aims of the work in the fourth grade.

Busy work and class exercises, closely correlated with drawing and geography, are also prominent features of the work of the year. This constructive work centers around the use of the ruler, of surface and solid forms, of problems involving the use of diagrams, and of drawing to scale.

\section{A fourth grade teacher ${ }^{1}$ says of this work:}

On coming into the fourth grade the children can use the inch, half-inch, and quarter-inch, and they soon learn the eighth-inch also. By using the ruler

Fractional Measurements the children readily learn to add such examples as the following: Draw a line $1 \frac{1}{4}$ inches long; add to it a line $2 \frac{1}{8}$ inches long; how long is the line thus made? Draw a figure $2 \frac{1}{2}$ inches ${ }^{1}$ Miss Maud Southworth. 
by $3 \frac{3}{4}$ inches. Tell what you did. Find the perimeter. How long is it?

Later, such examples as the following are mastered: I have three pieces of string; one is $2 \frac{1}{2}$ inches long, another is $3 \frac{1}{4}$ inches long, and the third is $2 \frac{1}{8}$ inches long. If laid end to end, how long a piece of string would I have?

Towards the end of the school year the pupils will add such numbers without actually drawing the lines, and many can add them mentally.

Comparisons of lines are also made. Lines are drawn on the board with colored chalk or put on a square of cardboard. Different objects in the schoolroom are considered, width, height, length, being compared one with the other. The objects for drawing are reasoned out in the same way, and proportion becomes easier. Thus the children become accustomed to measuring and to estimating the perimeters and surfaces of objects varying greatly in shape and size.

Until Christmas, the end of the first term, the children are busy with measurements, fractions considered concretely, addition, subtraction, multiplication, and short division. One problem is given every day and the children are taught to read it and to reason it out. After the Christmas vacation comes the real work of the year, long division.

In the third grade, in learning the tables, the children found $\frac{1}{4}$ of 12 ; in the fourth grade they find $\frac{2}{3}, \frac{3}{4}$. Later, they find mentally such parts as $\frac{3}{5}$ of 480 .

For mental drill such combinations are given as:

$$
\begin{array}{r}
\mathrm{I} 4 \mathrm{I}^{20} \begin{array}{l}
30 \\
\mathrm{I}
\end{array}+\mathrm{I} 4 \\
\mathrm{IO}+\mathrm{IO}+\mathrm{IO}+\mathrm{II} \text { or } \mathrm{I} 4+\mathrm{IO}+\mathrm{I}
\end{array}
$$




$$
\begin{array}{rrrr}
20 & 40 & 60 & 30 \\
-10 & -20 & -40 & -19 \text { or } 30-10-9 \\
- & - & - & - \\
76 & & \\
-48 \text { or } 76-40-8 &
\end{array}
$$

For help in long division such tables as the following are given:

$$
\begin{aligned}
& \text { I3 } \times 3 ; \quad 14 \times 3 ; \quad \text { I5 } \times 3 ; \quad \text { I6 } \times 3 \text {; } \\
& 17 \times 3 ; \quad 18 \times 3 ; \quad 19 \times 3 ; \quad 19 \times 9 \text {; } \\
& 39 \div 3 ; 42 \div 3 ; 45 \div 3 ; 48 \div 3 \text {; } \\
& 5 \text { I } \div 3 ; 54 \div 3 ; 57 \div 3 ; \text { I } 7 \text { I } \div 9 \text {. }
\end{aligned}
$$

Compound numbers are begun in the earlier grades by actual measurements. In the fourth grade also the pint, quart, and gallon measures are in the room. Pupils are using the inch, foot, and yard with their rulers; and they find the square foot and square yard by measurements. If all this has been done before it is so much easier in the fourth grades; it is never unnecessary training, for to be accurate in estimates the pupils must be kept in frequent touch with the actual measurements.

By the last of the year the pupils can find the area of such surfaces as this:

A piece of paper is 9 inches long and 6 inches wide; what is its area? Pupils draw the surface, divide it into square inches, and write the answer in a sentence, telling how the work has been done. The pupils are then shown that the same result is obtained by multiplying $9 \times 6$. In time they 
use much larger numbers, without drawing. The process of solving the problem mentally is often followed by drawing the area to scale.

Thirty minutes a day are given to arithmetic in the fourth grade. Most of this time is taken for oral exercises, unless some entirely new subject is to be presented. Thirty minutes a day are also used for seat work by every pupil. This generally consists of ten examples. Much of the grade work is based on problems drawn from the experiences of the pupils.

\section{FIFTH YEAR GRADE}

With the close of the fourth grades there begins among the pupils that constant dropping out of school that does not cease thereafter. Consequently, persistent effort is made to give every child as thorough a preparation as his mental development will permit for the world into which he is entering. Arithmetic is one of the necessities in all lives, but the processes are not many that are required for a boy or girl who leaves school when but eleven years old. Such a child does need, however, thorough knowledge of those few processes, rapidity and accuracy in their use, and a quick recognition of the proper operation.

The fifth grade outline of arithmetic aims to give careful and extensive reviews of the uses of integers in numbers through three periods and of the handling of simple fractions. In using integers there is drill in rapid addition of ledger columns; mental work with such combinations as, $33+42,84-47,6400 \div 8$; long multiplication and division are completed; pupils become very familiar with factoring; numbers of three periods are written and read; the 
greatest common factor and the least common multiple are introduced, but drills on these subjects are in connection with addition and subtraction of fractions; Roman numerals are treated incidentally, as they appear in reading.

Fundamental operations with small fractional numbers are a constant part of the fifth year course. They are studFractions ied concretely by means of lines, diagrams, solids, as in the lower grades, so that the pupils are led to think of fractions as having representative bodies in the world of realities. Puzzling and complex forms are omitted, for there is no desire to confuse the child; on the contrary, the aim of the year in regard to fractions is that every pupil become able to form clear mental images of fractions, so that all operations with them may be simplified. Such fractions as are commonly met in business transactions are used for the drills and problems given in the class. The most frequent are,- halves, thirds, fourths, fifths, sixths, eighths, twelfths. The pupils are expected to learn to find the least common denominator by inspection. Aliquot parts are studied, and fractions are compared.

Measurements are continued. The various linear, surface, cubical, liquid, and weight units are in the room, and Compound Numbers in a concrete way the pupils become familiar with them all. Drill is given in changing any unit of these measurements into the next larger and the next smaller unit. Estimates are made of lengths, weights, surfaces, cubical contents, and the estimates are verified. The area of rectangular surfaces is found by multiplying the number of units in a row by the number of rows. 
Problems of some practical nature, but simple enough to be within the grasp of the pupils, are in daily use. Mental work is given as much time as written work; it always comes first, so as to prepare the mind for more rapid thinking in the written exercises. Considerable constructive work is given in connection with drawing and geography. About fifty minutes a day are given to arithmetic, mental and written, in this grade.

The following is summarized from an account of the year's work and the method of developing its various features, as given by one of the regular teachers:1

For convenience in handling fractions the subject is divided into three topics,-preliminary work, addition and subtraction, multiplication and division. Under preliminary work the following points are taught,-denominator, numerator, formation of a fraction, raising to higher terms, reducing to lower terms, changing whole or mixed numbers to improper fractions, changing fractional forms to whole or mixed numbers, finding the least common denominator of two or more fractions.

To develop the idea of the denominator an exercise similar to the following is taken: Divide the pages in your Denominator readers into two equal parts. What is each part called? What are the two halves equal to? Show $\frac{1}{4}, \frac{4}{4}, \frac{1}{3}, \frac{2}{3}$ of the readers. Find $\frac{1}{5}, \frac{1}{6}$ of your rulers. These exercises are continued with lines, squares, yard-sticks, and circles.

Development exercises for the numerator follow. The teacher tells the class to draw a line showing the denomina.

${ }^{1}$ Miss Harriet M. Keating. 
tor $\frac{1}{2}$. A brace is placed above one of the parts, and the class is asked to express in words and by the proper fracNumerator tional writing how many parts have thus been taken. The pupils then show $\frac{2}{3}$ of a line, $\frac{3}{4}, \frac{4}{5}$. The same is shown with squares, circles, objects, until the meaning of the numerator is clear. The formation of the fraction is then dwelt upon, until the meaning of both numerator and denominator is thoroughly understood.

A line is divided into two parts and one-half is taken. Directly beneath the first line a second one is shown, havHigher and Lower Terms ing the denominator 4 .

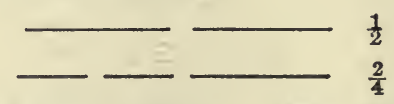

Then come questions and observations. How many parts have we? One-half of the line is the same as how many fourths? Write $\frac{1}{2}, \frac{2}{4}$. Each term of the first fraction has been multiplied by what? Has the value of the fraction been changed? Illustrate many times. Use squares, circles, lines, objects. Make the rule for what has been done. Reduce to lower terms by reversing the operation and the illustrations. Drill thoroughly.

Factoring is developed through questioning, and numbers to 145 are factored. Rules for factoring by inspecFactoring tion are copied into the notebooks and used for reference. Two numbers are then used for factoring by inspection and for comparison, as 52 and 78 , and cancellation is developed and explained. It is soon understood, and its use minimizes the labor.

Integers are changed to fractional forms. How many halves in 4 ? How many times $\frac{8}{3}$ are there in 2 ? How 
many times $\frac{4}{4}$ are there in 3 ? Thus there is developed the rule for changing an integer to a fractional form.

Fractions are next reduced to a common denominator, as $\frac{1}{2}$ and $\frac{1}{4}$. This is a repetition of the process of finding

\section{Common}

Denominator

higher terms for a fraction, and is developed with lines and circles in a similar manner. This includes fractions whose denominators are prime to each other, as $\frac{1}{2}$ and $\frac{1}{3}$. The drills in factoring immediately suggest 6 . By means of circles divided into sixths the common denominator is illustrated.

Fractions having different denominators are compared as a preparation for the operations for which the pupils are

Comparison of Fractions about ready. A pupil is given ten circles, cut into halves. From these $\frac{1}{2}, \frac{3}{2}, \frac{4}{2}$ are taken and fitted into wholes. $\frac{9}{2}$ are taken up and $\frac{7}{2}$ are removed from them. After many exercises of this sort, fourths are made from a portion of the halves, and twelfths from some of the fourths. Fourths and twelfths are added, subtracted; combinations are also made with the halves. Five circles are cut into thirds; some of these are cut into sixths; some of these into twelfths. Thirds are added and subtracted; sixths; twelfths; combinations are made, and the pupils .work out the results. Mental and oral drills are given. Addition and subtraction of fractions now follow with comparatively little hesitation or confusion.

Multiplication of a fraction by an integer is first pictured with lines. One line is divided into eighths, and one part

Multiplication of Fractions is taken. A second line, of equal length, is drawn just below the first; it is also divided into eighths, three of which are taken. The pupils readily see that the second line that is 
ond line that is marked off with a brace is three times the length of the first one. They write the two fractions, $\frac{1}{8}, \frac{3}{8}$, realizing that to obtain the latter they have multiplied the first by 3 , and that only the numerator has changed. Many drills follow, that, in spite of their simplicity, fix the fact that to multiply the numerator of a fraction by an integer multiplies the value of the fraction.

To multiply a fraction by an integer by dividing the denominator is also illustrated by lines and circles. Many illustrations, continued at intervals for several days, fix the fact that the smaller the denominator the fewer and larger are the parts into which an object is divided; hence, dividing the denominator by any number multiplies the size of the part by that number.

Division of fractions reverses the illustrations for multiplication of fractions; consequently, because of the resultant confusion in the minds of pupils, special care must be ob-

Division

of Fractions served in making the illustrations, which should be frequent and numerous. The steps taken are: I. To divide a fraction by an integer by dividing the numerator. 2. To divide a fraction by an integer by multiplying the denominator. 3. To divide a mixed number by an integer. 4. To divide an integer by a fraction whose numerator is 1 . 5. To divide an integer by a fraction when the integer is exactly divisible. 6 . To divide an integer by a fraction when the integer is not exactly divisible. 7. To divide a fraction by a fraction when the numerator of the dividend is exactly divisible. 8. To divide a fraction by a fraction when the numerator is not exactly divisible. 9. To divide a mixed number 
by a fraction. I0. To divide a mixed number by a mixed number.

It is desired that the pupil shall be able to do more than "work" fractions; he must be able to see them, to visualize the operations so that he understands them perfectly. In this ability will lie his real mastery of their use in later life.

Compound numbers and tables are also a part of this year's work, and the aliquot parts of a dollar are studied.

Money

$\frac{2}{2}, \frac{4}{4}, \frac{10}{10}$ of 100 cents are found mentally; $\frac{12}{12}, \frac{8}{8}, \frac{6}{6}$ are worked out by diagrams. For $\frac{12}{12}$ an oblong is ruled, 6 by 4 inches in size, divided into spaces one-half inch square. By inspection of the ruler the children estimate $\frac{1}{3}$ of an inch and add a strip that wide to the width of the oblong. This gives a surface $12 \times 8 \frac{1}{3}$ inches, or the equivalent of 100 squares. One row equals $\frac{1}{12}$ of 100 , or $8 \frac{1}{3}$ squares; two rows equal $\frac{2}{12}$ of 100 , or $16 \frac{2}{3}$ squares.

For $\frac{8}{8}$ an oblong is ruled, 4 inches wide by 61 long, divided into half-inch squares. This gives a surface of $8 \mathrm{x}$ I $2 \frac{1}{2}$ squares, or 100 squares. One row is $\frac{1}{8}$ of 100 , or $12 \frac{1}{2}$ squares. Two rows are $\frac{2}{8}$ of 100 , or 25 squares.

For $\frac{6}{6}$ an oblong is ruled, $1 \frac{1}{2}$ inches wide and 4 inches long, and divided into quarter-inch squares. By inspection of the ruler the children estimate $\frac{2}{3}$ of a quarter-inch space, and add that amount to the length of the line. This gives a surface of $6 \times 16 \frac{2}{3}$ squares, or 100 squares. One row is $\frac{1}{6}$ of 100 , or $16 \frac{2}{3}$ squares. Two rows are $\frac{2}{6}$ of 100 , or $33 \frac{1}{3}$ squares. Some of the most important parts of 100 are learned by the pupils, as : $8 \frac{1}{3}=\frac{1}{12}$ of $100 ; 12 \frac{1}{2}=\frac{1}{8}$ of $100 ; 16 \frac{2}{3}=\frac{1}{6}$ of 100 . Other aliquot parts are also memorized, as: $\frac{5}{8}, \frac{2}{8}, \frac{1}{5}, \frac{1}{4}, \frac{3}{4}$, etc. 
The other weights and measures, mentioned above, are reviewed, in order to test, rectify, and strengthen the children's knowledge and ability to estimate. Then the tables and the various abbreviations in use are learned.

\section{SIXTH YEAR GRADE}

The general outline of the subjects to be studied in the sixth grade is similar to that for fifth grades, only the work Course

becomes more intensive, and the subjects are treated more broadly. Decimal fractions added to common fractions means that percentage, bills, and many business transactions in money matters can be studied more fully than in the earlier grades. Complex fractions are also taken up this year. Exercises and drills are numerous to fix the tables of weight and measure learned and used in the preceding grades.

Mental and oral exercises are given one-third of the time allotted to arithmetic during this year; concrete measureDistribution of Time

ments are continued at intervals; constructive work is still associated with the drawing, and, in addition, pupils are required to draw to scale the surfaces mentioned in assigned problems or to make illustrative diagrams, showing that the operation to be performed is understood thoroughly. This illustrative work is continued in the seventh and eighth grades.

The special new feature of the year is the study of decimal fractions, particularly in their application to percentage Percentage and to other business forms. At first, the pupils are led to see that the underlying principles of fractions, both common and decimal, are identical with those of percentage. They are also led to see 
and to think the percentage relations by the use of lines, circles, squares, just as was done with common fractions, until fifty per cent. of a body has as concrete an existence in their minds as one-half of that same body would have. Drills are used on giving parts of numbers as decimals, common fractions, aliquot parts, and percentage. The aim is that pupils know at sight the decimal and percentage values of the following fractions: $\frac{1}{2}, \frac{3}{2} ; \frac{1}{3}, \frac{2}{3}, \frac{4}{3} ; \frac{1}{4}, \frac{3}{4}, \frac{5}{4}, \frac{7}{4} ; \frac{1}{5}, \frac{2}{5}, \frac{3}{5}$, $\frac{4}{5} ; \frac{1}{6}, \frac{4}{6}, \frac{5}{6} ; \frac{1}{7}, \frac{8}{7}, \frac{5}{7}, \frac{8}{7} ; \frac{1}{8}, \frac{3}{8}, \frac{5}{8}, \frac{7}{8}, \frac{9}{8} ; \frac{1}{12}, \frac{1}{16} ; \frac{1}{20} ; \frac{1}{25}$.

The following definite suggestions come from a sixth grade room: ${ }^{1}$

Common fractions having been introduced in the fifth grades and the principles learned there, the work in the

Decimal

Fractions sixth grades is a review of the subject, combined with more thorough and difficult work by the introduction of more difficult problems, correct analysis, decimal fractions, and complex fractions. In presenting the subject of decimals, the pupils are led to see that they are studying another kind of fraction. The parts of the unit are first given in the form of a common fraction, then as a decimal fraction. The numerator and denominator of a decimal are considered, and the use of the point as well as the importance of always noticing it. While learning to read decimals, the pupils also spell the denominators and the corresponding term in whole numbers, so as to fix the distinction in spelling, pronunciation, and meaning. Careful attention is given to writing and reading decimals before any examples are given, for the majority of the mistakes in working with decimals come from the fact that the pupils do not under-

${ }^{1}$ Mr. Edward P. Liesy. 
stand these first steps, consequently the real value of any decimal is obscured.

The pupils are taught that decimal fractions, like common fractions, can not be added or subtracted until they are reduced to a common denominator.

Adding

and

Subtracting Illustrations by comparing decimals placed correctly and incorrectly with common fractions show how this common denominator is to be found. As:

$$
\begin{aligned}
& .125=\frac{125}{1000} \\
& .15=\frac{15}{100}
\end{aligned}
$$

The fact that placing decimal points under each other removes the difficulty is usually hailed with delight for ease of operation, and the illustration usually tends to greater care in writing decimals. As: ${ }_{.15}^{.125}$. The pupils are led to see that with this position tenths are being added to tenths, hundredths to hundredths. Many examples are given through all of this preliminary work with decimals, because of the importance of getting started right. Special drills are necessary where whole numbers and decimals are to be added or subtracted, as : $25+.125=$ ? $2+$ $.00 \mathrm{I}=$ ?

Multiplication and division of decimals are introduced through common fractions, in order to fix the need and the reason for the pointing off of the product. Multiplication Examples are given as follows: $\frac{2}{10} \times \frac{2}{10}=$ and Division $\frac{4}{10 \%}$. Written out as a decimal the pupil observes that to say $.2 \times .2=.04$, he must put in the cipher to make his decimal read correctly. Drill 
is frequent, comparing constantly with equivalent common fractions, until the processes and the reasons for them are thoroughly learned.

After studying fractions and decimals percentage is comparatively easy. Much oral work is given before any writ-

Percentage ten work is attempted. No terms, such as base, rate, are required in the beginning. The first problems are similar to the following: What is 25 per cent. of $\$ 160$ ? What is I7 per cent. of I 40 gallons? Common fractions are substituted for the per cent. and the indicated multiplication is also performed.

The next problems deal with finding out what per cent. one number is of another; as: $\$ 9$ is what per cent. of $\$ 12$ ? This is so closely related to fractions that the same solution is required, only the answer is finally given in per cent. From a knowledge of aliquot parts many of the fractional answers are given as per cent. at sight; others can be given by a little mental work; still others must be thought out more laboriously. This last, however, is an exercise that belongs to more advanced grades. Problems in profit and loss and many miscellaneous examples, including all of the principles that have been developed in percentage, complete the work of the year in percentage.

To secure accuracy in business forms and letter writing requires much careful work. There are so many little

Business

Forms points to be observed that pupils are liable to overlook some of them; consequently, repetition and rewriting are necessary. The proper forms are placed before the class and explained. After copying and studying them, many bills and letters are dictated. The result desired is that every pupil shall be 
able to write a letter ordering a bill of goods, to make out a bill to be sent with the goods ordered, to write a letter sending the money to pay for the goods, and to write the receipt for the money paid. Every paper must be accompanied by the proper addresses of the person to whom the letter is sent and of the sender. The pupils also write many original bills and letters. While making out these bills and orders, the pupils are asked to learn from the daily paper the actual prices of produce, and to use them in their transactions. From these newspaper price-lists a great deal of information is obtained concerning articles bought and sold. In connection with letter writing, there is taught how to subscribe for a newspaper or magazine.

No written work in measurements is taken during this year, but many applications of the tables already learned are made, work with the ruler is frequent,

Measurements and the tables are reviewed whenever it seems necessary. Some new measurements are drawn on the board; the square rod is drawn on the floor of the school room; the square mile is indicated as lying between certain boundaries, and the pupils are encouraged to walk or ride over its area so as to become familiar with its extent. Square and cubic measure are emphasized, as being the least understood of all the tables, but the work is in the nature of simple problems to make the principles clear, rather than difficult problems for the sake of the work itself. Drawings are made to represent some of the solids measured by cubic measure, and the contents are found.

Simple interest is taken as a part of the money topic. The subject is given in a very elementary manner. The 
pupils are told how men borrow money, pay for its use, and return it; how securities are given as a safeguard for the Simple money borrowed. No difficult problems are Interest given, and no special rule or method is insisted upon for finding the interest. Many problems are given, the simpler ones being worked orally, while the more difficult ones are worked out on the board or paper.

\section{SEVENTH YEAR GRADE}

Accuracy, rapidity, neatness, these are the three requirements kept constantly before the seventh grades. Pupils Course

who have remained in school until this year will, if passed in their studies, ordinarily continue until the end of the grammar grades. Consequently, the work of the seventh and eighth grades can be planned together as a whole more safely than any other two consecutive grades. There are many and frequent exercises in rapid addition of ledger columns and of simpler sums. Mental work is continued in combinations of two or more figures, a feature of the exercises in all of the grammar grades. The Arabic and Roman notations are completed. The textbook presentation of common and decimal fractions is finished during this year, although drills on these subjects are important so long as the pupil is in school. The pupils are made familiar with several more tables, taken concretely at first, if possible. These are troy weight, dry measure, paper and books, English money, and counting table. Subtraction of dates; lumber measure; city blocks; cost of building walks, fences, grading streets, excavating, and similar work, all belong to the seventh grade. The pupils measure walks and fences that 
are being built, cellars that are being excavated, rooms that are being plastered, and report on the measurements taken and the data secured. This work may be done by one pupil, by the whole class, or by a committee appointed for the purpose. In connection with geography, a simple course in longitude and time is given.

Percentage is applied more extensively to business operations by familiarity with the following topics: percentage, profit and loss, commission, simple interest, accounts, insurance, and simple work in partial payments. In connection with these subjects the pupils are trained to write all the business forms required by them. Simple algebraic equations are used in many solutions.

The principal of one of the grammar schools and the teacher of a seventh grade gives the following suggestions from his work : ${ }^{1}$

Much oral work is given to oblige correct thinking; there are frequent short oral drills for quickness and accuracy; computations are tested both by rough estimates and by exact means; unusual technical terms and formal rules are avoided except when necessary for good work, careful expression, or complete understanding.

Since the cry of the business man that pupils can not even add or multiply correctly is only too well founded, much Reviews practice is given for acquiring facility in calculations. Hence, addition, subtraction, multiplication, and division are reviewed, reviewed, and reviewed. All kinds of problems, especially those that are based on actual business transactions, are used to prevent monotony in these reviews. Common and decimal frac${ }^{1}$ Mr. O. H. Grubbs. 
tions are reviewed and completed, special attention being given to pure decimals. As in the drills on integers, innumerable problems are given in fractions to develop speed and accuracy. Much stress is placed on cancellation, actual multiplication and division being performed by the shorter process whenever possible.

Believing that any one, "good at figures," can readily adapt himself to his environments when placed on his own

Denominate

Numbers resources in business, only a few tables in denominate numbers are required; but, by a concrete use of linear, surface, and cubic measures, weights, money, and counting, pupils are led to make more and more definite their ideas of number relations. Constructive diagrams, drawn to scale, illustrative of the assigned problems, are required very frequently. In objective work, measurements of lumber at the lumber yards, of excavations being made, of special points in houses under construction, of fences, sidewalks, streets, are usually obtained through efforts of the class as a whole. An individual or a committee takes the measurements whenever it is not convenient for the whole class to do so. This work is very interesting and instructive for both teacher and pupils.

As we are working for mathematical power, its development is not retarded by forcing unnecessary assistance upon Percentage the pupils. In percentage, for instance, where the problems are similar in every respect to those given the fifth grades in fractions and the sixth grades in decimals, the pupils are expected to reason out their own work. Knowing this, the children respond to the requirement, usually with readiness and success. 
Little stress is laid upon the various terms, insurance, commission, profit and loss; the pupil who has been well taught in fractions and decimals handles any of these topics without further help. Simple problems are given, and emphasis is laid upon the fact that per cent. means hundredths, or a fraction with 100 for a denominator. The pupil is trained to ask himself of what the per cent. is to be taken. This is, of course, largely a matter of language. Making use of aliquot parts connects percentage with fractions easily, and helps prevent falling into rote methods.

In mental arithmetic the aim is to cover the same work done in written arithmetic, fixing the principles by short,

Mental

Arithmetic simple, practical examples. Part of every period for recitation is devoted to oral analyses. Every day from five to ten examples are given by the teacher, the pupils writing only the answers.

As there is nothing beyond the intelligence of the average child in the application of simple algebraic formulas to the

The

Equation

solution of problems, the use of the equation is often required. It is always employed in a simple manner, and the pupils soon learn to enjoy its use and to appreciate the greater ease of solution thus made possible.

\section{EIGHTH YEAR GRADE}

The chief work of this grade is a thorough review of all the subjects and processes of the preceding grades, laying Course special stress on the fundamental operations with integers, common fractions, such of the tables as are in frequent use, and percentage. Abundant drill is given in problems, both oral and written, for the 
accuracy, rapidity, and precision of work that is considered essential for every pupil before finishing the grammar grades.

The advanced work deals with ratio, proportion, partnership, taxes, compound interest, trade discount, powers and roots with application to mensuration. Mental work is still a prominent feature, one-third of the time, approximately, being given to exercises that are to be solved mentally. Some work in book-keeping is introduced, familiarizing the pupils with the meaning and use of the terms debtor, creditor, cash account, day book, and ledger. Keeping small personal accounts is usually an interesting method of study with the pupils. In connection with these exercises, there is opportunity for considerable training in writing business letters and making out necessary forms. The simple algebraic equation is used as in the seventh grades in the solution of many problems.

The principal of one of the grammar schools and teacher of an eighth grade $^{1}$ gives some of the methods used in his class :

The idea of training for habit is kept constantly in mind, while the thought of the year concerning knowledge is to Aims give the pupils a familiarity with number processes that will assist them definitely in bread-winning pursuits. Many pupils and people have ability, but they are lacking in the power of concentration; they have brains, but are handicapped by an inability for continued effort. Consequently, if pupils can work intensely on some problem for one recitation period, endeavoring, while working out the solution, to express their ideas

${ }^{1} \mathrm{Mr}$. William H. Murray. 
logically, systematically, and neatly, valuable power is being gained. Certainly, concentration is being developed. Extremes in this mental discipline are avoided, for ability to reason out a puzzle does not always imply that the power gained can be applied in other directions.

The problems and general treatment of insurance as given in our textbook having been pronounced obsolete and imInsurance practical by a half dozen of our local insurance agents, the teacher has made a study of modern methods and presents the subject as business is actually transacted in the offices. One of our local agents kindly favored us with a talk on insurance methods, which proved very instructive. From him we obtained a rate book and insurance maps of the city. The superintendent of streets loaned us his rubber stamp of a city block. Every pupil was given a diagram of a block, upon which, after locating the lot where he lived, he made a diagram of his own home and of other buildings if there were any. From the rate book was obtained the rating of the property, after which finding the premium was an easy matter.

In considering insurance such questions as these are asked: Why is A's house (which is isolated) rated so much lower than B's (which is crowded among other houses)? Why are brick buildings rated lower than frame buildings? The pupils are asked what rates they would think livery stables, planing mills, paint factories, would have to pay. In most cases the answers are readily given. Pupils who live in the country discover that their rates are higher than those of many living in the city, and they are eager to know why. The fact that Chinatown has a high rate af- 
fords food for thought. One member of the class discovered that his rate had been almost doubled during the last year. A committee of the pupils sent to investigate concluded that it was because a large hay barn had been constructed on the adjoining lot.

Comparisons between the school house and other buildings are made. The pupils are encouraged to bring in all the questions that they can, and by the time that we are ready to take up a new topic the ground has been very well covered. The teacher is often surprised to see how interesting a dry rate book becomes when put into actual use. Many oral and a few written problems are given, and every pupil writes a paper summarizing the knowledge that is gained.

In computing interest the hundred month method is used. The basic idea is that the interest on any principal for one Interest hundred months at 12 per cent. is equal to the principal, and that the interest for a number of months, an aliquot part of one hundred, is just that part of the principal. The interest for one month is $\frac{1}{100}$ of the principal, and the interest for a certain number of days is equal to so many thirtieths reduced to the lowest terms of $\frac{1}{100}$ of the principal. If we desire the interest for eight months, we point off two places in the principal and multiply by 8 . Having found the interest at I2 per cent., the interest at any per cent. may be found by first seeing what part the given per cent. is of twelve, and then by taking that fractional part of the interest at I2 per cent. The advantages of this method are speed and the avoidance of bothersome fractions, for the work is largely of a decimal nature. 
Square and cube root are developed by the blocks. When the pupils understand the principle, they are allowed to work Square and Cube Root by rule. After the demonstration is made by the teacher, a pupil, generally one of the brightest, is called upon to present the same to the class, using the blocks while so doing. In a very short time every pupil in the class is able to present the subject intelligently. Finally, the pupils are required to make the drawings representing the different steps, and to describe the process in writing. Problems involving the application of square and cube root follow.

In measuring surfaces and contents, a special effort is made to lead the pupils to see that shapes and forms have Mensuration a certain relation to one another; and that, when a few truths are well understood, it is possible to discover others. Few rules are required, the pupils developing their own whenever possible. The rectangle and triangle are first mastered. When a new figure involving area is presented, the thought is, first, find the rectangle; then, find the triangle. The pupils are led to see that the faces of most solids are related to one or the other of these figures: that the side of a hexagonal prism is a rectangle, and that the base is a hexagon, which can be divided into triangles; that the base of a cylinder is a circle, made up of triangles; that the sides form a rectangle; and that the cone and the pyramid can be resolved into triangles.

In our work with solids, we follow the idea so well expressed by Griffin: "Lead the children to see that, when finding the volume of a solid, they are finding the number of cubic units it contains, which are found in layers, of a 
given number of rows, of a given number of units in a row."

The relation of the volumes of the pyramid, prism, cone, and cylinder to one another is shown by experimenting with tin measures. The pupils see by experiments that the cylinder and prism hold respectively three times as much water as do the cone and the pyramid. Hence the rule for finding their volumes. The volume of the sphere, from a model divided into pyramids, is seen to be the aggregation of the volumes of a number of pyramids. The relation of the great circle to the surface of a sphere is shown by wrapping the flat and the convex surfaces of a hemisphere with a string. The pupils see that twice as much string is required in the latter as in the former case; hence, the rule. It is found by experiment with a string that the circumference of a circle is about $3 \frac{1}{7}$ times the diameter. It is convenient to have the class learn the formulas: $D \times$ 3.1416 $=C$; and $D^{2} \times .7854=A$.

Considerable attention is given to drawing to scale plans of rooms, yards, and gardens, then finding the areas. A great deal of time is required for this kind of work, as much as a week having been spent on our school yard alone. 

PART III

NATURE STUDY GEOGRAPHY 



\section{CHAPTER X}

\section{PLANT STUDY ${ }^{1}$}

Nature study is an attempt to place the child, through interest, in intelligent touch with the natural objects and processes which surround him. It turns to practical use the restless spirit of investigation which is so characteristic of healthy childhood. This innate curiosity that marks the child mind is the natural, wide-open door through which multitudes of little experiences reach their places in the storehouse of knowledge. It is the province of nature study to direct and develop this form of interest; to guide the child to correct solutions for the many problems that arise in his actively growing mind, and thus help him in securing an education that is both liberal and practical.

Thus far the tendency has been toward plant and animal study; but, while these subjects are admirably adapted to the work, every course is enriched and interest is better sustained by including lessons on air, water, evaporation and condensation, steam, air and water currents, light, heat, sound, electricity, minerals, including the useful metals, soils and soil formation, and other topics. Plant study has already taken the eminently practical form of school gardens. In these the elements of plant physiology, soils and other plant foods, preparation and cultivation of the soil,

${ }^{2}$ The chapter on Nature Study is written by Mr. Edward Hughes, Supervisor of Nature Study in the Stockton city schools and Principal of the El Dorado Grammar School. 
and many other phases of agriculture are taught objectively. This movement, wherever directed with intelligence, will be an important step toward a condition in which trained men and rational methods will supersede our present "hit and miss" practices in farming. Other phases of nature study promise much for other industrial pursuits as well as for public health and sanitation.

Nature study is a common sense subject and does not require special preparation of the teacher. Experience in teaching is a great help; tact and good judgment are essential. All of us are in conscious contact with nature somewhere. Let the first lesson or series of lessons be drawn from something that will commend itself to parents as practical or useful. Make the lessons short and simple. Study results. That which appeals to a child's interest and understanding will form the nucleus of a course. When a beginning has once been made every day will contribute something for the enrichment and extension of the work.

A common mistake by teachers and supervisors is the attempt to make science of the subject. The child sees one thing at a time well. Class interest flourishes in the study of the isolated object or phenomenon. It dies when we try to establish causes and effects which are not almost selfevident. Our knowledge comes to us as isolated facts and experiences. The classification into a body of knowledge is the work of maturer years.

Pupils should find out things for themselves; they should not read too much. Those who get into the habit of accepting the statements of others at the expense of the power of independent observation have gained nothing from the work. The use of nature study readers may arouse inter- 
est, but it is not nature study. The work should be recreative in its nature. It should be a break in the monotony and drill of the more intensive application of the essential subjects.

Nature study should have its own time on the school program; it should be taught for its own value. At the same time it furnishes valuable material for oral language; it may be used to some extent in written work, although pupils should not feel that they are to be held to writing up everything studied in nature work; nature study and drawing are mutually helpful; the value of nature study to geography is self-evident.

Every phase of the work discussed in the ensuing chapter has been tested and its usefulness demonstrated by teachers of experience and good judgment in the schools of our city. For a country so wide in extent and so varied in climate and other conditions as ours, it is impossible to indicate in all cases at just what time of the year a particular kind of material will be available for the different regions included.

\section{Plant Study}

A subject well suited to the time at which schools usually open in autumn is seeds and seed distribution. It should Seeds and Seed Distribution be introduced by a study of such seeds as the bean, squash, acorn, or any large seed in which the embryo plant is easily seen. Each pupil should have specimens of the different seeds to be examined. Avoiding technical names, draw from pupils such facts as they already know concerning the seed and its work in the continued life of the plant. Add to this knowledge anything within the pupil's comprehension which may 
be necessary to impress upon his mind the great importance of the seed in the perpetuation of the plant species. The collection of seeds should follow. In this work the teacher may indicate a certain class of seeds to be collected by each grade. Thus, grade one, cereals; grade two, vegetables and flowers; grade three, fruits; grade four, forest trees; grade five, common weeds.

Discuss with classes the advantage of such appendages as make seeds easily carried by the wind. Examples: dandelion, thistle, milkweed, salsify, maple, ash, and linden. In some cases the whole plant breaks off at the surface of the ground and is rolled by the wind for long distances, scattering seeds as it goes. Examples: tumble-weed of the western states and the specially troublesome Russian thistle. Other seeds have hooked or barbed spines for taking hold of the hair or fur of animals or the clothing of man. Examples: cockle-bur, burdock, hound's tongue, beggar-lice, Spanish-needle, and the barbed beards of grain. Still others have spiral "clocks," very sensitive to moisture. These, by their motion, help the seed to bore into the soil, thus insuring its growth. Some plants, as the fruits and the nuts, depend upon birds and animals to scatter and plant the seeds. Thus the jays, woodpeckers, squirrels, become tree-planters and conservers of forests. Each plant must in some way solve the problem of effectually scattering and planting its seeds. These are interesting problems, and perhaps nothing in nature tends more to develop the habit of close observation than such work as here indicated, and much more that will suggest itself to the teacher.

Another phase of the subject and one better suited to the needs of higher grades is seed production and rate of in- 
crease among plants. Most plants produce an enormous number of seeds. Have pupils count the number of grains Seed of wheat produced by a single "stool"; the Increase number of seeds in a single poppy head, and from these estimate the number produced by an entire plant. Estimate the possible increase for crop after crop. Beginning with a single seed, how long would it take under perfect conditions for any one of the plants studied to occupy all the land in a single city block? in a square mile? in the state? in the United States? That plants do not increase at any such rate is apparent. Why not? What becomes of the seeds thus produced? In early spring have a careful, persevering pupil measure off a square foot or a square yard of ground and carefully pull up and count all the plants that come up in the space. In the same way measure a similar space and let all grow that will. How many of the plants in this space are able to reach maturity and produce seed? Compare this number with the number that started in the space where they were counted. Plants struggle with other plants for space in which to grow. They also struggle for life against animals, poor soil, climatic conditions, and other obstacles to existence. Why do plants produce such a great number of seeds?

Secure any thrifty plant, six to ten inches high, and place its roots in a bottle of water in the schoolroom. Place a

Parts of

a Plant bottle of the same size, also filled with water, beside it for comparison. Note after a day or two that more water has gone from the bottle containing the plant than from the other. The plant has used some of this water. Which part 
of the plant has taken in the water? What would happen to a plant if its roots were placed in perfectly dry soil? Call the attention of pupils to the root hairs near the growing tips of the smallest roots. Tell them that these are the parts of the roots that take water from the soil. What else do roots take from the soil? In what form must plant food be before the roots can take it in?

In a similar manner develop the use of the stem, leaves, buds, flowers, and fruit of the plant. With young pupils this should be done very simply, but with the aim of giving correct ideas of the uses of plant organs as far as they are able to understand them. With older pupils, the work should be carried farther. Such subjects as osmosis, sap circulation (shown by the use of colored water), transpiration by the leaves, the absorption of carbon dioxide from the air, and the giving off of oxygen by the green parts of the plants when exposed to sunlight, and many other phases of plant physiology, are easily shown by experiment, and they add wonderfully to interest and understanding. If a compound microscope is available, the pupils will be much interested in seeing the stomata of leaves, plant cells, and chlorophyl grains. The latter can be shown best in a little green scum from ponds.

From the study of the simple plant as suggested above, it is only a step to the study of the tree through its annual

The Life of a Tree

cycle. Let the class adopt some individual tree as the "class tree." Review and identify the parts of a plant as found in a tree. Have the class note in a series of properly timed lessons extending through the year, the following phases of the tree's vegetative activity, beginning soon after school opens 
in the autumn: ripening of fruit; dropping of leaves; period of rest, during which a study of twigs and buds will be found very interesting; opening flower buds; opening leaf buds; period of growth, during which the twigs are lengthened by growth of the terminal bud and a new layer of wood deposited just under the bark all over the tree, and at the same time an inner layer added to the bark; formation and maturing of buds for next year; maturing of fruit (seeds). During the study, call attention to the means by which the tree heals wounds in its bark; how its seeds are dispersed and planted; and settle with the class such questions as whether or not the heart wood grows, and whether the bole of the tree lengthens by growth near the ground. What other forms of life are found in the tree? Lichens? Moss? Mistletoe? Insects? Birds? Animals? Extend the work to other trees for comparison. Compare with palm or other endogen if available. The palm grows from a single bud of enormous size. This bud never assumes the dormant form, because the climate of the tropics is never cold enough to render this necessary. In the endogens (inside growers) no annual rings are formed. Note the differences between the seeds and the venation of leaves of exogens and endogens.

In the germination of seeds shallow boxes, three to five inches in depth, are best for indoor work. For deepest

Jermination If Seeds interest the work should begin before the advent of the growing season out of doors. Lima beans, peas, pumpkins, squash, Inlian corn, and some of the larger wild seeds from the seed ollections will be found well adapted to the work. While vaiting for the germination of the planted seeds, have the 
pupils examine some well-soaked lima beans. They should make out the skin-like outer covering and the small opening near the scar of attachment to the ovary. This opening admits water to the germinating seed. The bean shoulc then be split and the parts of the embryo plant made out The pupil will see the parts better if he is asked to draw them. Other seeds should be examined in a similar man ner. The embryo of Indian corn can be well seen by splitting the grain through a little to the right or left of it: center.

When the young plants appear, pupils should watch closely their manner of breaking the soil crust, noting which of the parts previously seen in the seed are showr in the unfolding of the young plant. Have them make ou the seed leaves of the bean and pumpkin, and find what has become of the body of the seed in the case of the corn and peas. Serial drawings will help them in remembering the stages of growth. When pupils are too young to make these satisfactorily, blackboard drawings by the teacher wil suffice. By questions lead the pupils to see that the con ditions necessary for proper germination are moisture, heat and air. If they do not see these as needful, they can be readily convinced by experiment. Try planting some seed in soil that is constantly soaked with water to the exclusior of air. Try planting lima beans with the opening befor mentioned just above the surface of the ground. Plan others at the same depth with the opening down, leavin the back of the seed exposed. Which of the seeds thy planted develop? The use of the seed leaves (cotyledons should be made clear. The growth of the roots and ros hairs can be better seen by the germination of a few radis 
seeds or grains of barley on gauze or cheese cloth. The material should be tied loosely over the top of a drinking glass filled with water. Invert a saucer over the glass until the roots of the germinating seeds reach the water in the glass. This forms a moist chamber in which the seeds will start readily. The logical continuation of the work thus begun in the school is the home or school garden, in which the planting and tending are done by the pupils under the direction of the teacher.

For the simpler work with flowers have the pupils bring to school the first wild flowers of the spring. The common

Flower

Study

names are written on the board with the name of the child who made the collection. By the end of the school year there will be established a speaking acquaintance with the common wild flowers.

For pupils of the higher grades the work may be extended to the study of the parts of a perfect flower and the uses of each part. Having familiarized themselves with these, the problems of fertilization (pollination) and cross fertilization and nature's methods for insuring these vital processes are opened to the pupils. If possible, show the growth of the pollen tube from the pollen grain as follows: Place pollen of the sweet-pea in a ten per cent. sugar solution. This is made by mixing a teaspoonful of thick sugar syrup with nine teaspoonfuls of water. Examine under the low power of the microscope two or three times at intervals of as many hours. Explain the significance of this growth to the pupils: the pollen grain adheres to the sticky surface of the stigma and sends its pollen tube down through the style to the ovule in the ovary. The proto- 
plasm of the pollen grain and the ovule are thus united in the latter, resulting in its development into a seed. Let the pupils prove by experiment that pollination is necessary for seed production.

For the purpose of study flowers may be divided into two classes: those that depend upon the wind for pollination; as, Indian corn, willow, walnut, pine, wheat, and other grasses. Those that depend upon insects; this class including all flowers conspicuous through bright colors or peculiarity of form. The following are particularly interesting for study, alfalfa, Scotch broom, perennial pea, snapdragon, evening primrose, milkweed, Smyrna fig, the melons and squashes, and the perfect and imperfect flowered varieties of the strawberry. Indian corn and the strawberries are especially adapted to the experiment above mentioned. In studying the milkweed have the pupils brush the flowers gently over the hairs on the back of the hand. The pollen masses will be found tight-clutched to the hairs. Catch some of the insects that visit these same flowers; their claws and long hairs will often be found loaded with the pollinia, which are thus dragged over the stigmatic surfaces of the flower, insuring fertilization.

Pupils will find it very interesting to watch insects at work among the flowers, seeking the nectar, or pollen. Careful observation will usually disclose the method by which the bee or other flower-loving insect thus becomes the unconscious but indispensable servant of the plant. There is a side to such work as this that has proved more than practical. It is practice, based upon wide knowledge of this character, that enables a Luther Burbank to produce fruits, flowers, and other plant products almost to order. 
Plants furnish to men and many other animals a very large part of their food supply. Perhaps the most important foods which man obtains directly from

Food

Substance

Formed by plants are the starches, sugars, and oils. Plants Of the starch producing plants the following are well known: potato, sago palm, arrow-root, the manioc from which tapioca is derived, rice, and the common cereals. Mix a few drops of dilute iodine with a little flour paste, and note that the mixture changes immediately to a bright blue. A thin section of potato treated with very dilute iodine and examined under the low power of the microscope will show the blue starch grains in the colorless potato cells.

Sugar is derived mainly from three sources,--sugar cane, beets, and the evaporated sap of the maple tree. It is also found in many ripe fruits; as, grapes, figs, prunes, apples, pears; it is also present in small quantities in the sap of other trees than the maple, notably in the sugar pine of the Pacific slope. Pupils in the higher grades will be interested in knowing that sugar, wood fibre, and starch are very much alike chemically. Each is a chemical union of carbon (charcoal is a familiar example) and water in slightly different proportions. The following experiment demonstrates this for sugar:

Fill a test-tube about one-sixth full of thick sugar syrup. Add the same amount of sulphuric acid. Set the tube in a glass and put the glass on a piece of heavy cardboard. Note that the mixture slowly turns brown and then very black. The mixture rises in the tube and considerable heat is generated. The acid has decomposed the sugar by taking out the water, leaving the almost pure carbon. If the 
substance is now washed thoroughly in running water to free it from all traces of the acid, and then thoroughly dried, it is found to be quite like soot, and it may be burned as other forms of carbon are burned. Pupils already know, perhaps, that in digestion starch is converted into sugar. The same process takes place in the ripening of some fruits and in the germination of starchy seeds. See malt and beer making.

Vegetable fats, also nearly pure carbon, are obtained from the seeds and fruits of many plants, notably the olive, cotton-seed, and practically all the nuts. Other vegetable fats, as turpentine and linseed oil, are important in the arts and manufactures. These substances are, of course, stored up for the plant's own use; man and other animals appropriate them and apply them to needs of their own.

All plants store food in their seeds or in those parts used as seeds, - as tubers, bulbs, spores. This stored food is manifestly for the use of the young plant

Food

Substances

Stored by

Plants until it becomes able to support itself. Other plants store food in quantities for the purpose of having a large amount of quickly available material out of which the flower-stalk, flowers, and seeds are formed rapidly in the proper season. Some of these mature in one year; as, radishes, lettuce, alfileria, mullein, and many others. Some require two years from seed to seed again; examples, beet, carrot, onion, cabbage, celery. Still others require several years, as is the case with the so-called century plant.

Food is thus stored in the roots, as in parsnips, radishes, beets, turnips; in the leaves, as in cabbage, lettuce, and mullein; in the leaf bases, as in celery, onions, and lilies; 
in the flower-stalk, as in the cauliflower; in portions of the stem, as in the potato; and in the seed cases, as in the fruits generally. The purpose to be gained with the fruits seems to be to cause the seeds to be scattered. This is largely accomplished by those animals which use the fruit for food. Among the plants useful to man may come first the food plants. These may be divided for convenience into cereals,

\section{Plants}

Useful to

Man vegetables, fruits. Let pupils prepare lists of those that are produced locally; those grown in other portions of the country; those that are imported from other countries. Have samples of the most important ones for examination. Which part of the plant is used for food? What is its appearance? Where is it produced? Etc. Etc. Treat similarly the textile plants, cotton, flax, ramie; the timber used in building and cabinet making; medicinal plants may also be considered.

Besides the movements of growth noticed in the growing parts of any plant, there are a number of motions that are

Plant

Movements very interesting when shown experimentally. Some of these movements would indicate that plants have something akin to the nervous system in animals. At least, certain parts of plants have sensibility and the motion that results from it. The common sensitive plant, easily grown in a pot or box in the schoolroom, furnishes perhaps the best illustration of plant motion. Working from this as a beginning, pupils will find many examples of flowers that either close their petals or droop their blossoms at night to protect their pollen from the dew. Many flowers also show a more or less 
marked inclination to follow the apparent diurnal motion of the sun. The leaves of many plants, notably oxalis, varieties of acacia, anemone, and lupines are folded at night or during stormy weather. The movements of twining plants, such as the morning-glory, pole-beans, and others can be studied easily from plants in boxes in the schoolroom. When such a plant begins to "run," it takes a slow revolving motion, the tip feeling for some support upon which to climb. As soon as this is found the twining motion begins. What is the direction of this motion? Is it similar or opposite to the motion of the hands of a clock? Do any plants twine in the opposite direction?

The motion of tendrils in such plants as peas, grapes, passion vines, wild cucumber, and pumpkin is also easily seen. Leaf stems of some plants are similarly sensitive and act as tendrils. The nasturtium is a familiar example. Root tips show a marked sensibility. This enables them to seek the line of growth that offers the least resistance in their extension into the soil, also to locate plant food even at a considerable distance. The following is a simple experiment that will illustrate the movement of root tips:

Suspend several peas or beans in a moist box until they begin germinating. To the growing points of the roots of two or three attach a very small bit of thin card by means of a little mucilage or glue. Note that the root tips so treated tend afterward to grow toward the bit of card, resulting in very crooked roots. The roots of the others grow straight downward.

There are tramps and paupers in the vegetable world; they are the parasites. Through parasitism they have long 
lost the power of independent existence. The different varieties of mistletoe are interesting plants that never have Parasitic any direct connection with the soil. The Plants viscid material surrounding the seeds serves to make them adhere to the bark of trees, where they germinate and grow. The common dodder, or love vine, is a degenerate morning-glory. Its seeds germinate in the ground as other seeds do, but, unless the young plant finds a host upon which to prey before the food substance of the seed is exhausted, it dies. Through disuse, it has lost its leaves, which are represented by scale-like organs that are functionless. It has also lost the power to produce chlorophyl ; hence, the absence of the green color characteristic of plants, and of the power to assimilate plant food taken directly from the soil. Therefore it does not retain connection with the soil after the first week or two of its life. It forms its snake-like vines, its flowers, and its seeds from food stolen through many root-like organs, which it thrusts through the bark of its host, the plant upon which it lives. This parasite is known by its yellow or orange color. The story of its life contains a strong moral lesson which applies to human affairs, the loss of power through a lack of use.

A subject that abounds in interest for pupils and that is of great practical value is the propagation of plants. Fill

Propagation of Plants

pots or boxes with coarse, sharp sand. Make cuttings of two or three buds each. In planting, leave one bud above the surface of the sand. Keep the sand moist, not wet. Try cuttings of the following plants,-grape, currant, fig, rose, geranium, carnation, and chrysanthemum. For the best 
results place the cuttings in the sand in November or December. In the spring try rooting oleander and willow in bottles of water.

A modification of propagation by cuttings is known as layering. A branch of the plant from which the cutting is to be made is cut partly off and pegged down in a shallow trench. It is then covered with soil for a few inches above and below the point where the cut was made. Plants which refuse ordinarily to grow from cuttings root easily by this method. If the branch to be rooted is part of a tree, or if, for any reason, it can not be bent to the ground, it can be layered by pegging it in a box of earth, which is placed upon a support high enough for the purpose. Very interesting, also, are the processes of budding and grafting, so indispensable in horticulture. These are very simple, easily taught, and of unquestionable value to any pupil.

The work of plants in the disintegration of rocks, both by growth of roots into faults and seams of rock strata and

Plants as

Soil Makers by the dissolving action of acid secretions will furnish material for experiment and discussion, as will also the work of the roots of leguminous plants, clover, peas, etc., in furnishing free nitrogen to the soil. Have pupils dig up roots of clover and examine the nodules which stud them thickly. These nodules contain bacteria which have the power of making soil nitrogen from that in the air, thus making it available for plant food. The importance of this work will be better appreciated by pupils if they understand that, of the plant foods, nitrogen is one of the most difficult to supply to 
soils. It explains, also, the value of the clover crop when used in rotation with other crops.

Discuss with pupils the work of plants in the formation of the coal series,-peat, bitumen, lignite, bituminous and Plants in Land Building anthracite coal, and graphite. Also the effect of plant growth in delta regions and low coasts in holding and increasing deposition of sediments, thus adding to land area. In this connection mention especially the swamp grasses, reeds, mangroves, and willows. 


\section{CHAPTER XI}

ANIMAL STUDY : THE AQUARIUM; THE INSECT CAGE; OTHER ANIMALS

At least two lines of animal study will commend themselves to the teacher because of the relatively large returns obtained from a small expenditure of time. These are the study of life by means of the aquarium and of the insect cage. The uses of the aquarium in nature study are so The Aquarium many and so important that it may be considered almost a necessity. To be successful with the aquarium, we must imitate somewhat closely the conditions that exist in open ponds, for these are natural aquaria. During the warmer season such ponds teem with animal and vegetable life. Ponds present a great amount of surface to the air; in a sense, they breathe. That is, they are constantly giving off carbon dioxide, and receiving oxygen by diffusion. In ponds containing a large amount of plant life this exchange is largely between the water and the plants. Our aquarium presents relatively less surface to the air, so it must contain a greater amount of aquatic plant life, such as normally produces its green tissues under water. Some plants of this nature are the different varieties of swamp grasses, water-crowfoot, water milfoil, and the fresh water algæ. Plants which produce their green parts above the surface of the water and those which float upon it do not supply oxygen to the aquarium, although they may add to its beauty or may serve other important purposes. 
Any clear-sided vessel having a large mouth and a capacity from a quart up may be used in the study of some form

The

Vessel of aquatic life. A more pretentious rectangular aquarium may be secured at moderate cost, and with proper care will be an ornament as well as a center of unfailing interest in any schoolroom. Having secured a suitable vessel, place in the bottom a layer of washed sand and gravel. In this place cuttings of swamp grasses, bulbs of the calla or arrowleaf, or roots of the umbrella plant, if the vessel is a large one. Fill with clear water, preferably from a pond, taking care that in pouring it in the force of the stream is broken so that the material already in the bottom is not disarranged. After filling add water milfoil (myriophyllum), or if this can not be secured, any plant that grows with its green part submerged. In the absence of more suitable plants fresh water alga, the green scum of ponds, may be used. If this is used, care should be taken to secure that which is in vigorous growth, as will be shown by its bright green color. The aquarium is now ready for animal life.

Certain forms of life, although living in the water, are air breathers, and so do not tend to exhaust the water of

Animal

Life

its oxygen. The aquarium may contain any number of such creatures, consistent with the food supply. Turtles, waterbeetles, back-swimmers, water-boatmen, and the larvæ of mosquitoes and gnats are of this kind. Turtles exist upon animal food, which should be supplied very sparingly, as whatever is not eaten quickly contaminates the water. They are not veky satisfactory animals for the aquarium, unless it is very large. In case they are kept a float should 
be provided for them to climb upon when they wish to leave the water. The insects mentioned, if kept in reasonable numbers, will find food for themselves. Such insects are found in ponds and watering troughs. The eggs of the mosquito will be found in little rafts, which look like flakes of soot floating on the surface of the water. Placed in the aquarium these eggs hatch in a few days. Pupils should see the insects emerge from the eggs; they should continue their observations until the final change into the perfect insect takes place. This will occur in from ten to fourteen days after hatching. For close examination place a half dozen of the wrigglers in a glass of water and use a hand lens of moderate power. Soon after hatching mount a very small one in a drop of water. Place cover-slip on it very lightly and examine under the low power of a compound microscope, as a transparent object. Make out the digestive canal, mouthparts, eyes, and the air tubes (trachea) where they connect with the breathing pore at the caudal end of the insect. Aside from their nature study value, mosquito larvæ furnish food to other animals which may be kept in the same vessel.

The dragon flies are also very interesting creatures for the aquarium. In autumn, along the reedy margins of

Dragon

Flies permanent ponds, several species of dragon fly may be found depositing their eggs. Certain of the larger species pierce the reed stems just below the surface of the water with the ovipositor, and deposit the eggs in the slit-like openings thus made. Watch the female at work, and when she has finished cut off the piece of reed containing the eggs and transfer it to a small clear-sided jar of water. When the 
young appear a week or two later, place some mosquito eggs in the jar. These on hatching will provide food for the young dragon flies for a time. As they grow larger, supply any small soft-bodied insects or even small earthworms, in addition to the young mosquitoes. Still later, small poliwogs will be acceptable to them. Dragon fly nymphs are voracious feeders, and, if their food is not supplied, they will eat one another. Children will be interested in their manner of feeding, breathing, moulting, and locomotion, as well as in the final change when they emerge from the water, make their last moult, and take the adult form. This should occur in May or June; and, if at this time there are no plants with stems projecting above the surface of the water in the aquarium, some reed stems should be placed in it for them to crawl out upon. The children should now be told something about the life of a fully matured insect. Boys know it as the "mosquito hawk," " darning needle," "snake doctor," and "snake feeder." "Its first name is deserved, for it does feed upon small insects taken upon the wing; but the last names are misleading, as it sustains no known relations with snakes.

Water beetles, both larvæ and adults, are interesting objects in aquaria, but they are quite destructive to other

Water

Beetles

forms of life with which they are associated in nature. If kept alone they may be fed on bits of fresh meat, earthworms, tadpoles of frogs. The larvæ, sometimes called water-tigers, should be kept in shallow vessels, as they are air breathers and must be able to reach the surface of the water with their breathing organs.

The water boatmen and the backswimmers, two very 
active water bugs, add much to the interest in the aquarium Water Boatmen Backswimmers

by their rapid movements and by their peculiar method of carrying a bubble of air with them for respiration. Under water, this has much the color and brightness of a drop of mercury.

Pond snails are easily obtained. The eggs, deposited on the glass or on stems of plants, are valuable for showing Pond Snails active cell division. Mount some in a little water in a watch crystal, and examine with a microscope of low power. If the eggs are taken when quite fresh, an hour or two after they are deposited, the beginning of segmentation can be followed for the first ten hours, or until the cells become too small to be seen with the low power. Later, the developing eye and heart can be made out, and still later, the motion of the young snail itself in the egg. These snails are found in permanent ponds, watering troughs, and streams. Daphne, cyclops, and other "water fleas" are very small crustaceans, numbers of which are to be found in temporary rain ponds in spring. They add interest and furnish food for other forms of life, looking out for themselves and requiring no attention on the part of those who care for the aquarium.

If muck from the bottom of a permanent pond or of a sluggish stream is used on the floor of the aquarium instead Fresh Water Mussel of the layer of coarse sand or gravel, or if the muck is mixed with this regular covering, a small specimen of the fresh water mussel can be kept.

With the first heavy rains of winter and spring the adult salamanders appear in considerable numbers in the ponds. 
Owing to their nocturnal habits they are seen by comparatively few people. They are easily secured, however, Salamanders at this time of the year by raking out the leaves and other debris from ponds. These adults, after being kept a few days for examination, should be returned to the ponds. The eggs are deposited singly or in masses, enclosed in a jelly-like substance adhering to twigs or to the stems of plants in the ponds.

Secure the eggs as fresh as possible, place them in small vessels, and note development. If secured very soon after being deposited, the division of the egg can be seen with the unaided eye. Later, note the formation of the spinal groove in the embryo; and still later, just before the young are ready to hatch, note the budding and growth of the external gills at the neck. Two or three days after hatching, the young salamander begins to feed. At first, it finds food in the microscopic forms that are normally present in the aquarium; later, it feeds upon the water fleas and mosquito larvæ; and, still later, the tadpoles of frogs will supply its needs. In the absence of the latter it may be given a small earthworm. If fed in this way it soon learns to rise and take food from the hand when hungry.

Note that the young salamander is fish-like at first, and that the fore-legs appear soon after hatching as bud-like growths just behind the gills. The hind legs appear much later. A few days after hatching, the circulation of the blood through the gills can be most beautifully seen under the low power of the compound microscope. Place the young salamander in a watch crystal of water and examine the gills as transparent objects. Note that the blood in such small amounts is not red, but a very light straw color. 
Explain why to the pupils. Note the interruption of the blood current by the pulse. Note also the currents of water flowing past the gills. These currents are kept up by rapidly moving cilia, difficult to see even with the high powers, owing to their small size and rapid motions.

To see all these things requires time and much patience, as the little creature frequently moves out of the field of view and must be brought back again by moving the watch glass so as to bring the animal again under the objective. It is worth all the trouble, however, for there is probably no better object lesson on the circulation of the blood.

A little later in the season the frogs and toads appear in great numbers in the ponds, adding their choruses to the Frogs other subtle sounds and influences of spring. The eggs are similar to those of the salamander, but they are loosely coherent in masses of fifty or more, attached to plants or floating free according to the species by which they are deposited. The development of the tadpole is similar to that of the larval salamander. It has no external gills except when very young, and it feeds almost exclusively upon vegetable matter. The legs develop in the reverse order to those of the salamander, and in the final change the tail is completely absorbed. At the same time the digestive system undergoes pronounced changes to fit it for the exclusive insect diet of the adult stage. Respiration in frogs and salamanders takes place not only through the gills, but through the skin everywhere, and through the widely expanded tail-fin, which is plentifully supplied with capillary vessels. In the adults of both forms lungs take the place of gills. 
Fish are, perhaps, the least desirable of all the animals

Fish suited to aquaria. One or two very small fish may be desirable during seasons when other material is scarce.

The price of success in all work with the aquarium is extreme care against overstocking with animals which take Caution oxygen directly from the water. For the best practical results use several vessels having capacities of from one to six quarts, rather than one large aquarium. As young forms, such as tadpoles, develop, remove all but two or three of each kind, as crowded conditions and insufficient food are fatal to good results. Food supply is very important with the young of all animals. Once started, the whole care of the aquarium may be given over to trusty pupils.

\section{The Insect Cage}

The rearing of insects in an insect cage is much simpler than the caring for animals in an aquarium; consequently, the former is better adapted to work with young children, although its value is just as great with older pupils.

The cages may be very simple,-a flower pot with a wire cover, a small box or a glass jar with a little slightly moist The Cage earth in the bottom, or a more elaborate affair made for the purpose. A good form for the latter is a rectangular box, two feet long, one foot wide, and sixteen inches high, with space in the bottom for a tray three inches deep for soil. The sides may be of glass, and, to secure ventilation, the ends may be of wire screen. The lid should be on the top and hinged; it may 
be solid or covered with wire screen. Fill the tray with loose soil, slightly moist, and the cage is ready for use.

As a beginning ask the pupils to bring in any caterpillars, noting on what plants they are feeding so that fresh food Caterpillars may be supplied every day. If there is any difficulty in finding caterpillars, direct the children to look for them on parsley, sweet anise, milkweed, tomato, cabbage, tobacco, and cheese weed. Secure some of the eggs, for it is desirable to have the pupils see the development of some of the species from the egg stage.

When the caterpillars reach full development, they will become restless and crawl about seeking a place in which to make their transformation. Note whether a cocoon is formed or the chrysalis is simply hung in position, and how. Some of the caterpillars found in the early spring and late summer will complete their changes into moths or butterflies in a few weeks; others, especially those taken rather late in autumn, will remain in the chrysalis stage until the next spring.

The eggs of grasshoppers may be secured in autumn by catching the females and allowing them to deposit their eggs in the soil in the bottom of the cage. Early in the spring sow barley or wheat in the soil to furnish food for the young when hatched. Eggs of the katydid are sure to be found on twigs. Place these in the cage for hatching. The young will feed upon the leaves of black walnut. The caterpillars of the sphynx moths, found upon the tomato, tobacco, and grape, burrow into the soil when they have finished feeding.

Other insects profitable for study are the aphids, or plant lice; the lady bugs, which feed upon them; the lace-winged 
flies; the ant lions, which form the curious, funnel-shaped traps for catching their prey; and, where the leaves of the white mulberry are found, there are the silkworms. Any of the insects mentioned can be reared successfully in a closed cage containing a little soil, if there is good ventilation and a daily supply of fresh food. Most caterpillars can be reared in open pasteboard boxes, but mice destroy them, and they wander much just before entering the chrysalis stage.

\section{Lessons on Other Animals}

In the lower grades it will be found worth while to make comparative studies of such animals as the chicken and the duck, the cat and the rabbit, the dog and the sheep, the cow and the horse, and other familiar animals. Have the pupils discuss under guidance and in a comparative way structure, food, general habits, keenness of sight, smell, and hearing, and the various uses of animals to man.

The common birds should be known by name; there Birds should be discussions on the habits of those that are well known,-nest-building, food, song, migration.

Study the dog as to the general features of his structure. Compare with the cat. Tell the pupils what is known of The Dog the origin of the domestic dog. Discuss varieties and their uses to man. Lead the pupils to a consideration of the characteristics which make dogs interesting companions or servants,-faithfulness, affection, obedience, courage, strength, speed, and the wonderfully keen senses. With older pupils discuss peculiar habits, such as howling, burying bones, turning about before 
lying down, and other instinctive acts that persist to link the dog to his wild ancestry. Discuss the wild dogs,wolf, jackal, hyena, dingo, fox.

Discuss with older pupils the importance of animals in subsoiling and admitting air and moisture to the soil. This Animals as Soil Makers is performed by earthworms, ants, moles, field mice, gophers, prairie dogs, ground squirrels, and by the animals that burrow or bury articles; also by the many forms of animal life that hasten the decay of dead trees and other vegetable matter by boring and tunneling, thus letting in air and moisture.

In connection with geography discuss the animal origin of limestone, chalk, anu coral islands. 


\section{CHAPTER XII}

\section{NON-LIVING THINGS}

In the lower grades evaporation may be presented very simply. Take plenty of time to prove that, while some of Evaporation the water that disappears after a rain is absorbed into the ground, much of it passes into the air as invisible water vapor. Show that water in closed vessels will remain indefinitely, while that in open vessels is soon taken away by the air. Boiling a small quantity of water shows that heat hastens evaporation.

For grades above the first two, the experiments may be extended to the evaporation of volatile liquids, such as alcohol, gasoline, ether, chloroform, carbon-bisulphide, cologne, and many others. Only a teaspoonful or two should be used of those substances which vaporize rapidly into highly inflammable gases. Pour into the hollow of a pupil's hand a small amount of one of the liquids mentioned, and caution him not to spill it. The liquid soon disappears; if it has a strong odor it can be smelled throughout the room, so helping tell the story of its diffusion through the air.

- Next make a series to test the comparative rapidity of the evaporation of several liquids. Arrange small, shallow dishes with labels showing what each one is to contain. The following liquids may be used,-glycerine, water, coal oil, turpentine, alcohol, gasoline, carbon-bisulphide, and chloroform. Use equal amounts of these substances, and 
determine the order of the rapidity of evaporation. Saturate some cotton with the liquid that evaporates most rapidly, wrap the cotton around the bulb of a thermometer, having first noted the temperature indicated by the dry bulb. Swing the thermometer in the air to hasten the evaporation, and note the rapid fall of the mercury. Bring out in discussion that evaporation cools the surface from which it occurs. Why does moistening the skin even with warm water make it feel cooler when exposed to the air? Why does it feel cooler when moistened with alcohol or ether instead of water? Why are wet cloths put around jugs and casks of drinking water? What is the effect of the evaporation of perspiration upon the temperature of the body? Where would this effect be greater, in regions where the air is moist or dry? Why are sunstrokes more common in moist climates than in dry ones?

Discuss the formation of dew, fog, clouds, rain, and snow. Have the class see the clouds growing larger on Condensation days when there is a falling barometer, and smaller when the weather is clearing. Distinguish between true vapor, which is invisible, and fogs and clouds, which are visible. The immense, flat-bottomed cloud masses that fill the sky on spring days, and the great. cumulus clouds commonly called "thunder heads" are. really parts of vapor masses reaching to the earth; only the tops are visible, however, because these lie in currents of air sufficiently cold to condense them into fog. The lower and warmer layer may be from half a mile to a mile in depth. Often two layers of air can be made out above this, when the clouds at different heights float in different 
directions. In quiet weather the column of smoke from a large fire will often have a cloud-tipped top. 'Explain.

It is a fact not very generally known that water vapor will diffuse through a vacuum as quickly as it will through air. In other words, the presence of air is in no way essential to the process of evaporation, which is even prevented if the air is already saturated with water vapor. Why then does not the earth lose some of its water supply by evaporation into space? Why should high ranges of mountains prove barriers for moisture in winds?

Experiments in magnetism are full of interest for the younger pupils. These should include a study of both the Magnetism bar and the horseshoe magnet. Show the lines of magnetic force by covering the magnet with a sheet of paper upon which iron filings are gently sifted. If blue print paper is used and exposed to sunshine for two or three minutes, a permanent print may be secured showing the lines of force. Suspend magnetized needles by fine silk threads, noting their direction when the motion stops. Show the practical application of the magnet in the mariner's compass. What other uses might it have? With older pupils take up in an elementary way the electro-magnet in some of its simpler applications, such as the electric bell, a part of telephone receivers, telegraph instruments.

- Provide a florence flask fitted with a rubber stopper which has been bored to fit small glass tubing. Secure a Expansion By Heat piece of glass tubing five or six feet long; put it into the opening in the stopper so that all connections are air tight. The resulting piece of apparatus is of course full of air, and the 
attention of the pupils should be called to this fact. Immerse the free end of the glass tube in a shallow dish of water and clasp the bulb (flask) with the hands. Almost immediately bubbles of air begin to escape from the tube. Why? Hold the bulb some distance above a Bunsen burner or an alcohol lamp; heat carefully, until as much of the air as possible has been driven out. Keeping the end of the tube submerged in water, allow the bulb to cool slowly; note that water travels up through the tube into the flask. Why? Now empty the water from the flask and tube. Warm the bulb as before by clasping the hands about it. When a small amount of air has been forced out, let the bulb cool enough to suck up three or four inches of ink or colored water. Hold the flask upright and let the water sink through the tube almost to the bulb. The instrument will now be found to be very sensitive to the slightest change of temperature in the bulb, the short column of water being forced up or down through the tube by the expansion or contraction of the air in the flask. With a little practice in handling this "air thermometer," very interesting, positive results may be obtained. In such experiments pupils should furnish the explanations for the phenomena observed. They should also be able to explain the popping of corn and chestnuts when heat is applied, the blowing out of bicycle tires when left in the hot sun, and similar occurrences.

For showing the expansion of liquids the same apparatus can be used. Fill the flask full of water that has been boiled to remove the air and afterward allowed to become cold. Press the stopper into the mouth of the flask until 
the water rises in the tube a few inches. Mark the height of the water in the tube by tying a string around it at the point to which the water rises. Heat the flask slowly over a gas or alcohol flame, and note the rising of the water in the tube. Why does it rise? Does it expand as much as air? Which is more elastic, air or water? Water which has been expanded to a gaseous form (steam) is very elastic.

The expansion of water by freezing may be taken up here or in connection with dynamic geography. Experiments along this line are very interesting to pupils. Fill a heavy glass bottle, a small necked one is best, and stop with a tight-fitting cork. Place in a freezing mixture of broken ice and salt. In a few minutes the bottle is broken in pieces by the expansion of the freezing water. The experiment is more striking if a short piece of heavy iron pipe is used instead of the bottle. The pipe should be capped at the ends with the regulation caps or plugs used by plumbers.

For the purpose of showing the expansive action of heat upon metals, secure a piece of brass or iron tubing about an inch in diameter and six inches long and a solid brass or iron ball which will just pass through the bore of the tube when both are cold. If the tube is difficult to get, an iron ring will answer the purpose. Heat the ball a few minutes, and it will be found too large to go through the tube. Set the tube upright in a shallow vessel with the ball resting in the opening at the top. Pour cold water upon the ball, which, upon cooling, passes easily through the tube as before. Another method of showing the same effect is 
as follows: Take a rod of iron, copper, or brass, about two feet long, and place it in a horizontal position with one end against any solid object. Let the other end touch the short arm of a lever which acts as an indicator. Now heat the rod, and it will be noticed that it expands and moves the indicator. Why does the blacksmith heat wagon tires before putting them upon the wheels? Why are small spaces left between the ends of rails on a railway? Why does the column of mercury rise in warm weather and fall in cold?

In connection with the expansion of gases and liquids by heat, air and water currents may be taken up. For the Air and Water Currents study of air currents there should be provided a glass-sided box, air tight, except for openings which may be closed when necessary. Such a box may be eight or ten inches high, eighteen inches long, and from six to ten inches wide. The sides should be of glass, puttied in, and a door at one end should be as nearly air tight as possible. Augur holes, of a size that they may be closed by means of large cork stoppers, should be bored in the top near each end, and some may also be bored at different heights in the end opposite the door. ${ }^{1}$ A burning candle will act as a stove in the room thus made. If the box is fairly tight and all openings are closed, the candle flame will go out in a few moments after it is lighted. Why? Now open the holes at the top and place the lighted candle under one of them. Test the direction of the air currents by holding smoking punk or touch

${ }^{1}$ The glass-sided box described above is very satisfactory for the work indicated, but it is not indispensable. A pasteboard box without glass may be used, although it will be less satisfactory. 
paper $^{1}$ over the opening under which the lighted candle was placed. The smoke from the punk indicates the true direction of the air current. Now hold the punk near the other opening. In which direction is the air moving here? Which is lighter, air that is expanded by heat or cold air? Explain the direction of the currents as shown by the movements of the smoke. Take the temperature of the schoolroom at the floor and at the ceiling. Where is the warmer air? Why?

Close the openings at the top of the box and open two at the end, one near the bottom, the other near the top. Test with the burning punk as before. Which shows an inflowing current, the upper or the lower opening? Is air flowing out of the other opening? Explain. Make clear the cause of the currents thus set up. Does the cooler, heavier air flow in to take the place of the warm air that is rising, or does the cooler air, owing to its greater weight, cause the warmed air to rise?

On a quiet day, when there is a brisk fire in the schoolroom, close all openings except one window. This should be open at both top and bottom for six inches or a foot. Test the air at the bottom to find the direction of the current by suspending a light sheet of paper from the lower edge of the window sash. Test in the same way the current through the upper opening. If conditions are favorable the results will speak for themselves very definitely. Now open the window from the bottom only by raising both sashes as high as possible. Test the upper and lower

${ }^{1}$ Touch paper is easily made by soaking blotting paper in a saturated solution of saltpeter. When dry the paper burns slowly and with much smoke, making a good substitute for Chinese punk sticks. 
parts of this opening for the direction of the air currents. Explain. Have the pupils draw a diagram of the room, representing by arrows the direction of the air currents in it, and indicating which are warm and which are cold.

For showing currents in water, fill a florence flask or other thin-sided glass vessel with water which has been previously boiled to free it from air bubbles. Floating particles of sawdust or paper may be placed in it to show the movements of the currents. Heat very gently, and note the results. Or, with a glass tube which has one end drawn to a fine capillary tube, let into the bottom of a thin glass jar or flask some ink or colored water. (The vessel should, of course, be filled with water before this is done.) Touch the bottom of the jar with a heated rod or with the blaze of a match, and a column of ink will quickly rise from the bottom. This is a striking experiment, but its preparation takes some time and patience.

In discussions with pupils in the higher grades connect the experiments on air currents with the larger movements of air upon the surface of the earth. Air Currents Over

The Earth Areas of low pressure are heated areas in which air currents are moving upward from the surface of the earth; they are indicated by the word "low" on weather charts. "Highs" are areas in which cooled masses of air are sinking to the surface of the earth. The equatorial calms are a heated belt characterized by upward currents of air. The calms of the "horse latitudes" are characterized by descending currents. All upward movements of air ("lows") tend to produce rain storms; downward moving masses ("highs") generally indicate fair weather. 
Pupils already know that water and other liquids have weight. Discuss with them the comparative weight of water, oil, molasses, mercury, and other

Pressure of Liquids and Gases.

liquids. Construct a hydrometer as follows: Fit a piece of light pine about the size of a lead pencil into a large cork, one about an inch in diameter by an inch and a quarter long will do. Load the bottom of the cork, so that when placed in a deep vessel of water the hydrometer will float perpendicularly. When properly loaded, mark carefully upon the stick the level reached when the instrument floats at rest in pure water. Why does the instrument float? Because it is lighter than the water that it displaces. That is, it is lighter than the amount of water which would exactly equal it in bulk. To prove this, fill a vessel holding a gallon or more brimful of water. Set this in a larger vessel that will catch the overflow. Select some object that is heavy enough to give a considerable displacement and that does not watersoak. A drinking glass will do. If too light at the bottom to float upright, load it with a few nails or shot or even sand. Place it in the full vessel, and have the class note that as it sinks to its level the water overflows into the larger vessel. Now weigh both the object used as a float and the water that overflowed, and the weights will be found to be equal.

When pupils understand this simple demonstration of the law of floating bodies as it applies to objects in water, discuss with them the density of different liquids. What liquids are lighter than water? Those most easily secured for experiment are alcohol and the various kinds of oils. Liquids heavier than water are salt water, sugar solutions, 
molasses, and mercury. Test with the hydrometer. Test mercury with shot, pieces of iron, and pebbles.

Into a test-tube about six inches long and one inch in diameter put equal amounts of water, mercury, and oil. Do the liquids mix? Drop a buck-shot or other small piece of metal into the tube. Note that it sinks in both the water and the oil but that it floats on the mercury. By careful trial find a substance that floats on water but which is too heavy to float on oil ; and, finally, find some substance that is light enough to float on gasoline. Cork the tube tightly, invert it, and note that the liquids rearrange themselves according to their several weights. Demonstrate by means of the hydrometer that strong salt water is heavier than fresh water. Show the same fact by actually weighing equal amounts.

Water weighs about sixty-two and a half pounds to the cubic foot. In a tank, ten feet deep, what is the pressure on each square foot of the bottom when the tank is filled with water? Would a fish near the bottom of the tank be under a greater pressure than one near the top? Divers can work successfully only in comparatively shallow waters, from fifteen to thirty-five or forty feet deep. Why? Why are tanks for private water supply usually placed high above the ground? Have you ever seen standpipes used in connection with city water systems? Why are they used?

We live at the bottom of a great sea of air which is variously estimated at from fifty to four hundred miles deep. Air Pressure The pressure at the bottom is equal to the water pressure at the bottom of a tank about thirty feet deep. Our bodies, developing under this constant pressure, are not only used to the tremendous 
weight thus always borne, but they need it to keep them in compact, solid form. Thus air seems to us as nothing, except in its unusual manifestations. We commonly say that a vessel is empty when it is full of air, and the fact that air and other invisible gases are really forms of matter is not always easy to make plain to the child mind.

In the lower grades this fact should be made plain by discussion and by simple experiments. Discuss with the children the movements of air that can be felt,- the blowing of the wind ; rising currents from heated stoves ; movements of clouds, which are simply masses of fog high above the earth, floating in variable currents of air; the movement of dust and other light objects or even of small pebbles by the wind. We can hear, feel, and in a sense even see air. It supports the bird in its flight, the boys' kites, and toy balloons. Under compression it is even used for cushions and mattresses; it can be made solid enough to sustain yreat weight, as when it is pumped into bicycle and autonobile tires, thus being greatly compressed.

Invert a jar and force it mouth down into a vessel that :ontains water. Does the water rise to fill the jar? Why 1ot? Fill a drinking glass nearly full of water. Put a ard over its mouth and invert the glass, holding the card luring the process. Now take the hand away from the ard; it will be found that the card remains in place and hat the water does not flow out. Why not? Now lower he glass mouth down into a vessel of water, and as soon as is touching the water remove the card. The water still emains in the glass. Why? With a crooked tube let air ito the upper part of the glass, and the water flows out ntil it reaches the level of that in the vessel. Why? Fas- 
ten a toy balloon to a glass tube ten inches in length, and thrust the other end upward through a bored cork that will fit a large florence flask. Thrust the end having the balloon attached into the flask until the cork fits snugly the mouth of the flask. Try to inflate the balloon by forcing air into the outer end of the tube. It can not be done. Why not? Withdraw the cork a very little way, inflate the balloon, and replace the cork. The balloon remains inflated. Why? Take two test-tubes, one of which is enough smaller than the other to slide easily into it. Fill the larger one nearly full of water; put the end of the smaller tube into the larger one until it displaces the water to a depth of about an inch and a half. Invert the tubes in this position over a vessel to catch the water. As the water slowly trickles out of the larger tube, air pressure forces the smaller one into it. This is a very striking experiment for pupils of any grade above the fourth.

Another that holds interest quite as well is the following: Secure a board, two feet long, ten inches wide, and half an inch thick. It should be of tough wood. Place it upon a table or desk so that nearly half of it projects over the edge. Now spread two or three thicknesses of newspaper over the end that is on the table. Direct one of the stronger boys of the class to strike a quick, heavy blow downward on the projecting end. The class, as well as the boy, will be greatly surprised to find that the board is scarcely moved owing to air pressure acting upon the board and paper The paper, of course, simply prevents air from passin quickly under the board. Thus the blow meets the resis tance of the pressure on the upper surface of the board, th whole of which in this case would amount to nearly a tor 
Other manifestations and uses of air pressure are seen in the use of the siphon and the common lifting pump.

The measure of air pressure may be taken up with pupils of the sixth grade and above. Introductory to the work of making a barometer the following will be helpful: Bend a piece of glass tubing into the form of the letter U. Fill the bend of the tube with mercury, and have the class note that when the tube is perpendicular the mercury stands at the same height in both sides. Call attention to the fact that the air presses with equal weight on the mercury in both tubes. Ask the class what would be the effect of blowing into one of the tubes, thus increasing the pressure on that side. This they will readily see. What is the effect of sucking some of the air out of one of the tubes? Why? Be sure that the class sees that difference in the force of air pressure makes the mercury stand higher in the tube in which the air pressure has been reduced by drawing out some of the air.

The making of the barometer should follow. For this the following will be needed: A piece of glass tubing about Barometer thirty-six inches long and one-fourth of an inch in diameter inside. This tube should be closed at one end. A piece of tube, the same diameter, twelve inches long, and open at both ends. Two pieces of strong rubber tubing, about six inches long, and large enough to fit snugly over the ends of the glass tubes. Enough mercury to a little more than fill the longer tube. A small funnel having a stem equal in diameter to that of the glass tube.

Connect the open end of the long tube to the shorter tube by means of the rubber hose. This should be tied tightly 
with stout string at both connections. In the same way connect the funnel to the free end of the short tube. Now run a straight wire to the bottom of the tube thus formed, leaving a few inches projecting from the mouth of the funnel. Pour the mercury in very slowly, being careful to dislodge air bubbles by means of the wire. When the wire is finally removed, the mercury should a little more than fill the longer tube. Remove the funnel and its rubber connection. Keeping the short tube in a perpendicular position, elevate the longer one until it is parallel with it. Notice as the longer tube assumes the vertical position, that the mercury falls a few inches in it and that there is a corresponding rise in the short tube. How much air pressure in the closed end of the long tube? Pupils readily see that there is none, for there is no air there and the tube is closed. They also see that at the open end of the short tube air pressure acts normally. With a little thought they will be able to see that the weight of the column of mercury is supported by air pressure acting upon the surface of the mercury in the short open tube. Would the same result be reached if the tubes were either larger or smaller? Yes. What is the height of the column of mercury supported? (Measure from the level of the column of mercury in the short tube.) If near the sea level, it should approximate thirty inches. A column of mercury one inch square and thirty inches high weighs fifteen pounds. Could we make a water barometer? How long would the longer tube be? Why can not water be pumped with an ordinary lifting pump more than thirty feet above the water level in the well or soil?

Work in solution and crystallization may be undertaken 
with pupils in any of the grades. Pupils should provide themselves with pieces of common window glass, about five Solution and Crystallization or six inches square. Prepare a saturated solution (one in which there is as much of any given substance as will dissolve in the fluid) of common salt, and put a small puddle of it upon the pupils' pieces of glass. If the weather is dry and warm, salt crystals begin to appear in a few minutes. Watch their formation, using low power microscopes or hand magnifiers, if available. For larger crystals pour some of the solution into a glass or small dish and set it away for a few days. When the water has evaporated, discuss the shape and size of the crystals, how th y form, the time required, and many other points noticed. Then try solutions of sulphate of copper ("blue stone"), saltpeter, borax, epsom salts, hyposulphite of soda, or any other crystalline substance soluble in water.

With older pupils extend the work by considering substances soluble in alcohol, as shellac, camphor gum, or crystals of iodine; substances soluble in oils, as resin, soluble in coal oil or gasoline; paraffin, soluble in turpentine; lime, soluble in dilute sulphuric acid. With these simple experiments as a basis, discuss any crystalline rocks which may be found in the region, such as crystal quartz, granite, marble, calcareous spar, stalactite formations. Call attention to the different forms in which some substances are found, as in the case of carbon, which may be in the form of a gas, common charcoal, mineral coal; as a part of vegetable and animal tissues; graphite, of which lead pencils are made; or the crystalline diamond, which because of its 
beauty, its rarity, and its durability, is one of the most valued of gems.

Children in general have little knowledge of the common metals. Specimens of these are easily secured, and should Common Metals form a part of every school equipment. Where practicable, there should also be a collection of the common metallic ores. Of the various useful metals perhaps iron is best known; for this reason it should be studied first. Draw from the class what is already known concerning the sources of the iron supply in this country; distinguish between the terms wrought iron, cast iron; steel and cast steel. Discuss with the class such properties of iron as its strength, hardness in various forms, elasticity in tempered steel, weight, color, and ductility. Discuss its uses, adapting the discussion to the age and experience of the pupils. Direct attention to some of the many ways in which it is used in the schoolroom or building; in the home; in the city. What enditions hasten its decomposition? (Oxidation or/rusting.) Why do we paint iron? - By what other means do we exclude the air from iron and steel? The use of oil, zinc, tin, or silver for these purposes. The use of iron as a conductor of heat. Compare with wood in this respect; with copper; lead; aluminum. For this purpose place rods of several different metals in such a position that one end of each is in contact with an alcohol or gas flame. At the same distance from the heating ends of the rods, stick pieces of paraffin or tallow. Note on which one of the rods the tallow melts soonest, and the order in which it melts on all of them. Which metal is the best conductor of heat? Which is the poorest? 
The following list of metals is suggested for a continuance of the work: lead, tin, copper, zinc, aluminum, silver, and that to the child most interesting of all metals, mercury. Compare each with iron in such properties as hardness. weight, strength, and discuss uses. Discuss also important alloys, as bronze and brass; also the reasons for making alloys. Whiere sufficient heat is easily available, young children especially will be much interested in seeing lead melted and used in casting bullets or even poured into cold water where it takes on peculiar shapes. Mercury, at ordinaty temperatures, remains in the melted state. At a temperature of forty degrees below zero, Fahrenheit, however, it hardens to a form somewhat like lead.

\section{Simple Chemistry of Air}

Provide a couple of ordinary candy jars; a shallow trough or basin with a capacity of two to four gallons; some rubber and glass tubing, one-fourth inch in diameter; and few medium-sized test-tubes with corks to fit. Have also some short pieces of wax or tallow candle, an ounce or two of potassium chlorate, three or four ounces of manganese dioxide (black oxide), and an alcohol lamp.

Experiment.-Place a short piece of candle upon a float that is small enough to go easily into the mouth of the candy jar. Float the candle in an inch of water in a plate. Light the candle and invert the candy jar over it, letting its edge sink into the shallow water. Call the attention of the pupils to the fact that the jar is filled with air. At first, the flame burns brightly, but it soon grows dim and small, and after a few moments it goes out. Repeat the experiment, noting the water that rises into the jar. Why is the 
flame extinguished? If no one is able to answer, explain, and repeat the experiment. Why does the water rise as the candle burns and for a short time after it is extinguished? Has any part of the air been actually used? Can anything be burned in it now? Slip a piece of pasteboard under the mouth of the jar and hold it in place while the jar is turned right side up. Light a taper and thrust it into the jar. Does it burn? No. Now invert the jar over a piece of burning candle on the table. Can air get into it now? The candle burns for a time and then goes out. Lift the jar gently while still warm, cover, and turn right side up. Pour into the jar about a tablespoonful of clear lime water, and shake it thoroughly. Note that it turns milky, showing the presence of carbon dioxide. Explain the lime water test to pupils, and as a control experiment, shake some lime water in a vessel filled with pure air. The absence of milkiness indicates that, if carbon dioxide is present at all in pure air, it is only in very minute quantity. As a matter of fact, it is about five parts in ten thousand.

Fill a jar with water, place a card over its mouth, and invert into a vessel which already contains an inch or two

Collecting

Gases by Displacement of water with a capacity for at least as much more as the jar contains. Insert the end of the delivery tube under the edge of the inverted jar, and the gas as generated will displace the water. Collect by the above method a jar of breathed air, and test for oxygen and carbon dioxide: the former, by means of the lighted taper; and the latter, with lime water. Repeat several times, if necessary, until the pupils see that air that has supported burning and air that has been breathed are very much alike in the fact 
that they are both deficient in oxygen and contain an excess of carbon dioxide. Collect another jar of breathed air. If the breath is held for a few seconds the results will be more positive. Test for oxygen. It does not support a flame. Place a branch of some plant with fresh green leaves upon it in the jar. Invert the jar into a vessel of water as before, and put it into the sunlight. After two or three hours, test for oxygen; it will be found to be present. Test for carbon dioxide. It has been absorbed by the plant and water.

Place a mixture of equal parts of pulverized potassium chlorate and "black oxide" in a test-tube. Cork with a

Making Oxygen bored cork, which has tightly fitted into it a delivery tube composed of eight or ten inches of quarter inch glass tube and about two feet of rubber tubing. Heat the test-tube over an alcohol or gas lamp, and collect by displacement the gas that is thus generated. This gas is oxygen. Test it by thrusting into it a piece of charcoal with a small spark of fire upon it, or a burning splinter after the blaze is extinguished, leaving a tiny, glowing coal at the end. In the oxygen these tiny sparks spring into life and burn fiercely. In a gas that so actively supports combustion green twigs, thin pieces of steel, as watch springs, and fine wire, burn brilliantly, and drops of the molten metal fall to the bottom of the jar. Two or three inches of water left in the bottom of the jar will cool these and prevent the glass cracking in the intense heat.

In a bottle holding about a quart, put a few marble chips or a couple of ounces of baking soda, and add water until 
the pottle is a little more than half full. The cork for the bottle should be bored for the delivery tube and for a Making Carbon Dioxide "thistle," or funnel tube. The delivery tube should have about two feet of rubber tubing attached to the outer end, and its inner end should extend only just through the cork. Pour small quantities of either sulphuric or hydrochloric acid into the bottle by means of the funnel tube, which should reach almost to the bottom of the bottle.

The gas that is given off is carbon dioxide; it may either be collected by displacement or, by reason of its being considerably heavier than air, it may be allowed to flow into any deep vessel in a room where the air is quiet. When sufficient amount is secured, test it by a burning paper. Does it support burning? Would it support animal life? If the jar is large enough, drop a small, light soap-bubble into it, and notice that it floats in the gas much as a rubber balloon would float in water. It may be dipped and poured, run through troughs and pipes, or it may be siphoned like heavier liquids. Make a deep trough of pasteboard and place short, burning candles in the bottom. Pour the heavy gas into the trough, after elevating one end of it, and note that the lights are extinguished in order as it flows down over them.

Call attention of the pupils to other forms of oxidation besides burning and breathing; such as decay of animal and vegetable tissues, fermentation, and the oxidation of metals,-iron, zinc, lead, copper. How is the oxygen thus used up replaced in the air? In connection with the experiments with carbon dioxide, discuss with the pupils "choke damp" of mines, and the "damps" that are sometimes found in 
wells and deep vats. How do people test wells for damps, and thus know whether it is safe to descend into them? How are such collections of the gas, carbon dioxide, removed?

Place a piece of lime the size of a walnut in a quart of water. Twenty-four hours later, pour off the clear water,

To Prepare Lime Water taking care not to disturb the lime at the bottom. The lime water thus simply prepared is as good for all purposes as is that bought from druggists.

Nitrogen can be separated from the other constituents of the air by burning a piece of phosphorus the size of a Nitrogen pea, instead of the candle, as in the first experiment with air. The dense white gas formed is phosphoric oxide. It is rapidly absorbed by the water, leaving nearly pure nitrogen. Care should be used in handling the phosphorus, and the gas should not be allowed to escape into the room.

Experiments in combustion may either precede or follow or be given with the study of air, as the subjects are closely Combustion interrelated. Substances which burn with a flame are always those which, under certain conditions, give off combustible vapors or gases; those which glow by incandescence but from no flame are commonly some form of more or less pure carbon, as charcoal, coke. The following experiments will serve to illustrate:

In different glasses place a few drops of carbon-bisulphide, gasoline, and alcohol. Cover the glasses for two or three minutes to allow the different liquids to vaporize and mix with air. Remove the cover and apply a red-hot wire. to the mouth of the glass containing the carbon-bisulphide. 
It flashes. Try in the same manner the other two substances. If they fail to ignite in this way, try the flame of a burning taper, and they flash as did the carbon-bisulphide. Place about a teaspoonful of each of the substances in saucers or shallow dishes. By trial, show that each ignites easily and burns with a flame. Extreme care should be used when handling such substances. Only small quantities should be used at a time, and the rest should be kept in tightly closed vessels. Children should also be taught the extremely dangerous character of highly inflammable liquids such as these, and the reasons why they are so. Discuss with them the difference between these liquids, which are very volatile-that is, throwing off large quantities of inflammable vapors at ordinary temperatures-and those liquids which give off such vapors only when heated.

Place a small quantity of kerosene in a saucer and try to light it by means of a match or taper. It refuses to burn. Now place a small quantity in a beaker and heat until it nearly boils. Try the taper in the air above the mouth of the beaker. It flashes about as gasoline flashes at ordinary temperatures, and continues to burn. Take hold of the two ends of a sheet of paper and bring it down quickly to the mouth of the beaker so as to exclude the air. The flame goes out. Why? Discuss the best means of extinguishing burning clothing, oil, etc.

Test various other fats and gums: first, by trying to set fire to them cold; then by melting them and trying the melted form; and finally, by heating until the inflammable gases are given off, when they will flash readily. The following can be tested easily by heating in an ordinary tin tablespoon:-butter, lard, tallow, paraffin, pitch, and resin. 
Each is found to flash when heated to the point where it vaporizes freely. To show that the blaze from burning paper, wood, or coal is due to inflammable gases given off by heating, try the following:

To show gas from paper, cut strips of foolscap or other heavy writing paper an inch and a half wide, and as long as possible up to eighteen inches. Roll into tapers, folding the larger end to prevent unrolling. Light the small end, and after the flame has traveled up the lighter three or four inches, note that there is still a flame at the small end, although the paper is evidently burned. Blow the lower flame out gently and observe that a dense gray "smoke" pours out in its place. Collect a quantity of this in a widemouthed bottle. Stop the bottle and set aside for a few minutes. While waiting for this, repeat the experiment by filling another bottle or a test-tube with the "smoke." While it is still hot apply the flame of the taper to it and note that it flashes somewhat as did the vapor of gasoline, leaving the bottle clear. Examine the bottle that was set aside. If sufficient time has elapsed the "smoke" should have entirely disappeared. Examine the sides of the bottle for a yellowish liquid,-creosote. Discuss the results with the pupils. Was what we called smoke really smoke or was it gas? that is, an inflammable vapor? Can this gas be burned after it is cool, or must it be heated to reach its flashing point? Repeat the experiment if necessary. After burning some of the gas from the bottle, test the air that remains for carbon dioxide. What is the result? Draw from the pupils the fact that the heat of the flame on the outside of the taper drives the gas off from the inner surface. Why does not this burn at the point where 
it is formed inside the paper tube? What prevents the air from entering the tube? Why does not the flame travel through a gas pipe when we light the gas at the burner? Collect some ordinary illuminating gas by displacement in a wide-mouthed jar; a quart fruit jar will answer. Light the pure gas and note that it burns rather slowly from the top downward. Repeat, by filling the jar with about one fourth gas and three fourths air. Light with a long taper and note that the whole mixture flashes at once. In this connection discuss the blow-pipe, also the bunsen gas burner, and the common gas stove burners, which have devices for mixing the gas with air and thus developing great heat by securing more rapid combustion.

Verify the taper experiments by placing a small quantity of torn paper in a baking-powder can (not soldered), and heating it over a gas or alcohol flame. When the gray vapor begins to rise in considerable quantity, test with lighter. Does it flash as before? What produces the flame, the solid paper or the gas that is driven off by the heat? Repeat the experiment, substituting small pieces of wood for the paper. Compare results with those of the previous experiment. What is left in the can after the vapor ceases to be, given off? Compare with common charcoal. Can this be burned? Will it produce a flame? Heat until incandescent, and catch some of the gas that is now given off by inverting a glass over it for a moment. Test the contents of the glass for carbon dioxide. The charcoal can be burned in shorter time if air is admitted by perforating the can near the bottom for this last experiment.

The experiment can be made a little more striking by 
using a section of thin gas pipe, properly capped and fitted with a delivery tube. Place some dry sawdust in the pipe and shake it down into the end to be heated. Heat over alcohol or gas flame until the vapor passes from the delivery tube in a sufficient quantity to light. With the same apparatus use pulverized soft coal instead of sawdust. By heating the coal gas is generated, which may be burned similarly at the end of the delivery tube.

By use of this simple generator collect a small quantity of creosote by condensing the gas from paper or wood. Show the pupils that this liquid can be expanded again into gas by heat. Place a few drops of the liquid in the barrel of a bicycle pump, and heat over the alcohol lamp. The liquid expands again into the heavy, gray gas, and flashes into flame on being tested with a lighted taper.

For experiments with a candle flame, a large candle is so much better than a small one that it pays to make it if it can not be secured otherwise. A mold

Experiments with the Candle Flame for this purpose can be made by rolling heavy writing paper into a tube about an inch and a quarter in diameter. The wick should be several times the size of common candle wicking. When this candle is lighted it does not catch as readily as the wick of a kerosene lamp. Why not? At first, the flame burns low, afterward it increases in size and brilliancy. Why? Call attention to its shape, which is the result of molding by air currents. Tell the pupils that its color is due to particles of carbon (soot) made incandescent by heat. Hold a cold slip of glass in the flame for a moment, and show the carbon that condenses upon its surface. Some of this carbon can be seen escaping unburned from 16 
the flame, which is not hot enough to consume it all. Compare the flame in this respect with the flame of a kerosene lamp without the chimney. The effect of the chimney is to cause this carbon smoke to be completely consumed, thus making the flame larger and brighter. Is the flame of the lamp hotter with or without the chimney? Call attention to the dark area in the center of the candle flame. Thrust a toothpick through the base of the flame and hold it there until it begins to burn. Remove it quickly and blow out the flame. Note that it began to burn at the two places in contact with the outer surfaces of the flame, but that it did not burn in the middle of the flame. The flame is hollow. Why? Because air does not get into the center and nothing can burn without oxygen. What is in this central portion that we have said was hollow? Take a piece of glass tubing about ten inches long, and, holding it at an angle of about $45^{\circ}$, thrust its lower end into the dark center of the flame. A gray gas, reminding us of the gas from the paper lighter, rises through the tube. Have some pupil light this at the upper end of the tube. Discuss its origin, and, if necessary, heat a small piece of tallow in a spoon until it vaporizes and takes fire? When pupils recognize this gas as vaporized tallow, ask again why it does not burn in the center of the candle flame? To fix this point still further, thrust the head of a sulphur match into the dark center of the flame, and call attention to the fact that it does not at once take fire and burn, although it may blacken by heat. When removed, it inmediately takes fire. Try again, this time only touching the head of the match to the outer surface of the flame, where the air reaches it. What is the result? 
Blow out the candle, noting that much gray gas rises from the wick while it is still hot. Condense some of this by holding in it a piece of clean, cold glass. Let the pupils see that it is really tallow, which assumes its original form when condensed and cold. Relight the candle, and, when it burns brightly, extinguish the flame as before. Have a paper tube half an inch or more in diameter and six to ten inches long; hold it so that the gas flows upward through it. Light the gas at the upper end of the tube, and note that the flame travels quickly down to the wick, relighting the candle.

The study of combustion can be extended indefinitely, according to the maturity of the pupils and the interest manifested. The work as here described has been found suited to our fifth and sixth grades, but much of it will bear repeating in grades as high as the eighth. It requires little in the way of apparatus that can not be made by the teacher and the pupils, and it results in an insight into many of the common things that none of us understand too well. With older pupils interest may be added to the work by discussions on the manufacture of illuminating gas, gas and gasoline engines, and many other things connected directly with combustion.

Teach pupils the relation of the moon to the earth, the relation of the earth and the moon to the sun, and the reSky Lessons sultant phases of the moon. Teach also the relation of the earth to other planets of . the solar system, and the differences between planets and stars. The constellations may also be taken up simply by mapping them upon the blackboard and asking the pupils 
to look for them at night. They should know, of course, whereabouts in the heavens to look for a given constellation at a certain hour.

The apparent motion of the sun may be shown by marking the position of shadows or spots of sunlight in the schoolroom at different times during the year. The shadow should be marked at about the same time, about twelve o'clock, every day that it is observed. If sunlight does not enter the room at that time, the class may be taken into the yard, and the shadow of any stationary object, as a post or a part of the building itself, may be used for the purpose. The length of the shadow should be noted, especially at or near the beginning of the different seasons.

Permanently fasten the barometer described elsewhere to a board, and tack beside it a yard stick, so that variations Local Climatic Studies in the height of the column of mercury can be seen easily. Note the height of the column in clear, cool weather, and use this as a standard for future observations. Call attention to any changes, until pupils form the habit of making use of the barometer in the study of climatic conditions. Dry, dense air is heavier than moist, expanded air. Therefore low barometer indicates storm conditions, and high barometer indicates fair weather. Study other local weather changes, the direction of winds and clouds when storms are approaching, and their direction in clearing weather which follows the storm. Local weather signs, if they are at all reliable, should be noted and discussed with a view to their better understanding. Daily weather records become very monotonous and are not to be recommended; but observa- 
tions may be recorded once a week or oftener by the class, if results justify so doing.

In the absence of an organized course in physiology for the several grades, based upon adopted texts, health lessons

Health

Lessons

on such subjects as the following will meet the more serious needs:-The skin. Its structure, glands, and other organs, including perspiratory and sebaceous glands, organs of touch: temperature, and pain; its appendages,-in man, hair and nails; in other animals, feathers, claws, hoofs, horns, beaks, and spurs; its functions, including excretion, regulation of temperature, and protection of underlying organs, and its hygiene, including massage and bathing. In a similar way the muscles, teeth, digestive organs, nervous system, may be treated.

Work under the head of alcohol and narcotics should be well considered and tactfully presented. Some knowledge Alcohol and Narcotics of the nervous system is almost imperative for the success of the work with older pupils, as it is upon this system that the profound effects of these things are produced. The effect of the use of tobacco upon growing minds and bodies should be emphasized with young pupils. In general a stronger case is made against alcohol and other narcotics by emphasizing the moral rather than the physical effects; but boys at the age when interest in athletics begins to develop, are deeply impressed by the fact that these things are inimical to normal muscular development. Teachers should not forget that it is through curiosity purely that most boys begin to tamper with tobacco and alcoholic drinks. 
In the space here available it is impossible to do more than suggest subjects and treatment. Such suggestions Conclusion will not, of course, take the place of textbooks in the various subjects from which work is taken, and which should form a part of every school library. 


\section{CHAPTER XIII}

\section{GEOGRAPHY}

Geography has been defined as the study of the earth and man's relation to it, but that which holds the attention of the student is rather, as is claimed by Dr. Charles A. McMurry, "the interaction between man and earth." The pupil should know more than the location of places and the boundaries of countries, he should also have some conception of his own social relation to the various parts of the world. This requires that he must first gain a knowledge of his own country, its institutions, industries, producțs, physical features, climatic conditions, and its commercial relations with other countries, for the value of the knowledge itself and as an illustrative basis for the comprehension of conditions in other parts of the world. The pupil gains this knowledge just in proportion as it arouses his interest and is grasped by his understanding. The normal child is blessed with curiosity; a keen desire to know; an intense interest in natural phenomena, in his neighbors, in industries, in commerce, in government. The satisfaction of this curiosity is the keynote to success in education. Only when the world is made unreal and foreign to the child does he lose touch with it.

Geography may be divided into physical and social studies. Under the former are grouped those conditions with

${ }^{2}$ Much of the subject matter of this chapter has been furnished by Mr. S. H. Cohn of the Stockton schools. 
which nature has surrounded man, as the physiographic and mathematical features; under the latter belong the condi-

Divisions of

Geography tions with which man has surrounded himself, as those pertaining to commerce, agriculture, government. Development of civ-

ilization is to a great extent dependent upon environments; but a child begins his study at the other end of the evolution, with results instead of causes, with the realities around him that are the results of man's efforts, passing later to the natural conditions and laws that govern his surroundings, and that promote or retard his development. The newer teaching recognizes what the older treatment overlooked, that the study of geography must be based upon material within the experience of the child, for all knowledge is concrete or it has a concrete standard of comparison. In order to secure this knowledge, to widen the child's mental horizon, to add to the sum of his experiences, to establish units of comparison, two ideas have come to take the lead in the methods of prominent teachers of geography,-the excursion and the establishment of a type form. That is, observation and representation.

Seeing is more than believing to the child; if it is the right kind of seeing, it is also knowing. In geography, the

The

Excursion

excursion is seeing, it is getting information at first hand. Two thoughtful objections are urged to the excursion,- - the difficulty in maintaining discipline and the great amount of time needed. Does not true discipline, however, take cognizance of the real child, training him for his life work? The excursion tends to put the real child under the eyes of the teacher, an opportunity not lost by an observant, sympa- 
thetic person. The time required for an excursion is certainly an important consideration; but does not the trouble in this respect usually lie in thinking of today only as time? If the knowledge gathered on the excursion is well seen, if it is so thoroughly learned that reviews and reproductions are less necessary than with the information gained from a book or through the teacher, is not time really gained in the course of the year?

Aimless wandering is not a geographical excursion. The teacher should know where the class is to go and why; the pupil should have some understanding of what he is to see and why. One teacher, before taking her class to the woolen mills, made three trips there herself, so that she might be familiar enough with it to direct attention profitably, and to answer intelligently any question that might be brought out by the pupils at the mill or in the class discussion that followed the return to the schoolroom. A paper written by a pupil after this trip was pronounced by the superintendent of the mill correct in all respects except in the use of a few technical terms, a result worthy of the devotion of the teacher. Not only must the eye see but the mind must record scientifically and correctly what is seen. The excursion and the discussions that follow offer excellent opportunities for such training, which is just what is required in many branches of life.

Our judgments are formed on certain established standards or units. The more definite the standards, the more The Type unerring the judgments. In geography, the pupil must have some means of converting the ideas roused by reading about distant lands and foreign conditions into known quantities. To do this he 
must be able to visualize, to typify. The local river, creek, slough, becomes his type for the study of other water courses; the distance from his home to some known place is his unit of measurement; the length of his play-time or his study period is his standard of time; the hottest day or the coldest morning is a unit for climatic comparison. When the local types have been fixed, the imagination is brought into play in order to understand distant conditions. Pictures, books, stories, all aid in giving that larger view by which the young mind passes to new types. Thus, from the local stream, the type changes to the Mississippi, a standard for measuring all great rivers. In similar manner cities, countries, governments, and peoples become known, but the home type is the point of departure.

\section{FIRST AND SECOND YEAR GRADES}

The geographical work of these years is incidental and is usually associated with nature study; the teaching is objective, and it should always be within the limits of the child's observation and experience. Distance, location,

Distance

Direction

Location

direction, are the first three thoughts presented to the class. The city block is the standard of measurement with these beginners, who are led to notice and remember how many blocks it is from home to the school, to the car line, to some public building. Cardinal points are learned in connection with objects outside the schoolroom; later, they are applied to the interior of the room and building. The child is led to observe in what direction a certain street car runs, where the sun rises and sets, how the shadows fall 
at different times in the day. That is, his attention is called to the directions that are within his experiences.

The children tell what some of the people whom they know are doing, thus beginning to study occupations.

Home

Industries

They talk about the public buildings of the city, locating them by the cardinal direction from certain well known points, and mentioning in terms intelligible to the child some of their uses; it is a foundation for later studies in government. The ways of going around the city are discussed, in order to understand the needs and the kinds of transportation. The most noted industries or manufactures of the city are mentioned and located if possible. Some of the most common fruits and vegetables are talked about, the children finding out where they come from and if any are shipped away.

Stories of children in other lands begin the pupil's acquaintance with foreign countries, they are the first steps

Stories of

Child Life in the geography of the world. This knowledge may be only of names, correctly pronounced and spelled; of simple facts about countries, as that Switzerland is a land of lakes and mountains, as shown in "William Tell"; or that Holland has dykes to keep out the sea, as the islands below Stockton have levees to keep out the San Joaquin river. Whatever the facts, if they are learned correctly and are well fixed in the memory, they are supplementary geographical knowledge. In the second grade, the globe and the wall maps are used freely with the stories, thus familiarizing the children with the representation of the world as a whole, with the shapes of the continents and oceans, and leading many of the brighter minds to locate the places talked about. 
The blackboard and the sand trough are used freely in developing the work of these grades both by the teacher Constructive Work and the pupils. By drawing and modeling the teacher presents thoughts more clearly and forcibly; by the same means the child expresses his comprehension of a subject, and visualizes for himself that about which he is studying.

\section{THIRD YEAR GRADE}

With the mile as an understood unit of measurement, in this grade many distances around the city are made intel-

Distance

Home City ligible to the pupils. Distance is also measured in time, a ten minute walk, bicycle ride, trip on the railroad, on the street car.

The principal work of the grade is to give the pupils a definite idea of the size and plan of the city, which is laid out as a rectangle, and of the location of the principal buildings, especially those belonging to the city. The printed maps of the city furnished the schools are used by the children for indicating parks, buildings, factories, hotels, schools, depots. In connection with the map work, the pupils learn direction as represented in drawing. In addition to the details of the city within its boundaries, the features of the country around the city are studied: the great plain in which Stockton is located; the mountain ranges in the distance; the rivers and other waterways; the nature of the soil. On maps of the city, drawn or modeled, or on the wall map, the children locate the streets, parks, and other points of interest, telling in what direction they would go if passing from one point to another.

Stories of child life are an important feature in the read- 
ing for the year, and care is taken that some of them shall Stories of Other Lands be of a nature to arouse the interest of the children in the world as well as in its people. Conditions in many countries thus begin to impress themselves upon the minds of the pupils. The globe and the wall maps are used in these stories, although no fixed amount of knowledge can be required. If the information is given accurately, if the locations are clearly pointed out, and if the children frequently hunt out places and countries for themselves, the results are almost sure to be satisfactory in regard to the amount of geographical information obtained.

\section{FOURTH YEAR GRADE}

Units of measurement of distance and time are developed through a comprehension of one mile, five, ten, a hundred Dis'ance Time miles; an hour, a day, a week, a month, a year. Pupils try to realize long distances by translating them into the time occupied in covering them by various modes of travel. This correlates well with number work, the children solving some really difficult problems for their grade through interest in the thought and a real understanding of what they are trying to do.

From six to seven months of the year are given to home geography. An elementary text-book is used, and the al-

Home

Geography lotted time is ample for collateral reading and for making experiments to illustrate some of the phenomena described. It is easy to show the children the carrying power of rivers in transporting soil; the way in which hills are washed down 
by rain and other actions of water; the effect of lateral pressure on the crust of the earth is easily presented by putting differently colored soils with layers of salt or some other white substance between them on a large blotting pad slightly raised in the center. Apply lateral pressure gently until the uppermost fold breaks.

Several careful experiments are made so that the children may understand the action of air. This is very inter-

Action

of Air

esting to the pupils and is preparatory to the study of climate in later grades. For one of these experiments a short section of gas pipe is filled with water, the caps are screwed on securely, and the pipe is placed in a bucket and surrounded with a mixture of salt and ice. The children watch the formations that appear on the outside of the pipe,-dew, frost, and ice, where a few drops of water have been placed on the outside. After a while the pipe bursts by the expansion of the water as it turns to ice. A thermometer placed in the bucket adds to the interest in the experiment.

Valleys are treated in connection with rivers, several weeks being devoted to the related subjects. Sandbars Valleys and Rivers formed in a river, channel, or creek are good examples of the work of a river. Several land and water forms are learned through the study of ponds and lakes. These are distinguished, named, and drawn by the pupil, who is led to form his own definitions. As new places are mentioned they are looked up on the map in the text-book, then on the wall map, if possible on the globe as well. The habit of locating a new place is to be classed with looking up a new word. 
In connection with the work on the home city industries and commerce are studied. The government is considered briefly, in terms comprehensible to the chil-

Commercial

and

Industrial

Life dren, correlating it with civics and the ordinances of the city government that are applicable to the lives of the children. Maps are drawn of places studied, not as perfect reproductions nor as examples of painstakng efforts, but in order to fix general proportions in the minds of the children.

The topics connected with the commercial and industrial life of the city are more than geography. They correlate so closely with local history that on many occasions there is no attempt to differentiate between these two subjects. Leading articles of export, as flour, combined harvesters, leather, woollen goods, fruits, are made the bases of class talks. During the year excursions to some local industries are made, the teacher visiting the factory first in order to become familiar with the processes, all or part of the class going later with the teacher. It is not necessary that all fourth grades should visit the same industry; the following are those inspected by some class during the year: the flour mills, glass works, woollen mills, briquette factory, cannery, harvester works, iron works, ship yards, planing mills, macaroni factory.

The order of the study is to procure any samples possible and usable in the schoolroom, to locate the works, study the raw material, observe the process of manufacture, study the product and its uses, review the excursion by means of photographs, write it up.

The county is studied, beginning with near-by districts and any portions of the county known to any of the pupils. 
The topics taken up are,-surface and drainage, position and boundaries, industries, products, roads, lines of trans-

The

County. portation, rivers, towns. A study is made of the wall map of the county, furnished every fourth grade. The county is drawn again and again until the children can reproduce it easily and accurately from memory. After the outline is firmly fixed in the mind, the principal towns are located and their leading industries are discussed. It is shown that Stockton is a distributing center, and that its intercourse is great with all parts of the county.

As a preparation for talks on the products of the county, the various kinds of soil are discussed, not in scientific lecSoil tures, but in the curiosity-satisfying, observation-loving methods, delightful and inspiring to the minds of children. The peat land of the islands, the adobe in and around Stockton, the alluvial bottom lands of the rivers, are treated briefly. A map on the board, locating these lands in colors, makes the work very graphic. Products grown upon the different soils are discussed; the teacher talks of the irrigation and reclamation near the city. On all these points the children are either already informed or they hunt up a great many interesting points to contribute to the class.

The children make a long list of local products,-fruits, vegetables, grains, animals, dairy products. In these stud.

Local

Products

ies it is usual to procure such specimens as it seems desirous to have in the schoolroom; to find out in what part of the county each is grown; to study a little about the life of the specimen on its home ranch; to collect samples indicating 
the nature of the growth, or to make illustrative drawings for the same purpose; to study the manner of handling the product, including the mode of gathering, packing, and the means of transportation; to follow the product to its point of sale, speaking briefly of the city merchant and his store. Written work, incorporating the results of these investigations, completes the study of any one product.

The dependence of occupations and industries upon one another and upon productions is easily shown; it forms an interesting feature of this part of the study, and partakes of the nature of geography, history, and civics. The industries growing out of any production are called to the attention of the children by such questions as the following about wheat raising: Why are there several flouring mills here? How is the wheat taken from the ranch to the mill? Where is the flour shipped to? By what means of transportation? In the shipments to China is there any reloading of the flour after leaving Stockton? How many occupations can be named that grow out of wheat raising in San Joaquin county?

Stories of children in other lands are continued in this year, forming one of the most interesting features of the

Children of other

Lands course. There are always discussions on the home of the child about whom the story is written; where it is located; what kind of a country this is; how it differs from our own ; personal appearance of the people ; clothing; food ; animals, and the uses to which they are put; occupations. There is an immense fund of delightful information to be gained in this way, over which children never tire. Map and globe researches are its constant accompaniment, favor- 
ing the acquisition of a great deal of accurate geographical knowledge. Much assistance is given by locating on the globe the world belt in which our home is found; this may be transferred to the wall map most frequently in use, thus furnishing the pupils with a quick and sure means of locating places north and south of the home zone, and establishing a means of comparison with places that are not in the same latitude. Pictures are used freely, and all illustrative material, such as articles of dress, utensils, products, all of which help to picture life in foreign countries.

Maps are drawn of the home city and county. The land and water forms are studied; sometimes illustrated by the

\section{Representation} puddles in the school yard after a rain storm, sometimes seen in objective form by trips to the harbor and river. Plans are drawn to scale, showing a surface as a bird would see it from above. Ideas of area and scale are developed. This work is closely connected with arithmetic and drawing.

The following extracts are from a teacher's account of her work : ${ }^{1}$

One of the first duties of the teacher is to lead the child to observe everything in nature around him,- - the air, the Observation water, the sky, the temperature, the clouds; animals, planets, rocks, hills, valleys, soil, streams, the habitations and the occupations of men. He should also learn the necessary terms with which to express the ideas gained by his observations. This is important preparatory work in geography, from which, in addition to knowledge, the child gains the power of accurate observation, inference, and expression; also the ability to make

${ }^{2}$ Miss Maud Southworth. 
clear his thoughts by drawing, modeling, painting, and constructing.

The work of the year includes oral lessons on distance, location, and direction. The use of the compass is investi-

The Work of The Year gated. The North Star is located. A weather record is kept during the winter months when the weather is changeable. A plan is drawn of the schoolroom, the school block, the home block. A map of the city is then drawn.

A topic, as rivers, is placed on the board, with such questions as the following:-What is a river? Name one near

Topical

Treatment

Stockton. Where is its source? Many other simple questions are asked to lead the children to consider a river from its source to its mouth, some of the work it performs in carrying soil and other ways, and the change in the country through which it flows from the hills or mountains to the sea. Many of these questions must be subdivided into new topics. Some pupils have seen the source of a river in the mountains; others have seen the mouth of the San Joaquin or the Sacramento river; all know about the overflow lands. So all the thoughts suggested by the above questions can be developed intelligently and concretely with the whole class. After the oral work is completed the children write up a story on the subject. Other topics, as mountains, valleys, lakes, soil, air, moisture, are treated in a similar manner.

After drawing a plan of our city Stockton is taken up according to the same method. Such topical questions are Home City given as:-How is Stockton governed? Who makes the laws? Who are the principal city officials? What are the railroads, the street car 
lines? What are the leading industries? Is the land in and around Stockton level or hilly? What are the nearest mountains? the rivers? After the children are thoroughly familiar with the topics by means of the oral treatment, outlines are made, and many are written up. In all our geography work as many pictures as can be found and used profitably are brought in by the children or are provided by the teacher.

During the past year, while studying about the local industries, the class visited one of the creameries. The day before

The

Creamery

the visit we talked of the things that we expected to see; of the number of creameries in Stockton; where they were located; how they got their milk and cream. We spoke of the skimming stations, and agreed to find out how many there are in the county and of what use they are to the farmers; also to find out about the means of transporting milk and cream. The following outline was then worked out with the class as a guide for the excursion and later for the paper on the subject.

Creameries.

Number.

Location.

Skimming stations.

Location.

Handling the milk-weighing.

-straining.

-separating.

Churning the cream. 
Handling the butter-working.

-moulding.

-packing for sale.

-shipping.

Centers for sale of butter.

Near home.

Shipping by rail or water.

The children copied this outline and carried it with them the next day. They were told to ask questions and to find out all that they could about everything that they saw. After careful inspection of the creamery, we returned to school and talked over what we had seen and heard. Paper was then passed to the pupils, and, from their outlines, they wrote an account of the excursion. For drawing that day an outline was made of Stockton, locating in reference to the city the principal dairy farms of the county as we had learned about them that morning at the creamery.

The class took up the flour mills of Stockton in the same way, but only two of the pupils visited them. These two reported to the class the day after their trip, outlines were then made, and the stories were written. Other local industries are taken up in one or the other of these ways, but not all are reproduced in writing.

The study of the state follows that of the city and county. In history California is studied with reference to the Indians,

The

Home State

the mission fathers, the discovery of gold, and the admission into the Union as a state. In this work the children draw maps showing California as it looked when the Indians were here; as the mission fathers knew it, locating the twenty-one mis- 
sions ; and as it is represented on the maps today. The children find interesting work in the discovery of gold and the different ways of mining still practiced in the state, especially in the Mother Lode region in the Sierra Nevada mountains.

Twenty minutes a day are given to geography. The work is mainly oral with, perhaps, two written lessons a month. The following paper was written by one of Miss Southworth's pupils after the excursion to the creamery. There are no corrections in any manner whatever.

"We went three blocks and a half to the creamery.

"The creamery is on the corner of Center Street and Miner Avenue.

"The owners of the creamery are Mr. Cy. Moreing, Mr. W. A. Hildreth, and the estate of Mr. W. F. Jordan.

"It is leased by Mr. F. H. Armsburger, its manager.

"When the milk comes from the farms they put it in large cans. Then they put them in country wagons and send the milk to the skimming stations which are scattered all over the country. There is one in Elks Grove, in Sacramento County, has twenty patrons; another in Lodi, in our country which is San Joaquin County, has twenty patrons; another in Bellota, in San Joaquin County, has twenty patrons and two private skimming stations; another at Holt, in San Joaquin County, is private; another in Lathrop, in San Joaquin County, is owned by patrons; and another in Modesto, in Stanislaus County, is owned by patrons.

"They have a machine called a separator in the skimming stations. It has two pipes, one for the cream and the other for the milk to run out. The milk is the heaviest so it stays at the bottom and the cream goes to the top.

"They have a kind of tube they put a little of the milk in 
and some liquid with it to tell how much the milk is worth.

"The purpose of this is to give the men the money that they ought to get. The men that have poor milk don't get much as the men that have rich milk.

"They take the skimmed milk off and give it to the calves. When the calves have too much the men give it to the pigs. "They put the cream on trains and send it to Stockton. When it arrives the wholesale milk wagon comes and gets it and takes it to the creamery. The cream is carried about forty miles to Stockton.

"The churn is wooden outside and tin inside. It is shaped like a cylinder. When the dasher is running the rollers aren't, and when the rollers are running the dasher isn't. It is large enough to hold fifteen hundred pounds of butter at once. It runs by steam power. It takes one and a half hours to make the butter. They have a man from the country come and get the buttermilk for his pigs.

"They wash and wash the butter in the churn. They put water in the churn and run it through the butter. After the butter is washed they let the water out. The rollers keep turning the salt into the butter while they go around. Then they take it out of the churn and put it in a kind of trough. They have four wires on and they push a stick fastened to the wires and cut the butter in cube shape. There are two pounds in each package. Then they take it out of the trough with a kind of paddle. After it is hard they wrap it up in paper which has their name on, "The San Joaquin Creamery.' They sell the butter to the grocers and dealers. When they send it to them they put it in boxes. They sell it to the skimming stations patrons, too. When the man at 
the creamery pays the patrons he takes so much off for his work."

\section{FIFTH YEAR GRADE}

The two principal topics for this year are the earth as a whole and Stockton and San Joaquin county. The earth as Course

a whole means that world units begin to take the place of local units. History helps develop an idea of the size of the world and of the location of other lands than our own. No detailed work is done, the desire being to grasp the larger ideas of the world first. The topic includes elementary geography and many studies on food products, especially those that find their way to our own tables near and far. The home geography of the year is

\section{The Earth} confined to two or three weeks. Mathematical and physical phases of geography, in forms that are intelligible to the children, are given at the beginning of the year. Every device imaginable to the teacher is used to give the pupils a clear concept of the form, size, daily motion, and zone division of the earth.

The various geographical sections of the United States are studied from an elementary text book, comparing conUnited States stantly with our own section. Each division is given a few days or a week or two as needed. The geographical study is followed by an examination of products, interest being sustained by outside reading and by comparisons with the products of the home county and state. For instance, how have the supplies of coal, iron, and oil benefited the New England states? Have we in Stockton been benefited by the opening of the Tesla coal mines? The price of coal in the East is compared with the 
price here. The child is led to see that there are reasons for cities being located in certain places, and for their growth. In discussing the Erie Canal, the conversation is turned upon the fact that Stockton owes its location and growth to its waterways.

Agricultural conditions in the Southern states are discussed, and two of their staples, cotton and tobacco, are grown in window gardens and yards. The Central states are taken up in the same way. Great cities, as Boston, New York, Chicago, New Orleans, are studied and imaginary visits are made to them. A week may be taken looking up information. about any one of the above named cities by some individual pupil or by the whole class. Then a letter is written, purporting to be from the city studied, describing conditions, and perhaps bringing in notable buildings and other objects of interest. It is often an incentive for the class if the teacher writes the first letter; interest is awakened and a model is given to the pupils. Such a letter may be read without giving the name of the place, the class deciding what section is described. In the Western States three ideas stand out prominently, the mountains and their mineral wealth, the Great Basin, and the fruitful regions on the Pacific slope. There are so many points of comparison, so many interesting features of knowledge in all this work that the pupils rarely tire of it. It can be so conducted that it is almost a record of travel to them. It should be. Geography is wonderfully interesting, but many people have to travel before they find it out; the children should learn it in the schoolroom.

The work on South America is brief and should not be intensive. Aside from Brazil, which receives individual 
treatment, it is taken up in sections. In studying Europe, a comparison of conditions and productions, already a little known to the pupils through the stories of

South America Europe

Asia, Africa children of other lands, is the method of approach. The dykes of Holland are compared with the levees along the San Joaquin river; the mountains of Switzerland with the mountains of California; the coal and iron of England with that of the Middle Atlantic states. Where comparisons are not easily drawn, the stories of other lands may be taken as points of departure or as centers of interest. In studying Asia, China and Japan are the two countries to be emphasized, especially for the growing commercial relations between them and the United States. The attention of the pupils is called to the marked contrast between the two countries. Africa is studied very briefly, for this continent touches but lightly the interests and knowledge of the children of this age.

The home geography for the year is an extension of that for the preceding grade. The city is studied with reference

Home

Geography to its location and advantages. Why is Stockton a commercial city? Of what advantage is transportation of freight by water? What railroads pass through the city? What ones terminate here? In what way do they benefit Stockton? The manufactures are reviewed; the sources, uses, advantages of the various kinds of power available for manufacturing purposes here are talked over, always remembering the limitations of a child's interest and comprehension. The lighting of the city is discussed, as are also the drainage system and the means of disposing of the sewage. Stockton 
in relation to the county, to the great central valley, to the state, are subjects for thought and discussion.

In this and succeeding grades the natural interdependence of geography with other subjects, especially history, must be

Methods of Work borne in mind constantly by the teacher. Pupils should be trained to consult the globe, atlas, wall maps, gazetteer, encyclopædia, when any unfamiliar geographical reference is met with in any work. They should be trained thoroughly in the use of all labor saving aids, as the table of contents, the index, the key to pronunciation. Frequent short exercises in map drawing should be given, beginning with copying either a state or a section of the United States, and repeating the map until a recognition of proportion and a facility in execution have been gained. This drawing is for general characteristics of a country, not for detail, and memory maps become a feature of the exercise. Blackboard work permits of freedom of movement by the pupil and ease of inspection by the teacher. Only such places are located as have some connection with the child's work, no matter what may be given on the printed map. Sections of the country are drawn rather than individual states, although for variety a section is sometimes built up by drawing the individual states.

\section{SIXTH YEAR GRADE}

The work for the year centers on North America, under the following topics:-California, the home state; a general North America study of North America; more detailed study of the United States, the principal topic for the year; somewhat detailed study on the remaining countries of North America. The leading 
thought of the grade is to give the pupil an appreciation of his own country. His own state, which is his unit of comparison, should now be well known geographically, industrially, and commercially; and a map of the state should be drawn readily from memory, with the principal rivers, mountain ranges, and cities located correctly.

As the development of certain industries in some localities and not in others depends upon physiographic and climatic conditions, the pupils should have a clear understanding of the broad principles that underlie existing conditions in any section of the country that is being studied. Whenever a new section of the United States is taken up it is well to recall the general laws and see how the particular section under discussion is affected by them. The simpler treatment of these subjects in earlier years is the basis for the work in every grade. The habits and habitats of animals and plants found in different sections provide material for short talks and papers.

The general geographical divisions for the study of the United States are, as in the fifth grade, the different sections

United States of the country, but the work is more intensive. Some of the principal topics are:New England, its forests, building stone, fishing, manufacturing, and early historical importance; Middle Atlantic states, agriculture, mining, manufacture of articles from mineral products, growth of New York city; Southern States, industrial awakening since the war, mining, manufacturing, growth and nature of New Orleans, including its sanitary problems, its cosmopolitan population, its streets; the great region of the Central states, the store house of so much of the nation's wealth, both materially and in 
the physical and intellectual power that have been influential in the progress of this country. The important points of study concerning the Central states are settlement, agriculture, mineral products, the lake cities, the river cities, Chicago. The great variance in physiography and climatic conditions in the different sections of the Western states requires that they be treated separately. The Great Basin of Utah and Nevada is different in every way from the productive Pacific slope. The points to be emphasized are physiography and climate, agriculture, irrigation, mining, scenery, and San Francisco, a typical Pacific coast city. A short time is spent on the territories and dependencies of the United States,Alaska, Cuba, Porto Rico, Hawaiian Islands, Philippines.

The study of British American possessions gives opportunity for reviewing adjoining sections of the United States

Remaining

Countries because of the similarity in conditions, industries and products along the boundaries. The points to be established are differences in people and government, lumbering, fishing, rapid development of the Northwest, transference of people, immigration of farmers from the United States into the Northwest, and settlements of Canadians in our own country. Mexico is the basis of the study of the countries to the south, and for a comparison with our own social, physical, and industrial conditions. The intermixing of races has brought about a social and an industrial deterioration. The laboring classes among the present inhabitants are ordinarily ignorant and indolent, adhering to the crude methods of life practiced by their ancestors. The great mineral wealth and the rich agricultural opportunities have caused an influx of Americans into Mexico and Central America, attracted by the chances 
for accumulating wealth. In Central America the instability of the government and the growing of coffee are the principal topics considered.

Many maps are drawn throughout the year. Progressive map drawing is valuable in fixing outlines and in giving an Map Drawing idea of a pupil's grasp on a subject. The following order is suggested :-outline map; physical map; rainfall map; isothermal map; produce; mining, or manufacturing map, according to the industrial nature of the section; political map, which may be colored.

The following paper was written by a sixth grade boy in connection with the geographical study of industries. No alterations whatever have been made in it.

\section{THE RECLAIMED LANDS}

A delta is a triangular alluvial deposit formed at the mouth of certain rivers.

The most interesting land of San Joaquin county is the tule land which extends from Stockton north to New Hope south to Tracy and Banta and west to the boundary of the county. This tule land covers as much as two hundred and fifty thousand acres. It was formed by the constant rushing of the water from the Sierra Nevada Mountains carrying the decayed vegetation and depositing it forming the San Joaquin delta.

This rich land is intersected by many navagable rivers which are the San Joaquin, Old, Middle, North Fork, South Fork, Calaveras, and Mokelumne Rivers. These rivers running along form many Islands which are Roberts, Union, Bouldin, and Rough and Ready islands. These islands were once covered with water furnishing irrigation for a small 
reed or tule which is about as large as your finger and grows to the height of twelve or fifteen feet.

The sediment or alluvium which was brought down by the rivers settled to the roots of these tules forming a very important peat land.

As this soil in the tule lands is peat it is the richest and most productive soil in the world. When this peat land is reclaimed a dredger is taken to throw levees up around the different claims leaving the water inside these levees. After the levees are thrown up men set fire to the tules and burn them. If they pumped the water off this land before burning the tules this peat or tule roots would catch fire burning a great deal of land.

When the tules are burned pumps are used to pump the water from in these levees. Then a ditcher is brought down which cuts a straight irrigation ditch through the different claims. After this work is through with the cultivating begins. The men plough this rich soil then they plant suitable vegetables to the soil. Some of these vegetables are onions, potatoes, beans, asparagus, and grains. When one crop is raised of one product there is a different product planted so as not to tire the soil.

\section{SEVENTH YEAR GRADE}

The work of the seventh year includes the following topics:-about nine weeks on physical and general geog-

Course of

Study raphy; four or five weeks on South America; from eight to ten weeks on Europe; five or six weeks on Asia; two to four weeks on Africa; three to four weeks on Australia and the Pacific islands. 
To give pupils a knowledge of geography sufficient for the needs of a lifetime is manifestly impossible and is not attempted. The work in the seventh grade practically completes the subject as presented in the grades. The aims should be to develop interest in this science, which in its entirety includes all natural sciences; to give the pupils a definite plan or method for the acquisition of geographical knowledge and for systematizing that which has already been gained; to lay foundations for future knowledge and studies by investigating some of the causes for present conditions of the earth and among its inhabitants.

The teacher must be satisfied to impress upon the mind of the pupil the larger facts which are strongly characteristic of countries and peoples. The attempt to hold pupils responsible for details of minor importance often renders first causes obscure and colorless. For example: England mines, manufactures, and engages in commerce. Why? She mines because her territory contains coal, iron, and other valuable minerals that are always in demand. She manufactures because the intelligence and inventive genius of her people enable her to put her cheap fuel and valuable mineral resources to the best possible use. She engages in commerce because she must import food supplies and raw materials as well as find markets for her manufactures. Such facts are elementary in their relation to English life and to much of her government policy; they should stand out even in the mind of the grammar grade pupil. Details are added for interest and clearer understanding, but they should never be allowed to befog that which is essential.

By the time children have reached the seventh grade they can hold some clear ideas on the relation of the sun to the 
earth and to the other planets. They should distinguish such terms as sun, planet, star, satellite, and be able to demonstrate by diagram and globes the motions of the earth which give us day and night, and the seasons. They should also understand the interrelations of the earth, the moon, and the sun, which give the phases of the moon.

Comparison of the sun, moon, earth, and other planets is always interesting to pupils if given in a manner that is readily understood. Many questions will suggest themselves to teachers for arousing interest and developing definite concepts, as: If the earth is represented by a globe three feet in diameter, what will be the diameter of a proportional globe to represent the sun? the moon? Jupiter? If the globe representing the earth were placed in a certain position, how far away would the other globes have to be placed to maintain proportions as to distance? If the earth were represented by a globe two blocks in diameter, how high would Mount Shasta appear on its surface? How high above the surface would clouds float if proportional distances were maintained?

The views of modern scientists regarding the condition of the interior of the earth can be noted and discussed, and the principal physical changes that are constantly in progress on the surface of the earth should be considered as fully as time will permit.

Pupils of this age are able to comprehend many of the factors which make up climate and to determine the distribution of animal and vegetable life. Thermal zones, winds, ocean currents, and the causes and distribution of rainfall all prove profitable subjects in this grade.

In connection with the study of races, some attention is 
given to the development of industries, religions, and governments, all of which indicate the degree of civilization attained.

The following thoughts are selected from a teacher's method sheet ${ }^{1}$ :

Before treating the methods employed in the seventh grade it is advisable to reconsider the knowledge already possessed by the child. In the fifth year the pupil becomes acquainted with the simpler physiographic forces, such as air, water, heat within the earth. He learns the result of the rotation of the earth and becomes familiar with the location of the zones. He learns in a large way about his country, the continent as a whole, the United States, the countries to the north and to the south. A similar view but with less of detail is given of the other countries of the world. In the sixth year there is a deeper insight into the physiographic forces. The continent of North America, especially the United States, receive more intensive treatment. On this foundation is built the work of the seventh grade.

The methods employed are treated under the following heads :-physical forces, physiography, industrial conditions, social conditions, maps and map drawing.

By the use of a globe and a baseball the revolution of the earth is shown. The earth's rotation and the phe-

Physical

Forces nomena of day and night are explained by shutting out the daylight and using a candle and the globe. A series of experiments is conducted to show the circulation of air and water in an

${ }^{2} \mathrm{Mr}$. S. H. Cohn, principal of a grammar school and teacher of the seventh grade. 
endeavor to simplify air and water currents. Diagrams and maps are drawn to emphasize and clarify the understanding of these points in reference to the world. Whenever a new section is studied the influence of the various air and water currents upon it are discussed.

The physiographic and climatic conditions are the basis for the study of productions, which in their turn give the

Industrial

Conditions key to the industrial conditions in any country. For example:- the physiography of the Andean section of South America suggests mining as a leading industry; the climate and physiographic features of the La Plata country recall the prairies of the United States, explaining the similarity of products in these two regions. Occupations and commercial progress grow naturally out of the industries; these form the basis for the study of the development of the people.

The rise and decline of a nation belong to the realm of history, but the geographical environment must be known Social

Conditions in order to have a correct understanding of the conditions that make for its progress or decline. In the study of Switzerland, the social conditions and development are brought strongly into connection with the physical characteristics.

In the study of a continent or a section of a continent Maps the development is brought out clearly by a series of maps. Skill is obtained by many short exercises; first, in copying, later, in drawing from memory.

\section{EIGHTH YEAR GRADE}

A final study of the subject of geography is given during the last two or three months of the eighth grade. The pupil 
now possesses a knowledge of his country's history, and his powers of observation are sufficiently mature to make of

Geography

Completed this final work more than a mere review. It becomes a study of cause and effect, in which results are attained that could not have been thought of in the lower grades. The study of the continent is now preceded by a discussion of the historical events that led to its discovery, settlement, development, and division into the countries of today. The physical and political geography is reviewed, stress being laid upon those features that constitute important causes in the development of the country; such as, navigable rivers, harbors, mineral deposits, agricultural possibilities, climate.

Physical and political maps of our country are carefully drawn, so that the pupil's knowledge shall be very exact of the location and boundaries of states, location of cities in reference to navigable waters and to railroad connections, and, later, with reference to surrounding areas of production. Memory drawing of individual states is one of the best means of securing familiarity with the location of important cities, rivers, mountain ranges, and boundaries. Groups of states may be taken up in the same way. The results of this kind of training in interest and accurate knowledge are surprising to those who try the method for the first time. Sketch maps of the United States, showing important mineral regions, forest areas, wheat and corn belts, and the regions in which cotton, sugar, rice, tobacco, and other staples are produced, prepare the pupils for the readings and discussions that are to follow. 


\section{PART IV}

\section{HISTORY CIVICS}





\section{CHAPTER XIV}

INTRODUCTORY WORDS. HISTORY IN THE PRIMARY GRADES

The greatest teacher of mankind is man. History is the reco'd of men and their achievements. The lessons that are set forth by history pertain to every field of life and labor. Success and failure, causes and results, are written large on every page. History is a teacher, silent but eloquent. It tells impressively of the need of character. Through history the far-reaching laws of existence, the causes and results of events in the life of an individual or of a nation, may be interpreted by students. Even children may read their signs, and who can say how lasting will be the effects upon their own lives? The personality of an individual and the importance of an event should be the basis of many a discussion in the history class.

The most important results can not be obtained if the pupils read principally about our own country. Modern history is too complex to form the best grazing ground for young minds. Interest in its events and some knowledge of its needs and development, we must have, but its problems are not the best ones for the young student to attack. Moreover, American life is an outgrowth from the older social and political bodies of Europe, whose conditions still continue to influence us. In the less complex life of older countries, of more primitive times, the unerring law of cause and effect can be traced with greater ease than in the 
complicated narratives of later days and countries. Besides, when a perspective view can be taken down several centuries, confusing details are subdued or entirely hidden, and there are thrown into striking relief the broad principles that have meant the making or the undoing of a country. Even a. sixth or a seventh grade child can see readily that the growing corruption, luxury, and vices of Rome were important reasons for the downfall of that country, and the whole study can be based upon stories so completely that these is no feeling on the part of the child that the teacher is moralizing or that history is prosy. On the contrary, the young reader is liable to feel that he has discovered a great truth. and he will pore over his readings with an intensity of interest. But, to produce this effect, the stories can not be taken at haphazard, they must be well selected to illustrate the phases of national or individual life that it is desired to teach.

History should begin with carefully chosen stories for the primary grades; it should not become a serious study

Story Material before the seventh year, and even in this grade the story element should still predominate. Throughout the primary and early grammar grades history stories should be for cultural and character development and for the accumulation of a great amount of information, so important in a wellbalanced, educated life. The training that can be derived from history studies is also a most important factor in the life of a child. As the pupil passes into the later grammar grades, the subject matter becomes more scholarly and the presentation grows more systematic.

There is so much material for story work that to choose 
is no easy task, as any teacher realizes who has tried to outline a well centered, progressive line of history stories for primary grades. The folk tales that so often form a beginning in literature are well suited to the same place in history, and in their use no differentiation of the two studies is desirable. Fairy stories belong to a different category. When used, the children should know that they are not at all true, but rarely will the pleasure in them be diminished by such knowledge; the change in attitude toward them that may be noticed is desirable,- - the stronger minds will begin to demand "true stories" very early in school life. Fairy stories rarely accord with history, they belong rather to the branching out into literature. Myths, if given their true value, are enjoyed at a later period of development. Myths are properly a part of history; they should not be given as fairy stories, except perhaps, those charming little nature myths that so delight the imagination of many children, especially in the first and second years. Myths should be told, read, enjoyed, while the children are still young enough to delight in their ludicrous, grotesque, impossible details; but when, on the other hand, the minds are mature enough to see the glimmering of truth and the dawning of investigation in these beliefs of people long passed away. In fifth and sixth grades, many pupils find great satisfaction in tracing out how many myths came into being, and in seeing why advancing civilization led to their abandonment or to their relegation to the realms of poetry and art. To put many myths into the first, second, or third grade is about as serious a mistake as to expect high school pupils to read with patience or pleasure detailed accounts of the amours of the Greek gods and goddesses. The absorbed student of myths 
must be either the child, just awakening into half amused, credulous interest in the world, or he must be the sedate student, revelling in the slow upbuilding of the mental processes of civilization.

Such poems as "Horatius," by Lord Macauley, stories like that of "William Tell," by Schiller, alternate delightfully with the folk tales of the second year; while history becomes more marked in the little biographies of such men as Washington, Franklin, and Lincoln. From the third grade on, knowledge of the world grows broader and deeper; and, while literature and history are frequently correlated and are mutually helpful, the two studies are clearly differentiated.

Although consecutive history does not belong to the first three grades, the stories gain in solidarity by grouping those Presentation that have a common basis. Topical arrangement becomes marked in the third grade, where the stories for two or three months may be devoted to the development of one line of thought, as Bible stories, lives of inventors, local history. A systematic way of working is developed if the teacher insists quietly but regularly upon acceptable forms. Even outlines, such helps in literary work, are used readily by children, provided they are active, working helps, not dead matter looked upon as the end to be attained. Power over books is gained steadily. Judgment is quickened by discussion. The importance of definite training in making decisions based upon proof is manifest when we think how many children reach the age of ten, eleven, even fifteen, before beginning to decide for themselves. A personal decision before this age too frequently means either willfulness or disobedience; hence, to 
"do as I like" too often means what the powers in authority do not like. If children grow up with this idea, we may be sure that they will not change it suddenly when they become men and women. The history recitation is one of the best places in the school for learning the value or the unimportance of one's own decision; history should teach how to sum up evidence, and how to make and test opinions.

Throughout the eight elementary grades several aims should be kept constantly in mind by the teacher:-improveAims ment in reading and language; acquisition of knowledge, especially through familiarity with many well known stories, for the children will never again be so fascinated by the pure story element, and they may never again have the time to give to it; constant and systematic mental training; development of the capacity for a citizenship that is rooted in love for country and appreciation of its institutions, and that is broadened and strengthened by some comparative knowledge of other countries; an unceasing effort for the conscious and unconscious development of the child's character, possible through historical training, the study of real men and women, and the observation of the great movements of the human race.

\section{FIRST YEAR GRADE}

There are three centers around which are grouped the stories for the first grade:-some of the holidays, Bible characters, Hiawatha. The holidays are attractive local centers of interest, and are good bases for beginning history through biography. They give to a holiday something of its true, value, and should lead out into just estimates of a few of our great men and events. The Bible stories are simple 
narratives, easily remembered because of the natural sequence of their pictures and the primitive simplicity of their Material thoughts, so at one with the period of the child's development. They offer fine opportunities for undogmatic character training, and for laying the foundation of a knowledge that will lead into rational views on historical evolution. These stories are so beautiful as literature, their accounts of migrations, customs, and events are so important and interesting as history, that only the literary and historical sides should be presented to children. Custom decrees that religious phases should be left untouched. Hiawatha takes the place of more purely historical material because of its charming and sympathetic treatment of the lives of the aborigines. First and second grade children love Hiawatha, as Longfellow pictures him to us; from this beautiful poem they draw a truer verdict about the lives of the Indians than is obtained from the stories of war and bloodshed that are so frequently the only knowledge possessed even by adults about the Indians.

Special tact and training should be possessed by the one who teaches beginners in the school room, for the task has Teacher's Problems peculiar difficulties. The history must be arranged with constant reference to the problems to be met. From the first sympathy must be established between the teacher and the little ones, for without it the best good of the year will be missed. One of the earliest lessons for the untrained little minds to master is the meaning of attention and how to concentrate the thoughts upon the lesson. A well told, interesting story is invaluable for this purpose; history is full of stories of absorbing interest for young as well as old. The teacher's 
preparation must be comprehensive, both for the presentation of the story to the class, and for the skillful drawing out of its reproduction from the pupils. The various desired results must be very clearly in mind, as must also the steps by which the children pass from the unknown story as it comes from the lips of the teacher to the completed product in their memories and notebooks.

For the first two years, perhaps longer, presentation of a story is identical in history and literature; later comes dif-

\section{Presentation}

ferentiation. There must be considered the divisions of the story, the mental attitude and development of the pupils, the length of time before the reproduction is to be made. The portion given must be very complete in itself, neither too short for the arousing of interest, nor too long for comparatively easy retention by the memory. All possible aids to the narration should be used, pictures, curios, blackboard drawings, sand table illustrations. Here as everywhere sweet discretion must never be overlooked. Too many pictures leave indistinct memories; too much work at the sand table becomes tiresome. Clearness of perception, alertness of interest, these are the guiding signs by which the teacher notes success.

When a division of a story has been well presented, it should be reproduced. The story interest should never be

\section{Reproduction}

lost nor frayed out by repetition after repetition. The division of the story for the day should always be accompanied by a specific mechanical aim, supported by the interest in the story itself; this may be a ready choice of words, consecutive thought, a really good story, or clearly presented "pictures." No one day will see the end gained, but every day may see a step towards 
the desired accomplishment. The majority of the children need to drill again and again on every means of progress; but there is no monotony if the stories are well selected. The stories are always a delight, and the progress in the mechanics of thought and language is a steady growth.

\section{SECOND YEAR GRADE}

In the second grade as in the first no attempt is made to teach history as a subject. The stories for the year are still Material grouped around the holidays, they are chosen because of some correlation with the literature, or they are simple biographies. The stories suggested by the holidays are as follows :-Admission Day, or " the birthday of California," in September; Thanksgiving Day; Christmas. The stories correlated with the literature are "Horatius," the poem for January; "William Tell," the story for March; and Indian life made interesting through the poem of "Hiawatha." The more purely historical narratives are about Columbus, in October; and Washington's boyhood and life during parts of the Revolution, given in February.

The work in the first grades is so simple that there is no repetition in the second grades even when the subjects reappear. For instance, the Thanksgiving story in the second grade tells of the Pilgrims, always interesting to little folks. The Christmas story tells of the babyhood of Christ, the flight into Egypt, and other points that belong to his youth or to the description of the country where he lived. The stories of the Indians become farther reaching than was at all possible in the first grade, including little studies of Indian wampum, the peace-pipe, canoe making. 
The aims of the work in history during the second year are a broadening out of those in the first year. The pupils Aims and Time should be learning more about the world, acquiring their knowledge in good form, and gaining the power to use readily whatever they learn. The time for history is the same as in the first grade, twenty minutes daily for two weeks out of every month. This period is used variously by the teachers, according to their own judgment of their classes; but, ordinarily, it is given to oral presentation and reproductions, the written reproductions being put into the time for penmanship or drills in writing, and the illustrative drawings belonging to the period for drawing. The history story is looked upon as furnishing material for these subjects, just as is the case with the literature and nature study. Written reproductions and drills in writing can be worked in together very well so long as both are formal, as in the simple copying of the stories. When original stories begin, their writing can not be associated with drills in penmanship, for the latter is purely formal while the story writing is largely creative, at least in the meaning of creative for this age.

Some teachers prefer to tell a portion of the story, having the reproduction follow immediately, so that the details will Method not be forgotten. In this method the teacher's narration will extend over all of the first week, and perhaps part of the second, accompanied every day by the pupil's reproduction of the story of the preceding day, and a résumé of the narrative as just given. The final review takes the form of either an oral or a written reproduction of all or of a chosen part of the story. If time permits, the story is both told and written by the children. 
The following is from a second grade teacher ${ }^{1}$ :

The teacher usually tells the story in preference to reading it in order to arouse greater interest and closer attention on the part of the children. The work is so arranged that every day's narration is a natural division of the story. For instance, the story of Columbus is divided into five sections, one for every day of the week. Monday, a talk on the world as people knew about it in the fifteenth century, including the dangers of sea navigation at that time; Tuesday, boyhood of Columbus, his love for the sea, his enjoyment in the sailors' tales; Wednesday, his early manhood, his knowledge of the compass; Thursday, his idea about the rotundity of the earth, his appeals for aid to test his theories; Friday, his voyage, with its dangers and difficulties, and the discovery of America. Every day the story as told in the previous lesson is rapidly reviewed, sometimes by the teacher, sometimes by questions answered by the pupils.

No real difficulties are given in these stories, neither do they go deeply into any part of the life of Columbus. They

Nature of Stories form a very brief sketch of some of the salient points known about the great explorer, upon which later studies can be built without wearisome repetitions of the trifling details that little children enjoy in these first glimpses of noted men. The desire is to give such events and efforts as can be readily understood and remembered; they must be simple enough to be grasped by children; nevertheless, they must be in accordance with accredited history, so that there will be nothing to unlearn in later years.

'Miss Mary E. McDougald. 
ILLUSTRATIVE PAPERS BY PUPILS, SELECTED SECTIONS.

I.

\section{The Pilgrims}

a.

These people were called Pilgrims.

First they went to Holland, but the Pilgrim fathers and mothers did not like it there.

The children were learning to speak Dutch.

$b$.

Some of them did not want to go to church. The fathers and mothers were not satisfied.

They said, "Let us go to America."

They fitted up two ships, the "Speedwell" and the "Mayflower," and started across the Atlantic ocean.

The "Speedwell" broke down, and the people had to come in the "Mayflower."

c.

Some friendly Indians came to visit the Pilgrims.

One Indian, called Squanto, spent the winter with them and showed them how to plant their crops.

In the autumn the Pilgrim fathers gathered their crops of wheat and barley.

\section{II.}

\section{OUR Flag}

June $\mathrm{I}_{4}$ is our flag's birthday. On that day, one hundred and twenty six years ago, the people adopted it as the flag of our country.

George Washington planned the flag. It was to have thirteen stripes, seven red ones and six white. These were 
to represent the thirteen states which then made up the United States. The field of the flag was to be blue, with thirteen white stars. A stripe and a star were to be added whenever a new state came into the Union.

New stars and stripes were added until there were fifteen of each. It was decided then to have always thirteen stripes in memory of the first thirteen states. But in the blue field were to be as many stars as there are states in the Union. Now the flag has forty-five stars. When a new state comes into the Union another star will be added.

The colors of the flag have a meaning too. The red means courage; the white, purity; and the blue, truth.

\section{THIRD YEAR GRADE}

In third grade history there is the same arrangement for time as in the two lower classes, twenty minutes a day for two weeks in every month. The growing powers of the child, however, make possible maturer methods of work.

The story is now read to the class as often as it is told. The relief to the teacher from preparing for an oral preDrawings as Aids in Presentation sentation makes room for the more careful oversight of written reproductions, becoming necessary on account of the increasing length of the papers and of the larger vocabularies used. Pictures and drawings are still, as throughout the course, an ever-present aid in teaching. Going from room to room among third grades, one notes with pleasure the growing power of the children in artistic illustration, indicated by the more ambitious drawings on the boards. These special pictures, by the best artists in the class, are preserved for days, valuable aids in the portrayal 
of characters and events of the story. In addition to them, every pupil is expected to use his own training in drawing in making original illustrations for his own written reproduction.

During the presentation of the story, questions are asked by the teacher to see that the thought has been fully grasped. This dropping into conversation is the more necessary because a story that is read in the author's own version usually contains many new words; the sentences are more involved than in stories which the teacher has carefully adapted to the development of the children; it is also more difficult to get the continuous thought out of reading than to grasp it from a well told story. Therefore reading aloud to the children is a training for them that must not be neglected. They must be learning to enjoy books, and the desire to read for oneself should be assiduously cultivated.

The reproductions begin to vary in their nature. Instead of trusting simply to the memory of successive events as

Use of

Topics

a framework for the complete story, the pupils are frequently called upon to tell about a certain event, to describe some person, or to narrate how an occurrence took place. That is, the child is being trained to recite topically; to keep to a certain assigned thought; to discriminate between the important and the trivial. Not much can be done in this line of development, but the first steps are important even if they are short and faltering. More pointed questions are asked than in the lower classes, in order to cultivate exact observation and accurate retention even of details.

Outlining, that valuable aid to later historical studies, begins in this grade in the most elementary manner. The 
children are asked to tell what are the principal events, or who are the most important persons, in the story. Then Outlines they are led to arrange the information given in some consecutive order. It is an interesting study of children's minds to notice how scattered the items will be when first given, and what an effort of memory is required to arrange all in acceptable consecutive form. This is the first step in outlining, in arranging material systematically. The little outline is developed in class, written upon the board item by item, as evolved by the pupils, and it is.then used as a basis for written work. From the first, the outline should be a help to the pupils; it is not an end to be worked for, it is an aid in the use of knowledge. The only use that the pupils of this age have for the outline is as an aid in writing a systematic, complete paper. Put it to this use, and, if possible, lead the children to see how much more systematic the work can be by its use. When an outline is voluntarily made use of in written reproductions an important step has been taken in developing the analytical powers.

This work is an aid in the regular composition exercises, for it is very easy to lead pupils to put thoughts by themselves. That which groups itself into a thought is often a natural paragraph, and it may happen that by this simple training in the separation of thoughts a third grade pupil will pass into an easy and comparatively accurate use of a third grade conception of a paragraph. The successive headings in the outline, as given by the pupils, are usually the subject thoughts for the successive paragraphs. No difficulties or uncertainties are presented to the young minds; they simply learn that that which we have to say 
about one related thought is put by itself in a paragraph. They see that Washington could not be made the subject of a paragraph, for it is the subject of the whole paper, and there are several thoughts, or paragraphs, about Washington; but they also see that Washington is not used as one of the headings in the outline, consequently the relation of the headings to the subject thoughts of paragraphs is not interfered with. It would be unreasonable to say that there is no difficulty in this training. It is exceedingly difficult, for it is analysis; but it is presented in so elementary a way that the children take the first steps with comparative ease, thus beginning to understand and to practice dividing a discourse into its parts, analyzing a subject into its thoughts. Pupils like to think; they enjoy the conscious training of the power to think logically; but such an exercise should always be short in order not to tire the minds. Of course, the thoughts as suggested by the children are never in their right order; subordinate thoughts are always appearing in coördinate rank with leading headings; but all are taken, written upon the blackboard, and considered by the children. Then comes the fun and the work of arranging everything in proper succession and subordination. In this third grade outlining very few subordinate thoughts are written down; only the principal thoughts, those that are to be the subjects of paragraphs, are written, the subordinate thoughts being talked over merely to show the pupils to which principal heading they belong. The outline as thus left on the board i.s a succession of headings that are really paragraph thoughts. In oral work the next day, every pupil may tell one paragraph, or, perhaps, all the story. 
The following are some of the results out of the experience of a third grade teacher ${ }^{1}$ :

The first oral reproduction is often started out by questions and answers. Narratives are based upon headings given orally by the teacher or written upon the board before the children. One device, frequently employed, is to ask the pupils for word pictures of people or events. The pupils are first asked to imagine the picture clearly to themselves, then to tell it aloud. Sometimes the whole is built up by several children.

The first stories for the year are written in class, the teacher at the board writing the sentences that, after careful

Story Writing deliberation, the pupils consider the best presentation of a thought, and that the teacher considers acceptable. The pupils at their seats copy; sometimes the copying is done later, as busy work. Very short stories are written by the pupils without outlines and unaided by questions. Short and frequent papers are more satisfactory from all points of view than long and occasional ones.

Illustration with this grade is very interesting and is productive of many good results. Pictures, relics, are kept

Illustrative Material before the class. Characteristic ways of dressing, houses occupied, and other facts are collected by the pupils. Perry pictures are used to adorn the papers, and the production that is to be thus embellished receives the utmost care in preparation. Sometimes these penny pictures are given by the teacher as a mark of recognition for an especially meritorious paper, or the children purchase them for themselves. The pupils

${ }^{1}$ Miss Elizabeth Perry. 
are easily encouraged to bring to school books and pictures relating to the subject in hand; indeed, care must be taken that they do not bring them too freely. Through this channel it is often possible to have before the class illustrative and supplementary material that would be quite inaccessible otherwise. Where no objection is raised by the pupil or is probable from the home so kindly loaning this material, it may be kept on a table in the schoolroom, where the pupils can look it over at their leisure and where the teacher can keep it under supervision.

Third grade pupils are interested in local industries and modern conditions, some of which are made special features

Industries

and

Inventions

of the year's historical course. When printing is taken up, a visit to the newspaper office is usually permitted by one of the daily papers. The class is taken in

sections for the greater convenience of the teacher, for more detailed investigation, and in order to be less trouble in the office. Before making this visit the modern newspaper is made the subject of study, how it is distributed, how news is collected, how it is printed. Some terms, such as type, stick, galley, form, proof-sheet, roller, are taught; the objects are brought to school, if possible, where they can be seen and handled by the children, so that they may know the various objects when seen in the printing office, and that they may talk about them more intelligently. Toy presses are brought to school, and some of the busy work time is devoted to setting up type. Many buy type and set it up at home. Then the visit to the printing office is made.

After the study of the modern newspaper, the children are told about conditions before there were newspapers or 
printed books, and the importance of printing is discussed. The story of its invention and inventors is then full of interest.

Another phase of third grade work is found in local history studies. Here, as elsewhere, the children make only a

Local History beginning, leaving real research for maturer minds. Nevertheless, this work is very real to the little folks, and it is of great importance in creating a taste for such investigations and in bringing together much valuable information about the home town. Old landmarks in Stockton are hunted out; grandparents and old residents, some of whom "crossed the plains" in true pioneer style, are interviewed about their early experiences and primitive conditions in the city and county; many interesting facts are brought into class, where they are talked over and most of them written out in the notebooks that the children are learning to keep. A map of Stockton is drawn, on which are located the principal places mentioned in the lessons.

A pupil's paper on local history is given below. It is uncorrected, but was written after oral reproductions of the subject had been made in class.

\section{The Bear Flag}

Many years ago California belonged to Mexico. A great many Indians lived here, a few Mexicans, and a few white people who came to trap animals.

The people in the East did not know much about California. They thought it was a desert. General J. C. Fremont came over the mountains to California to find a path. When he got here he asked the Mexican governor for per- 
mission to go through the state. But he refused. So he went up to the mountains and spent the winter. In the spring he started for Oregon. On his way he found that a war had broken out between United States and Mexico. So he took his men and went back to Sonoma. Here he took the Mexican governor prisoner. They took down the Mexican flag and raised the bear flag. This flag was made by taking a piece of white cloth and sewing a piece of red flannel across the bottom. With the juice of some berries they stained a bear in the center. In the upper right hand corner they made a star.

Commodore Sloat came into Monterey bay with an American war vessel. He told his men to haul down the Mexican flag and put up the American flag. So California belonged to the United States. They sent flags to San Francisco and Sonoma. When the flag reached Sonoma they hauled down the bear flag and with cheers raised the American flag.

\section{FOURTH YEAR GRADE}

History in the fourth grade continues, generally speaking, along the biographical lines of the three preceding years. History should mean to the children man and the development of mankind, and there is no means of producing this effect except by teaching it through men. On the other hand, the work should not be simply the story of a man. History is far broader than that, just as the life of one person can not be lived for himself alone. This, indeed, is one of the lessons that it is hoped the children will learn from history. Through the lives of the men about whom they are learning a little, they should see the broader movements of 
the period of time in which these men lived, and should begin to grasp the importance of a man to his period. This is one of the first lessons in estimating the relation of man to his surroundings, and one of special meaning in a republic.

The time devoted to history in the fourth grades is the same as in the first three grades, twenty minutes a day for Time two weeks of every month, history still alternating with nature study. The children usually enjoy bringing into class any reading or pictures that they find bearing upon the history, and, unconsciously, they are thus being initiated into historical research. The public library, with which some of the pupils began to be acquainted even in the third grade, grows constantly in use and value for the children, many a pupil commencing to delight in the books found there.

The study of inventors who have contributed greatly to the progress of the world is continued in this grade. The steam-engine in its modern uses is observed Inventions and

Inventors and discussed in class, until the importance of the invention to the world is called to the attention of the children. Then the lives of James Watt, George Stephenson, and Robert. Fulton are studied. Electricity, its many uses and its marvellous aid to modern life are talked over; Edison's life, which follows, is always fascinating to the children. A trip to the woolen mills is preceded by preparing the children for what they are to see, and is followed by a study of some of the primitive methods of weaving and the products of simple looms. Some attention is given to different materials, and considerable thought is directed toward the importance of the invention to the civilization of the world. An invention is never 
studied as an isolated fact. Its importance to man, its relation to the advancement of civilization, and its place in modern life, are all points for consideration. These studies are elementary, suited to the stage of development of the children; their purpose is to turn the young minds toward existing conditions, the way in which they came into being. and the part taken by man in their evolution.

Local history, first studied in the third grade, begins to take its place in relation to the history of the nation. The

Local

History

first local history concerns the Indians, but this year it is the California Indians that are studied. The children see the actual daily life of the Indians of our state woven into an interesting story, that of "Docas." After the work on the natives, there come the lives and adventures of some of the earliest explorers in California and along the Pacific coast. This naturally leads into the accounts of the Spanish gold seekers, then into the settlements made by the Spanish in the west. The connection is kept with explorations in Mexico and trips of Spanish galleons to the Philippines. Maps and the globe are in constant use, so that a fairly clear child's idea of these events is obtained, and deep interest in them rarely flags. As the first of this period antedates the settlements of the English on the Atlantic coast, it is a fitting introduction to American history in the following year.

The presentation of a story is similar to that of the third grade, except that the ripening powers of the children perPresentation mit the use of more mature methods. The teacher now rarely tells the story; it is read, if it is obtainable in a form suitable for the understanding of the children. The pupils are also reading for themselves. 
They usually become interested after a story has been commenced in class by the teacher and either read from the book used by the teacher or they succeed in finding other sources of information. In the latter case, considerable additional material may be brought into class, always a delightful digression from the regular form of presentation.

The children are now mature enough to be led to see the daily division of the story as a whole by taking a few Outlines moments at the end of the period for selecting essential points and writing them on the board. This systematizes the information, emphasizes the leading thoughts, and visualizes the whole lesson in a compact form that is readily retained in the memory. It is an invaluable touch of training. This simple outline must be a means to the end, or the weaker minds in the class will be repelled and discouraged by the real difficulty of analyzing and systematizing. The children must see the aid that they receive from the outline; they must not be left with the idea that they have worked in order to produce the outline. The outline was made in order to be used.

The treatment of the writing and correction of the many papers that accompany history belong to the section under language. The writing, the creative side, belongs to history; the correction, the mechanical side, belongs purely to language.

ILLUSTRATIVE PAPERS FROM PUPILS.

UNCORRECTED

I.

How Steam Does its Work

We had a glass tube with water in it, and it was corked tight at the top. And it opened at one side. 
We held this tube over a flame until the water in the tube boiled. We put a little stopper in the side hole and the steam which the water made pushed the stopper from a little way in the tube to the end and then popped out on the floor. It came out because the steam had such a pressure.

(There follow several papers on James Watt, George Stephenson, and Robert Fulton, showing the invention and development of the steam engine. The experiments with steam preceded the stories of the inventors, so that their work might be more fully appreciated.)

\section{II.}

One story is chosen from the many written by the pupils on early California.

\section{Finding Monterey}

Portola came back to San Diego discouraged and said there was no Monterey. But Father Junipero Serra who had heard Portola's story thought that they had found the bay, but didn't know it. Portola was so discouraged that he wanted to go back to New Spain. He said. "Our food is giving out, and we shall starve to death if we don't go back. Measure out the food and see how long we can stay, and on the next day we will start." So they measured out the food and it would just keep them twenty days. The days dragged by and the nineteenth day came. They packed their baggage, and fixed the vessel, and were already to start, but early on the twentieth morning a cry rang through the camp, "A sail! A sail!" They all ran out and there was a sail in a distance. This ship brought food and a letter. 
As soon as they could they started up the coast one party by land and the other by water. They soon got at Monterey and set up an altar and they swung the bells which rang out to the sleeping hills, they then fired volley after volley and they, too, rang out the claims of the Spanish King. 


\section{CHAPTER XV}

\section{HISTORY IN THE GRAMMAR GRADES}

\section{FIFTH YEAR GRADE}

In the fifth grade the pupils are considered old enough to commence a systematic study of the history of our country; Material a text book is put into their hands, and the story is made continuous. The time is also extended, in order to give a longer period for consecutive work, and history alternates month by month with literature. The daily period is also lengthened by the introduction of a definite time for the preparation of the lesson by the children, twenty or twenty-five minutes for study. The lives of men are still the centers of the stories, for with children no interest is stronger than that of human life; but periods of history are marked off far more distinctly than in the preceding years. This is very easily accomplished in the child's mind, but the teacher must be skillful in keeping the right proportion between periods and between men.

In the fourth grade the pupils have become somewhat familiar with maps and the globe, so the period of explorations and discoveries is preceded by considerable geographical study, in order to obtain an idea of what constituted the known world in the times preceding Columbus. Without such an introduction no clear idea can be gained of the reasons for the voyages that resulted in the discovery of America. The children can understand in part the frenzied 
search for the wealth of the Indies, and time can even be found to tell a little of the story of Vasco da Gama and of that of Marco Polo. Thus the efforts and voyages of Columbus begin to take their right place in the world's history, and his long trip to the west across the mysterious Atlantic has a new meaning to the children. They have already, in the fourth grade, heard some of the stories about the coming of the Spaniards; here is the opportunity, in the fifth grade, to show how these explorers had followed fast on the track of Columbus, eager to take advantage of his discoveries. This review of the fourth grade stories, the more detailed accounts of Columbus, round out sufficiently for the fifth grade the Spanish explorations. The discoveries of the French are omitted entirely; those of the English center around the Cabots, Henry Hudson, and the settlements in Virginia, Massachusetts, and Pennsylvania. The colonial life is given character and distinctive existence by the stories that cluster around the lives of such men as Miles Standish, Benjamin Franklin, William Penn, the boyhood of Washington, and the Indians.

It is not the accumulation of historical facts that is desired, there will be plenty of time for them later. It is the Aims picturing by the children of the life of a period that is valuable, the collection of many details, incidents, stories, that will vivify a period and give it reality in later history study. There should be a solidarity about every period. The life should be seen in those details that are dear to the hearts of all children: the houses lived in, the mails, the work done, the implements used, the means of transportation, the love for England, the kind of liberty that came to the dwellers in the new land. 
This is not difficult, for all of it can be found in the stories of the period, in illustrations, and from knowing what the men themselves did and how they accomplished their ends. The work should always be more than pure biography, it should be a picture of the time studied.

In the latter half of the year there are given stories of the Revolution, the Opening of the West, and the Civil War. To the child Washington is the man most intimately associated with the Revolution, and the war is grouped around his heroic struggles. Daniel Boone is the hero of the period of expansion that followed the establishment of peace, and intensely interesting he is to the children. Abraham Lincoln is the hero of the Civil War. Stories of this great American, heard by the pupils in the third grade, are renewed, and to them are added many others showing the determined effort of Lincoln that all human beings in our country should be free. The war is not studied as a war; it is a background on which are sketched some of the great incidents in the life and efforts of Lincoln.

The children are now delighted to read for themselves, if the way is only opened for them, and they will search Reading happily and persistently for reading on topics in which they have been interested. It is often surprising what mature books children will read understandingly, if they have only been given enough of the story to be able to follow its development through even unknown words and new sentence forms. While books for children are not to be decried, still much of the so-called juvenile reading is so puerile as to be a positive injury to young minds. As squirrel's teeth are kept sharp and clean by gnawing hard substances, so children's minds are sharp- 
ened and brightened by contact with invigorating mental food. What difference does it make if there are in a book many words that a child has never seen before? How is he to learn new words? To give a child interesting reading containing many words whose meaning he does not know is like giving a squirrel nuts to crack. If the story is alluring, the meaning of the new words will be found out by some means.

The outline, used tentatively in the third and fourth grades, becomes a recognized tool during this year. The Outlines teacher's outline may sometimes be used as a model and an incentive to progress, and the teacher should often work over with the pupils their outlines. As such a lesson is very instructive for all the class, board work is better than individual criticisms. The teacher must not be too ambitious for her pupils in this acquirement. It must be remembered that outlines are largely a matter of judgment, a faculty slightly developed with fifth grade pupils. The training to be derived from outlines in this grade is the help they afford in the development of the judgment, of the power of analysis, and of the ability to put together in a continuous, systematic form the thoughts of any whole. These three processes, at least, are involved. A story is before a child as a whole, as the teacher has told it, or as he has read it for himself. $\mathrm{He}$ is to mention the various important thoughts in that story; that is, he is to analyze it, selecting certain thoughts and rejecting others. Then he is to arrange those thoughts according to their proper relation to one another; that is, he is to exercise continuity of thought. When we think how many mature people are lacking in judgment, analysis, or 
continuity of thought, we must be very considerate about the young minds, and not tax them too severely. We wish to give them just the powers so conspicuously lacking in many people, but if too much is asked in difficult lines, a distaste for the work is created that may never be overcome. In fifth grades, and even throughout all the grammar grades and the first year of the high school, outlines should be very simple, rarely going to more than a second indentation, that is, to the second division of a thought. They should also be of use to a child, an aid in doing some work, for the thought should never be permitted that the outline is the end for which one is working; it is a tool. The outlines should be made because they are to be used in reproductions, in recitations, in writing, in memorizing, in examinations. Their frequent use in this way leads a child to depend upon them, which really means that the minds are being trained to depend upon order, system, judgment, analysis. Is this not a desirable end? Nevertheless, I have known teachers who stopped using outlines when they noticed that the children were beginning to depend upon them! Did such teachers comprehend the first uses of an outline?

Recitations must be varied in order not to become monotonous. The child is roused to strive for a clearer underReproduction standing of what he is studying if he does not know whether he is simply to tell the story, or to be quizzed searchingly, or to uphold his views and knowledge in discussions with fellow-pupils. Discussions are excellent eye-openers, and serve to make the children alert to ideas, judgments, and conclusions. The talkers should not be permitted to become personal in their arguments, but a discussion can be very brisk and instructive 
without any objectionable features. Quizzes put a child on the watch to know everything that he can find out about a lesson, and they give a teacher chance to probe deep into real and assumed knowledge. Reproductions give a pupil confidence in himself, by leading him to stand before a class, to try to express himself understandingly, and to tell a complete story in an interesting manner. Unless a story is very short, a child should rarely be called upon to "tell all he knows" about a story. Such a request leads to diffuseness, to scattering thoughts, to bombast. Give a topic, and hold a child to careful, well expressed reproduction of that part of the story, with no wanderings into any other portion. If it is really desired to test a child's memory of a whole story, it is better that he should reproduce it according to the outline, following the principal thoughts and omitting the details; but this is summarizing, not reproducing.

Fifth grade pupils understand and enjoy maps and the globe. During the whole period of explorations and disGeography of History coveries the globe is an essential aid. It should be used in connection with wall maps of the sections under discussion. In the period of settlements, the map of the United States is preferable to maps of states or of special localities, for the pupils are not yet familiar enough with the outlines of the whole country to study profitably the details of smaller portions. Trace out settlements, arctic explorations, crossing the mountains into the valleys of the Ohio and Mississippi. The pupils should draw many outline maps.

History made interesting to the children can not fail to be productive of results in character building. Love for some 
of our great men, admiration for their energy, self-sacrifices, and persistency, tend to elevate the ideals of children. They can not study the characteristics of men,

Results

to be

Gained watching a boy become great, as Washington, Franklin, Lincoln, seeing the strength of character behind the deeds, realizing the difficulties to be overcome, without looking on life generally, and their own lives in particular, in a broader, better way. One's own difficulties seem less when compared with what some one else has overcome, and on which he has risen to strong and noble manhood. From the warnings and examples of history one should learn better living and greater love for home and country.

The following thoughts are from a fifth grade teacher ${ }^{1}$ :

One of the chief values of history work lies in the opportunity which it affords for teaching good habits of study.

Habits of Study Every day some independent preparation must be made by the pupil. This should be carefully assigned, so that too much is not required in a given time. One of the principal reasons for poor preparation of work in all studies in the grades is that too much is expected for the length of the period for study. Lessons half learned a few times lead to careless habits of preparation that might have been avoided had but little been required but thorough mastery insisted upon.

Another fault is that the teacher works too much with the class, too little time being given to independent preparation. Some pupils thus gain nearly all of their knowledge from class work, and almost the only habit formed is the destructive one of dependence. The chief value of working in

${ }^{1}$ Miss Elma Hopkins. 
sections is that the child is forced to work without help from the teacher and to depend upon himself.

Outlines prepared by the teacher are used freely in the preparation of a lesson. Only important points are noted,

Pupils'

Preparation so that the pupils know for what they are to be held answerable. Their use while studying accustoms a child to a systematic arrangement of the material in a lesson from its assignment to the final writing. Sometimes the outline is screened from view while the class is studying the lesson for the first time; then, with book closed and outline in view, every pupil is supposed to go over the lesson again, testing his knowledge, discovering his weak places, and, finally, looking up whatever he does not know well.

The outline given below is a composite, made in class and copied from the board, showing how the pupils are trained to make and use outlines.

\section{I.}

\section{Henry Hudson}

I. Conditions three hundred years ago.

I. England poor.

2. Spain rich from gold mines in America.

3. Portugal rich by southern route to Asia.

II. Muscovy Company formed.

I. Wish to find northern route to Asia.

a. Failure.

b. Trade with Russia.

2. Henry Hudson employed by the Muscovy Company.

$a$. Found no northern route to Asia. 
$b$. Found many whales.

c. Stopped by ice on second voyage.

3. Muscovy Company discouraged.

$a$. Decide to make money from whales.

III. Hudson employed by the Dutch East India Company.

An original outline follows, showing how slowly the pupil's mind grasps the large headings which are to be subdivided. Details stand out unrelated to a main topic. No corrections have been made.

II.

Morse and the Telegraph

I. Difficulties before the invention of the telegraph.

I. Mail carried on horseback.

II. Morse sent to Yale College.

I. Interested in electricity.

2. Becomes a painter.

III. In I832 Morse sails to Europe.

IV. Morse plans the telegraph.

$\mathrm{V}$. Morse becomes a professor in 1835 .

VI. Morse meets young Vail..

I. Experiment by Vail and Morse.

VII. Judge Vail decides to give Morse money.

VIII. Vail improves Morse's invention.

IX. Judge Vail growing discouraged.

$\mathrm{X}$. Telegraph proves successful.

XI. Congress gives Morse money.

XII. Puts wires underground but fails.

XIII. In I844 Miss Ellsworth sent first message over the wires. 


\section{SIXTH YEAR GRADE}

As the pupils grow older their work should become more scholarly and their methods of reproduction and composition

Need of Material should be growing more and more mature. The grammar grades are the starved grades in many schools, although unconsciously so. Children in the sixth, seventh, and eighth grades can read much if they have the material. They long to know about the world, the whole world; no country is so remote that it can not arouse their curiosity, no people so quaint that it can not interest them. The sense of acquisitiveness is so strong at this time that, rightly managed, an immense amount of information can be gained between the years of eleven and fifteen. How much many children read at home! How eager they are to visit every "show" that comes along! It is the natural desire of the time of life. The world is beginning to assert its hold over the imaginations, and these are the years when habits of work and reading are becoming life methods. This condition is not fully enough recognized in our schools; to do so would be expensive, for it would mean equipping grade libraries. Consequently, children suffer from an ill-timed economy. There should be books in abundance where the children can use them freely. These should be on all subjects within the comprehension of the children, and some of them should be leading out into new fields of thought so attractively that inquiring minds will be charmed along hitherto unknown paths. Better equipments for children in science and manual training are being granted in many schools, and it is to be hoped that the purchase of well selected grade libraries for every school, or 
every small group of schools, will be one of the steps taken in the near future.

The history of the sixth grade is arranged to meet the craving to know about the world. There are stories of the earliest days, when human beings lived in

Sixth

Grade

Stories caves; then the life of mankind is traced down through the development of several nations. It is not intended to study history seriously, but it is desired to place before the children considerable reliable information about the past, so that a truer understanding may be gained eventually of our own life and place in the world. In this way, sixth grades read many stories of ancient history, before the era of Christ. Seventh and eighth grades take up stories of the Middle Ages and of England. During these last two years the United States history is the regular class work, and we find that it is more easily mastered because of all the story work on earlier nations that has preceded. It is interesting to note that the stories, read and discussed as such, are often more easily remembered than is the American history, the work for the class.

This distribution of time and application serves well the culture growth of the children; for, having once become acquainted with the true stories of history, few pupils lose their liking for this great study, "the story of man." To attain this end the pupils must like the stories. This can be done by remembering that knowledge is not the first and only object sought. The purposes are rather: the formation of a deep and lasting interest in history; an appreciative study of man and his development; mental training in rapid reading, accumulation of facts, ready discussion, 
formation of judgments based upon proofs, and systematic arrangement of the knowledge gained; historical knowledge.

In order to like history a child must read easily and widely, not narrowly and intensely on a short period of time where Cultural Training

he is expected to master all the details. To study the men about whom he reads, he must discuss their motives and characters, and he must compare them with one another. To acquire mental training the material used must be systematized, and the judgment must be exercised and developed. In all these efforts at education the teacher must remember that sixth grade training must be simple. Discussions and decisions will be crude, but the fact of using powers means their growth. The pupils are in the story age. They can read many accounts that turn about the same center of knowledge without tiring of the subject. Thus, by varying the stories but keeping the same center of thought, material is accumulated for discussions, comparisons, outlines; and broader knowledge comes from the presentation of a thought or fact in several different guises.

For instance, the love of the Greeks for adventurous expeditions comes out very clearly from reading the stories of Jason, the Iliad, the Odyssey. To the pupil there is no repetition of thought, but, if the discussions have been kept up, and if the teacher is skillful in drawing out the characteristics of the Greeks that led to these expeditions, at the end of the reading the pupil will have a knowledge of the way in which the Greeks during the period of colonization scattered their life, customs, and seeds of awakening intelligence all around the Black Sea, in Asia Minor, in Southern Italy and the adjacent islands. It is a knowledge that is import- 
ant to an understanding of the rousing up of civilization in Europe. Sixth grade pupils can see it as a matter of course, in a child's way it is true, but the fact will cling to their memories if it is well impressed by stories and maps; high school pupils, however, often finish ancient history without a thought of this strong connecting link between ancient and mediæval civilizations. What is true of this topic is equally true of many others. The pupils are reading stories and enjoying them, but, if properly guided, they are also laying an excellent foundation for later serious studies.

Another instance of this cultural training may be found in seventh grade reading on the feudal system and the Crusades. From well selected stories pupils can gain a surprising amount of interesting knowledge concerning the commercial, political, and social conditions of mediæval days, leading to a fair understanding of the reasons for the discovery of America and for the revolt against Old World customs that caused the establishment of our freer political institutions. Such readings and deductions are a delightful part of grammar grade history. No attempt should be made to build up historical structures, but the foundation laid for those of later years should be firm and true. During all this period of story reading the pupils will scarcely have realized that they have been working. Not that pupils should not work knowingly, but they will be learning one of the first important lessons in the acquisition of history, that work in history is thoughtful and systematic reading. If, then, children are learning to read history intelligently and with pleasure, they are also learning to work happily.

In the stories of Greece and Rome the pupils are now old enough to distinguish between the myth and the germ of 
truth at its root, and they can see how the myth grew up naturally in the lives of these beauty loving, inquisitive, primitive people. Consequently, the historical myths are more interesting here than in the lower grades, where the little children can not differentiate between the truth and the fancy in the story. The life and development of both Greece and Rome can be shown by a comparatively small number of stories, grouped around centers of national growth and enlivened by accounts of men and events. Institutions and laws belong to later years.

Methods as well as material should be progressing constantly. That which fifth grade pupils did well should be

Evolution of Methods the basis upon which the sixth grade builds. The teacher should know what the children were able to do in any given exercise, as outlining, in the preceding grade; she should try them to see just how much they can do well, and then advance them certain steps.

The fifth grade pupil did not attempt to outline beyond headings for paragraphs in separate, comparatively short Outlining stories, with a few indented suggestions for the body of every paragraph. His outlining was preparatory to writing. The sixth grade pupil will continue much of this paragraph outlining as an assistance to written reproduction; but he will also begin to outline a subject by its larger heads. In the fifth grade these larger heads have been given by the teacher as the subjects to be outlined, because the judgment and analytical powers of the children were still too immature for them to reason beyond the details. Sixth grade pupils will not go far beyond that point, but they can take a subject that has been under con- 
sideration for several days and give the most prominent headings, so leading out towards a larger, more complete view of a subject. This means that two kinds of outlines are being carried on in the sixth grade; or, more properly, that the new step added to the fifth grade outline seems temporarily like a new kind of outline. These can seldom be worked out satisfactorily on the same day. If the larger headings for a complete story have been developed, the teacher will find that the minds are tired by this stretching process, as it really is to the children, and that the hour would better be filled out with some interesting narrative. The following day one of the headings from this complete outline. can be treated in detailed, or paragraph outline. This will be far easier work than that of the preceding day. In developing the outline the reading from various books should be put together; this will have its special difficulties of amalgamation, usually confusing to children, who do not comprehend at first how to combine thoughts from several authors. The minds are still young.

It is good practice occasionally to write an outline on the board just as it is given by the class, and then to rearrange it for continuity of thought. In an outline of any length there will be much to do, and a great deal of guidance will be necessary. There are two reasons why continuous thought comes slowly: we are all prone to forgetfulness, leaving out something that we know full well belongs in the development, and putting it in when we think of it, out of its place, of course; continuity of thought is a power of maturity, whose fullness can not be expected from these children. It is being cultivated, but its growth can not be forced, it must be developed through careful, intelligent use. 
The outline may or may not be left before the pupils during the written reproductions. If the story is long, requiring several days for writing, the outline will be a great aid, and results will be better. If the memory is to be trained, the prop should be taken away by erasing the outline. Memory is a useful servant, but other faculties are of equal or greater importance of life work.

If the topic for writing is assigned occasionally a day or two in advance, the pupils have a chance to think over what Papers they wish to say and how best to say it. Careful workers soon learn to take advantage of the opportunity to look up the spelling of new words, to think out a satisfactory outline, and to prepare in many ways. The results are naturally better than when the efforts are extemporaneous. This kind of preparation also tends to cultivate a habit of self-examination concerning readiness for a task, a habit of incalculable importance in the production of satisfactory work and in the formation of character. Still more ambitious papers may be written by giving the pupils a week to prepare on either an assigned topic or on one chosen by the writer. Reading from reference books then becomes possible, and actual research in history is beginning. The reading references should be suggested by the teacher, so that too difficult tasks are not left to untrained minds. Selection of material is one of the most involved steps in the preparation of a paper.

There are the usual accessories of maps, illustrations,

Class

Accessories reference books. The maps are for fixing the larger features; the less important ones become known through repetition. The illustrations that are now used often have considerable 
value. These should be exposed somewhere in sight of the pupils so that they become a part of their germinating artistic and intellectual life. Reference books should be furnished every school ; they may be drawn from public libraries; sometimes they are willingly loaned for careful use by private owners. Reading is to history what plants and animals are to nature study, the material with which to work. Reading is a necessity.

From the sixth grade on throughout life as a student, note taking and the notebook have dignity and importance. In

Note

Books the book are collected all papers of value, separate sheets that are preserved as writ-

ten. The best form of notebook that has been evolved from our work is the one composed of separate sheets, comprising work of all kinds connected with the study, fastened together in a folder or a homemade cover of pasteboard. Paper fasteners are not satisfactory for hold. ing the leaves together as they do not permit the book to open freely enough. A string holds the sheets safely and allows ease in turning.

The time given to history during the year is twenty weeks, in two periods of ten weeks each, alternating with literature Time periods of the same length. The daily allotment of time is forty-five minutes, twenty for study, twenty-five for recitation.

The following thoughts are from a sixth grade teacher ${ }^{1}$ :

For the history of primitive man Ragozin's "Earliest

Early

Man

Peoples" is used. The book is too difficult to be put into the hands of the pupils for unaided reading and study, so it is read aloud by the teacher. Discussions and reproductions by the class

${ }^{2}$ Miss Charlotte Treanor. 
follow. By this means there is gained an introductory knowledge of the world before the age of Greek civilization. Attention is called to the westward movement in the life of the world, and this tendency is referred to frequently throughout the term. The stories of Kablu, Darius, and Cleon are read from "Ten Boys." A time line is begun and continued during the term. A cross in the middle indicates the beginning of the Christian era; time before Christ is put at the left, and time after Christ at the right of the cross.

Early Greek history is studied through stories of the gods, many beautiful myths showing the childlike attempts of the Greece

Greeks to explain the phenomena of nature. While reading about the heroes and the period of the Trojan War, fully two-thirds of the class have read large parts of the "Iliad" and the "Odyssey" in the children's editions in the room. A comparison of Sparta and Athens is made through stories of the life and training of the people in the two cities. The next age is best told by the lives of some of the great men; as, Pericles; Socrates, Demosthenes, and Alexander. Pictures are an important source of information, study, and pleasure. A brief glance is given to the overthrow of Greece by the rising power of Rome.

Through selected stories the children learn to see the Romans as an energetic, industrious race, fond of conquest, Rome intensely patriotic; training the young men carefully in the art of war, and according great honors to successful warriors. "Horatius," studied and partially learned in the second grade, proves an interesting foundation for some of the conquests made by the early Romans. Some rays of light are thrown on the long 
and bitter struggle between the patricians and the plebeians by a few of the most stirring tales of those days. There are pictures and descriptions of the temples, theaters, aqueducts; the military roads are admired by the pupils, who receive through them some idea of the necessity of marching armies quickly from one part of the Empire to the other. Greek influence is noted in the artistic life of the people. Chariot racing is made more vivid by reading the chariot race in "Ben Hur." The war with Carthage is intensely interesting, and keen sympathy is aroused for the conquered city. Augustus Cæsar is presented as one of the best emperors. Nero is selected as a contrasting type, with his cruel persecutions of the Christians. For many centuries the power of Rome weakened. The children read with interest stories of the barbarians who swept down upon Rome from the north, terrifying the Empire, and finally subverting the conditions of Roman life.

This is but a meagre outline of the work given. Everywhere it is presented through stories, whose meanings are often seen by the children without help. Connecting links between periods must be supplied by the teacher, but these are given in a few words that are made more comprehensible by keeping the trend of events in every period before the minds of the pupils.

A large map of the country being studied is drawn upon the board, and important places are located as they come up Maps in the recitations. This map is made permanent for the term by being outlined in thin white paint. The places are located temporarily in chalk, so that the day's lesson may be erased if desired without destroying the outline. In a short time the principal 
rivers, lakes, bays, mountains, cities, and provinces are quickly and accurately located whenever mentioned. At the end of the term the painted outline can be removed easily from the board.

\section{SEVENTH YEAR GRADE}

In the seventh grade the subject for the year is American history. This is introduced by stories of the Crusades, selected and prepared for the classes so as Introduction to American History to show the restlessness of the Middle Ages and the knowledge of the world that was gradually leading men out of their own home countries into distant lands. The pupils thus see how the Europeans came into contact with the higher civilization of the older countries of the East, imbibing many of the luxurious tastes there prevalent. To supply the commodities demanded by these new tastes long and difficult commercial voyages were undertaken, well suited to adventurous spirits that still held back from the more settled, monotonous habits of industrial life.

All the time desired can not be given this period of awakening in Europe, so fitting an introduction to the discovery of America, for it is also desirable to familiarize the pupils somewhat more specially with life and conditions in England just before the voyages of discovery and the beginnings of settlements in America. For this purpose a text is used. The whole book can not be read and discussed in class, and it is not desirable that it should be; but selections are made of stories illustrative of the periods most closely connected with American history. Many pupils read the entire book for themselves. 
After a rather too brief introduction of this sort, when its importance in our history is considered, the regular study of

Texts and

Library American history is begun. In addition to the text purchased by the pupil, three other authors are kept in sets in every seventh grade room, so that every pupil has four books to which he can refer in preparing his lessons. The use of the city library by the pupils broadens and strengthens in every grade. This is a fact of importance and magnitude. The children should not be simply turned loose in a library, to select anything that suits them; they are not yet old enough to be discriminating, nor will they be for several years to come. Neither is it ordinarily satisfactory to leave them to the guidance of librarians, unless there is a juvenile room in charge of a capable, sympathetic person. No one can know so well as the teacher just what topics and what phases of them are to be discussed and emphasized in the class. That the teacher keep in close touch with the reading becomes of more importance constantly as the pupils and the study become more mature. This is the source of supply, the subject matter, the red blood from which is to come the live tissue of the body of knowledge that is to be built up. If the library is large and if the teacher is very busy, and what conscientious teacher is not? it may follow that the library is not thoroughly canvassed for a year or two; but when this has once been done and the teacher knows just what books are applicable to her class work, it is not difficult to keep track of the new books that are added to the library. By putting the information about all these books into the topically arranged card catalogue of accessible books for the class, which should be a part of the outfit 
of every teacher, the great problem of supplementary reading is reduced to system, and ceases to be a constantly recurring bugbear. The teacher and the librarian should work together for the good of the schools. It is a most efficient aid in the use of books, and it is eventually for the best good both of the public and of the library.

In the seventh grade the time for history is doubled; it becomes forty-five minutes a day for the year, instead of for

Time

five months, as in the preceding grades. Twenty minutes are usually taken for preparation, twenty-five for recitation.

Pupils should be growing more independent in preparation, although the proportion indicated above of study time to recitation time shows that the influence

Preparation

and

Recitation of the teacher in guiding is still considered preponderant over the discrimination powers of the child in choosing for himself. Recitations must include time for careful suggestions about reading and methods of work. The value of definite assignments can not be over estimated, but a failure to make clear just what is to be done and how it is to be done is one of the most frequent weaknesses of teachers. The lesson should rarely, perhaps never, be assigned as so many pages. Topics, even if only the paragraph headings, should be plainly dictated. The alert teacher, however, will seldom be satisfied to use these summaries as topics for the lesson. More personal topics will be chosen, something that can be made more a part of the class life than the headings from any book, no matter how scholarly. They will be such as the teacher will select, through a knowledge of the class, as necessary to the promotion of some undeveloped thought in 
the recitations, or those that are most accessible in the reference books, or that lead directly into future studies. In short, here as everywhere, there should be that class personality without which all teaching palls. The topics are placed upon the board; pupils are expected to prepare themselves thoroughly either from the class text or from that and the reference books. This may be the material for the first day's recitation. The next day, after this preparatory systematizing of the topics, broader reference reading may come, perhaps for individual reports from different books, or as reading by all the class on some special phase of the lesson from any supplementary author. The latter method is usually preferred, for reproductions from individual readings tend toward dry résumés, appreciated by few, no matter how conscientious the child who makes the report. This method is more practicable with older students. The second manner of preparation, all looking up the same topic but from various books, is more liable to bring out discussions, comparison of opinions, expressions of differing ideas, all of which result in live, vigorous class work. The larger the number actively interested in a recitation, really taking part in furnishing details, or in presenting ideas for the discussion, the greater will be the life and energy of the recitation.

On some days, careful, thorough reproduction of the text that has been read is excellent drill. Pupils do what they are directed to do; they have a natural tendency to neglect what is not required. Consequently, in leading a class out into discussions, care must be taken not to permit a neglect of restating exactly the author's opinion. The teacher should call frequently, every day perhaps, for an exact rendering of what Fiske, Montgomery, or any other author 
used in the preparation, says in regard to any point in the lesson. Sometimes a reproduction of the whole lesson, topic by topic, should be called for. Two ends are gained by this kind of a recitation, formal as it may seem at first glance. The pupils are led to notice more carefully what they are reading, and, gradually, to form the habit of picturing mentally the thoughts of an author, a most important power; secondly, the memory is steadily developed, and this is a servant too useful to be left untrained. Every recitation can be made to vary in some respect from those immediately preceding, so that monotony of presentation, that deadly enemy of enjoyable class work, does not lay hold of the pupils.

Another feature of the instruction that is beginning to take shape is the presentation by the teacher of definite sup-

Talks by the Teacher plementary knowledge. While this is never so formal as to deserve the name of a "lecture," it partakes of that nature. From books that are inaccessible to the children or that are too difficult for them to assimilate in undiluted form, the teacher collects points of interest and importance. When these are given in sufficient abundance to warrant note taking, the pupils should be asked to keep track of what has been told them, incorporating it in some shape in their notebooks. Like outlining, this method is easily abused, for children never like taking many notes; but if the insistence of the teacher on taking the notes is in a spirit of helpfulness, and if the children are led to use the material in some way, and to appreciate the assistance furnished by their notes in writing or reciting, the majority of the pupils respond 
quickly and happily, and the talks by the teacher have an added force.

Outlines continue, still largely as composites, produced by all the pupils working together, guided by the teacher; some Outlines original efforts are made, and with very good results if the work can be analyzed in a manner already familiar to the children. The reasons for not leaving the children to their own devices are the same as in previous years. The powers of analyzing, judging, selecting, and systematizing material, upon which the value of an outline depends, are still immature. They are not being used so much as being trained, developed, through all these years, preparatory for later actual use. Consequently, the work should never be very difficult nor should it be left without supervision. It is like developing a muscle; there must be wise oversight or there may result injury rather than education.

The notebook may add greatly to the pleasure of the class, and every pupil should be encouraged to put together Note Books one of which he will be proud at the end of the year. These books are not to be left in desuetude under the desks, simply kept as receptacles for the papers of the term; they are for use; they are practical, indispensable aids. On certain days there are reviews of the month's work, based on the indexes of certain notebooks. This brings out friendly comparison of the number of papers and of pages written and preserved; of the notes taken from the teacher's talks and from supplementary reading; of the maps made; of the drawings by the pupils themselves; of the pictures collected. Some of the papers are read, a map is reproduced on the board, or an 
especially original outline is read, discussed, or recited upon. The notebooks are used as a partial proof of scholarship, of ability to pass the subject. The books sometimes go home for the approval of the parents before the end of the term, so that the stimulus thus obtained may come back into the class.

It is possible that the English history may have been given in a fragmentary manner throughout the year, fitted Summaries into the periods of American history so as to illuminate the relations between the two countries. When this is the case the detached lessons are put together towards the end of the year under the general headings of their particular periods; the Tudors and the era of explorations and early settlements; the Stuarts and the religious changes in England, leading to heavy emigration to America; the Georges and the Revolution.

To fix the history from the period of explorations through the Revolution, a topical review of two or three weeks is admirable exercise. The geography must be kept well in mind. The broad principles in the whole period are brought out for the headings of the smaller divisions; the relation of period to period is shown; the causes and results of events are analyzed; the children are led to generalize, to compare, to judge, as far as their powers will permit them to go. In a review of this nature details are not dwelt upon except to prevent the recitations from becoming dry and monotonous or to refresh facts; they are used constantly, however, as accumulated material which is for the purpose of forming broader views and for grasping the sure, uninterrupted movement of a nation. The details have been studied and gained through the preceding months, but the children 
should leave no important period without also seeing that these details are not the end for which we are studying, but that they make it possible to see the real meaning of the life of the nation, just as flying scraps of paper tell the direction of the wind.

\section{EIGHTH YEAR GRADE}

The administrative period, from the Revolution to the present time, and the history of California form the subject

Time

Material

matter for the history of the eighth grade. The time given is fifty minutes a day throughout the year. Half of the period is used by the pupils for preparation. According to the state law no study out of school can be required by the teacher, but many interested pupils read at the public library, or take school books home with them for the evening, through their own desire to know more about the periods studied.

This part of the history of our country has many difficulties for grammar grade pupils, for its development is along

Subject the lines of mature growth, it is the complex Matter history of modern times, and care must be taken that it is not overwhelming to the children. There are many topics that are important and interesting without going into the vagaries of the currency, the intricacies of the tariff, or the vacillations of political parties. Such are the questions of transportation; the opening of new roads; the conditions of the negroes; the attitude of the North and the South toward the freedmen; immigration, and the settlement of great stretches of our country through the influx of foreigners; the reasons for the development of certain states, as California, because of its mines, grain production, fruit raising, stock raising, climate; Kansas, because 
of the opening of its land to soldiers after the Civil War, and the vast areas there ready for the plow; the Northwest, with its seemingly inexhaustible wheat acreage and pasture land, and its vast wealth in mining. Such questions are of far greater value to the children and they are more intelligible than are the majority of governmental and political topics. Unfortunately, reading matter on them is less accessible, and it is rarely written for children; but if the teacher and pupils are working together for the accumulation of material, wonders can be accomplished. At least, the emphasis of the preparation and the recitation can be laid upon those topics that are nearest the pupils, while those that are so difficult as to be studies even for the teacher can be passed over lightly enough to prevent the pupil abominating forever afterwards the very name of tariff, finance, presidential election. In our zeal to prepare the children for statesmanship, we are prone to overlook the fact that they must first be citizens. Citizenship is far simpler than statesmanship, it is nearer the individual life, it must touch every one.

In the preparation of his lesson the eighth grade pupil naturally uses the methods of the preceding grade, even Preparation while he is being led out into broader uses of his maturing powers. The supplementary texts and the regular class text are first used, as a sort of summary on the assigned topics. Then the pupil turns to the public library, the home collection of books, periodicals, and papers.

The recitation follows the general lines of that of the Recitation

seventh grade. Frequent discussions involve the majority of the pupils and have more life than set reproductions. Searching quizzes and short, 
accurate reproductions occur at any time, so that preparation for them will never be neglected by the pupils. An eighth grade teacher ${ }^{1}$ says: "An effort is made to lead the pupil to talk from a topic and to know when he has exhausted his subject. He is encouraged to think and to give his own opinions. Before such a topic is assigned to an individual, the class is usually led to think about it, so that all are interested in the treatment. In this way pupils reason out many points, without the aid of books. When conclusions have been reached individual presentation is called for in order to clarify ideas. Sometimes a general talk of this nature precedes the studying of the lesson, leading the pupil to think and reason while studying. Library reading is done on many topics."

${ }^{1}$ Miss Belle Mitchell. 


\section{CHAPTER XVI}

\section{CIVICS}

The state supports the schools. The schools are the avowed training centers for citizens of our republic. ConseImportance quently, in return for the money lavished upon the schools, the state should be given citizens with a high degree of civic pride and honor, prepared to render willing support, and possessed of a knowledge of the possibilities and limitations of citizens.

It is true that the family is, and always must be, the strongest influence in character training. The school can only

Institutional

Sense supplement the efforts of the home; but the school may be a better instructor than the home in general information concerning the duties of citizens. To be thoroughly a part of a man's life, the conception of honest, unselfish citizenship must be commenced with the child. His understanding and appreciation of the institutional side of his own character and of its necessity in a well balanced life must be educated in his childhood. Many growing children are prone to cast off allegiance to any person or institution simply from the belief that it is a sign of strength to do so; but, if shown that such allegiance is courage, loyalty, patriotism, that it appeals to the best and bravest in man, it may be embraced with an affection that long years of worldly struggle can not weaken.

The object of the course in civics is to purify and render intelligible the child's institutional sense, and to direct it 
toward its legitimate objects of loyalty. The first steps in this training are to make clear to a child the nature of those

Character

Training institutions nearest to his life, as the home, the school, the neighborhood. These are broadened later to the town, the state, the nation. There is thus trained that part of the child's nature that finds expression in patriotism toward home institutions and in allegiance to constitutional government anywhere. This training has its foundation in character; hence, whatever elevation can be given to the character of a pupil is sure to be reflected in his citizenship.

Instruction in civics accompanies history, and, in all grades to the eighth, the recitation time is taken from the daily

Time period for history. No set time is arranged on the daily program, but it is expected that every week or ten days there will be careful work on some topic in civics. If two lessons are closely related they are taken on consecutive days. No regularly assigned work has as yet been followed in our schools, but every teacher selects from the summaries the material most suitable for her class, and comparison of work done in different grades prevents repetition of topics.

\section{PRIMARY GRADES}

Cultivate a spirit of social responsibility, of interest in and for companions. Man is a social animal, he must live in

Social Duties company with his fellow-men. He should realize, therefore, the benefits and responsibilities arising from such relations. The school is an excellent place for starting the education of this idea with children. Relations with others begin in the 
family. Discuss the family and the home with the little ones. Do more than talk to them; lead them into thinking and expressing their own ideas, so doing much of the talking themselves.

The family: Formed of whom? children must be loved and cared for; children should have consideration for

The

Family parents and an understanding of some of the burdens and responsibilities of parents; responsibilities should rest upon every member of the family; children need some fixed tasks in order to help and also to learn how to work; interdependence of members of a family.

Authority in the family: Its necessity, seen in the need of constant care for infants, of long continued training for children, and in the great number of things that there are for children to learn before being ready to go out into the world; necessity for punishment after wrong doing, its nature; parents the center of all authority; older children, if they are reliable, grow into a share in the parental authority; the honor to the child who shares this responsibility; the responsibility attached to it; the necessity for all children to learn how to govern themselves and how to help govern others.

Ownership: Individual, as in marbles belonging to one boy; common, as in a swing for the pleasure of all the children; care of property; accumulation of individual property and its relation to the good of all; increasing the scope of common property, and its relation to the individual.

Bonds of union: Mutual interests; its effectiveness in training for the future ; personal affection, the strongest bond in the life of many people in home life, patriotism, religion. Early in the school year discuss with the children the 
great change that has come to them by entering school. This may precede the discussions on the family as it ought

The

School to help fit the little ones into their new environments; but after the talks on the home the school should be reconsidered, so that the pupils fit it into their conception of the enlarging circle of their social relations. Interest in and for others is the true basis of social relations. See that the children live socially, that they play, work, chat, with others. Theory without practice is like looking at the apparatus of a gymnasium without being trained by its use. Notice difficulties that arise in adjusting games or schoolroom routine, and, without making direct application to the occurrences, discuss with the children the reasons for such disagreements, the rights involved, the possible injustice to some, and the means of settlement. There will be a response to good government and also an education toward an intelligent participation in it. In many cases, where absolute authority is not required, it is safe to allow the pupils to discuss and vote on the method of procedure, and so the children are learning to obey the will of the majority. Cheerfulness in such obedience should be inculcated.

Some of the rules for the schoolroom may be made more effective if the necessity for them is clearly understood by

Rules

and

Laws the pupils. Two broad divisions of rules and laws are readily seen,-rules for restraining and rules for direction or progress, The need for both is quickly recognized. The children develop for themselves that the rules for restraining are for the few, that those for guidance are for the many. They realize that there are comparatively few chil- 
dren in the room who are so lawless that they must be restrained by rules and regulations, for it is noticeable that in every class there are few evil-disposed pupils in proportion to the whole number; but they also reason out very easily that two or three noisy, quarrelsome, or disobedient pupils quickly disturb the peace and happiness of the whole class. Hence the need of restraint. Rules for direction, for training, whether in book learning or in conduct, are for the many; they are for progress, and all wish to advance. Some need more training than others; consequently, such rules may have to remain in effect longer for some pupils than for others. These thoughts, simplified for childish minds, made concrete by schoolroom examples, talked over in friendly, coöperative manner, prove remarkably helpful in fitting the individual into the social and governmental relations of school life, in arousing a desire for every one to control himself by responding to conditions, and in direct preparation for self government.

The children in the first two grades are too immature to be interested in the city government, but they take pleasure

City

Officials in learning the names of some of the public officials nearest to their lives. In talking over the school system, for example, it is easy to pass from the class teacher to the principal of the building, then to the superintendent of schools. It is even of importance to give names accurately, writing them upon the board when not well understood. The duties of the teacher, principal, superintendent, can be talked over briefly, so that the children begin to see the interdependence of the parts in a large system and their relation to the well-being of the whole. The mail service is traced out briefly from 
writing a letter to its being sent out of the city; and vice versa, from mail coming into the city to its delivery at the house by the postman. The police and the fire department are explained in a simple manner. General knowledge is thus gained and classified in an elementary way, observation is stimulated, personal interest is aroused, and the child feels himself more distinctly a part of the surrounding life.

In the third and fourth grades, in connection with local history studies, some of the institutions of the city, and possi-

Third and

Fourth Grades

bly of the state may be studied. As in the first two grades, the object is not to accumulate a great amount of detailed knowledge, but to develop and rationalize the institutional side of character.

In the third grade study of early Stockton and the growth into a city, there is opportunity to show the need of a mayor,

Home

Conditions

a city government, protection from fire, attention to streets and sidewalks, an organized police force, a city jail. This founding and developing of a town combined with the growth of its government is a correlation of history and civics that is always valuable to a student. The fourth grade, dealing with Stockton as it is today, studies the modern city in a simple manner. Attention is called to the division of the city into wards, the city council, the school board, the city parks and their care, and many other matters of interest to children that may suggest themselves to the teacher. The children talk about their immediate surroundings, the need of good sidewalks and streets, the pleasure derived from well kept parks and shady trees. They learn who is the member of the city council from their own ward, how large 
the ward is, they inquire at home and report in school about some of the duties of a councilman toward his ward. Local interest and patriotism quickly adapt themselves to the larger units of city, state, nation; but if the local spirit has never become real and intense, broad patriotism is never truly quickened. Love for beautiful, sanitary, honestly won surroundings in one's own neighborhood is the foundation on which to build the desire for similar conditions in the wide nation that is our heritage.

In discussing with the children the desirability of such moral attributes as honesty, bravery, truthfulness, unselfish-

Dangerous

People ness, develop the reverse of the picture. That is, have them talk over why the opposite traits of character are dangerous to the happiness and well-being of the home, the city, the state. Include idleness, ignorance, and drunkenness in these discussions. Find out whether the laws concerning them should be those of restraint or of training.

An important part of the teacher's duty is to train pupils in courteous habits. This is a part of the child's character Conduct formation that goes on steadily at school, it is also one of the points of closest contact between the home and the school. The teacher deals with the child in his relation to a larger, more formal society than is met in the home life. The teacher should realize the social as well as the intellectual meaning of this change and should be equal to the needed guidance. Many a child is more courteous, truthful, honest, and unselfish at home than in school, and the opposite is also sometimes true. Either condition is almost wholly dependent upon the atmosphere 
of training and discipline in the home or the school rather than upon the child himself. Short, pointed, friendly talks with the children help wonderfully in establishing a general response to genuine, kindly courtesy; and, since such talks help form the child's character, they are an important and legitimate division of civics, the making of the future citizen.

There should be informal discussions with the children in which they express their own opinions on such points as kindness to each other at home; or at school, where there is less intimacy than in the narrower circle of home and immediate friends. Between persons where there is no desire for a close friendship, there may still be that courteous friendliness that makes even strangers feel at ease in each other's presence. Discuss in a similar way the honesty that precludes cheating in school as well as stealing money; respect for the old and infirm; unselfishness; the bravery that dares stop a fight, or use correct language on the playground in place of slang; manliness and womanliness.

The subject matter must be adjusted constantly to the maturity of the class. Lessons on the postman in the first or second grade should be so different from any treatment of the post-office in the fourth grade, that the children have no sense of repetition of old material. The same is true of every topic. The work that belongs to one's own grade is what should be attempted, not that of a year or two in advance.

\section{GRAMMAR GRADES}

Instruction in the grammar grades includes a maturer treatment of the topics used in the primary grades and the 
study of more difficult subjects. A summary of the latter

General

Outline is given in the following outline, suggestive for teachers of all grades; brief class outlines are given under the different years.

The machinery of government: ward, city, county, state, nation; the development of this machinery through the family, tribe, community, city, nation; early governments in the United States,

Laws: necessity, makers, interpreters, enforcers, penalties for violation.

Finances: cost of government, taxation, assessment of property, expenditures, safe-keeping of money.

Voting: machinery, benefits, will of the majority.

Citizenship: the "American race," a conglomerate; foreign born element, its helpful and dangerous sides; duties of all citizens ; responsibilities; interests; patriotism; dangerous citizens ; "graft."

International relations: friendship with foreign nations, possible benefits and disadvantages.

Democracy: its opportunities for all; justice of its government; dangers from bribery, carelessness, dishonesty, indolence; need of educated citizens; higher education in the high school and university should make better citizens of boys and girls ; patriotism; the temptation offered by rank in foreign countries and the meaning of such a society to the "lower classes."

Some topics fit naturally into history, but correlation should not be made so close that useful, easily comprehended topics in civics are excluded because they do not also occur in history.

Certain phases of taxation and of the expenditures of 
public money can be studied in the fifth and sixth grades as well as in the seventh and eighth. Americans are proverbially careless of public buildings. Instructions concerning their acquisition and care are very necessary. Children often deface public buildings because they are ignorant of the fact that the people themselves must either endure the displeasing appearance or they must pay for the renovating. Waste of public supplies, whether by oneself or permitted in some one else should be considered.

Through the last three years of the grammar grades a class society is very helpful to the pupils in acquiring some

Class

Societies knowledge of how a meeting should be conducted, and of how to work together in organizations. Such a society should have a definite reason for existence; it should not be conducted in a haphazard manner; some recognized set of parliamentary rules should be followed in all the forms needed by the children.

In order to become familiar with the needs of government, the difficulties attending a democracy, and the consequent Selfnecessity for public spirit and unselfish atGovernment tention to details let the children of any of the higher grammar grades undertake some degree of self-government. By the will of the majority, expressed in regular form, they can make some rules for their own government in school, in the yard, concerning their games; members of the class can be appointed or elected to enforce these rules; some form of punishment may even be decided upon for any violation of the rules. Such a self-government committee may become the very life and inspiration of a school. The teacher must, of necessity, be 
the guiding spirit; the years of childhood are the years for training, and pupils of the grammar grades are not mature enough, they are not well enough trained, to be allowed a large degree of independent self-government. On the other hand, that which is granted them must be real; to feel that the committee is simply enforcing the teacher's rules, or that it has no liberty of decision and action, quickly kills the effectiveness of a so-called self-government. If entered into seriously and lived up to by the pupils, there is an invaluable training and an insight and growth into actual self-government.

It is far easier to begin such a system than to carry it out. While the novelty lasts the pupils are enthusiastic; but, as time passes, the repetition of the common details of government seem monotonous to some; or the evil of influence, which passes so easily into bribery of some form, becomes apparent. Here is the opportunity of the teacher. The greatest dangers to our democratic institutions lie in corruption and the apathy of honest, common-sense citizens. If a teacher or principal possesses the power to guide pupils past this danger point into steady, regular administration of petty details, he has done more for the establishment of a dependable public spirit than can be accomplished by any other study.

The following outline indicates centers of discussion and instruction for the different grades.

\section{FIFTH YEAR GRADE}

The City (not to be carried far into details).

Mayor: name, length of office, principal duties.

Council : number of members, election, principal duties. 
Departments : fire, police, school, health.

General topics :

Hospitals and charitable associations.

The pound, animals at large in the city.

Dredging channels.

Paving streets and laying sidewalks.

Sewers.

Street sprinkling.

Water supply.

Board of education, principal powers and duties.

The schools.

Public library.

Lighting the city.

Misdemeanors, especially such as may concern the conduct of children. Many offenses begin in ignorance or in lack of respect for authority.

City property.

Telephone.

Wharves.

Which of the above regulations are for restraining citizens? Which for training? Which for convenience, pleasure, well-being, health? Are there any that refer to companies acting with the permission of the city?

Perhaps the most important thought for the children in the above outline is that pertaining to misdemeanors. Bring before the class regulations that may concern their own lives, -riding a bicycle on the sidewalk, the speed of an automobile, defacing public buildings, petty thefts. Throw a little light on the laws of the city so that the children may act more intelligently. Remember that general information and the 
cultivation of an intelligent and obedient public spirit is the object of this instruction, not the accumulation of detailed facts. Indigestible knowledge creates in the mind of the pupil a reaction against all study of civics; assimilated knowledge means deep and lasting interest in local government.

\section{SIXTH YEAR GRADE}

The general outline is that of the fifth grade, with special elaboration of certain topics. Local self-government: its need, benefits, dangers; need of honest, capable citizens and officials, the latter experienced in business in a large way. Legitimate matters for local control: making roads, building bridges, erecting public structures, educating children, caring for poor and infirm, restraining dangerous people, protecting the city from fire. Other topics will suggest themselves to every teacher for the greater fullness of treatment in this grade.

Some very brief, elementary work should be done on the state and nation. The principal offices and their incumbents may be mentioned, and some illustrations of the relation between city and state, or state and nation, may be made. These general studies serve many purposes. They illustrate the similarity of organization throughout our various governments; the power of the people in making their cwn laws; the growing boundaries of authority through city, county, state, nation; the more intense local interest in the smallest unit of government; the petty details in the smallest unit; the growing gravity of interests involved in the affairs of larger units; the need of broad, loyal citizenship everywhere. 


\section{SEVENTH AND EIGHTH GRADES}

Texts are used either in the class or as supplementary reading; in the eighth grade a recitation period in civics

Utility of

Government should be arranged for on the daily program, either once or twice in the week throughout a definite portion of the year, or for a few consecutive weeks. In both grades the work concerns itself less with details of the machinery of government than with what is being done for the people by the government; the meaning of government; its defects and sources of strength; the reasons why, in a democracy, the people should understand the government. As, for instance, a study is made of the care of the poor on a county poor farm, the hospitals or asylums for the insane, reform schools for incorrigible children; of what this care consists, why it is given, by whom, who pays for it, effects to the public if it were not given. There are many topics that can be followed out in this manner, arousing lasting interest in actual social conditions. Details of government must also be studied, but they should not exclude what is being done by putting in its place how it is done.

Some of the topics for guidance of the teacher are:

Government: necessity; the family, school, societies, city; various forms,-democracy, kingdom, absolutism; abuses and perils; good citizenship; personal character in its relation to government; public spirit, knowledge of state affairs, industries, relations to one another.

The city: guided by the preceding outline, selecting those points about which the pupils show least knowledge.

The county: geographical importance; board of supervisors and their duties; relation to the city government; county 
schools, roads, bridges; county seat; any topics from "the city" that are applicable to the county.

The state: governor; state legislature; state duties toward people; care of poor; of criminals; many topics from the text.

The nation: historical connection with the development of the constitution; points of contact with the pupil's life; signal service; life saving stations; weather bureau; post-office; harbors; army and naval cadets. Make the nation a living, active entity in the mind of the children. Details as to the government will be mastered later if they seem tiresome and dry in these years. 


\section{PART V}

\section{DRAWING. MUSIC. PHYSICAL CULTURE. SEWING}





\section{CHAPTER XVII}

\section{DRAWING. MUSIC. PHYSICAL CULTURE. SEWING}

\section{DRAWING AND ART'}

Art is added to drawing because drawing hardly covers all the work that is at present given in our schools. The

The Past

and the

Present

oldtime drawing consisted mostly of copying from the flat and the drawing of geometric figures, and had at its best the narrow aim of training only the eye and the hand. The chief aims of drawing as taught in the best schools today are to lead the pupils to acquire first, the power of accurate observation; second, keen perception; third, sound reasoning; fourth, the development of a taste for the beautiful in nature and an appreciation for the achievements of man in art. To promote the first three aims object drawing and color work are given; while the study of the principles underlying designing, the study of historic ornament, and the observation of pictures are means to secure the fourth.

Art is the oldest language; it is the most natural; it is universal. The oldest records of the human race are the

Art as a

Language works of the artists of their day. Art is a means of expression for the ignorant child and for the untutored savage; it is a communication of thought for the most highly civilized races. The works of the great masters of all ages and all nations,

${ }^{1}$ This section on drawing and art is taken very literally from the course of study for the Stockton city schools. 
such as those of Phidias, Raphael, Dürer, Murillo, Rosa Bonheur, Landseer, need no translation. They are universally understood.

Considered in this light, a knowledge of drawing and art are essential in a well-rounded education. Instead of addCorrelation ing to an already crowded school curriculum, in the hands of a skillful teacher these branches become aids in mastering other studies; as, arithmetic, geography, nature study, history, literature. A pictorial representation, as a drawing, a photograph, or even a few touches with pencil or chalk, often makes a thought clearer than when it receives only oral or written descriptions. Consequently, the correlation of drawing and art with other subjects is of great importance, although their teaching as a separate study is never lost sight of. The first thought in arranging the work for the grades is to have a natural, gradual growth and development along all the lines included in these branches throughout all the years of school life.

Formerly the individuality of the child was not sufficiently respected; today there is more danger of not doing enough class work. To foster individuality original

Individual

and

Class Work exercises, as narrative drawing and designing, are given frequently; general drills and training are found in directed work, as drawing objects and geometric designs. While there are many reasons for the original work, the training under guidance must not be neglected, or no progress will be made along general, systematic lines. The two forms of exercise are necessary in public school work if good results are to be obtained. 
The work of the course for the schools is arranged under four general headings: constructive work, object drawing, creative drawing, and the æsthetics of art. No marked division line is drawn between these phases of art study with the children of the grades, and each is liberally interpreted in its relation to all the others; but the four lines of growth are carefully nurtured throughout the eight years of the elementary schools.

The constructive work consists of paper folding, drawing geometric figures and designs, using the ruler, drawing to

Constructive Work

scale. The various exercises are carefully planned to train accuracy and attention, and are arranged to correlate with the more mechanical studies of the course, as arithmetic and geography.

Object drawing consists of the drawing of objects either singly or in groups. For this purpose models are used, such Object

Drawing

as geometric solids, vase forms, and other figures; leaves, flowers, seeds, animals, fellow pupils. These all afford desirable training in the power of accurate observation, keen perception, and sound reasoning. Suitable subjects are also assigned in nature study for the object drawing whenever it is possible.

Creative drawing is subdivided into narrative drawing and designing. The first is more suitable for primary grades, Creative Drawing while the second is better adapted to the greater maturity of the grammar grades. The material for narrative drawing is taken largely from history and literature. This should be an opportunity for the free expression of the child's own 
thoughts and conceptions; but, at the same time, his attention should be called to the proportions of the various parts; he should be encouraged to make use of the knowledge gained from object drawing, thus aiding in the development of a healthy imagination. Designing should also be individual work, although the attention of the child should be called to the underlying principles. Here is the opportunity to make use of the geometric drawing of the constructive training and of the freedom and observation of the training in object drawing; for the designs must be based upon constructive lines, and the conventionalized forms of foliage, flowers, and seeds are the most frequently used units. Designing is the practical channel for the development of taste through individual effort.

Under the fourth heading of the course is placed everything which tends to awaken an appreciation for the beautiful; but no attempt is made to teach the The Esthetics of Art theory of art. Growth in such knowledge is induced by teaching color and calling attention to color harmony; secondly, by studying historic ornament, and by acquainting the children with the lives and some of the works of a few of the great masters in the world of art; thirdly, by more general picture study as connected with tasteful schoolroom decoration. All these efforts and acquisitions give an unconscious tendency toward a fuller appreciation of the beautiful and a clearer understanding of the higher standards of art. In all this work it must not be forgotten that one of the highest aims is to develop in the child the power to see for himself the beautiful in nature. 
Blackboard drawing should be encouraged, for the drawing can be done on a larger scale, a necessary consideration

Blackboard

Drawing for little children with still undeveloped muscles. It admits of greater freedom of movement and stroke; criticism by the teacher is more easily made and observed by all the class; it is an invaluable means for training all children, especially timid ones, in freer and bolder work. In the lower grades, some time every day should be given to drawing on the boards.

The necessity for training in the use of color must be fully recognized. Color work begins in the first grade,

Color

Work where the earliest steps are taken by means of the spectrum and color slips, and by letting the children draw with colored crayons on the blackboard and with wax crayons on paper. From the second grade water color boxes are used.

Brush work begins in the third grade, writing ink or

Brush

Work neutral colors being used. For this and all color work Chinese brushes are used.

A few lessons in pen and ink are given in the upper grades.

The general medium of expression is the pencil, but other mediums are also used. Pencils for drawing are furnished

Material from the third grade through all the upper classes. The "Eagle Academic, Soft Medium," is used in the primary grades and also in the fifth grade; in the sixth, seventh, and eighth grades "Eagle Draughting, No. 314," is used. For pencil and brush work a rough manilla paper is used; for the color work, a rough white paper; while for special work the children are furnished at times with white or gray paper, well adapted for 
color or pen and ink work. The paper is put up in pads $6 \times 9$ inches in size for use in the grades up to and including the fifth; in the higher grades, pads $9 \times 12$ inches are used. Every school building has shelves for drawing models. These are well proportioned vase forms and type solids. To give variety and to add to the interest, the children bring natural forms and interesting objects used in every day life.

The lighting of the schoolroom has been little considered in connection with the drawing. It is an essential. Poor Lighting lighting is a great drawback to the work in regular class rooms; while proper lighting, as it is provided for in modern buildings of the better kind, greatly facilitates all work in drawing.

\section{PHYSICAL CULTURE ${ }^{1}$}

There is no longer a question as to whether physical culture shall be taught in the schools. Nature has not provided for an unaided development of the mind, Development of Mind and Body and we cannot assume that of itself the body will acquire right habits of performing all its functions, especially under the artificial conditions in which the growing child is placed. The development of the mind and body must go hand in hand, for a healthy body is the basis of intellectual, moral, and spiritual growth. Complexities of modern life make constantly increasing demands upon mental and nervous forces, and children must be trained physically if they are to have sound, sturdy bodies, capable of withstanding the wear and tear of the struggle before them. Nature demands the cultivation

${ }^{3}$ The section on physical culture is compiled from the course of study for the city schools as arranged by Miss Emily Dodge, supervisor of that branch. 
of all our activities, and there can be no proper training that does not educate the whole system of man.

The exercises used are selected and arranged with the following points in view: Real value in the development of the body. The limitations of the school room as regards time and space. Systematic training of large numbers without confusion.

In the first lessons the children are taught the correct rest and active positions of the body while seated, the manner of Positions rising and sitting, and the correct standing position. The simplest exercises are selected for the first and second years in school, and the work is made as objective as possible. For example, in stretching the arms upward the teacher says: "Try to touch the ceiling;" or something to arouse the conscious effort of reaching up after an object. In the horizontal arm stretching for chest expansion they are told, "Try to touch the sides of the room." Exercises in marching are given in all the lower grades as helpful in forming correct habits of carriage for the body. The position for marching, "head erect, chest leading, hips back, hands at sides, weight on the balls of the feet" should be retained as the children march around the room or through the aisles, keeping step as they sing some bright marching song. No exercise is more thoroughly enjoyed than marching, and none is more helpful in affording the needed rest and relaxation from the study period.

The attention given in the first years to the position in sitting and standing is continued throughout the course. In the upper grades special stress is laid upon the correct carriage of the body. This is essential, not only as a matter of gracefulness, but also for health. The result of regular, 
systematic exercise in the schools is visible in the improved health and physical development of the children.

\section{MUSIC}

Music holds a distinctive place in education, one which no other study can fill. It develops the emotional nature and

Place in

Education reaches to the higher and inner life of the heart and the soul. "The meaning of song goes deep. Who is there who in logical words can express the effect music has upon us? A kind of inarticulate, unfathomable speech which leads us to the edge of the infinite." Martin Luther says: "Music admonishes man, renders him mild, gentle, modest, and reasonable. $\mathrm{He}$ who knows the art is ennobled by it and has aptitude for all things." How carefully must this subject be presented so that it may perform its true office of developing high and noble ideals which may become realities in the life and character of the child.

Great care is exercised in selecting songs both as to words and music, for impressions that are to be lasting are being Songs formed. Every song should represent a mood that the child can feel and express; the music should be suited to the words and in a key that is adapted to the voices. The songs are often chosen with reference to the season of the year, correlating when possible with nature study, literature, or history. No song should ever be sung in a lifeless or indifferent manner. "There is a correspondence between the soul of a song and the heart of a child," and if the teacher is enthusiastic, in sympathy with

${ }^{1}$ The section on music is compiled from the course of study for the city schools as given by Miss Emily Dodge, supervisor in music. 
the children, and susceptible to the sentiment of the song, it is not difficult to establish this correspondence. The music lesson should always be a happy period.

When singing there should be a natural erect position of the body with chest active and head up. If the chest is inPosition active the breath is impeded, and if the head is down the chin presses upon the larynx. preventing its free action. In the motion songs and the games of the primary grades there should be entire freedom from self-consciousness. The more natural and spontaneous the play, the better for the music and the child.

The breathing exercises may be given during the music lesson, or in connection with the physical culture, or at any Breathing Exercises time during the day when rest from the study period is needed. The criterion for correct inspiration is " an increase in the size of the abdomen and lower part of the chest. Whoever draws in the abdomen and raises the upper part of the chest in the act of filling the lungs breathes wrongly."

Simple vocal drills are introduced in the first year and continued throughout the course in order to overcome the Vocal Drills tendency of the ordinary child to scream his notes and so as to secure pure, sweet, sympathetic singing. Loud, harsh singing not only injures the throat but it emphasizes those very traits of character that it should be the province of music to overcome.

Sight reading does not mean simply a mental exercise of

Sight

Reading

reading from note to note. "Singing is the expression of the emotions and not of the intellect," consequently sight reading should include the sentiment of the song as well as the mental 
exercise of reading the notes. If the exercises are sung in phrases and with expression, it is not always necessary to have words with which to express the emotion. The order of the lesson should be varied frequently to prevent monotony, and so that the children do not become weary and inattentive by dwelling too long on any one feature. The exercises should be selected to meet the needs of the class, and when a difficult one is mastered needless repetition should be avoided.

Every morning session should be opened with singing, and in the primary grades there should also be a closing song.

The first lesson in the receiving class consists of a few simple exercises for placing the tone and uniting the voices.

Rote

Songs

Then come the rote songs which are the principal feature of the lessons in the first year. These are chosen for a pleasing melody and a strong rhythm. Words and music are presented at the same time. The rote songs for the primary grades are selected with the utmost care so that the form of the song is correct, the rhythm perfect, and the words suited to the melody and within the comprehension of the children.

As the lessons proceed the scale is taught, beginning with the upper tone and singing down; then follow the simple Scales intervals and the combinations of tones. Realizing that the ear is especially sympathetic at this age, great care is taken to have the pitch of every tone absolutely true and every interval thoroughly fixed in the mind. From this simple beginning a course has been outlined for primary, intermediate, and grammar grades, so that a teacher knows what is required in music from month to month, just as in all other branches. 
The course includes opening and closing songs, songs of home life, songs descriptive of various occupations, and

Course songs of nature. The latter are arranged to harmonize with the California climate. In the intermediate grades, where the pupils have learned to read at sight, part songs are given, soprano and alto being taken interchangeably by boys and girls. When the higher grammar grades are reached the change in boys' voices has to be considered, and care is exercised to keep the voice within a suitable range so that it is not overtaxed. The music for these grades is divided into soprano, alto, and bass. The part songs and choruses that are used consist of folk songs and strong, characteristic hymns and melodies.

The time allowed for music on the daily program is fifteen minutes. The supervisor visits every class once a week,

Time and Supervision taking charge of the instruction the first and third weeks on the occasion of the visit, overseeing the lesson as given by the grade teacher the second and fourth weeks. Teachers' meetings are held once a week for the instruction of new teachers and of any others needing the help.

\section{SEWING}

The economical and practical value of manual training to the future mother and housekeeper can not be over-estimated. The early habits of industry and the standard of good workmanship thus fostered, the uplifting of hand work by placing it among the studies of the public school, will add dignity to the woman and give pride in an accomplishment

${ }^{1}$ The accompanying pages on sewing are taken from a short description of the work by Mrs. Marie Reimers, supervisor of sewing in the Stockton city schools. 
so essential to good housekeeping. The immediate wholesome educational effect upon the girl is of no less value. Order, patience, perseverance, concentration, determination, and ingenuity are stitched into every garment; and to develop thoroughness, independence, originality, and individuality should be the aim of every system of manual training.

The practical teacher of sewing is soon confronted with the fact that individual teaching is necessary to attain the best results. If need be the regular plan of the work must be made so elastic as to suit the pace of those who are swift of eye and hand and who, after all, are the teacher's best assistants; for through their grit and enthusiasm the whole class may be fired to greater efforts, and the slow of eye and hand may come out triumphant in the end.

The general outline of sewing in the public schools of Stockton comprises cutting and neat preparation and sewing of the work by the pupils. Objects similar in practice but different in form are given, thus arousing zeal and interest in the children. Sewing is taught in the seventh and eighth grades, one lesson a week. The period is three-quarters of an hour long in the seventh grade, an hour in the eighth. At the beginning of the term every pupil in the seventh grade is provided with a half yard of checked gingham and a quarter of a yard of muslin. Later on in the term both grades furnish their own material, thus giving full scope to individual taste and originality.

The different stitches, seams, and fastenings of threads are first taught on a frame and copied by the child on a piece of gingham. The child is then ready to put the first lessons into practical use by cutting, basting, and joining by hand 
twelve squares, as part of a larger quilt. Then follow in succession in the two years' course:

(I) Sewing bag: practice in cutting, hemming, overcasting, and outline or embroidery stitch for initial. (2) Needle case; practice in cutting, backstitching, and overcasting. (3) Apron: practice in cutting, hemming, gathering, and putting on band; also, for advanced pupils, the cross stitch or simple drawn work. (4) Sleevelets: practice in cutting, French seam, and hemming. (5) Darning. (6) Patching. (7) Mending woolen dress goods. (8) Buttonholing. (9) Handkerchief : practice in hemstitching and sewing on lace. (10) Corset cover: practice in cutting by pattern, repetition of former work, facing. (II) Shirt waist. (12) Skirt.

In December embroidery and other fancy work suitable for use as Christmas gifts are taught, and complete freedom of choice is given.

In these lessons no attempt is made to teach by chart, but the pupil is familiarized with handling patterns, so that by independent use of scissors and needle she can in the future expand and achieve her operations as taste and purse will allow. The resurrection of our grandmother's art proves indeed a blessing to the girl of today, and industry and usefulness are fast becoming ideals of our times. 


\section{REFERENCE BOOKS}

\section{LITERATURE AND READING}

\section{TEACHERS' LIST}

Arnold. Reading: How to Teach It.

Arnold. Waymarks for Teachers.

McMurray. Special Method in Reading,

Teaching Reading in Ten Cities. A series of articles published in Primary Education for 1899-1900.

\section{For Class Use \\ First Year Grade}

Open Sesame I. For poems for reading by teacher and for memorizing by the pupils.

Scudder. Fables and Folk Stories.

McMurray. Classic Stories for the Little Ones.

Kipling. The Jungle Books.

Stevenson, Robert Louis. Some of his poems for children.

Blaisdell. Child Life.

Bates. A Fairy Tale of a Fox.

\section{Second Year Grade}

Andersen, Hans Christian. The Little Match Girl, and other stories. Craik, Mrs. D. M. Adventures of a Brownie.

Dodge, Mary Mapes. Hans Brinker.

Beale. Stories from the Old Testament.

Kingsley, Charles. The Heroes, or Greek Fairy Tales for Children. Hawthorne, Nathaniel. Tanglewood Tales.

Wonder Book.

Blaisdell. Child Life in Tale and Fable.

Smythe. Old Time Stories Retold.

Chaplin. Little Folks of Other Lands.

\section{Third Year Grade}

Arabian Nights, Six Stories from Eliot. Lamb, Charles. Adventures of Ulysses. 
"Ouida" (Louise de la Ramee). The Dog of Flanders.

The Nurnburg Stove.

Mulock, Miss. The Little Lame Prince.

McMurray. Robinson Crusoe.

Baldwin. Fifty Famous Stories Retold.

Heller. Snowdrop and Other Sturies.

Fourth Year Grade

Swift. Gulliver's Travels.

Andrews. Seven Little Sisters.

Cooke. Nature Myths.

Lang. The History of Whittington.

The Princess on the Glass Hill.

\section{Fifth Year Grade}

Hawthorne. Tanglewood Tales.

The Paradise of Children.

The Miraculous Pitcher.

Sewell. Black Beauty.

Kingsley. Water Babies.

Brown. Rab and His Friends.

Thompson, Ernest Seton. Wild Animals that I have Known.

The Biography of a Grizzly.

Schwatka. The Children of the Cold.

\section{Sixth Year Grade}

Ruskin. King of the Golden River.

Dickens. Little Nell.

Scott. Stories from Waverley.

Hawthorne. The Great Stone Face.

Browning. The Pied Piper of Hamelin.

Lamb. Tales from Shakespeare.

Alcott. Little Women.

Little Men.

Andrews. Ten Boys on the Road from Long Ago.

Pratt. Stories of Colonial Children.

Brooks. The Story of the Iliad.

The Story of the Odyssey.

\section{Eighth Year Grade}

Lamb. Tales from Shakespeare.

Johnson, Dr. Rasselas. 
Yonge. The Prince and the Page.

Warner. Being a Boy.

A Hunting of the Deer.

Hale. A Man without a Country.

Hughes. Tom Brown at Rugby.

Dana. Two Years before the Mast.

Cooper. (Several of his stories.)

Kingsley. "Westward Ho!"

\section{LANGUAGE}

Teachers' List

Primary Grades

Arnold and Kittredge. The Mother Tongue, Book I.

Tarbell. Lessons in Language, Book I.

Badlam, Anna B. Language and Reading.

Sheldon. Primary Language Lessons.

\section{Grammar Grades}

Lewis. A First Book in Writing English.

A First Manual of Composition. (Especially applicable for eighth grades.)

Chittenden. Elements of English Composition.

Lockwood. Lessons in English.

Scott and Denney. Composition-Rhetoric. (A book for high schools, but an excellent guide for teachers in eighth grades.)

Kittredge and Arnold. The Mother Tongue, Book II.

Tarbell. Lessons in Language, Book II.

Davenport and Emerson. Principles of Grammar.

Sheldon. Advanced Language Lessons.

\section{For All Grades}

Bechtel. Slips of Speech.

Allardyce. Punctuation.

Hardy, Irene. Composition Exercises. (Full of valuable suggestions for devising subjects for compositions.)

\section{WORD STUDY}

Arnold. Reading: How to Teach It.

Pollard. Manual of Synthetic Reading and Spelling.

Ward. The Rational Method in Reading. 


\section{ARITHMETIC}

Speer. Elementary Arithmetic.

McLellan and Ames. Public School Arithmetic.

Prince. Arithmetic by Grades.

Eaton. The New Arithmetic.

Walsh. Higher Arithmetic.

The Psychology of Number.

\section{NATURE STUDY}

Bailey, L. H. Lessons with Plants.

Elementary Botany.

The Nursery Book.

Gray, Asa. How Plants Grow.

Newell, Jane H. Outline Lessons in Botany. 2 vols.

Parsons-Buck. Wild Flowers of California.

Comstock, John H. Insect Life.

Miall, L. C. Natural History of Aquatic Insects.

Keeler, Charles A. Bird Notes Afield.

Miriam, Florence. Birds thru an Opera Glass.

Parker, T. Jeffrey. Elementary Biology.

Jenkins and Kellogg. Lessons in Nature Study.

Murche, Vincent T. Object Lessons for Infants. 2 vols.

Object Lessons in Elementary Science. 3 vols.

Woodhull, John F. Simple Experiments.

Laurie, A. P. Food of Plants.

Bulletins of United States Agricultural Department. Monthly lists furnished on application. (Teachers should by all means make use of this source for literature on school gardens, agricultural methods, etc.)

\section{GEOGRAPHY}

Farnham. Oswego Methods in Geography.

Geike. Physical Geography.

Shaler. First Book in Geology.

Parker. How to Study Geography.

Mill. Realm of Nature.

Tarr and McMurray. Home Geography, Book I.

North America, Book II.

Frye. Child and Nature.

Redway. Advanced Geography.

King. Methods and Aids in Geography. 


\section{HISTORY}

Beale. Stories from the Old Testament for Children.

Brooks. The Story of the Iliad.

The Story of the Odyssey.

Ragozin. Earliest Peoples.

Guerber. The Story of the Romans.

The Story of the Greeks.

Harding. The City of the Seven Hills.

Stories of Greek Gods, Heroes, and Men.

Moore. Pilgrims and Puritans.

Eggleston. Story of Great Americans for Little Americans.

Household History of the United States.

Brooks, Elbridge. True Story of Abraham Lincoln.

True Story of Columbus.

True Story of Washington.

Fiske. History of the United States.

Montgomery. Leading Facts in American History.

Sheldon (Mrs. Mary Sheldon Barnes). Studies in American History.

McMaster. School History of the United States.

Towle. Heroes and Martyrs of Invention.

Mowry. American Inventions and Inventors.

Powers. The Missions of California.

James. Old Missions and Mission Indians of California.

Winterburn. The Spanish in the Southwest.

Royce. California. American Commonwealth Series.

Hood. Tales of Discovery on the Pacific Slope.

Snedden. Docas, the Indian Boy of Santa Clara.

Dole. The Young Citizen.

\section{CIVICS}

The American Citizen.

Judson. The Young American.

Macy. Civil Government.

Young. Government Class Book.

Fiske. Civil Government in the United States.

American Political Ideas.

Ford. American Citizen's Manual, Parts I. and II.

Bryce. American Commonwealth. 2 vols. 


\section{INDEX.}

Addition, 129, 136, 137, 138, 139, $140,141,145,149,161,162$

Adjective, $71,76,80$ modifiers, 72,85

Adverb, 67, 76, 80

adverbial connectives, 68,72 , 86

adverbial modifiers, 72, 76, 85

Africa, 250, 255

Air, action of, 238

chemistry of, 217

currents of, 206, 208, 257

pressure of, 210

Alaska, 253

Alcohol, 229

Algebraic formulas, 162, 164

America, 287, 306, 307

Animal study, 173, 190

animals as soil makers, 200 Aquarium, 190

vessel, 191

life, 191-197

Arithmetic 127

first grade, 134; second grade, 136; third grade, 139; fourth grade, 145 ; fifth grade, 149; sixth grade, 156; seventh grade, 161 ; eighth grade, 164

group work, 133

incidental period, 133,134 mental, 129, 151, 161, 164, 165

problems in, 130, 142, 146, $151,161,162,164,167,237$ Asia, 250, 255

Australia, 255
Barometer, 213

Bible stories, 9, 20, 267

Birds, 199

Brush work, 337

California, 245, 251, 280, 283, 313

Candle, experiments with, 225227

Carbon-dioxide, 220

Carbon-bisulphide, 221, 222

Cary sisters, 11, 12

Caterpillars, 198

Central America, 253

Civics, 316

primary grades, 317

grammar grades, 323

fifth grade, 326; sixth grade, 328; seventh grade, 329; eighth grade, 329

City, 236, 243, 320, 326, 328, 329

Climate, 228, 238, 258

Color work, 337

Columbus, 270, 272, 287, 288

Combustion, 221-227

Composition, 53, 54

first grade, 60 ; second grade, 64 ; third grade, 69 ; fourth grade, 73 ; fifth grade, 80 ; sixth grade, 87 ; seventh grade, 90 ; eighth grade, 96 in literature: first grade, 10 ; second grade, 12,14 ; third grade, 17, 19; fourth grade, 19, 20 ; fifth grade, 30 ; sixth grade, 39, 40; seventh grade, $42,44,45$ correcting papers, 55, 56, 69, $75,91,95,97$ 
Compound numbers, 148, 150, Fractions, common, text-book 155

Condensation, 202

Counting, 136

County, 239, 240, 329

Creamery, 244

excursion to, 246

Crusades, 42, 299

Cuba, 253

Cube root, 168

\section{Dickens, 46}

Dictionary, use of, $25,27,116$, 117

Division, $129,136,138,141,145$, 162

long division, 148,149

Dog, 199

Drawing, 333

blackboard drawing, 337

Creative drawing, 335

object drawing, 335

in history, 274

in literature, $7,11,25,36$, 46,83

in nature study, 175

England, 256, 297, 306

Europe, 250, 255, 299

Evaporation, 201

Expansion, by heat, 203, 205

by freezing, 205

Factoring, 152

Fairy stories, 265

Field, Eugene, 11, 12

Figures of speech, 25, 31, 35, 82

Flowers, 181

Folk tales, 9, 265

Fractions, common, 127

by constructive work, 142

by measurements, 146

fundamental operations with, 150-155

Greeks, 298

presentation of, 161

reviews of, 162

decimal, 127, 156, 157-159, 161,162

Gases, collecting by displacement, 218

pressure of, 209

Geography, 231

first grade, 234; second grade, 234; third grade, 236; fourth grade, 237 ; fifth grade, 248; sixth grade, 251 ; seventh grade, 255 ; eighth grade, 259

Geographical excursion, 232

to the creamery, 246

Geographical type, 233

Grammar, applied, 49, 59, 61, 66, $70,72,79,84,88,95$

formal, or technical, 49, 52 , $79,83,88,92,95$

Greece, 299, 300, 304

Hawaiian Islands, 253

Health lessons, 229

Heat, expansion by, 203

Hiawatha, 10, 267, 268, 270

History, 263

first grade, 267; second grade, 270; third grade, 274; fourth grade, 281; fifth grade, 287; sixth grade, 296; seventh grade, 306 ; eighth grade, 313

local, 280, 283. (See also Stockton.)

Horatius, 13-15, 270

Insect study, cage, 197

life, 198

Insurance, 166

Interest, 127, 160, 167 
Language, 48

$$
\text { oral, } 49
$$

written, 53

first grade, 59 ; second grade, 61 ; third grade, 66 ; fourth grade, 70 ; fifth grade, 78 ; sixth grade, 83 ; seventh grade, 88 ; eighth grade, 95

Laws, $319,324,328$

Letter writing, $81,86,90$

business letters, 130, 159

Library, 282, 307, 314

Lime water, preparation of, 221

Liquids, pressure of, 209

Literature, 3

first grade, 9; second grade, 11 ; third grade, 16 ; fourth grade, 19; fifth grade, 23 ; sixth grade, 31 ; seventh grade, 41 ; eighth grade, 46 Longfellow, 11, 12, 23, 24, 26, 268

Maps, 25, 46, 236, 238, 240, 242 Map drawing, 243, 254, 259, 260

Magnetism, 203

Measurement, 127, 128, 135 138, $143,145,146,148,160$, 161,168

Metals, common, 216

Metaphors, 25, 35

Mexico, 253

Midas, 17

Middle Ages, 297

Money, 155

Multiplication, 129, 136, 138, 140, $145,149,162$

Music, 340

Myths, 265

Narcotics, 229

Nature study, 173

Nitrogen, 221

North America, 251

Notebooks, history, 269, 303, 311
Notebooks, literature, $20,43,44$, $46,60,87,93,97$

Odyssey, 20

Outlines, history, 275, 284, 290, 300,311

literature, 25, 44

Oxygen, making of, 219

Paragraph, 19, 74, 82, 86, 91, 276, 277

Paraphrasing, 26, 89

Partition, 136, 138, 145

Percentage, 127, 156, 159, 162, 163

Personification 25, 35

Philippines, 253

Phonics, 100, 102, 110

first grade, 103; second grade, 106, 107; third grade, 111,112 ; fourth grade, 113, 114; fifth grade, 116

Phonograms, 104, 105

Physical culture, 338

Plant study, 173

flowers, 181

food stored by plants, 184

seeds and seed distributing, 175

seed germination, 179

tree, its life, 178

movement of plants, 185

parasitic plants, 187

propagation of plants, 187

plants useful to man, 185

plants as soil makers, 188

plants in land building, 189

Poems teaching of, 17, 23, 26, $27,28,31,33-36$

Porto Rico, 253

Pronouns, second grade, 62 ; third, grade, 67 ; fourth grade, 76 ; fifth grade, 80 ; sixth grade, 85,86 
Pronouns, relative, $68,76,88$

Punctuation, 19, 40, 58, 60, 63, $70,78,89,96$

Pupils' illustrative papers, arithmetic: third grade, 143 geography: fourth grade, 246 ; sixth grade, 254

history: second grade, 273; third grade, 280; fourth grade, 284, 285; fifth grade, 294, 295

language and composition: first grade, 60,61 ; second grade, 65, 66; third grade, 69,70 ; fourth grade, 76 , 77 ; fifth grade, 82,83 ; sixth grade, 87,88 ; seventh grade, 93, 94 ; eighth grade, 97,98

literature: second grade, 15 ; third grade, 17, 18; fifth grade, 29, 31 ; sixth grade, 37

word study: second grade, 111 ; fourth grade, 115, 116 ; sixth grade, 119 ; seventh grade, 119 ; eighth grade, 122,123

Reading, 3, 28, 32, 33, 41

Reproduction, history, 269, 275, 291, 309

language and composition, $49,50,53$

first grade, 60 ; second grade, 61,64 ; third grade, 66 ; fourth grade, 70,73 ; fifth grade, 81 ; eighth grade, 96

literature: first grade, 10 ; second grade, 12,14 ; third grade, 17 ; fourth grade, 19 ; fifth grade, 26,28

Rivers, 237, 238, 243
Rome, 299, 300, 304

Scott, 46

Seeds, 175

distribution of, 175

increase of, 177

Sentence, structure of, $19,30,66$, $68,69,71,72,82,85,86$, $87,91,97,98$

Silkworms, 199

Similes, 25, 31, 35

Sky, lessons, on, 227

Soil, 240

made by animals, 200

made by plants, 188

Solution, 215

South America, 249, 250, 255, 259 Spelling, 101, 110

first grade, 105 ; second grade, 107 ; third grade, 113 ; fourth grade, 114 ; fifth grade, 116 ; sixth, seventh, and eighth grades, 118

Square root, 168

State, the, 245, 251, 328, 330

Stockton, in arithmetic, 131,132 , 133

in geography, 236, 240, 243, 250,254

in history, 280. (See also local history.)

Story, presentation of, 5

first grade, 9; second grade, 13 ; third grade, 16 ; fourth grade, 19,21 ; seventh grade, 41

in history, 268, 269,274, 275

dramatic element, $7,9,10$

Subtraction, 136, 137, 138, 139, 145,162

Switzerland, 235, 250, 259

Teachers' method sheets, arithmetic: fourth grade, 146 ; fifth grade, 151; sixth 
grade, 157 ; seventh grade, 162 ; eighth grade, 165

geography: fourth grade, 242 ; seventh grade, 258

history: second grade, 272; third grade, 278; fifth grade, 293; sixth grade, 303 ; eighth grade, 315

language and composition: first grade, 58; sixth grade, 84; seventh grade, 89 ; eighth grade, 96

literature: first grade, 9; second grade, 12 ; fourth grade, 21 ; fifth grade, 26 ; sixth grade, 33 ; seventh grade, 42

word study: second grade, 107

Technical drills in language, 51, $59,62,66,70,79,80,84$, $86,88,93,97$

Tobacco, 229
United States, in geography, 248, $251,252,253,260$ in history, 42, 297

Valleys, 238

Verbs, drills in use of, $40,51,52$ first grade, 59 ; second grade, $62,65,66$; third grade, 67 ; fourth grade, 71, 76; fifth grade, 79

Water, currents of, 206, 208, 257 pressure of, 210

Whittier, 31, 32, 35, 36

Word study, 100

first grade, 103; second grade, 106; third grade, 111 ; fourth grade, 113; fifth grade, 116; sixth, seventh, and eighth grades, 118

in literature, 25

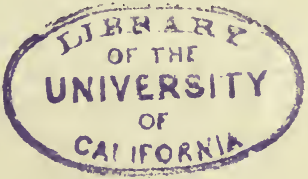




\section{Methods in Elementary Education}

A SERIES OF EDUCATIONAL BOOKS IN TWO GROUPS COVERING THE GENERAL PRINCIPLES OF METHOD AND ITS SPECLAL APPLICATIONS TO THE COMMON SCHOOL

BY CHARLES A. MCMURRY, Ph.D. Northern Illinois State Normal Schoor, Dz Kalb, Ilz.

\section{The Elements of General Method}

Based on the ideas of Herbart. New edition, revised and enlarged. Cloth. r2mo. 331 pp. 90 cents net. (Postage ro cents.)

The Method of the Recitation

New edition, revised and enlarged. Cloth. 12mo. 339 pp. go cents net. (Postage 10 cents.)

Special Method in the Reading of Complete English Classics in the Common Schools

Cloth. r2mo. 254 pp. 75 cents net. (Postage 9 cents.)

Special Method in Primary Reading and Oral Work with Stories

Cloth. $x 2 m$. $x g 8$ pp. 60 cents net. (Postage 8 cents.)

Special Method in Geography

New edition, revised and enlarged. Cloth. 12mo. 228 pp. 70 cents net. (Postage 9 cents.)

Special Method in History

A complete outline of 2 course of study in history, for the grades below the high school.

New Edition, revised and enlarged. Cloth. I2mo. $29 x$ pp. 75 cents net. (Postage 9 cents.)

Special Method in Elementary Science for the Common School

Cloth. 22 mo. 285 pp. 75 cents net. (Postage xo cents.)

Special Method in Arithmetic

Cloth. $12 \mathrm{mo}$. $200 \mathrm{pp}$. 70 cents net.

Special Method in Language in the Eight Grades

Cloth. 12mo. $200 \mathrm{pp}$. 70 cents net.

Type Studies from the Geography of the United States

$$
\text { First Series }
$$

Cloth. $12 \mathrm{mo} . \quad 3^{82} \mathrm{pp}$. 50 cents net.

Excursions and Lessons in Home Geography

Cloth. 12mo. $184 \mathrm{pp}$. 50 cents net.

\section{THE MACMILLAN COMPANY}




\title{
Source Book of the History of Education
}

\section{FOR THE GREEK AND ROMAN PERIOD}

\author{
By PAUL MONROE, Ph.D.
}

Adjunct Professor of the History of Education

Teachers College, Columbia University

Cloth

$12 \mathrm{mo}$

$\$ 2.25$ net

"I have decided to recommend it to my class in the History of Educa. tion as the basis of their work for this fall term. I regard the material a very carefully and judiciously selected-by far the best book of extracts with which I am acquainted."

-DR. WM. J. TAYLOR, Lecturer on the History of Education Yale University.

\section{A Modern School}

By PAUL H. HANUS

Professor of the History and Art of Teaching, Harvard University Author of "Educational Aims and Educational Values," etc.

\section{$\$ 1.25$ net}

The chapters of which this volume consists, except the last, deal with various phases of one central theme; the scope and aims of a modern school and the conditions essential to its highest efficiency. The last chapter offer: some testimony on the working of the elective system, - a contemporary ques tion of great importance to both schools and colleges,-but the testimony offered pertains only to the college. The first chapter deals specifically with the secondary school; and in it the author has endeavored to extend anc strengthen certain conceptions set forth in his earlier book. The next sever chapters contain a fuller treatment of certain topics than was appropriate or expedient in the first chapter, and discuss the internal and external condi. tions essential to a high degree of success in the work of any school.

\section{THE MACMILLAN COMPANY}




\section{A History of Education in the United States}

By EDWIN GRANT DEXTER, Ph.D.

Professor of Education in the University of Illinois

$\$ 2.00$ net.

This new work has been prepared in the belief that the greatest need of the student of our educational history is a considerable mass of definite fact upon which to base his own generalizations, or with which to interpret those of others, rather than extended philosophical discussions of historical trend. Current educational literature is rich in the latter, though comparatively barren of the former. The present book deals, therefore, with the fact rather than with the philosophy of education in the United States. It contains an exceptionally valuable equipment of references and bibliographies.

\section{The Philosophy of Education}

BY HERMAN HARRELL HORNE, Ph.D.

Assistant Professor of Philosophy and Pedagogy in Dartmouth College

\section{$\$ 1.50$ net}

This volume is a connected series of discussions on the foundations of education in the related sciences of biology, physiology, sociology, psychology, and philosophy. It is not another of the many current manuals of practice, but a thoroughgoing interpretation of the nature, place, and meaning of education in our world. The newest points of view in the realms of natural and mental science are applied to the understanding of educational problems. The field of education is carefully divided, and the total discussion is devoted to the philosophy of education, in distinction from its history, science, and art. The conceptions of evolution, society, and genetic psychology shed their light upon educational phenomena, yielding in the end a comprehensive definition of what education is. The various conflicting modern educational opinions are organized to a considerable extent, and are made to appear as partial truths of a common system. The whole is suffused with the spirit of an idealistic philosophy in which education is finally made to yield its ultimate meaning as to the origin, nature, and destiny of man.

\section{THE MACMILLAN COMPANY}





UNIVERSITY OF CALIFORNIA LIBRARY

THIS BOOK IS DUE ON THE LAST DATE STAMPED BELOW

Noบ 19 1918

\section{Alif 221928}

NIA 1923

ocf 231930 


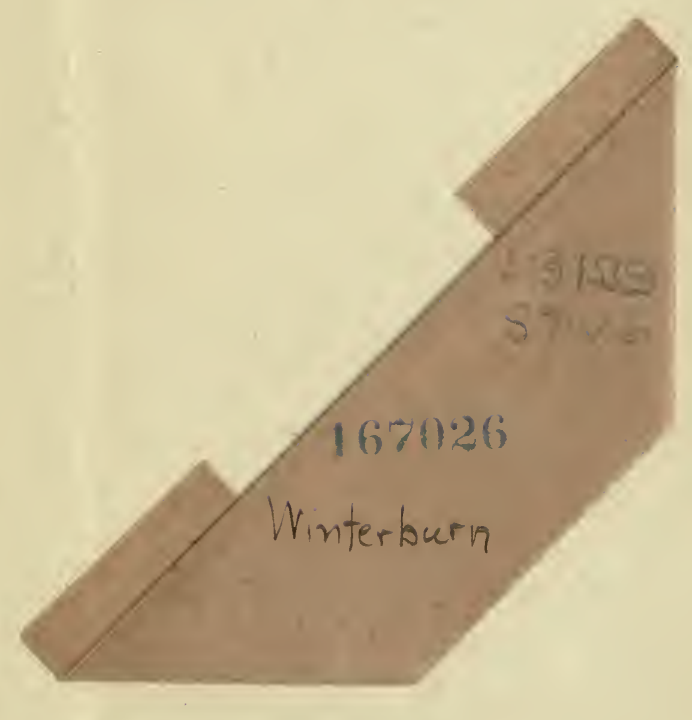


